\title{
AN ANALYSIS
}

OF

THE QUALITY OF LIFE

OF OLDER WOMEN IN NEW ZEALAND 2001

“I'M STILL ME INSIDE”

A thesis submitted to Victoria University of Wellington in fulfilment of the requirements for the degree of Master of Arts in Women’s Studies 


\section{Acknowledgements}

Without the time and energy given by the women who responded to the questionnaire this work would not have been possible.

Without the support of my daughters Jane, Ruth and Sarah who insisted that "mum could do it" the project would not have left the ground.

Without the prompting and guidance of my supervisors Alison Laurie and Prue Hyman it would never have been completed.

I am indebted to Jane Allison, Judith Dale, Susan Gee, Marg Gilling, Raewyn Good and Mary Mowbray for encouragement and technical assistance when the going was rough, and to the Ministry of Social Policy for a seeding grant without which, as a superannuitant, I would not have been able to resource this project.

Isobel Munro, 2002 


\begin{abstract}
This study explores the quality of life for one hundred and seventy-five older women from many parts of New Zealand, who are no longer in full-time paid employment. The women were self-selected through a process of social networking and have responded to a questionnaire on the quality of their life. Sixteen of the women living in the greater Wellington area were interviewed. Demographics such as age, marital status, income and education were obtained.
\end{abstract}

The project examines some of the variables and their interactions, which contribute to the quality of life for older women. These are income, housing, health, social connectedness and life cycle events within the context of individual and societal attitudes. The respondents have been grouped in younger and older cohorts, those women under or over 75 .

The study records their subjective perceptions of material wellbeing and health together with their thoughts and feelings about this stage of their life. The women's awareness of being valued, and by whom they were valued made a significant contribution to the quality of their life, as did a sense of belonging and being useful in the locus of family and community. Good health coexisted with illness and disability, but costs associated with healthcare were of concern. They took pride in the skill of 'making do', a legacy of war and depression. Respondents were clear that a positive attitude was necessary for coping with older age and that owning your own home contributed to their feeling secure. For most participants New Zealand Superannuation was their main source of income.

While there was considerable diversity in their situations, relating to their previous life history, this study indicates that most of the older women felt comfortable with their life, despite some perceptions of 'ageism' in the community. They expressed concern for others rather than themselves. 


\section{Table of Contents}

Acknowledgements

Abstract

Table of contents $\quad$ iii

Prologue viii

\section{Chapter One: Introduction}

1.1 A personal statement 1

1.2 The thesis topic and its limitations 5

1.3 Reviewing the literature on ageing 6

1.4 The feminist context 8

1.5 The social context 9

1.6 Summary 11

\section{Chapter Two: Ageing in New Zealand}

2.1 Introduction 12

2.2 The struggle for a universal old age pension 13

2.3 The contemporary context: Its genesis 19

2.4 Recent New Zealand activities relating to age 28

2.5 Summary 30

\section{Chapter Three: A Review of Literature 0n Women and Ageing}

3.1 Introduction 31

3.2 Theorising age 37

3.3 Concepts and images of ageing: 46

3.4 Concepts and images of ageing:
The other side of the coin

3.5 What is this thing called ageism? 57

3.6 Factors affecting the quality of life for older women 63

3.6.1 When do I know that I am old? 63

3.6.2 What does society expect of the elderly and who tells me this? Issues of power and language 66 
3.6.3 Where do I belong and am I useful? Issues for family and community

3.6.4 What shall I live on? Economic resources 70

3.6.5 Where shall I live? Housing and transport 80

3.6.6 How shall I stay well? Issues for health 81

3.6.7 This is where I have been: The life course 86

$\begin{array}{lll}3.7 & \text { Conclusion } & 87\end{array}$

\section{Chapter Four: Methodolgy}

4.1 Introduction $\quad 88$

4.2 Reason 89

4.3 Objectivity and neutrality 90

4.4 Feminist methodology 92

4.5 Issues in feminist research 94

4.6 Feminist use of research methods 100

$\begin{array}{lll}4.7 & \text { Conclusion } & 103\end{array}$

\section{Chapter Five: Data Collection}

5.1 Overview 106

5.2 The focus group: Intention and setting up 107

5.3 The characteristics of the focus group 107

5.4 The pilot questionnaire 108

5.5 The focus group discussion 109

5.6 The focus group conclusion 112

5.7 The redesigned questionnaire and

5.8 The level of response 113

5.9 The questionnaire: Recording responses 113

5.10 The interviews: Overview 115

$\begin{array}{lll}\mathbf{5 . 1} \text { Interview procedures } & 115\end{array}$

5.2 Processing interview data 117

5.13 Archiving 117

$\mathbf{5 . 1 4}$ Conclusion 118 
Chapter Six: Participants, Problems and Themes.

$\begin{array}{lll}\text { 6.1 Introduction } & 119\end{array}$

6.2 Ethnicity 122

6.3 Confidentiality 122

6.4 Participants 122

6.5 Themes 131

$\begin{array}{lll}\text { 6.6 Conclusion } & 132\end{array}$

Chapter Seven: Analysis and Discussion of Questionnaire Responses Part One

7.1. Overview 133

7.2 Age of respondents 134

7.3 Marital status of respondents 135

7.4 Household income of respondents 137

$\begin{array}{lll}7.5 & \text { Income and marital status }\end{array}$

$\begin{array}{lll}\text { 7.6 Income and age } & 144\end{array}$

7.7 Income, education and employment 145

$\begin{array}{lll}7.8 & \text { Home ownership } & 147\end{array}$

7.9 Housing satisfaction 148

$\begin{array}{ll}\text { 7.10 Living alone } & 149\end{array}$

7.11 Use of car and availability of public transport 150

7.12 Use of the Internet 151

7.13 Medical insurance 152

$\begin{array}{lll}\mathbf{7 . 1 4} \text { Summary } & 152\end{array}$

Chapter Eight: Analysis and Discussion of Questionnaire Responses Part Two

8.1 Overview 153

8.2 Preparation for retirement 153

8.3 Changes in the allocation of household tasks
on retirement

8.4 Retirement villages 163

8.5 Satisfaction with life 164

$\begin{array}{lll}\text { 8.6 } & \text { Disabilities } & 165\end{array}$

8.7 Health 166

$\begin{array}{lll}\mathbf{8 . 8} & \text { Exercise, sleep and holidays } & 167\end{array}$ 
8.9 Concern for safety 168

8.10 Being a grandmother 168

$\begin{array}{lll}\mathbf{8 . 1 1} \text { Voluntary work } & 170\end{array}$

8.12 Things that please, worry or concern 172

8.13 Being valued 174

8.14 Spirituality, and belief systems 176

8.15 Additional matters and conclusion 178

\section{Chapter Nine: Conclusions and Avenues for Future Research}

9.1 The end of the journey 182

9.2 The question of representation 182

9.3 The implication of level of response 183

9.4 What I have found 183

9.5 Avenues for future research 186

$\begin{array}{ll}\text { Epilogue } & 189\end{array}$

$\begin{array}{ll}\text { Bibliography } & 190\end{array}$

Appendix I a Introductory Letter and Questionnaire 213

I b Consent Forms and Interview Confirmation 221

Appendix II a Locations of Respondents

Requesting Project Reports 223

II b List of Respondents’ Formal Voluntary Activities

Appendix III Selected Responses to the Question on Values 225

Appendix IV Audrey Harper’s Advice on Retirement 227

\section{List of Tables}

2.1 Times and Trends

7.1 Legal Marital Status of Women Aged

Sixty and Over 1996 
7.2 Levels of Income for Respondents

7.3 Rates of payment for NZ Superannuation, before tax, March 2001

7.4 Median Income of Respondents, by Marital Status

139

7.5 Respondents' Levels of Education

7.6 Respondents' Homes

7.7 Respondents' Satisfaction with their Home

148

7.8 Respondents' Use of a Car 150

8.1 Life Satisfaction Percentage Ratings 164

8.2 Respondents' Ratings of Health 166

$\begin{array}{lll}\text { 8.3 Respondents’ Exercise } & 167\end{array}$

\section{List of Figures}

3.a Median Personal Income, by Age, 1996

3.b Personal Income Quintiles, by Sex, 1996

7.a Age of Respondents 135

7.b Marital Status of Respondents 135

7.c Age of Respondents by Marital Status 36

7.d Household Income of Respondents by Marital Status 140 


\section{Prologue}

Research process, similar to life, is about ambivalence, dilemma, paradox and vulnerability. It is an ongoing process of negotiating, inherent incongruity, both emotionally and intellectually. The constant negotiation entailed in the research process implies that the private is always embedded in the production of public knowledge.

In researching the quality of life of older women I have been teasing out the threads, but have endangered the texture of this rainbow-coloured fabric. There is a mismatch between the representation of the parts and the reality of the whole. Listening to the women in this study and reading their written responses, I have been constantly aware of the 'insider' 'outsider' paradox; as the researcher, outside, and as an older woman, inside. 'I' cannot be 'you', but we have common meeting grounds as older New Zealand women. Negotiating the roles and boundaries has not been easy. The acknowledgement of diversity and commonality is the product of my personal lens. Like Shirley Meredeen I can rejoice in the freedoms age has granted, like Cynthia Rich and Barbara Macdonald I can rage against the oppression of ageism. I can be a grandmother, tend my garden and write a thesis. Like many of the women in this study I take life as it comes with its worries and its pleasures, negotiating our interdependency in the family and in the community.

The inner sense of self is strong in the women participants in this study and while change is acknowledged they experience a continuity of identity and the will to remain in control of their own lives regardless of exterior appearances. The mask of age cannot extinguish the 'me inside'. 


\section{Goodbye To All That}

No more periods, no more pain,

No more trying to be gloriously vain.

No worrying day by day

When kids are late and stay away.

No more striving after unreal wishes

No more sinks of dirty dishes.

No more menopause, no more flushes

No more adolescent crushes.

No more darning children's socks

No more chasing round the clock.

No more cleaning others' messes

No more backcombing unruly tresses.

No more arguing day by day

What to wear and what to say.

No more belief that men are stronger

Women are tough and we live longer.

No more victim, no more affairs

No more flaunting of physical wares.

No more pretence, this is me

No sleeping princess nor false modesty.

What I am is what I do

Even if it won't please you.

No more leaving things unsaid

No more wishing I was dead.

No more guilt, no more scorn

I may be old-but I'm glad I was born.

Shirley Meredeen (1993, p.126) 


\section{Introduction}

No matter how restricted its topic every philosophic discussion is likely to bear the stamp of the time it was written.

Maurice Mandelbaum (1967, p.vii)

\subsection{A personal statement}

The quotation opening this chapter bears witness to the importance of context in any study, to the locus of its author and for this reason I open this introduction with a personal statement.

This study is the outcome of my interest in the status of older women in New Zealand. It records the experience of some women, no longer in full-time employment, who have been willing to write or talk about the quality of their lives. I came to this project as an older woman myself, no longer in employment, with grandchildren, living alone and coming to terms with approaching old age.

My academic qualifications were dated, begun in 1950 in the sciences, interrupted first by the need to earn a living since I had left home and later by marriage and the birth of my five children. I finally completed a B.A. in the seventies through distance education and this qualification gave me an economic advantage when later parenting alone. Subsequent postgraduate study was limited to professional extension in teaching and counselling with some additional papers in social work, economics and psychology. I had not formally undertaken Women's Studies, but felt that this was an appropriate base for a study of older women and have concurrently with this research sat or audited papers in Feminist Economics, Gender Analysis of Economic and Social Policy, Oral History and Feminist Theory.

As a younger woman I had been caught up in various phases of the Women's Movement looking for legal and political remedies to ameliorate the inequalities in income and opportunity between men and women. I saw education as a way for women to gain some freedom from their traditional roles as nurturers and carers and by political action to access better paid employment. 
In 1969 I moved from Bluff to Invercargill and was fortunate enough to arrive in time for a meeting set up by Jocelyn Harris, then a lecturer at the University of Otago. The Invercargill Women's Collective was set up from this meeting. Most of us were married with children, and our ages ranged from late twenties to mid forties and we came from both the city and the country. Our first activities were in consciousness raising, but we moved on to take part in the abortion and contraception debates, some of us assisting with S.O.S. ${ }^{1}$ We were active in promoting the election of women candidates to local bodies and the then existing Hospital Boards. We letter boxed leaflets, produced newsletters, arranged cottage and lunch hour meetings for local body and national political candidates and ventured into public speaking ourselves.

We lobbied local and national politicians on issues of importance to women and produced submissions on proposed legislation and affiliated nationally with the Women's Electoral Lobby. Political action seemed a road that would lead to women gaining legislative and administrative power in local and national government resulting in better conditions for women and children. We hoped that by providing lists of strong well-qualified women that the government would appoint them to advisory boards and to executive positions. Certainly much was gained, for instance some changes to the Married Women's Property Act and an increase in the numbers of women participating in Parliament and in Local Bodies.

Token women began to appear on Boards of Directors and in managerial roles, but this did little for ordinary women. Gender prejudice still remained. It soon became apparent that slogans such as 'Girls can do Anything' had a hollow ring and that legislation for equal pay had not addressed the remuneration issue, as women were concentrated in the low- paid secondary employment market and union activity was mainly the preserve of men. Women were taking on the double burden of homemakers (unpaid) and of full-time or part-time work to further the interests of the family.

Affordable, quality child-care became a burning issue, as well as the right of

\footnotetext{
${ }^{1}$ Sisters' Overseas Service, a confidential service to assist women seeking an abortion in Australia when it was not possible in New Zealand.
} 
women to control their own bodies. The equitable division of property on marital breakdown and women's access to loan funds in their own names became strong rallying points. The formal representation of women on local bodies and at parliamentary level were issues supported and fought for by many women's organisations from both sides of the political spectrum, and from both town and country. Sexual harassment, pornography, rape and child abuse became issues, but at this time little was heard of the situation of older women. The feminist movement was focused on women's rights over their own bodies and the exploitation of women in poorly-paid employment and in their role as family caregivers.

During the seventies some feminist action was visible in the field of mid-life. Its main concern was the extent to which the natural changes of menopause had been medicalised by a controversial promotion of hormone replacement therapy. While some women experienced unpleasant symptoms, which could be alleviated by this treatment, it was promoted as a panacea for all women, building on visions of eternal youth and the fear of ageing. It was not surprising that the drug companies found a ready and profitable market in anxious women including feminists. Although many older women in the movement were active in promoting issues to empower 'all women', little attention was given to the quality of life of older women.

The Society for Research on Women in New Zealand (SROW), born in the sixties, had documented women's journey in search for a better deal. This organisation, which was community based, addressed the immediate needs of its women members, satisfying a social and political need for factual information about New Zealand women. To date some seventy publications have presented studies on almost all aspects of New Zealand women's lives in the second half of the twentieth century and SROW has recorded in lectures, publications and on tape the experiences of women both old and young.

The 1982 publication In Those Days was based on life history interviews with fifty-one older women aged from seventy to ninety-two. This was of particular interest to me as I had found little in the feminist literature at that time which addressed the lives of older women of whom I was now one. 
In 1997 I became part of a SROW group which produced a small study, Towards Retirement, Women's Views, published in 1999. I had interviewed many of the women for that study and was aware of the hopes and fears they had for retirement and the preparations that they were making or not making as they coped with the many unforeseen events in their lives. They dreamed of leisure and pleasure, of moving to a better climate and of labour free homes with flat access. However in the political climate of the day, they doubted their capacity for personal savings, over and above providing for the education of their children. They feared that the reality of retirement may be poor health, dependency and poverty since they expected less public provision to be made for an ageing society and that too much would be left to the individual. Their beliefs about retirement had come mainly from the experiences of their grandparents, parents and parents' friends living in a more positive economic climate, which no longer existed. They were sure that their retirement would be different.

Most of the women I interviewed had long since decided that "a woman's work is never done" and asked in what sense would they be retired from their traditional roles as care-givers of parents, partners, children, grand-children and in some cases siblings? And what of their voluntary work gifted to a multitude of community based projects; to schools and sports organisations, to political advocacy addressing social needs, to all the traditional caring activities of parish work, of Care and Craft, of food banks, of care for the sick and the disabled? Paid employment might cease, but 'work' continued. Retirement seemed a concept more suitably applied to men.

The idea for this present study came to me late in 1999, at the end of The International Year of the Older Person. Despite publicity from the Senior Citizen's Unit of the Government's Social Policy Agency, the existence of this designated year seemed to have had little impact on the older women I knew, or within the voluntary organisations and professional associations to which I belonged. It was only later, in 2000 that much of the work carried out by government and community organisations during that previous year became visible with the publication of many reports on a variety of projects concerned with older people. 
Once Towards Retirement: Women's View was launched we set out to sell it and set up a stall at the November 1999 Conference of the Women's Studies Association at Victoria University of Wellington. By chance I met a member of the academic staff, who suggested that I might be interested in undertaking further study including a research project relating to older women. With a great deal of trepidation I embarked upon this thesis.

My study has been made possible by accessing a student loan and having later received a grant from the Social Policy Agency, for which I am very grateful, as research is a costly business. I hope that this small study of some older New Zealand women's experience of ageing will add to our knowledge base on gender issues and inform future social policies relating to older women.

\subsection{The thesis topic and its limitations}

Research, as defined in Chambers Twentieth Century Dictionary, is "systematic investigation towards increasing the sum of knowledge”. The Oxford Dictionary refers to the "the study of materials and sources... an endeavour to discover new or collate old facts...by critical investigation.” These definitions, however, do not imply the ethical questions all researchers must ask. Who is this for and who will benefit? Who may incur disadvantage? These questions have determined the processes used in this study which is not only about older women, but is for them, attempting to discuss their quality of life using their own words.

The words of one hundred and seventy-five older New Zealand women have been collated and analysed. These women are no longer in full-time paid employment and live in their own homes. No age restriction was given for 'older,' this being determined by the participants themselves. The problem of defining age by chronicity is addressed in section 3.6.1. Had I adopted the common practice of defining age by the eligibility for New Zealand Superannuation, at age sixty-five, I would have eliminated several women from the study.

Quality of life was not defined for the participants, but the questionnaire was built on the hypothesis that it encompasses material, emotional and spiritual wellbeing. The variables considered were income, health, housing, transport, previous life events, autonomy, social connectedness and belief systems. The thesis 
examines these variables and their interrelationships in the context of the women's lives. The situation of older women living in institutional care has not been addressed.

In listing the variables above the important issue of ethnicity has not been addressed. The well-documented disparities in the areas of health, housing, education and employment for Maori, Pacific Islanders and more recent refugees from the non-western world have serious implications for the well-being of older women in these cultures. These issues have had considerable exposure in the media and this area remains an important area for research and may well take place within the government's stated policy of 'Closing the Gaps'. Although other demographic data was obtained, I did not solicit ethnic identity. Some women told me that they felt that the question would be intrusive, others that it was inappropriate for me, a fourth generation New Zealander of European descent, to question or interview women from Non-European cultures. I should not presume that, since we were all women, we would share experiences in common. I decided to omit ethnicity from the questionnaire despite my perception of its importance, but to interview any woman if she indicated a wish to be interviewed even though her questionnaire responses indicated that she belonged to a Non European culture.

\subsection{Reviewing the literature on ageing}

While the literature reviewed constitutes a thread throughout the thesis, chapter three is its formal expression. It examines the general theoretical approaches to age from a number of disciplines, the concepts and images of ageing, of ageism and the problems encountered in defining older age. The power of language in creating and perpetuating societal attitudes is addressed and health, material resources, social relationships and life courses are examined. In much of the material resourced no distinctions were made in relation to gender, but where possible I have used texts relating specifically to women, particularly New Zealand women. The work of Peggy Koopman-Boyden, Ruth Bonita, Jocelyn Armstrong, Susan St John and Ann Else has been invaluable. They have raised issues for older women in respect to diversity, ethnicity, health and income support. Although recent university theses at Massey and Victoria have focussed 
on women's health promotion, voluntary work, social support, fear of crime and the use of the Internet, using qualitative methods, there is still the need for more input from the women subjects themselves.

Bibliographies of research on older persons in New Zealand already exist. Gilling and Gilling (1997, pp. 9-10) discuss the points made by Wither and Hodges in a 1987 Ministry of Health update of a previous bibliography of New Zealand research on older persons (Cresswell and Wade, 1971). They noted that earlier approaches had been limited to the use of "structured questionnaires, statistical surveys and clinical examination," and that these had failed to address the complex reality of older people's experience. It was proposed that a better understanding could be gained by the use of research methods that emphasise life histories, interviews, participant observation, and other forms that actively involve elderly people. This was acknowledged in The Royal Society of New Zealand's report on research strategies for the intergenerational impacts of ageing (1999, p.7). While excluding the work of Anne Opie (1992), Gilling and Gilling argue that mainstream research on the elderly is done for the benefit of others.

The mainstream research agenda tends to treat older people as a 'subject group' to whom and upon whom research is done...it tends to be designed not for older people, but for younger generations to enable them to deal with, or to, older people.

Gilling and Gilling (1997, p.10)

I have found this to be so during the course of this study. Research which deals with ways to organise and structure the daily lives of older persons, especially those in care, is easy to access. The bulk of much gerontological research is concerned with the medical aspects of ageing and its containment, with the morbidity of the last few years of life and its attendant costs. The voices of older people living in the community are rarely audible. Two exceptions, Gluckman and Tagg, (1995, Ageing is Attitude) and McLean (2000, At the End of the Day: Ten New Zealanders in Their Eighties Reflect on Life in Old Age) are edited accounts of interviews with the elderly designed for the general public. Although the latter features some high profile New Zealanders, the former presents the voices of more ordinary folk, both men and women. The growing politicisation of older people, however, was noted by Nigel Roberts and Stephen Levine (1993, pp. 231-233) when they examined the composition, organisation and the aims of 
groups such as Grey Power and Age Concern who form an advocacy lobby for the elderly.

While substantial information is available about the small proportion of frail and dependent older women in rest home care (Gibson, 1998) little has yet appeared about the lives of older women living independently or interdependently in the wider community. The New Zealand Royal Society (1999, p.7) refers to the fact that there are many studies on the epidemiology of ill health and ageing, but little on older people in good health. I hope that this study will help to fill the gap.

\subsection{The feminist context}

A feminist perspective has guided my interpretation of the readings. Thus in economic terms women's limited access to material wealth has created a substantial difference between the ageing experiences of men and women. "A person's role in production and reproduction during working life has a profound influence on the material and health resources they have at their disposal (Arber and Ginn 1991, p.178).

Older women face a double oppression when ageism is added to sexism (Bonita 1993, Palmore, 1997). In the past feminists have in the main ignored the issues of ageing and in so doing have contributed to the invisibility of older women as Macdonald and Rich (1983), and Copper (1988), demonstrate from their own experiences in the women's movement in North America. As will be shown in chapter three, it is only recently that feminists have seriously addressed issues for older women. Colette Browne (1998) asserts that the study of older women requires a feminist gerontology based on a life span perspective. Much of the research on older persons has been interpreted from an androcentric perspective, that of male retirement from the work force. Data from gerontological research has not been systematically disaggregated by gender and has frequently focused solely on male subjects so that some of the literature reviewed in chapter three encompasses both men and women. While this study is centred on the quality of life for women, the lives of men and women intertwine over the life course. We have lived in a patriarchal society and although this may be changing, the effects of men's decisions made with their own needs in mind are still evident. 
As an older woman, a feminist, and a socialist, the theoretical framework of this work is that of socialist feminism. As an older woman and a researcher I am both 'inside' and 'outside' this study. This paradoxical position relating to reflexivity is discussed in chapter four. Methods and procedures have been selected to avoid, as far as possible, the exploitation of the participants. Both quantitative and qualitative methods of data collection have been used, the one supporting the other. My access to knowledge in this framework may be considered privileged, but cannot be value free. The diversity of the participants required that I recorded many points of view and I have done this using their own words. The selection and interpretation of these reflect my own experience and knowledge. This is open to the criticism of lack of objectivity, but from a feminist perspective Reinharz $(1993,1992)$ argues that objectivity may not be possible nor may it be desirable. It is my belief that positions of objectivity and neutrality are partial only and are frequently chimeras.

\subsection{The social context}

This study takes place at a time when demographic age-related changes in the structure of the New Zealand population are a matter of economic and political concern. While in 1996 the proportion of adults in the population aged 65 and over was 11.6 per cent, by 2051 the Government Statistician's projections indicate that this ratio will have risen to somewhere between 23.1 and 28.3 percent. $^{2}$ Because of their greater longevity women will outnumber men among the older population and will also constitute a large majority of those aged over eighty-five. Older women are increasing not only in numbers, but also as a growing proportion of New Zealand's population in the twenty-first century, and particularly as members of the group of those aged over eighty. This has raised questions about the country's future capacity to provide for such a high proportion of elderly who are perceived as dependents needing expensive healthcare in their later years and who will be supported by a relatively small base of economically productive adults.

\footnotetext{
${ }^{2}$ The Royal Society Report on the Intergenerational Impacts of Ageing, revised edition, 1999.
} 
I have placed this study within New Zealand's historical record of providing for the needs of the elderly, which seems driven by a tension between two recurrent themes. On the one hand is the belief that individuals should provide for their own needs in old age, and on the other, that this should also be a concern of the state. Consensus on the desirable mix of public and private provision of income for the elderly or how this is to be achieved has not been yet been reached and is subject to changing political and economic climates. Without the present government funded superannuation scheme, and the high levels of home ownership made possible by an earlier scheme for low interest home loans in a period of economic prosperity, the relative security of the present generation of older women would not have been possible.

The current government policy is to support positive ageing. The Minister for Senior Citizens and the Senior Citizens' Unit of the Ministry for Social Development have initiated community discussions on this concept. Fiscal issues have been addressed by increasing the age of eligibility for the old age pension from 60 to 65 and by outlawing age discrimination against older workers, thus affirming their value to the economy. Such value, however, is not reflected in the policies of many employers as evidenced in MacGregor and Gray's study of mature job-seekers (2001) where older workers experienced ageist discrimination in hiring procedures. Such prejudice may relate to negative social views of older persons as unproductive. The productive capacity of healthy older people has possibly been obscured by visions of the minority frail elderly in residential care. Positive Ageing has been related to lifestyles promoting good health. These lifestyles often correlate with access to material resources. In New Zealand, the Ministry of Social Policy's Social Report (2001, p.73) shows that the gap between the poor and the wealthy has grown steadily. It may be that positive ageing may be more readily accessed by the affluent.

While positive images of older people are not new ${ }^{3}$, some writers consider the recent promotion of 'positive' or 'successful' ageing may be a double-edged sword creating false standards and promoting a norm only possible for some

\footnotetext{
${ }^{3}$ See for example the Roman writers Seneca the Younger ( c.45 a.d.), in his letters and Tullius Cicero (c.44 b.c) who, in an essay De Senectute, wrote of the pleasures and advantages of old age. Representative of the general biblical view was King David who "died in a good old age, full of days, riches and honour.” ( 1 Chronicles, xxix, 29)
} 
people, more particularly those under eighty with economic security and good health.

The currently fashionable positive mythology of old age shows no more tolerance or respect for the intractable vicissitudes of aging than the old negative mythology. While health and self-control were seen previously as virtues reserved for the young and middle-aged they are now demanded of the old as well. Unable to infuse decay, dependency and death with moral and spiritual significance, our culture dreams of abolishing biological aging.

Thomas Cole (1986, p.129)

In 1998 the Royal Society of New Zealand was commissioned to prepare a research strategy for the intergenerational impacts of ageing in New Zealand. Their proposed priority topic areas for new research into ageing populations focuses specifically on "what is needed to maintain the capacity of older people to remain independent and secure, and able to contribute to families, the community and the workforce” (p.19). They acknowledge the need for a wider range of research methods than the purely quantitative, and citing Gilling and Gilling (1997, pp. 9-12), refer to the qualitative options that "actively involve older people and bring out their perceptions and views.” I have followed this rubric in using both individual questionnaires and interviews allowing the women's personal input. While the collection and selection of data is subject to my personal choices, I believe that this thesis provides a view of the realities of this group of older women.

\subsection{Summary}

This chapter has introduced the topic of the thesis, its limitations and its personal and social context. It has signalled the ethical, economic and political issues present in the current climate of concern with the future demographics of ageing. The concepts of ageism and sexism that affect older women have been introduced as have the conflicting social attitudes towards the aged. It has raised feminist issues and indicated that feminists are now contributing to gerontology, both in theory and in the promotion of qualitative research. This study highlights and is informed by the need for older women's voices to be heard in the context of their everyday lives. 


\section{$2 \quad$ Ageing in New Zealand}

\subsection{Introduction}

In researching for this chapter, I found the first substantial feminist studies addressing the current problems of older women in New Zealand were those of Peggy Koopman-Boyden (1988, 1999, 1993) and Ruth Bonita (1993). These studies drew attention to the demographics of ageing, the disadvantages in health and healthcare experienced by older women, their lower incomes and assets, and the effects of ageism and sexism. They also drew attention to the relationship between quality of life and good health, adequate income and continued social contact. More recently researchers such as Anne Else and Susan St John (1998) have taken up these issues. For historical references I am indebted to the work of Margaret Tennant (1989), Ann Beaglehole (1993), Erik Olssen (1980) and an earlier source, W. B. Sutch (1966 and 1969), has also been invaluable.

New Zealand has had a public pension system since 1898, but this did not come about easily. From the early times of European immigration the country was seen primarily as the domain of the younger man, a hardy pioneer or adventurer breaking in a new land. This stereotyped male is well represented by Jock Phillips in A man's country? The Image of the Pakeha Male, A History (1987). Pioneer women also led lives of great fortitude and hardship as noted by Barbara Harper in Petticoat Pioneers (1980). From the earliest years of colonisation, they were particularly vulnerable to poverty due to their economic dependence on men (Tennant 1989, p.103). There was a culture of self-sufficiency and little thought was given to support of the old or indigent. The poor laws of Britain were not imported along with British immigrants and when illness, loss of work, or the exigencies of age struck and relatives of the poor could not be found, what little assistance was available came from church or charitable aid (Sutch, 1996). Widows, deserted wives and unmarried mothers had little or no support, the two latter especially being viewed with a prejudiced eye; their misfortune due to immorality or failure as wives (Tennant 1989, p.108). In Britain Levin and Levin (1980, p. 35) similarly note the culture of blame attached to the aged. The 
historical material in the following section was referenced from Sutch (1966, pp.88-94), Beaglehole (1993, pp.36-45) and Fergusson et al. (2001, pp.2-5).

\subsection{The struggle for a universal old age pension}

In 1846 provincial governments made near relatives responsible for the support of the destitute, the orphans, widows, deserted wives, the sick and the old. At the time the provinces were abolished in 1876 the country entered a period of economic recession and under the 1877 Destitute Persons Act, 'near relative' came to include the stepmother, stepfather or brother of the destitute person (Sutch, 1966, p.84). The responsibility was to rest with the family and any costs incurred by the state or local body in support of the indigent could be recovered in court, the debt bearing interest of eight percent. The overriding factor in the state provision of welfare related to the health of the nation's treasury, the budget constraints of government and a firm belief in the responsibility of individuals to provide sustenance for themselves.

Local bodies were supported by the rates of property owners who were naturally loath to accept financial responsibility for hospitals and charitable aid. Many of the early male settlers did not marry and as they aged had no family to turn to for support. When the long depression of 1865-1895 took hold, broken only by a brief boom in the seventies, the unemployed farm labourers and tradesmen, widows and deserted wives swelled the numbers of the indigent. Many men sought employment overseas or chanced their luck on the goldfields and the plight of women and children without support became a national disgrace. The government's answer was to grant local bodies a subsidy to assist with the maintenance of hospitals and the support of the indigent. By the late 1880's however the elderly, particularly men, were identified as a social problem and the young country had no suitable social structure to deal with it.

In 1882, Harold Atkinson, a conservative Member of Parliament, introduced a scheme for national insurance to parliament, pointing out that the only solution to 'pauperism' was compulsory co-operative thrift and this could be obtained by a 
contributory scheme to provide support in sickness, old age, or widowhood and for orphans. Contributors between the ages of 16 and 28 would finance the scheme and for persons over 65, payments would be made out of revenue. For widows and orphans in the current generation money could be set aside from rents of crown lands. As Sutch notes (1996, p.87) these proposals for national insurance to finance sickness and old age were strongly resisted by the liberals. Despite charitable aid alone being unable to support the growing army of poor, of which large numbers were the elderly, women and children, the wealthy saw it as a scheme to sap self-reliance, break up the family and inimical to Christian values. Later as Prime Minister 1883-4, Atkinson could still find no support for his scheme.

By the early 1890's trades unions and the Knights of Labour ${ }^{1}$ were pressing for a programme of old age pensions to be paid for out of a progressive income tax rather than by personal contribution. Many workers were unable to keep up payments when so much labour was seasonal, casual and subject to long periods of unemployment. Denmark and Germany had pensions for the elderly and they argued that New Zealand should also establish a more sympathetic treatment of the aged poor. Provision of an old age pension became a political issue. By 1896 a bill was before the House of Representatives, but because of disagreement over the scope of the bill, the Prime Minister, Richard Seddon, withdrew it rather than accept its universal application. In 1897 it was introduced again, with no differential in the payments for men and women, but this time with the proposed payment reduced from 10 shillings to 6 shillings and 11 pence, to come from general revenue. This offended the conservative landowners who foresaw increased land and income tax to fund it. They preferred workers' contributions. The old arguments opposing the pension were rerun. It was claimed that pensions would discourage thrift, attract degenerates and imbeciles to the country, create an army of sturdy beggars and "gradually destroy our civilisation” (Sutch, 1966, p.91). In committee the House decided that the pension should be the right of all old people, but Seddon again dropped the bill. Its fortunes became dependent on factors other than the plight of the poor. Unemployment was taking working men

\footnotetext{
${ }^{1}$ An American organisation dedicated to labour federation in the world active in New Zealand, 1888-1894.
} 
out of New Zealand to the goldfields of the Klondike and Richard Seddon could not afford to lose the votes of workers and small landowners in the coming election.

Although Seddon himself had opposed the 1893 enfranchisement of women, by 1898 their votes may very well have been a consideration because a pension system would ameliorate the poverty of many older women, and its anticipation could possibly have increased the Liberal vote. In her article in the Evening Star on September $19^{\text {th }}, 1914$, the anniversary of suffrage day, Kate Sheppard looked back on the positive gains of women's enfranchisement and referred to pensions for the poor having been provided for both sexes equally (Macdonald, 1993, p.10). Many of the suffragettes and members of The New Zealand Women's Christian Temperance Union had been active in the 1896 establishment of the National Council of Women which had some success in calling for government action on issues for women such as a universal old age pension (Dalziel, 1993, p.57). ${ }^{2}$ At this time, however, the invention of refrigeration was fuelling the country's economic expansion and the argument about how the old age pension was to be funded became less relevant. Sutch (1966, p.92) argues that this technological advance which increased the country's wealth was advantageous to the Liberal campaign for the pension as a social palliative.

In 1896 a survey of potential beneficiaries was undertaken for the Registration of the People's Claims Act. At a time when approximately one in twenty persons could give proof of age and many others were illiterate, over 8,000 elderly registered, of whom a very large proportion were women employed in domestic labour. Seddon, the premier at the time, was opposed to the concept of universal eligibility sought by other parliamentarians and withdrew the proposed bill rather than lose its provisions for means testing. When the Old Age Pensions Act was finally passed in 1898 it was a social palliative limited to the group of people in the community generally regarded as the 'deserving poor'. Tennant makes clear the distinction made between the 'deserving' and 'undeserving poor' They were

\footnotetext{
2 The Auckland Women's Political League, 1894, supported women's rights issues, but was opposed to the pension, which they considered "an impost on the prudent to benefit the improvident” (ibid. p.79).
} 
respectively, those modest and retiring and disdainful of charitable aid and those who sought relief. She describes the circumstances of one forty-year old Dunedin widow.

All the elements of deservedness are here: an exemplary, if insufficient level of family support; the widow herself defying ill-health and a doctor's advice to supplement her pauper dole. Above all Mary L. was honest and clean: the point is made twice in the inspector's report (Tennant, 1986 a, p.39).

According to the Act these were a man or woman over the age of 65, of good moral character who had resided in New Zealand for 25 years and who met stringent tests concerning income and assets. Income was not to exceed 34 pounds a year, of which free board and lodging was valued at 26 pounds and any other property such as house and furniture must be under 270 pounds in value (Sutch 1966, p.92-93). Beaglehole (1993, p.36) cites the 1972 Royal Commission on Social Security which when recommending an increase in benefits to the elderly refers to a pension applicant under the 1898 provisions as having had "to be a saint to qualify for a pension”. Both 'Asiatics'3, whether naturalized or not, and aliens were excluded from eligibility for the pension as were those who had served gaol sentences of various terms for offences 'dishonouring in the public estimation' (Sutch, 1966, pp.92-93). A pensioner convicted of drunkenness could lose his or her pension. Any claim for an old age pension was registered and subject to investigation in a magistrate's court. Further penny pinching by the government in 1900 reduced the allowable income of a married couple from 68 to 45 pounds. Maori were doubly disadvantaged by their entitlement to shares in ancestral land, which counted as a property exclusion, and by the requirement to prove age. According to Sutch (1966 p. 94) staff numbers in the pension department were increased specifically to find reasons for removing pensioners from the register. The amount and availability of the pension were continually subject to government's evaluation of the state of the economy and the deserving nature of the poor.

\footnotetext{
${ }^{3}$ Chinese immigrants worked for very little and were seen as reducing wage rates and 'Asiatic' carried derogatory connotations.
} 
In the years since its introduction, the pension has undergone many changes, but often as a political football to win votes, as a response to economic recession, or to a predicted age imbalance in the population. At various times women have benefited or been disadvantaged by the changes in its provisions. In 1911 women became eligible for pensions at the age of 60 and for those with dependent children at 55. This was later changed when the 1938 Labour Government addressed some inequities by creating a two tier system, an income-tested benefit at age 60 and a smaller universal superannuation benefit for those who were previously excluded by the income test. There was some overlap and confusion between the two and the discriminatory nature of the income test was considered demeaning. For the first time deserted wives became eligible for a pension, but this was not easy to access (Beaglehole, 1993, p.36). In 1955 unmarried women unable to find employment were able to receive the age benefit at 55 instead of 60 , a reflection of the social expectation of the time that women, being weaker beings (perhaps related to menopause) needed to leave the work force earlier than men. This provision was withdrawn in 1976.

In 1974 a later Labour Government introduced a compulsory contributory scheme designed to address the increasing costs of superannuation. This was disadvantageous to women because of their low earnings over their working life. However, the scheme was repealed by an incoming 1976-78 National Government that replaced it in 1977 with a non-contributory scheme more popular with voters. The new scheme, National Superannuation, was generous, with a flat rate paid from general taxation and available to all New Zealanders over age 60. Although taxable, it was not income tested and for a married couple it was set at the rate of $80 \%$ of the gross average wage. Women received the pension in their own right regardless of marital status and for many this was their first independent income.

In the ensuing years the increased costs of superannuation ${ }^{4}$, together with deterioration in the economy, led to a reduction in its rate of payment relative to

\footnotetext{
${ }^{4}$ According to Fergusson, Hong, Horwood, Jensen and Travers, 2001, Living Standards of New Zealanders: A Technical Account, the gross cost of public pensions rose from about $4 \%$ of GDP in 1975 to nearly $7 \%$ in 1978.
} 
the average wage. A claw back process was introduced in 1985, a surcharge on those with high incomes, which was in effect, an income test (Fergusson et al. 2001, p.3). This surcharge levied through the taxation system was softened by a reduction in the top marginal rate of income tax in 1980 from $66 \%$ to $33 \%$, but remained a political minefield and after many adjustments was abolished in 1998.

In 1991 a taskforce was set up to investigate how private provision for retirement might be improved and how this would interface with public provision. Subsequently, in order to implement changes in the age of eligibility from 60 to 65 by 2001, a timetabled schedule to raise the age of eligibility for National Superannuation was introduced and the current rates of payment were temporarily frozen. The need to address the problem of income support in old age on an inter party basis was finally recognised and in 1993 the major political parties $^{5}$ signed an accord to remove the issue from the political arena, an agreement which lasted until 1996. Agreement was achieved on indexation, the surcharge which taxed affluence and the public pension was renamed New Zealand Superannuation (NZS). In a 1997 referendum the option of a compulsory retirement savings scheme was rejected by $92 \%$ of voters. As well as objecting to the compulsory nature of the scheme, many people foresaw the difficulty of making payments for those on low incomes with part-time or casual work and an employment history marked by time out in caring capacities, the bulk of whom would be women. By 1998 as stated above, the surcharge had been abolished, but the value of payments had been reduced to lower than the original National Superannuation of the nineteen seventies. Subsequent adjustments have brought the payment for a couple into the range $65-72 \%$ of the average weekly wage, net of tax, adjusted annually by the percentage movement in the consumer price index. Despite the brief inter-party accord, a task force reporting six-yearly, and the on-going work of the Office of the Retirement Commissioner, which constantly reminds people to save for retirement, ${ }^{6}$ New Zealanders seem no nearer to attaining a secure system for the public provision of retirement income

\footnotetext{
${ }^{5}$ Alliance, National and Labour; the United Party signed later.

${ }^{6}$ In addition to television advertisements on public channels, and public seminars, it has produced pamphlets on Investment, Retirement Planning for Women, Setting Priorities, Paying off debt, and practical workbooks for retirement planning.
} 
than in the past. Then as now, provision is dependent not only on the extent of the nation's wealth, but also on the governing party's ethos in relation to social support and the need to win votes. The government is currently setting up a New Zealand Superannuation Fund designed to allow some of the future fiscal cost of NZS to be brought forward and financed out of current tax revenue. The present National Opposition may undo this legislation should it become the government in the future. Both Government and Opposition are promoting a 'sensible savings' ethic, but such exhortations on air, on television and in our letterboxes are only realistic for those who have adequate disposable income. While presently benefiting from basic support in old age, women today have no guarantee for the future. This is of particular significance to those women who have incurred student loans, who have experienced single parenthood, broken and poorly paid employment, or breakdowns in personal relationships resulting in financial loss and the likelihood that they will be unable to own their own home.

\subsection{The contemporary context: Its genesis}

The women in this study have lived through enormous societal change and there are recognisable differences between cohorts. The oldest participant was eight years old at the outbreak of World War I and the three youngest were born during World War II. Those in the median age range, now in their early seventies, started work before the introduction of equal pay legislation. Their personal provision for retirement may therefore be less than that of men. As some of the women interviewed in this project stated, access to private pension schemes was not possible for them at that time. For some the National Superannuation may be the first income they have had since leaving the workforce when they married. The contemporary context of older women cannot be seen in perspective without reference to the past and their traditional roles.

The nineteenth century's strong belief in women's role as wife and mother, dependent on a male provider, has persisted well into the twentieth century. In positive terms she was perceived as the stable centre, the hub around which the family revolved and a moral arbiter in society (Dalziel, 1986). Despite the heavy physical labour entailed, many women found satisfaction and pleasure in a well- 
run household and their skills as carers and nurturers of both their menfolk and children. Marriage was their main occupation and according to Dalziel there was an expectation that they would raise the moral standards in the colony and exert a civilising influence on men. However it is also clear that they contributed to the family budget in ways other than their skills as housekeepers. The wives and daughters of both the middle and working classes gave unpaid assistance on family farms and shops. Very few women took up paid employment outside the home once they were married, although sewing was taken in and home produce sold. Dalziel notes that in 1891 twenty-four percent of women worked outside the home, but that only a limited range of work $^{7}$ was available to them, mostly domestic. Tennant (1986) demonstrates the formalisation within the education system of women's preparation for domesticity, for her vocation as wife and mother and hence the need to train her in domestic skills. Few women had the opportunity for tertiary education and many, especially the poor, left school at thirteen or even younger. They were needed to help at home or to contribute wages to the family. "It was the middle class that invented the slogan, a woman's place is in the home, not the small farmers or wage workers” (Sutch, 1973, p.12).

There were differences based on social class. A wealthy woman was a manager of servants from the working classes, a middle class woman may very well have been her own servant in the home, but unless she were widowed or deserted her own social status would fall should she take paid employment outside the home. Sutch (1973) describes the wife of a rich man leading a somewhat parasitic existence. Neither she nor her daughters were required to work for money although they may engage in charitable works in the community. For girls who had a little education, nursing, teaching, and clerical work were seen as suitable employment. For working class girls their occupational choices were shop, office and factory work or an apprenticeship in a useful trade such as millinery, dressmaking and baking, but this was still expected to cease on marriage. Should the marriage fail, a widow or deserted wife was considered the responsibility of male kin, fathers or brothers. For women without male support much of the work

\footnotetext{
${ }^{7}$ Graham (1992, p.125) gives figures for female employment in 1891: Domestic employment including providing board and lodging 19,400. Clothing, textiles and food production 10,900, teaching and nursing under 6,000 and shops and offices less than 3,000.
} 
then available to them, was of a casual and menial nature, earning a pittance from cooking and cleaning, or taking in washing, sewing and mending for the wealthy.

The mixture of hard work and the limited opportunity for work and education is well described by the 51 older women interviewed in 1980 for the Society for Research on Women in New Zealand (SROW). They speak of their early years and the lives of their mothers. ${ }^{8}$ Educational opportunities were facilitated or constrained by the socio-economic status of their fathers, parental prejudice, financial constraint or the accepted custom of the time which was that girls would leave school and stay home helping in the house until they married. Twelve left primary school aged 13-14 some having gained the 'Proficiency Certificate' which would have given them access to two years secondary education. Twentyfive had some secondary education and fourteen attained tertiary levels. This study indicated that unpaid work at home reigned supreme as described by Connie aged ninety who describes the drudgery of cleaning and cooking before the advent of electricity.

You spent all day doing housework. It really was full-time. Wash day was a big day. Light up the copper in the back yard and wash. Really you wouldn't do anything else on wash day except cook the dinner and gather up sticks for the copper.

SROW (1982, p.51)

Mary Barkas in 1937 wanted "to abolish the wageless slavery of the housewife" and Elizabeth Kelso, in a 1938 article entitled "Do you Stoke or Switch?" suggested that:

...labour saving machines, especially washing machines-be regarded as necessities in the home and that they be classed with certain surgical instruments and educational material and allowed into the dominion duty free.

MacDonald (1993, pp. 113, 116.)

As well as ceasing paid employment on marriage, some women in this study described themselves as having been expected to care for other family members, especially parents in their old age. Josephine, in the SROW study cited above,

\footnotetext{
${ }^{8}$ Wellington Branch Society for Research on Women in New Zealand (SROW), 1982, In Those Days; A Study of Older Women in Wellington.
} 
left school at 17 to look after her blind father and on his death looked after her sister's children who had no secondary school in their country district and so came to live with their aunt. Obligation to family was paramount and the duty of care fell particularly heavily on unmarried daughters. Annabel and Martha had their teaching careers cut short by their families' need for help. A telegram brought Annabel home: "Come home, Grandmother very ill, doctor says long illness. I need you.” and Martha explained her circumstances as follows:

I had a very strenuous time because my father fell and injured his back and was an invalid for two years. I helped mother nurse him, then the war came and my father died and I cared for her for about twenty years.

SROW (1982, p.5)

This pattern is also shown by Ford and Sinclair (1987, pp.74-75) in their interview with Miss Stewart, aged 81. As the youngest of five girls and unmarried, she was expected to look after her parents and support them financially although her work was poorly paid. She did not achieve some independence until her parents' death by which time she was in her late forties. My own family situation was similar. My grandmother's marriage was delayed for five years while she returned to Britain to care for her ageing parents until their death. My mother looked after her parents in law and I looked after my father. That women's role as care givers of the elderly has changed little over time is evidenced by the situation of Gwenda, who until she was 80 cared for her handicapped daughter. In turn, they were both looked after by Gwenda’s daughter Rayna, who left a career at 52 to care for both her mother and sister ('Caring Times' No.1, July 1999, p.6). The relevance of caring activities to the accumulation of savings is discussed in section 3.4.

Other crises such as illness, death of a spouse, desertion or the birth of a child outside of marriage created further hard times for women. There was little support for them outside the immediate family and that was not always available. In a country of immigrants there were many whose families of origin had remained in the 'Old Country.' Sources of help were churches, a few private charities and the charitable aid function of hospitals (which persisted into the nineteen thirties). Social norms valued pride in the ability of a family and individuals to support themselves. Worldwide depression and growth of unemployment from 1927 produced increased poverty, and the conservative 
government of the time reduced aged widows' pensions and cut health and education services. Between 1931 and 1932 Civil Service wages were cut by $20 \%$, thousands of farmers became insolvent, 100,000 men were unemployed, and State Advances, a Government lender, reduced loans for housing by seven eighths (Sutch, 1969, pp.270-271). Men, women and children suffered, but under these conditions it was the women who bore the brunt of managing to feed and care for families. The older women in this study have learned habits of 'making do,9 through direct experience as young women with no access to the unemployment benefit during the depression years, or through the experience of their mothers coping with bringing up families in the straitened conditions of those times including the rationing and shortages of wartime. The continuing expectation that women should be supported by men was reflected in government policy. In spite of women paying tax for the relief of unemployment (introduced in the 1930 Unemployment Act), they did not receive unemployment benefits until 1938. This was part of the social policy platform of New Zealand's first Labour Government. Reforms such as free schooling for all without examination until age nineteen, and increases in the range and value of pensions including pensions for deserted wives (1936) were followed later by free milk in schools, abolished in 1967, increases in family benefits, and free hospital and general practitioner services. These measures improved the material quality of women's lives.

The Second World War brought more times of austerity, worry and the personal loss of family members. The death of so many men reduced the opportunities for marriage and children for many women. As in World War I, women entered a wider range of occupations, but post-war the expectation was that they should to return to the nursery and kitchen and leave paid employment to men. Many women however continued in part-time employment and some returned to fulltime employment when their children were older. The unavailability of good quality child-care prevented many from gainful and interesting employment. Table 2.1 below, taken from the Ministry of Women’s Affairs, Panui (April 1999,

\footnotetext{
${ }^{9}$ This phrase 'making do' was common in my own childhood and represented many household activities such as substituting buttons for elastic in bloomers, making children's underwear from flour bags, turning collars and cuffs, sides to centreing sheets to extend their wear and using cut newspaper squares and apple wrappings for toilet paper.
} 
p.9) shows the main events from the First World War to the end of the twentieth century and the progression of age cohorts through it.

Table 2.1

\begin{tabular}{|c|c|c|c|}
\hline Year & Times and Trends & Born 1934 & Born 1914 \\
\hline 1999 & Rise of the global economy & Now 65 & Now 85 \\
\hline 1980s & $\begin{array}{l}\text { s Structural reform, changing nature } \\
\text { of employment }\end{array}$ & 55 & $66-75$ \\
\hline 1970s & $\begin{array}{l}\text { Revival of feminism, Maori } \\
\text { resurgence, rising levels of } \\
\text { education }\end{array}$ & $36-45$ & $46-55$ \\
\hline $1960 \mathrm{~s}$ & $\begin{array}{l}\text { s Sexual revolution, political } \\
\text { activism, Vietnam war }\end{array}$ & $26-35$ & $46-55$ \\
\hline 1950s & $\begin{array}{l}\text { sost war era, economic security, } \\
\text { baby boom }\end{array}$ & $16-25$ & $36-45$ \\
\hline 1940s & $\begin{array}{l}\text { s Second World War, many women } \\
\text { in the workforce }\end{array}$ & $6-15$ & $26-35$ \\
\hline $1930 \mathrm{~s}$ & $\begin{array}{l}\text { s Depression, development of } \\
\text { the welfare system }\end{array}$ & Born 1934 & $16-25$ \\
\hline \multicolumn{4}{|c|}{ Twenties” } \\
\hline First V & World War 1914-18 & & Born 1914 \\
\hline
\end{tabular}


It is clear how different some of the experiences of women who are now in their eighties will have been compared to those now in their sixties and seventies. The figure does not include those added experiences, which were the effects of ethnicity, disability and social class.

The participation of women in the workforce has increased markedly since World War II (Giddens, 1992, p.509), but women’s employment is still characterised by part-time and casual work in the relatively low paid occupations of the secondary labour market (Statistics, New Zealand and Ministry of Women's Affairs, 1999, pp.83-105). Full-time work is broken by family responsibilities, resulting in a limited capacity to save for retirement. As argued by Prue Hyman (1994, pp.79100 ), equal pay legislation has not necessarily produced equity for women in the labour market, nor has this eventuated in the area of job opportunities to which it has been linked (see also section 3.6.4).

The 1988 Royal Commission on Social Policy Volume IV Social Perspectives recognised that while husbands care for disabled wives, many women care for children, elderly relatives and non-family members as well as for their dependent spouse, and many more daughters and daughters-in-law care for dependants than do sons-in-law. They pointed out that women's unwaged work may result in long term vulnerability, hardship and financial dependency for themselves.

Marian Bywater (1989, pp.2-15) points out that the amounts that women can save are small and irregular especially if they parent alone or child-care costs are borne unequally within a partnership. She argues that they are disadvantaged in employer-run superannuation schemes that are geared to the male life cycle rather than the female. In addition to broken or less service time accrued, a woman because of her greater longevity must save more than a man.

As stated above, since the end of World War Two, women have expanded both their range of occupations and rate of participation in paid employment. The 1962 introduction of the contraceptive pill enabled them to control their fertility and so influenced their choice of work after marriage. Dunstall (1981) notes that in 1951, a quarter of the females aged 15 and over were in paid employment and 
that by 1971 this had risen to one third. However, despite the increased proportion of girls leaving school with University Entrance from the 1950's onwards, two thirds of the female workforce were employed in the growing white collar service sector, but found "mainly in semi-skilled jobs and professions of low status” (p.415).

Currently many women and low paid New Zealanders with families are not in a position to save for old age. The increasing costs of education and the burden of student loans together with the uncertainty of employment make it unlikely that future retirees will have achieved home ownership, which has represented security for most of the present generation of elderly. Uncertainty remains as to the future provision of New Zealand Superannuation. Perhaps the age of eligibility will be raised to seventy, the rates of remuneration lowered, and an abatement regime instituted to limit the recipient's savings. These issues remain unresolved. For many women whose capacity to save is still limited by inequities in the labour market, and whose life expectancy is greater than men's, the changes suggested above would be matters of concern.

In 1997 the Prime Ministerial Task Force on Positive Ageing put out a document for public consultation, "Facing the Future: A Possible way Forward." It discussed attitudes towards older people and the ageing process, challenged the negative myths about ageing and suggested three goals (p.18) that could address these concerns and promote positive ageing.

Older people are acknowledged as trustees of our culture, their skills and life experiences valued and celebrated by all New Zealanders.

Competence and Choice rather than age, are the primary determinants for participating in work, community service, learning and leisure.

People of all ages can participate together in the diverse range of activities and institutions that characterise New Zealand culture.

The Taskforce believed that two key influences would affect the capacity of our country to achieve these goals, the strength of the economy and our attitudes to age and the ageing process. The latter is a reminder of the opening remarks of a 1982 New Zealand Department of Health report to the World Assembly on Ageing. This found that the greatest handicap to the interests of the elderly in 
New Zealand was public attitude, " the elderly are portrayed as rather outdated members of society who have very little to contribute. To the public, old age is an inevitable deterioration of mind and body for which nothing can be done" (Barker et al., 1982).

In 1998, concern with the changing population structure in New Zealand prompted the Ministry of Research, Science and Technology to commission The Royal Society of New Zealand to prepare a research strategy on the intergenerational impacts of ageing. With input from government departments, which provided information on key research areas, strategic knowledge and policy issues, the society produced a report highlighting four priority areas for research (pp.21-22):

- Capacity and ability in older age

- Changing patterns of family dependence.

- Changing retirement outcomes for different cohorts

- Relative responsibilities of individuals, family, community and state

A central objective of the research was to generate knowledge that would improve the capacity of the older population to support itself: That is, "to remain independent, secure and able to contribute; limiting the negative intergenerational impacts of ageing” (p.16). Such knowledge was crucial for social policies that would address the issues of an ageing population.

It is important to generate knowledge of the ageing processes, the heterogeneity of situations and the capacity in the older population themselves, either in terms of high degrees of self-reliance, or the ability to provide intergenerational caring and support. Research into values would reveal how older people view their contribution, and give insight into their self esteem, as well as how society perceives their contribution.

Royal Society of New Zealand (1998, p.18). 
The input from bureaucracy strongly focussed on the interaction of the older population with the economic, social and political environment, and the fact that intergenerational support will be less necessary when older people are able to continue to support themselves, thus reducing intergenerational fiscal transfers. The Ministry of Health, addressing the issue of retirement income and government policies, was very explicit in its comment on the need for, "more certainty [and a] change in attitudes of the population's belief of 'cradle to grave care’ by government” (ibid, Annex 3).

These are the concerns of a society based on the pre-eminence of individual responsibility for the provision of life's necessities, the 'I' rather than 'we'. While assuming the traditional support of families, the report does express and acknowledge the public concern with the current breakdown and reconstitution of families and their limited capacity to support elderly dependents. On the other hand some families may in fact be substantially supported by the regular income of a superannuitant present in the household and by the contribution of their savings or unpaid labour, particularly as care-givers of the young.

The current trend is for women to continue to work while rearing children. Whether this is through career choice or the pressure to provide an adequate income to support a family, which is no longer guaranteed by one wage, it has led to a scarcity of workers in the unpaid voluntary sector and this is increasingly being serviced by the elderly. While more women are working, they have, as described above, a limited capacity to save for retirement and can no longer rely upon the provision of a male partner. In addition, as Beaglehole notes, they do not fit easily into conventional pension schemes designed for men (ibid. p.40). They are a less attractive risk for companies selling superannuation products and due to their greater longevity, women have to pay in more to receive the same annual annuity as men do.

\subsection{Recent New Zealand activities relating to age}

Since the late nineties, non-government organisations, academia, local bodies and the government have actively generated knowledge about ageing. Conferences 
and seminars have been held concerning welfare, health and retirement provision for the elderly. Some of these such as the 1996 Conference on Retirement Income and Women sponsored by the Ministry of Women's Affairs have specifically focussed on women. Others such as the Wellington Gerontology Conference, 1999, Challenges and Opportunities: Issues for the Millenium and the Tower Conference, 2000, Learning From the Past, Looking to the Future: Ageing and Intergenerational Relations in the New Millenium, have encompassed both genders, but have produced some work specific to women. Older women have also been the subjects of some recent university theses concerning health (Milligan, 2000), volunteering (Cave, 1998), use of the Internet (Roorda, 1998), perceptions of ageing and support of the elderly in the community (Lim, 1990), and older women's fear of crime, (Knaggs, 1996). Government funded research has produced research strategies on ageing (The Royal Society of New Zealand, 1998; Super 2000 Task force, 2001) and a review Living Standards for Older New Zealanders (2001).

The Senior Citizens unit of the Social Policy Agency has issued the Final Report for the International Year of Older Persons, 1999. This provides a full listing of the activities, conferences, seminars and publications of community and government agencies that promoted the interests of older persons during this designated year. The unit has also has sponsored regular and ongoing seminars on ageing and the activities of community volunteers many of whom are elderly and predominantly women. The designation of 2001 as the Year of the Volunteer recognised the contribution to the community made by voluntary unpaid work, a large proportion of which was supplied by older women. Local bodies ${ }^{10}$ have promoted the welfare of the elderly and organisations such as Carers New Zealand, Age Concern, and Grey Power have been active in drawing the attention of the government to the needs of the elderly. In 2002 there is a planned update of the Annotated Bibliography of Research on Older people in New Zealand, 1986 to 1996 (Gilling and Gilling, 1997). Also significant is the recent establishment (2000) of the New Zealand Institute for Research on Ageing, NZiRA; this is a

\footnotetext{
${ }^{10}$ See 40+ Project Report 2000, Creating Communities for all Ages: Local Government and Older New Zealanders, Hamilton City Council 1999, Older Persons’ policy.
} 
multidisciplinary centre for ageing-related research, based at Victoria University of Wellington whose inaugural director, Dr Judith Davey, was appointed in 2002.

It is clear from the above that the issues of ageing are no longer being neglected, nor are they solely the preserve of gerontologists and social workers. Attention is being paid to the needs of women because of their greater longevity and the projected increase of the aged in our population. However, the structural issues of women's employment and lack of pay equity referred to above will require the further development of national social policies. A heartening aspect has been the active participation of the elderly in seminars on age and the recording of what they have to say.

\subsection{Summary}

Historical and contemporary contexts relating to the provision of support for the elderly have been reviewed here. I have argued that such provision of support has been enmeshed in conflicting beliefs. On the one hand it is claimed that individuals should support themselves in old age, and on the other that this should be, in part at least, a government responsibility. Although the state is currently funding superannuation from the public purse there is lack of agreement as to its future structure and provenance. The ethics of distribution to the 'deserving' and the 'undeserving', to all or some, and how this should relate to the earnings of those in paid employment are still before us. While research recognises the limited lifetime opportunities that many women have to save for old age, there is as yet no clear government strategy to address this issue.

The recent burgeoning of interest in the study of the elderly has been documented, and specific studies of older women have been noted. I have also recorded some positive steps taken by government and non-government agencies in engaging ordinary men and women to participate in studies of their own situation as older citizens. 


\section{A Review of Literature on Women and Ageing}

Population ageing is an identifiable and inexorable major international sociodemographic trend. Through its intergenerational impacts, it will have implications for every aspect of national life within the next few decades, and thus will strongly affect the sustainability of social and economic development.

New Zealand Royal Society (1999, p. 9)

Old age is not interesting until one gets there, a foreign country with an unknown language to the young and even to the middle-aged.

May Sarton (1983)

\subsection{Introduction}

The quotations above represent two aspects of ageing, the public and the private, the perspective of the state and of the individual. These two perspectives will inform my approach to women and ageing. The quality of life for older women is not determined by individual attitudes, beliefs and material resources alone, but also by social structures and Government policies, which interact with personal experiences. Although ethnicity constitutes an important factor in a study of ageing, it has not been addressed here for reasons detailed in the introduction to this thesis. Most of the literature reviewed here, concerned with concepts of ageing and theoretical approaches to old age, comes from overseas research and relates to cultures in the western world other than our own. This, however, is relevant to the understanding of age in a pakeha context. I have also used specific data from New Zealand sources, from both institutional and academic publications including recent feminist theses Knaggs (1996), Hasan (1998), Roorda (1998), Cave (2000) and Milligan (2000) and the earlier work of Peggy Koopman-Boyden and Ruth Bonita. This review does not include the details of research on older women in residential care. As stated in 1.3, this study concerns only older women living in the community, although the possibility of being institutionalised in this way is a cause of concern for elderly women. This was evident in my interviews and discussions with some of the older women in this project. 
The concepts, theories and descriptions of the ageing process reviewed below cannot focus exclusively on women because so much of western culture has represented old age through the eyes of men, and has focussed on their own ageing. Other than noting the preponderance of females in the older age groups and their tendency to suffer more from chronic illness than men in older age groups, little of the research I found had been disaggregated by gender. Early research on ageing in the social context appears not to have considered the differences in the ageing experiences of men and women despite the greater longevity of women in the twentieth century. The legacy of a patriarchal society has been an ideology saturated with androcentric values whereby men are considered the 'standard' or 'norm' and women the 'other' Gannon (1999, p.2). Calasanti (1993) argues that in the main, gerontological theories are based on the experiences of white middle class males. Early theories of ageing are clearly related to the modern Western World's concept of the male working life outside the home and his retirement; however, the last decade of the twentieth century has produced feminist analyses of women and ageing, which have increasingly informed the work of gerontologists in both theory and practice.

The meanings of age and ageing are expressed in many forms and are mediated by culture, social class and gender. Age has been studied chronologically, physiologically, psychologically and in social contexts both historical and contemporary, but age can only be fully understood when its multiple facets are integrated. The study of ageing is essentially an interdisciplinary text. Images of ageing are found not only in the formal disciplines of gerontology, sociology and medicine, but also in literature and art, in newspapers and magazines, on radio and television. These public images both reflect and create social attitudes to the aged. Since the elderly have been constructed as yet another segregated social group with age related boundaries, age has become a subject for market research. Like adolescents, young adults and the middle aged, older people have become a target for exploitation in a consumer-led society where commercial interests, in the search of ever increasing profits, reconstruct wants as needs. Advertisers focus on both the positive and negative images of ageing, with a flattering appeal to the elderly's maturity of judgement, which legitimates a sense of 'deserving', 
and with reminders of increasing dependency, which plays upon an older persons' fears and insecurities relating to safety and health.

Wisdom and respect have been almost universally ascribed to the aged of both sexes, to sages and wise women, but there is little evidence to show that it has been a dominant feature of the delineation of age at any one time in history. It is rather, that the predominant written and visual images of the past have been of physical decay, cognitive decline, feebleness, decrepitude and non-productivity. These negative images still pervade contemporary attitudes to the elderly, despite current catch-cries of successful and positive ageing. In the public eye older people are often grouped together, the younger old with the older old, and the ascribed weakest of the latter applied to all. While the vicissitudes of age should in no way be overlooked or minimised, neither should they occupy the forefront of approaches to age in a society characterised by a greater longevity than at any other time in recorded history. Both aspects of this dichotomy of positive respect and negative dismissal are examined in sections 3.4 and 3.5.

The second wave of feminism drew attention to reproduction, sexism, menopause and middle age, but older women did not feature as subjects of research. The writings of MacDonald and Rich (1983) and Copper (1988) stand out as a challenge for feminists to address the apparent low social status and invisibility of older women. In the decade since then, women have more actively researched older women. This may be in response to the personal ageing of feminists, or to a general awareness of the demographic projections of population ageing, which place women as a majority of not only all elderly, but the main constituents of the 'old olds', those over eighty-five ${ }^{1}$. This population trend is worldwide, not confined only to New Zealand or the western world; the number of all women over age sixty will more than double in the next quarter century; by 2025 women will account for fifty-four percent of all older people, Armstrong (1999, pp.4-5).

\footnotetext{
${ }^{1}$ In 1996 there were 244 women for every 100 men in the 85 and over age group, and based on expectations that the female advantage in life expectancy will reduce from 5.3 years in 1996 to 4.5 years by 2051, there will then be 162 women for every 100 men. (Statistics New Zealand and Ministry of Women’s Affairs, 1999, pp.16-17)
} 
This has become known as the 'feminisation of old age', which was a focus for the 1999 United Nations International Year of Older Persons.

In the research on older women since the mid-eighties, work of particular importance is that of the British sociologists Sara Arber and Jay Ginn (1989, 1991, 1995) who have focussed on social class and gender-based life course outcomes for older women. They show that the material disadvantages experienced by large numbers of women in later life originate in women's earlier experiences in a segregated labour market, and in their unpaid domestic production. In 1986 Marilyn Bell edited a compilation of articles by American women, Women as Elders: The Feminist Politics of Aging, which reflected their growing concern with the position of older women and affirmed the value and strength of the 'crone' and the importance of black Americans' foremothers. It featured reviews of three books on older women demonstrating a growing interest in the gerontology of women. More than a decade later, however, Nancy Hooyman, Professor and Dean of the School of Social Work at the University of Washington, notes that, "while the concept of feminist gerontology (e.g.Troll, Israel and Israel, 1977) has been discussed for many years, it is only recently that it has been taken seriously” (1999, p. 115).

From diverse feminist perspectives a common feature of their critiques is that androcentrism has denied women's centrality in the aging experience. In her review of three significant books on women and ageing (Dailey, 1998; Mehta, 1997 and Coyle, 1997) Hooyman wonders at the absence of an explicit feminist perspective on the issues facing older women in 1998. All three books acknowledge the feminisation of ageing, the effects of women's earlier life experiences and the greater problems faced by older women than men. While there is an implicit recognition of the need for structural change, and some recommendation of changes to policy and practice, they stop short of explicitly articulating a feminist stance. She surmises that, even in the nineties there may be a reluctance to use the " $\mathrm{f}$ " word for fear that feminist analysis is not legitimate. The point at issue for Hooyman seems to be that a feminist perspective should not only analyse gender-based inequities, but should set forth new possibilities for women; she agrees with Ray (1996) that it involves both social critique and 
ultimately social change. In Dailey's case the structural variables which will effect the retirement of 'baby boom' women are presented, but since she concludes that social policy changes are unlikely, the burden for the provision of adequate income in retirement remains an individual responsibility. Dailey's important finding was that, despite their greater participation in the workforce than previous birth cohorts, for the 'baby boomers' the financial results of their labour would not necessarily ensure an adequate income in retirement and that they may find themselves increasingly as caregivers of society's elders.

While agreeing with Hooyman in principle on the necessity to promote social change, I nevertheless found Coyle's Handbook very useful. This was particularly so in its presentation, by various authors, of the interactions between sexism and ageism, in the terminology of negative stereotypes of older women and in the role played by the segregated labour market in depressing the economic status of women. Other feminists have taken up the challenge of structural change. Ray (1996) cites the work of Estes, Jones and Swan (1984) and a special issue of the Journal of Aging Studies edited by sociologists Toni Calasanti and Jon Hendricks, in which many of the contributors seek to explain, among other things, the comparatively high rate of poverty among older women, and to propose changes in the ideologies and institutions that perpetuate it. Another example of this is Linda Gannon's 1999 avowed feminist text that clearly sets out some strategies for change supportive of women's health which are not based solely on changing individual lifestyles. Theoretical approaches to ageing that focus only on personal adjustment rather than social reform are recognised as inadequate by socialist feminists. Lynott (1996) quotes Stoller, who requires major change, “...a restructuring of the economic relations between men and women and increased societal recognition and support for the unpaid work women perform throughout their caring careers” Stoller (1993, p.165).

A postmodern approach to ageing is exemplified in the work of Haim Hazan, (1994) and informs my approach to ageism as does the critical theory approach to ageing, used by Anne Jamieson, Sarah Harper and Christina Victor (1998). These lead to the questioning of many assumptions about age and fit well with a feminist framework which seeks social change. 
In a search of explicitly feminist texts by New Zealand authors, other than those of Koopman Boyden and Bonita, I found no substantial articles on women and their experience of ageing other than in reference to pension provision. The contents pages and indexes of Feminist Voices: Women's Studies Texts for Aotearoa/New Zealand, bore no references to older women, the index pages in Feminist Thought in Aotearoa, New Zealand, (1998) provided references for a variety of bodies, but not 'old' bodies. In Twenty Years of Broadsheet Magazine, a selection introduced by Pat Rosier (1992) there was no mention of elderly women, and The Vote, the Pill and the Demon Drink: A History of Feminist Writing in New Zealand 1869-1993 (1993) again produced only references to the old age pension.

I have focused on the access of older women to economic resources, on the perceptions of personal value that underpin their health and well-being, and on the social status of older women in the community. Since the women in this study range in age from fifty-six to ninety-four they belong to different cohorts and cover more than one generation. They will therefore have experienced a diversity of life courses across the historical context. The work of Tamara Hareven (1995) in women's life course transitions and of Glen Elder $(1975,1982)$ on the effects of experience of the 1930's depression have informed my understanding of this aspect of the quality of life for older women. This has already been discussed in chapter two drawing on the work of Tennant (1989), Olssen (1980) and Beaglehole (1993) in relation to the social roles expected of women in $20^{\text {th }}$ century New Zealand and the consequent linking of their economic status to a male breadwinner. Within any single cohort there may be a commonality of experiences, but this will have been moderated by the individual demographics of marital status, income, educational attainment and ethnicity.

This chapter has been divided into five sections with many overlaps and interconnections. Following this introduction section two discusses theories of ageing, section three the concepts and images of ageing both positive and negative, section four the phenomenon of ageism and section five material and social factors affecting the quality of life for older women. However diverse the contexts of their lives may be, women share some common ground. While not 
definitive or exclusive the variables constituting the context of their lives include ethnicity, economic resources, health, housing, transport, life histories, social connectedness and society's expectations for the elderly.

\section{2 Theorising age}

Many disciplines have contributed to theories on ageing. There are those originating in the biological sciences, which are based on progressive changes over time, evident in the physiology of the body as its capacity for cell renewal declines. Developmental psychologists track the changes in cognitive functioning and autonomy as people age, sociologists trace the changes in role and social status, life span theorists, historians and anthropologists draw attention to the contextual frameworks of ageing in real life, which demonstrate the diversity in life courses. There is perhaps greater heterogeneity among the aged than in any other age group within a society because the passage of time allows for more experiences. Economists theorise what effects the assumed dependency of the elderly may have on the health of the economy. Feminists across all disciplines analyse ageing from a gender perspective and the influence of postmodern philosophy and critical theory has militated against global and universalising theories (Ray, 1996).

Biologists have provided a variety of answers to why ageing occurs. Researching the primary cause or causes of senescence they have posited a number of ways in which bodily cells fail to reproduce normally. According to Moody (1998) these may arise from: random mutation, the limits set by a genetic clock, hormonal triggers, the Hayflick effect whereby cells have internal limits set on their capacity to regenerate, the accumulation of free radicals, wastes that interfere with cell metabolism, altered proteins or replicative errors in DNA. Whatever the genesis of these changes, they result in morbidity and eventual death. Understanding these processes is leading to the development of technologies that may delay the effect of wear and tear on the ageing body thus forestalling dysfunction and compressing morbidity to the last few years or months of life. This has important implications for the costs of medical care in an ageing population. It creates ethical issues about the prolongation of life in relation to its 
quality, and questions the locus of power in the possible rationing of healthcare for the elderly. Who is eligible and who can pay?

The present debate on theories of ageing relating to mortality and morbidity has significance for policy outcomes in health and social support. In 1980 Fries produced the hypothesis that human life had a natural span of eighty-five years. He argued that with individuals accepting greater responsibility for their own health, and better lifestyles due to improved healthcare services and education, older people would be vigorous for longer thus extending the disability-free years of life. Chronic illness and disability could be compressed into the very last years of life reducing the costs of health care to the elderly. According to Victor (1991) and Bernard (2000) the evidence is not clear as most studies have been crosssectional rather than longitudinal. They draw attention to the counter arguments of Bytheway (1982), Verbrugge (1984) and Bury (1988) who challenged both the concepts of lifespan limitation by 'wearing out' at a fixed point, and the notion that morbidity could in fact be compressed. If the focus is solely on compressed morbidity then the possibility that recovery from illness and disability will also extend the more active years of life is overlooked. Verbrugge (1989) also noted the gender differences in men's and women's survival rates which suggest that a mixture of social and biological factors are responsible. For men, smoking and a stereotypically dangerous lifestyle contribute to their failure to survive while biological factors maintain the mortality advantage for women in later life. Victor (1991, p.45) records the difference between male and female rates of mortality in Britain. Early in the $20^{\text {th }}$ century there was little difference between them, but now at all ages, female death rates are substantially lower than those for males. In the period 1981-85 men between the ages of sixty-five and seventy-four had mortality rates eighty-seven percent above females in the same age group, and in the over eighty-five age group the male rates were still twenty-five percent above those for women in the same group.

Theories of ageing appear in various typologies and have received different classifications. Koopman Boyden (1993, p.15) groups them by a range of disciplines; biology, psychology, anthropology and sociology, by their general and specific theoretical approach and by the questions which each attempts to 
answer. "Why do we age? Who adjusts best? What explains the status and adjustment of the elderly and what is the meaning of old age?” The general theories to which they attach themselves are cognitive, functionalist, interpretive and marxist. The specific theories are discussed in more detail below.

Another typology is that of Victor Marshall (1996, p.13) who classifies only social science theories of ageing placing them in three categories; macro, focused on the societal structures encompassing the aged, micro, which engage with the individual, and linking, which construct the relationship between the two. He further analyses them on the normative and interpretive dimensions and the bridging category between these two, creating greater complexity. Like Calasanti and Zajicek (1993) he perceives feminist theorists in gerontology as presenting "a critique of mainstream theories for their neglect of the gendered nature of work life, family life and stratification” (op.cit. p.23).

Gerontology because of its interdisciplinary nature already presents a complex picture in the field of theory, both overlapping and disjunctive. Robert J Lynott and P. Passuth Lynott (1996) trace the course of theoretical development in the sociology of ageing and note the contributions made by feminist and critical theory perspectives developed in the late 1980's and early 1990's as does Marshall cited above. They refer to two transformations in gerontological thinking in the twentieth century. The first was the development of the concept of 'disengagement' by Cumming and Henry (1961) This occasioned an intense debate among sociologists and psychologists coming from a functionalist position of adjustment, which is outlined below. The second transformation in theorising age, according to Lynott and Passuth (op. cit.), occurred in the late 1970's and early 1980's and was greatly influenced by postmodern thinking with its deconstruction of language and rejection of scientific positivism and global narratives. Critical Gerontology acknowledged the humanistic dimensions of ageing (Gubrium, 1993). This is evidenced in the work of Hazan (1994) and of the critical theorists, Moody (1988) and Dannefer (1994) who explored both the subjective, interpretive aspects of individual ageing and the wider structural components relating to the locus of power. This resulted in a focus on praxis, and the production of 'emancipatory knowledge' to initiate social change and create 
"positive models of aging emphasising strengths and diversity of age” (Bengston, Burgess and Parrot, 1997, p. S83). Fundamental issues arose with the questioning of the assumed 'facts' of ageing which marxists feminists and phenomenologists then began to analyse. While differing in their ontological bases and forms of analysis they nevertheless came up with criticisms of existing theory for its use of 'data' without acknowledging its own subjective positions. As Lynott and Passuth asserted, "The approach, interest, orientation and other subjective features of the researcher and his or her world were significantly connected to the nature of the data” (1996, p.753).

Returning to the earlier theoretical phase, it is important to understand the role of disengagement theory and the reactions it generated in advocates of activity, continuity and exchange theories. Disengagement, it was argued, was an adjustment to age achieved by older people who, recognising their diminishing capacities, voluntarily withdrew from society in order to cope with the expected biological decline of ageing and the imminence of death. According to the authors Cumming and Henry (1961; 1969.) there was an inevitable mutual withdrawal between the ageing person and society. An important aspect of this theory is that it posits the role of societal structures of policy and attitude in constructing old age, not just the functioning of the individual. As people age they may present a drag on society and the social system must itself find a solution to this problem. This was provided by legislation for age-related retirement and the social expectations that these older persons occupy a lower status than people in paid employment. Developed in the early sixties it has a strong androcentric outlook in encouraging early retirement to promote the career prospects of young men. It has now been largely discredited as a universal explanation of adjustment, but has encouraged the development of other theories.

Alternative positions to that of disengagement in ageing were provided in the application of the concepts of activity by Rose (1964) and Palmore (1970), of continuity by Atcherly (1972) and of exchange by Dowd (1975). Atcherly argued that the approaches of disengagement and activity were too global and that satisfaction in later life rested on the continuity of previous lifestyles of the elderly, of their usual interests and activities. Dowd argued that the life 
satisfaction in the old was an outcome of exchange, the nexus of costs and benefits that existed between the old and the young. Disengagement only occurred when this balance was upset and the old could no longer contribute to society and became burdens on the young. Gubrium (1973) took a socioenvironmental approach and argued that theories of activity and disengagement were too narrow and did not take into account the meanings which activity or withdrawal might have to individuals within specific environments with different systems of social value. Yet another challenge to disengagement came from Riley (1971) and her associates Johnson and Foner (1972) who proposed theories based on age stratification. They argued that the individual's experiences of ageing could best be understood in the context of their age group or cohort. As successive birth cohorts move through time their life experiences may differ from those of previous and subsequent cohorts. Each age stratum is perceived to have specific characteristics. In Britain, the experiences of women living through the 1930's depression were identified as influencing attitudes in old age. The diversity in these effects was related to social class and Elder (1975) noted the emergent image of 'a strong woman' with coping skills based on experiences of deprivation. In New Zealand Thomson (1991) identified a 'welfare generation' born between 1920 and 1940 who as adults had benefited from the active provision of the state for people's welfare. The cohort who suffered most from the benefit cuts and economic reforms since 1984 may well constitute another such characterised age stratum. An age stratification approach however does not necessarily cover the different experiences of individuals within a cohort resulting from the distinctions of social class, gender, education or ethnicity. This is better addressed by a life-span approach presented in the work of the historian Tamara Hareven (1982) and the understandings provided by transitions within the life course.

Anthropologists use a functionalist approach focusing on developmental theory of societies to determine who adjusts best to old age. Cowgill and Holmes (1972) use the concept of 'modernisation' to explain the status of the elderly. This suggests that the status of the aged is inversely proportional to the rate of social change. For example changes from the extended families of the pre-industrial past to the modern nuclear family has produced a less caring society which has 
reduced the power held by and respect due to the aged. The increased levels of education required for a more technologically developed society have raised the value of the young compared to the aged, creating a 'generation gap'. Social historians in the United States and Britain have challenged the past existence of a 'golden age' for the elderly (Elder 1974, 1982: Fry 1995). Tamara Hareven argues that historical evidence about family relationships dispels this myth. Even though they may have been revered and accorded high status, older people in the past suffered insecurity. She instances the fact that "aging parents had to enter into agreements with inheriting sons to secure old age supports in exchange for land” (1982, p.3). Change of status in ageing is related to the loss or acquisition of social roles and there are seen to be gender differences (Gibson, 1996). The debate over loss of role or role substitution relates to the perceived continuities and discontinuities in the lives of men and women. In today's society there is already fluidity in perceived roles as more women have entered the paid work force and many expectations are changing. The experience of work related redundancy and unemployment has already changed the domestic scene for many men.

Psychologists use both functional and cognitive approaches focusing on both adjustment and cognitive decline or continued potential in the old. The concept of individual adjustment is a prime focus and stems from the theories of Erikson (1950, 1968 and 1986) and Havighurst (1953, 1968), who theorised ages and stages in human development leading to the establishment of stage related norms for behaviour. Challenged by the disengagement theory, developmental psychologists surmised that individuals retained their personalities in old age and desired continued social involvement and only disengaged from society when society withdrew from them. Havighurst, Neugarten and Tobin researched these opposing views in 1968. As described by Nadien and Denmark (1999, p.133) they repeatedly assessed the personal and social engagement of older individuals in terms of their daily activities and their roles as spouse, neighbour or parent. The outcome of their investigation was the identification of two trends. One pattern was that adaptation to ageing in some men and women was not related to either disengagement or activity, but to features of personality. The other finding was that the elderly retained the personality dispositions and activity levels of 
their earlier adult years and that a relevant theory of ageing is marked by personality continuity, not by personality change. They argued for continuity rather than disengagement in ageing. Further studies by others including Atchley (1989) appeared to discredit the disengagement theory and confirm continuity, i.e. the stability of patterns of personality and well-being, as appearing to favour adaptation in old age. Nadien and Denmark (1999.) point out that the frequently quoted Guidance Study (Erikson et al. 1986) had been done with older people who were advantaged ${ }^{2}$ by "enjoying excellent physical and mental health, economic security, social supports and physical mobility” (p.137). A different picture might have emerged from a study of people who had experienced the stresses and crises of ill health, impoverishment and the losses due to relocation or the death of those close to them. They consider that a theory of integration inclusive of both continuity and discontinuity might better inform the issues of adaptation in older age.

The concept of adaptation common to most cognitive theoretical approaches to ageing stems mainly from Erikson's analysis of human development where the successful resolution of crises at each of the eight stages of the life course will provide the 'ego strength' required for future success. This epigenesis, where later development builds on earlier growth, applies to the last two stages of the life course where the individual is faced with the crises of Generativity and Care versus Stagnation and Integrity versus Despair. The earlier tasks such as the achievement of autonomy and basic trust may also be reworked in the new contexts of the elderly landscape (Nadien and Denmark, p.140).

Autonomy is an important concept in the Western world as it connotes effective personal control and self- direction, which give individuals the power to access their desired goals. Primary control relates to belief that one can make outer events conform to one's own personal needs and secondary control occurs when primary control is not available and a person accommodates to their environment, the control is internalised and facilitates adaptation. Nadien and Denmark relate this to some of the inevitable changes of age, "When we face the reality of

\footnotetext{
${ }^{2}$ The guidance study carried out by Erikson et al. on surviving parents of the Berkeley, California children in a longitudinal study over the period 1928 through 1945 to 1968 and 1981.
} 
undesirable, but irrevocable changes we increase our chances of dealing effectively with them, especially if we integrate them into a somewhat revised sense of self ” (Nadien and Denmark, 1999, p. 144).

One means of achieving this shown by the model provided in Baltes and Baltes (1990) is that of selective optimization with compensation. As material and personal resources reduce with age, people may conserve flagging energies and reduce activities and interactions, prioritising those that provide maximum satisfaction. This concept has been further developed by social exchange theorists and applied to the emotional interactions of older people when their self-interest, the need for physical and emotional support, results in increased interaction with some persons rather than others (Carstensen, 1993).

A further general theoretical approach is the interpretive, which attempts to present the 'meaning of old age' and encompasses theories of subcultures, labeling, symbolic interactionism and social phenomenology. While functionalists, for instance, focus on the activity of aged persons, a symbolic interactionist is more concerned with what meanings that activity has for the individual or group. Labeling reflects the perception that groups act on the social expectations for that group. A society preoccupied with youth and health may define age as an abnormal condition with negative stereotypes, In this context certain behaviours appropriate for one group, the young, are considered inappropriate for the old. I see everyday examples of this in the common instances of dressing and sexual activity. An older woman is considered "mutton dressed up as lamb” if she adopts a young fashion and deviant when she takes a younger lover. In this case the woman experiences the double censure of sexism and ageism. Sub cultures and social phenomena theories also focus on everyday events and the meanings of stereotypical descriptions of the elderly and what the meanings are for the elderly themselves and those who use them. Turner (1995, p.258) refers to the contradictory relationship between the subjective sense of inner youthfulness and the exterior process of biological ageing.

The Marxist approach to ageing examines the political economy and reveals which groups hold power and how this is achieved and how wielded. I find this a 
useful approach which when combined with gender analysis explains much of the situation of older women. While it places most women in the economically disadvantaged group it also allows for those women who have been enabled to benefit from the capitalist system, whether through accessing a good education, making an advantageous marriage or through their own efforts and some good luck. A theory of ageing that characterises women only in terms of dependency, whether through poor health, widowhood or lack of economic resources, ignores the positive attributes a woman may bring to her old age from her life-course experiences. She may have the advantage over men through her longevity, and her transition from mid to late life according to Diane Gibson "will contain more continuities in terms of interests, activities and social participation than it does for men” (1996, p.22). Gibson also argues strongly that academic discourse has focused on the differences between men and women, resulting in a negative view, and contends that this due to a "preoccupation with male and midlife perspectives” (ibid. p. 27).

Theory arises from considerations of past events, present awareness and conjectures about the future. The diversity of subjects, time frames and the individual orientations of the researcher indicate that global outcomes in gerontological theory are unlikely and possibly undesirable. In the post-modern context of the late seventies and early eighties the second transformation challenged theorising itself and questioned the real nature of the subjects of theory and the methods by which particular ways of thinking about the elderly served the interests of groups other than the elderly themselves. Is it really possible to have an overarching theory of ageing? Moody argued that gerontological theory was impoverished by its focus on the logic of science and its neglect of the humanities. He called for, "a critical gerontology, that is theories of aging that contain self-reflexive rules for their construction, interpretation, and application to the life-world” (1988, p.33).

He compares this with instrumental gerontology, the domain of conventional social research, which he claims, acts to entrench the status quo and provides new tools to predict and control human behaviour. He seeks a new gerontology that will offer a positive ideal of human development: it must have an emancipatory 
purpose, a movement away from domination to freedom, which he characterises as autonomy, wisdom [and] transcendence.

Researchers in gerontology, sociology and physiology together with historians and anthropologists, economists and marketers have studied age in its many facets. Hypotheses have been offered, but the evidence for these is constantly being challenged. What is clear from feminist, post-modern or critical theory frameworks is, that one size does not fit all. As stated above, there is more heterogeneity in the older age groups than in any other social grouping by age. Besides race, gender, social class and cohort differences, the sheer accumulation of experience in varied life courses and practices makes universalising theories problematic.

\subsection{Concepts and images of ageing: The dismal picture}

Ageing is an integral part of the life course and whilst the earlier stages of growth and maturation have been extensively studied viz. childhood, adolescence and adulthood, the study of old age has lagged behind. Since the life course ends in death, the later stages of life may have had little appeal to young researchers looking forward to productive lives, or to older scholars for whom such study would be a constant reminder of that stage between maturity and death. This view is supported by Featherston and Wernick in their introductory comments to Images of Aging, "It has something to do with the fact that we resist the thought of bodily decline, deep old age and our eventual death” (1995, p.2).

Old age has been systematically associated with debility, weakness, and loss of power and dependency. The earlier stages of life present more attractively than age. Childhood, despite its dependence, promises a future. Youth and early adulthood represent physical beauty, generativity, strength and productivity. These have fuelled more research than age, with its connotations of disability and decline that are linked with the illness and disease of medical pathology. While wisdom and experience in age may be acknowledged (see section 3.4), it is the perceived problems of ageing which receive the most attention. 
Featherstone and Hepworth (1998, p.150) discuss the historical continuity of the positive evaluation of youth and the concomitant revulsion towards physical decline. They quote David Lowenthal, an authority on Western attitudes towards the concepts of age, "Preference for youth and antipathy toward old age are immemorial and almost universal sentiments” (1986, p.129). For women the prospect is even more bleak considering the double standard of ageing for men and women discussed later in this section.

Our understandings of life and society rest in the language we use in constructing and deconstructing our daily experiences however diverse the contexts, and the derogation of age is firmly entrenched in our oral and written language texts. I noted entries for age and old in the Oxford Dictionary of Quotations. Even the most cursory inspection confirmed the prejudice against the aged. The quotations were from male writers who revealed their attitudes towards age; I found none from women. The words and phrases used were ache, penury, decay, illness, cold and woe. The connotations were almost universally negative: darkness, night and winter or with a softer edge, evening and twilight. Age was weary, empty, abhorr'd, crabb'd, full of care, full of grief, slow-consuming, weak, decrepit, despised and unregarded. The old were guilty of both arrogance and folly, the exemplar King Lear, “a weak, despised old man”. The images were of regret, fear and loss; loss of youth, of wealth and of power. Shakespeare expressed all three.

That time of year thou mays't in me behold when yellow leaves, or none, or few, do hang Upon those boughs which shake against the cold, Bare ruined choirs where late the sweet birds sang.

To let the wretched man outlive his wealth, To view with hollow eye and wrinkled brow An age of poverty. The Merchant of Venice, IV: i Last scene of all.... Is childishness, and mere oblivion, Sans teeth, sans eyes, sans taste, sans everything. $\quad$ As You Like It, 11: vii

Few indeed were the references to positive old age among these authors. It could be venerable, serene and bright; it was possible to be benign and rosy cheeked, even to be a lusty and manly man; an age of ease could crown a youth of labour. 
As for women, I found little other than 'ugly old maid' and Laurence Sterne's reference in Tristram Shandy (Book 1v, Chapter 16) to "The nonsense of the old women (of both sexes)," expressing both sexism and ageism.

The search for immortality or the postponement of death is not a new phenomenon, but in the twentieth century people in the West have found many means of insulating themselves from the inevitability of death. Hazan (1994, p.68) sees the social separation of the elderly as one of the barriers which together with the territorial segregation of cemeteries protects the non-aged from death. Even the term 'old' has its euphemisms to reconstruct age.

to ameliorate the separation of the old from the non-old, linguistic devices reconstruct those bearing the physical signifiers of age as the more socially acceptable elders, elderly, senior citizens, old age pensioners or those over sixty.

Hazan (1994, p.14)

My personal experience of teenagers today, indicates that language allows them to separate themselves directly from their elders. Parents become 'olds' and those even older 'wrinklies'.

Gerontology is a relatively new academic discipline combining knowledge from the biological sciences, psychology, sociology and economics. It is complex and contested generating ethical issues both in the allocation of scarce social resources for health and in income support, most particularly in the context of elderly care and the prolongation of life (Evans, 1999; Campbell, 1999). Old age has been problematised and this is most notable in the context of older women's lives. They have been perceived as dependants with chronic age-related ailments, non-productive and therefore an economic burden on the community. In the market led economies of the Western world they have not, until recently, been identified as niche markets for products which claim to prolong youth or youthful appearance. Their capture by the consumer culture has been well documented by Featherston (1991) and Sawchuck (1995).

As stated in the previous section, early literature from the fields of medicine, psychology and sociology came from a male ‘scientific' perspective and rarely 
presented an analysis by gender. Not only were male and female subjects aggregated, but also in some studies from the seventies women were excluded. Marilyn Bell (1986, p.64) gives an example of this prejudice in the United States. After having examined men only for over twenty years the Baltimore Longitudinal Study of Ageing did not include women until 1978. The landmark report on healthy aging published by the National Institute of Mental Health in 1963 only involved men. Bould and Longino (1997, p.211) in their comments on the Baltimore and Framingham longitudinal studies of aging find this disturbing because the greater longevity of women accounts for their subsequent preponderance in the very oldest age groups. They noted that while heroic men in literature survive into old age to tell the story, women are often perceived as victims, bereft of family and friends, having outlived their contemporaries. Older women were also discriminated against in medical research, where a disproportionate amount of funding had gone into the study of cardiovascular diseases, the primary cause of death among mid-life and older men, whereas morbidity and death from breast cancer in women had only received substantial funding after protests from women’s organisations.

Dependency and disablement have constituted a major focus for images of ageing. These have been spotlighted by the considerable numbers of research studies carried out both with and on the residents of rest homes and those hospitalised for full-time or terminal care. Some studies by social workers have drawn attention to the lack of control that incapacitated elderly have over their day to day living. Criticism has been directed at the ways in which professionals have usurped the autonomy of the aged, particularly in their roles as gatekeepers to social support and health service (Kendrick, 1987). Very little of early New Zealand research on the elderly stepped outside the medical model which focuses on morbidity and nursing needs. Of the thirty-six papers presented at the 1999 Wellington Gerontology Conference, Challenges and Opportunities: Issues for the Millenium, twenty-two focused on the debilitating aspects of ageing mainly in the context of residential care or access to it. They addressed topics such as drug and alcohol addiction, hip fractures, dementia, communication problems resulting from the stereotypes of the aged held by some health professionals and the lack of research or barriers to research with the aged. An exception was Jocelyn 
Armstrong's opening address that highlighted the experiences of women from different ethnic backgrounds and the contribution to positive ageing made by their friendship networks and roles as grandmothers. Nevertheless, negative representations of age persist. This is characteristic of a social construction of old age where the focus is on the ethical and economic problems that old people, supposedly unproductive, impaired and dependent, pose for society. It ignores the possibility that society may pose a problem for the elderly.

In the post-modern world researchers have come to re-examine and deconstruct those categories of thought dominated by global and universalistic conceptualisations which assume homogeneity. They have paid particular attention to the language with which we construct our respective realities, our tendency to use dichotomous oppositions which at the best provide a continuum between two poles, at worst an unbridgeable gulf. In 'Sagacious, Sinful or Superfluous' Markson (1997, pp.53-69) delineates the duality of historical images of older women from ancient Greece to the present day. The dichotomies of sexual desire and spirituality, of fair and foul, of wisdom and danger are ever present. Women's reproductive role cleansed of sexuality may have been sanctified as in the Christian Madonna complete with male child, but once this function was over and the sexual attractiveness of youth gone, where was woman to fit in the social structure? Being immortal the Greek and Roman godesses, Athene and Minerva, and the Nordic Freya, all personifying wisdom, were not portrayed as young women. Markson (ibid) asks how it is that the powerful 'crones' of Gaelic mythology have translated to ugly and useless old women; how the Greek hagia, the holy ones revered for their magical qualities as old women, have become the wicked witches of children's fairy tales and the pejorative 'hags' of contemporary abuse. The word scold, a derogatory term for a vituperative or nagging woman was once the revered skald of Nordic culture, a poet or bard. In Proverbs (xii and xxxi, King James Version) the Bible personifies wisdom as a woman and provides a positive image of a mature woman whose price is above rubies. However occurring within the same text is the image "a virtuous woman is a crown to her husband”. This is based on a woman's use to the household as a producer, provider and carer. It is clear that any such judgement is based on her subservience to a male, while he is the one who 
through her good offices, "is known in the gates, when he sitteth among the elders of the land.”

Kathleen Woodward (1995, p.87) discusses the connections between sexuality and identity in Freudian psychoanalysis and observes that its interpretation of menopause commits women to historical dismissal. She quotes Simone de Beauvoir's analysis, despite the fact that it too may be symptomatic of gerontophobia,

As men see it, a woman's purpose in life is to be an erotic object, when she grows old and ugly she loses the place allotted to her in society: she becomes a monstrum that excites revulsion and even dread.

La Vieillesse, 1970

A woman is valued not for herself, but for her social role, for the services sexual or other that she provides for men. If a woman is perceived as old and frail she may be ignored or discarded as useless. Such negative images do a disservice to older women.

With such a pervasively dismal picture of old age it is not then surprising that in the wealthy developed world a culture has arisen based on youth and the preservation of youth. This has especially distressing connotations for older women in a society that largely ignores them. Women are acutely aware of the double standard of ageing; the lined face, grey hair and more solid body of the ageing male guarantee him a desirable status not conferred on a similarly ageing female. The naturally changing body shapes of age are strongly resisted. Therapists Joan Chrysler and Laurie Ghiz (1993, p.8) discuss the damaging effects on the self esteem and body image of older women when society insists that they pursue the elusive ideal of youth enshrined in the beauty industry. "We're told that we're only as old as we feel, and the media drives home the message that older women should grow old gracefully by hiding the signs of aging.” Naomi Wolf, (1991, pp.82-83) documents the airbrushing of wrinkles and other signs of age in women photographed for magazines, thus successfully representing sixty-year olds as forty-five. Ann Gerike (1990, p.21) refers to a recent television series “The Golden Girls” aimed at older women and designed 
to fit the current American image of 'successful ageing'. Only two of the women have grey hair, Sophia, at least twenty years older than the other women, and her daughter Dorothy who is tall, deep voiced and powerful ---clearly not the essence of traditional femininity. Germaine Greer reminds us that “A grown woman should not have to masquerade as a young girl in order to remain in the land of the living” (1991, p.4).

Shevy Healey (1993, pp.41-54), graphically describes her personal fears of ageing, greatly exacerbated by the social effects of ageism as she confronted her own ageing. She re-examined her own ageist expectations and found her way through "the swamp of ageist myths and assumptions" that surround women and came to accept the signs of wear and tear in her body. She was supported by Cynthia Rich's article on Ageism and the Politics of Beauty. This points to the exclusion of the old and disabled and society's subsequent impoverishment, “Our task is to learn, not to look insultingly beyond these features to a soul we can celebrate, but to look at these bodies as part of these souls---exciting, individual, beautiful” (Rich 1988, p. 146).

Today it is not only women pursuing the goal of prolonged youth, because of their perceived loss of beauty and reproductive function, but men, too, who provide a market for modern equivalents of the mediaeval 'Elixir of Youth'. Since the 1980's, with the advent of premature retirement from the workforce due to unplanned redundancy, men have also dyed their hair, undergone cosmetic surgery, dieted and exercised to forestall the inroads of age with its threat of enforced unemployment. A whole lucrative industry is built on the need to eliminate the natural signs of ageing; pills, potions and cosmetic surgery designed to remove wrinkles, to elevate sagging muscles, to tone up skin and disguise discolouration. Dyes and implants are available to restore hair to youthful vibrancy, and never ending dietary and exercise regimes to promote not just good health, but the illusion of youth. The current images in the media promote 'successful ageing', but in revamped images of youth. It is debatable whether or not these pressures are stronger for women than for men. The contemporary focus on creating positive images of ageing is not only an attack on the negative presentation of age but may indeed provide a means by which some aged will act 
in ways to improve their well-being. However, the leisure and pleasure lifestyles with secure housing, holidays and medical insurance currently promoted by advertisers, are often beyond the economic resources of all but the wealthy. This may be a double-edged sword for the elderly as while promoting a positive image it tends to ignore the realities of maintaining ageing bodies and their intimations of death. Positive ageing is discussed in the next section.

\subsection{Concepts and images of ageing: The other side of the coin}

In less complex and segregated societies than that of the twentieth century, older women clearly had a place within the household if they survived the dangers of childbirth. Not, only were they caregivers of large families, preparing and preserving food, making clothing, nursing and nurturing, but they also worked in the home-based production of goods for sale and exchange. Elaine Morgan (1974, pp. 257-259) argues for older women's vital function in earlier societies. She categorises menopause as adaptive of community survival in humans; a mutation seen in no other primates. Annual parturition did not continue to the point where life was drastically threatened. Outside the reproductive role older women had many functions. "Grannies were good for them" (p.258); the advantage was not to the individual alone, but to the tribe as a whole. Older women were a repository of wisdom and of child lore, they could "remember, think and communicate memories and thoughts” (p.259). They were a source of seasonal wisdom in the recognition of planting times, and in their ability to lead the community to favourable sources of food and shelter. Older women had a primary role in the survival and care of children in early human societies when younger women were engaged in production and reproduction.

Not all representations of age are negative. Poets sometimes find it a time of reflection and opportunity.

For age is opportunity no less Than youth itself; though in another dress And as the evening twilight fades away 
The sky is filled with stars, Invisible by day.

Henry Longfellow, ‘Morituri Salutamus’ (1875)

The notion that negative stereotypes of age can be reframed finds expression in the labels of 'successful' and 'positive ageing', currently in vogue. The increase in longevity in the post-industrial age and the development of modern medical technology has provided a high standard of living in the Western world. With it has come the prospect of 20 to 30 years of 'retirement', a time when those with good material resources can be enabled to enjoy a new lease of life with opportunities for life long learning (Ross, 1990; Laslett, 1989). Beyond childhood and adolescence and a working life there is now the possibility of a 'Third Age' of leisure, activity and opportunity for new learnings. Laslett was instrumental in establishing the University of the Third Age (U3A), an organisation run locally on a volunteer basis by older people to provide themselves with intellectual stimulus and outlets for creative energies. Together with Probus groups and Senior Citizens clubs they provide positive social networks. This new positive approach to ageing finds advocates in organisations such as Age Concern and Grey Power, which act as watchdogs against the exploitation of the elderly. Armstrong (1999, p.14) cites the United Nations Principles for older persons, 1991:

1. Seeing older persons as both contributors and beneficiaries;

2. Including older persons as leaders and consultants;

3. Promoting intergenerational collaborations;

4. Providing environments for healthy ageing;

5. Investing in middle age as a prelude to old age.

Traditionally age has been associated with wisdom and there is an expectation that older people's longer experience of life may have value for the younger generation. While this appears to have been eroded in the sense that technological 
knowledge ${ }^{3}$ may have outdistanced the elderly, they have nevertheless developed knowledge of the broader aspects of life and human relationships. Wisdom is a multifaceted concept and like health and life satisfaction finds no uniformly accepted definition. Clayton and Birren (1980) based a study of wisdom on its historical representations across both Eastern and Western cultures and the perceptions of wisdom from three contemporary adult age groups, young, middle aged and old. The eighty-three subjects, drawn from the university community, were asked to relate the word 'wisdom' to fifteen descriptors drawn from previous studies. No gender differences were found in the responses; the oldest group was less likely than the younger groups to associate 'age' closely with 'wise', but all groups perceived wisdom as, "the integration of cognitive, reflective and affective qualities". The authors expressed a concern that present "technological society encourages productivity rather than reflection, and values problem solving abilities rather than perceiving the assets of a broad questioning approach”. They see future studies of wisdom as holding value in evolutionary, cross-cultural and developmental terms (ibid, pp.130-131).

Monika Ardelt (1997) relates wisdom to life satisfaction in old age and refers to knowledge in the complexities and uncertainties of life including the awareness 'that we do not know'. Wisdom is interpretive knowledge rather than descriptive knowledge and the attribution of wisdom appears to be in the older person's perception of self and adds to their self-esteem. There is no suggestion that wisdom is solely the attribute of all old people, or of old people solely, but that wisdom is possible and beneficial in age. Her hypothesis is that,

people experience satisfaction and a sense of fulfillment in life as a consequence of achieving greater wisdom over the life course and that wisdom rather than objective life conditions explains most of the variation in life satisfaction in old age.

Ardelt (1997, p.16)

Her study shows that wisdom and a person's subjective well-being are highly related to each other and that for women, “only wisdom and financial situation

\footnotetext{
${ }^{3}$ A point of dispute as the 2001 New Zealand census showed that one in six persons aged over sixty-five had household access to the internet, Statistics New Zealand, census snapshot, 2001.
} 
have a significant impact on women's life satisfaction in old age” (ibid. p.26). In Ogonowska-Coates' study of residents in a Christchurch rest home who were survivors of the Depression and World War II, Isabel aged 87 felt comfortable with life: "You can’t live for that length of time without learning things.” (1993, p.74).

'Successful ageing' and 'ageing well' are concepts presently receiving much attention. They are embedded in the notion that older people have the ability to lead positive lives with high levels of satisfaction. Rowe and Khan (1997) summarised the central findings of studies supported by the MacArthur Foundation Research Network on Successful Aging. They suggest that the key is an absence of disease and the risk factors for it, the maintenance of high cognitive and physical function, engagement with life in interpersonal relationships and productive activity. They noted that a high level of education was the strongest predictor of maintaining cognitive function, which was positively affected by good pulmonary peak flow and self-efficacy. ${ }^{4}$ The amount of strenuous physical activity in and around the home was also a predictor of maintaining cognitive function, indicating that exercise may enhance central nervous function. Earlier views that disease and disability were the inevitable concomitants of age were inconsistent with recent studies citing life-style factors, which may be age related, but which were not caused by ageing itself. These factors could be modified by behavioural and environmental changes. The concept of productivity in the elderly is also a contested issue. As long as the Gross Domestic Product is measured only in goods and services paid for, the valuable unpaid activities of the elderly are excluded from recognition. In the maintenance of interpersonal relationships, two kinds of supportive transactions were significant, the expressions of affection and respect and the provision of instrumental assistance such as helping with chores, transport or money. These had positive effects on health and avoided isolation, but needed to be appropriate for individuals and situations.

\footnotetext{
${ }^{4}$ Bandura (1997) Self-efficacy: The Exercise of Control, defines self-efficacy as people's belief in their capacities to organise and execute the courses of action required to deal with prospective situations.
} 
In the previous section attention was drawn to the negative effects of older people having become a target market for those who would supply their needs and wishes. In so far as this meets the needs of the old it can be a positive development, but the question of exploitation, control and deprivation arises. Answers are dependent on what input older persons have had into what is being marketed to them, who has made the decisions and how available the products are to those on low incomes, especially women. Some feminist writers have resisted the humiliating stereotypes of old women. Barbara Walker (1985) has rescued the 'crone' from history and creates a powerful female image. According to Bell (1986, p.89) this archetypal older woman is seen to represent death, but she also represents wisdom, healing and teaching. She is never old and useless. Her framework is absolute and moral, aligned with the forces of nature.

Rejecting the negative images of ageing has been a labour of love for six English and American women born between 1918 and 1930 who constitute the Hen Coop. In Growing Old Disgracefully (1993), the authors presented older women with new ideas for getting the most out of life. Each woman tells her own story of resisting the stereotypes of older women and regaining control of her own life and growing as an individual within a supportive group. In the prologue to this thesis Shirley Meredeen's poem celebrates the falling away of unloved trappings of younger days, and the freedom for an older woman to be herself. This antiageist stance is also present in Betty Friedan's The Fountain of Youth (1993) where she rejects biological determinism and promotes personal growth not decline, and shown by Maggie Khun who founded the Gray Panthers in 1970. This organisation and The Older Women's League (OWL) challenge ageism and address a wide range of social and health issues for older women in the United States. In New Zealand, as shown in chapter two, local bodies, government and voluntary agencies are doing much to change the negative stereotypes of ageing and to promote positivity in age.

\subsection{What is this thing called ageism?}

Ageism has been clearly defined as a social prejudice disadvantaging the elderly. The term was coined by Robert Butler who described ageism as: 
A process of systematic stereotyping of and discrimination against older people just because they are old, just as racism and sexism accomplish this with skin colour and gender. Old people are categorised as senile, rigid in thought and manner, old fashioned in morality and skills...Ageism allows the younger generation to see old people as different from themselves, thus they subtly cease to identify with their elders as human beings.

(Butler, 1975, p.12).

This accords with Ann Gerike's (1990) delineation of the connotations of 'old' in our society as incompetence, misery, lethargy, unattractiveness, asexuality and poor health while those of youth are competence, happiness, vitality, attractiveness, sexuality and good health. Simone de Beauvoir in La Vieillesse (1970) reviewed the literature on gerontology and found that it consistently emphasised decline, whether physical, psychological or social, and raised issues which put the whole of society to test in its limiting and possibly harmful effects on ageing individuals.

Ageism is a cultural phenomenon according to anthropologists Cowgill and Holmes (1972) who surveyed ageing in many different societies from pre-literate to modern times. They found that while all societies treated older persons on the basis of their age status, usually reflected in their assignment to less physical roles or occasionally in their promotion to advisory and supervisory positions, modernisation has tended to decrease the relative status of the aged, thus undermining their security within the social system (ibid. p.13).

Binstock et al. (1995, pp.362-381) provide an interesting example of ageism in the community. In discussing political alliances of interest groups concerned with long term care for the disabled, they queried whether a coalition of advocates for aged and younger disabled people would be possible. A clear barrier was evident in the symbolic and political identification with the elderly, whose traditional stereotype was that of frailty, of chronic illness, decline and marginality to society. Advocates of the young disabled rejected identification with such a medical model. 
Romantic images of revered ageing in the past are not borne out by research. That the old have not always been privileged is clear from historical and ethnographic sources. Fry (1995, p.129) shows that gericide was practiced, by murder, withholding food from frail and decrepit individuals or by self-destruction. This suggests that those who experienced a favourable old age were those who could control their environment socially and materially, which is true today for those with social status and wealth.

Ageism was not operative in all industrial societies, for example Japan and Russia. In Japan the cultural norm of filial piety explicit in Confucianism has counteracted this (Palmore 1975). Later American studies considered that the position of elders in Japan has suffered from relative power deprivation, as instanced by high rates of suicide and obasute (abandoning granny) a term originating in folktales and now applied to the increasing number of older people living alone or in old age homes. Suichi Wada (1995) critiques both a Western and Japanese interpretation of this situation. Western scholars had idealised Japanese society as an utopia for the old, now lost through economic growth, while the Japanese critic Sugahara had based his judgement on an idealised image of older Americans as individuals, active and independent, a far cry from the older lifestyles of Japan. Wada makes a strong case based on historical events, which demonstrate how, when extreme patriarchy was replaced by a less autocratic paternalism, the state through moral education in the primary school, perpetuated traditional concepts. These were ko, filial piety (which extended to older brothers to other elders and seniors) and on which signified the reciprocity of a debt owed between generations and between individuals. Such a system of obligation assured interdependency. This combined with the semi-religious meanings of old man, okina and old woman, omina, as being close to the gods and their connotations in the arts of elevating older persons to positions of seniority in the social system.

Frailty though negative was not a barrier. Images drawn from older periods in Japanese history show the old "playing with pleasure and having fun like children” (ibid, p.56). The 'second childhood' of the elderly was a positive image unlike that of western cultures. Contrary to the Japanese image are the images of 
infantilisation ascribed to the very old demonstrated in the work of Hazan (1980 p.31) and Hockey and James (1995, p.136). Hazan documented the practices in a London day care facility for older Jewish people where activities were arranged as though the elderly were children, and the language used was of adults patronising children. Hockey and James referred to twin ninety- year olds celebrating their birthday as having been represented in the press as 'birthday girls'. This use of language is also common in rest homes I have visited as a choir member, providing 'entertainment' for the captive audience of incapacitated elderly women, who are obviously not 'girls'; it is not only patronising like 'dear or 'love', but a powerful term of control. "By linking old age with childhood, the hegemony of adulthood remains unchallenged” Hockey and James (1995, p.138). Older women among themselves may accept the use of 'girls', but it is a different matter when used by those who have power over them.

Levin and Levin (1980) describe Western culture as pervaded by ageism. They pinpoint the practice of blaming individuals for their own dilemmas and misfortunes. The elderly are the victims of their own former life-styles. Lack of resources or ill health stem from their own negligence (shades of Dean Swift). The disengagement theory of ageing, discussed in section 3.2 is rejected for its effect in justifying mandatory retirement and images of the old withdrawing from active life or 'stepping down' to make way for the young as a matter of course. The encouragement of the wealthy elderly to retire to 'Sun Cities' or 'Leisure Worlds' increases the physical and social segregation of the old by chronicity and sometimes leads to the ghettoisation of age while serving the needs of property developers. On the other hand, Pong (1998) describes the successful transformation of a former mining town, Elliot Lake, in northern Ontario, doomed to become a ghost town when its natural resources were depleted. Vacant low cost houses were used to attract retirees and consequently the town's demographic profile changed almost overnight. Subsequent research showed little intergenerational tension and interviews indicated that many of the town's original residents felt that the community had been 'saved from economic collapse' by the advent of the retirees. This project was very different from the exploitative actions of developers who see population ageing as another opportunity to profit. Pong (ibid, p.37) reports that one of the 1996 non-fiction 
best sellers in Canada was Boom, Bust and Echo: How to Profit from the Coming Demographic Shift, by David Foot and another recent publication is The Pig and the Python: How to Prosper from the Ageing Baby Boom, by David Cork.

Prejudice against the aged is related to prejudice against other minorities in race, ethnicity or religion; they are seen as 'Other', in some way posing a threat to the non-aged. It is clear that such attitudes will have repercussions in the perception of self by the elderly. Self-esteem is closely related to both psychological health and physical well-being and the practice of ageism can only have negative effects upon the elderly. In more extreme forms it may result in elder abuse from which New Zealand is not immune. This is an ongoing concern both within institutions and the community and has been documented in a 1997 Age Concern Report. In 1983 Ian Douglas, the then chairman of the New Zealand Planning Council, writing on the prejudice of 'ageism' in community attitudes, referred to the subtle discrimination and artificial environment created by the euphemisms of 'senior citizens' and 'golden years', effectively consigning the elderly to a "limbo of uselessness." We did not "appreciate the cost to the community of cutting off or severely limiting a continued capacity to contribute of such an important section of society” (Douglas, 1983 pp.99-100). A Department of Labour report (1977) noted that

...clear, systematic differences between the aged, older workers and the workforce generally...These problems have been shown to be rooted in stereotyped ideas about the capacities of older people; prejudice seems to be stronger when leveled at older women.

McGregor and Gray (2001, p.5)

Ageism is of particular concern for women. Palmore (1997, p.3) characterises the combination of sexism and ageism as “malevolent”. In New Zealand Ruth Bonita (1993 p.189) describes the twin prejudices of both age and sexism that women may experience, especially in relation to their need for health-care in later life. Like the British sociologists Arber and Ginn she sees women's life-long lower employment status with its lack of access to power and income and their traditional pattern of socialisation as wives and mothers cumulatively contributing to their lack of material resources in old age. Older women may be 
perceived by both themselves and others as 'non-persons' or burdens, dependent on their families or the community and requiring considerable support from the state. The media portrays them in negative images and advertisers exhort them to purchase products claimed to conceal the signs of age, or to relieve pain and ameliorate the physical ills of ageing. Bonita (1993 p.190) also refers to the fact that feminists too have been guilty of this form of discrimination, so pervasive is the negative attitude towards the aged. While feminists provided documentation of the disadvantage experienced by women in the procurement of adequate assets and income to support old age, it can be argued that they have tended to neglect other aspects of ageing and later life (Jay Ginn and Sara Arber, 1995, p.2). Likewise Linda Gannon (1999) refers to the neglected health issues of older women and to their origins in androcentrism and social structures unsupportive of women's well-being. Diane Gibson (1996) bears witness to older women's erroneous categorisation as social problems, and to researchers' failure to document the positive attributes of older women. Ageism and sexism combine.

The ageism that feminists have practised consciously or unconsciously against their own was most clearly documented by Mcdonald and Rich (1983). This described Barbara's experience of being 'other', not only because of sexual orientation, but because she was old. She was both ignored and patronised by younger feminists. Copper trenchantly declares that,

The ageism that women experience is firmly embedded in sexism- an extension of male power to define, control values, erase, disempower and divide. Woman-to-woman ageism is an aspect of the horizontal conflict which usurps the energy of the colonized-part of the female competition for the crumbs of social power.

$$
\text { Copper (1988, p.73) }
$$

However, not all women bow down to or are victimised by ageism. All is not doom and gloom. Like the playful Japanese elders there is pleasure to be had when they assert themselves as shown in Jenny Joseph’s poem Warning. 
When I am an old woman I shall wear purple.....

And run my stick along the public railings

And make up for the sobriety of my youth.

I shall go out in my slippers in the rain

And pick flowers in other people’s gardens

And learn to spit.

Joseph (1987, p.1)

\subsection{Factors affecting the quality of life of older women}

The following sections address the literature on a woman's life history and the material, physical, social and emotional needs that contribute to her well-being in old age. The ways in which these are met will largely determine the quality of her life. Our pakeha society has inherited a culture from the west that prioritises individual responsibility and values personal independence, but also acknowledges the responsibility of the state towards its citizens. The point at which they meet is contestable. The notion of dependency is seen by most older women as undesirable and it is often difficult to realise that there is an alternative view, that of interdependence. The following sections reflect the questions I asked myself as an older woman.

\subsubsection{When do I know that I am old?}

Concepts of ageing cannot be separated from notions of time, development, maturation and dissolution. The human body exists not just spatially, but through time, and is subject to change, both physical and mental. While change in the early years is seen as maturation, changes in the later years are often perceived as 'deterioration'. The chronicity ascribed to this may be arbitrary and varies historically and culturally, and relates to norms of longevity specific to time, place and culture. In the twentieth century western world we have extended the period of childhood and adolescence, characterised by dependency, beyond the usual biological limits related to sexual maturity and in so doing have postponed adulthood with its presumption of social responsibility. Thus, in New Zealand we see young people requiring student allowances expected to be financially 
dependent on parents until age twenty-five. Middle age has been shifted from the forties to the fifties and sixties, and old age to the seventies, with advanced old age beyond eighty-five. This, no doubt, has been a response to the better living conditions and the need for higher education in a technologically advanced society where longevity has increased. It has many implications for what may be termed older age and old age.

Society finds chronicity a convenient category to allow or disallow access to specific activities. Age in years is an administrative tool. It is both an entrée and a barrier, applied variously to starting school, consenting to sexual intercourse and to purchasing tobacco. Chronicity determines when one can apply for a driver's licence or the need to reapply as an older person. It governs the public consumption of alcohol, the right to marry, to vote or to enlist in the armed services and signifies eligibility for the receipt of transfers from state funds in the form of unemployment and superannuation benefits. Chronicity as an identifier of 'age', is however, a weak reed. In relevant research I have found the old defined as those over forty ${ }^{5}$, those over sixty, over sixty-five (Bonita, 1993) or over seventy. In various studies the category defined as the oldest old have been those over seventy-five, eighty or eighty-five. Janet Ford and Ruth Sinclair (1987, pp.14) discussing ageism and older women in Britain and the effects of stereotyping, refer to 60, "the age at which we are officially labelled old, eligible for a pension, and expected to retire from paid employment." The boundaries of age, measured in years, increase or decrease in relation to contemporary estimates of longevity and their numerical prevalence in the community or as a matter of economic or political expediency ${ }^{6}$. The difference between Maori and Pakeha ageing in New Zealand provides a different picture of who counts as old. The first available life expectancy figures for Maori were for 1950-52 and these showed that the life expectancy in years for Non-Maori male and female was 68.29 and 72.43 respectively, while for Maori it was 54.05 and 55.8 (Davis 1982, p.218). The

5 The 40+ project which is part of Victoria University of Wellington's Positive Ageing and Intergenerational Relations research programme.

${ }^{6}$ In the 1970's and 1980's in both USA and New Zealand workers were encouraged to take early retirement to make way for the younger worker. When the costs of early retirement rose in both the private and state sectors, the age for eligibility for pensions rose. 
2002 report of the 40+ Project on Positive Ageing and Intergenerational Relationships 'Ageing in a diverse New Zealand / Aotearoa' includes a $\underline{30+}$ report for Maori. Such a disparity casts doubt on using chronology to define who is old or what old may mean in different cultures.

In her introduction to New Zealand's Ageing Society (1993, p.2), KoopmanBoyden points to the changes in defining old age over time. Archeological evidence suggests that life expectation at birth for the early Maori in New Zealand was only twenty-eight to thirty years and that the socially valued status of elders, kaumata and kuia would have been reached by age thirty-five. Armstrong (1996, p.17) finds that age defined by chronicity is a feature of New Zealand society and is at odds with women's own usage in defining old as someone older than themselves. Chronicity as an age signifier relates to specific historical circumstances and to cultural practices. There is no simple consensus as to the definition of who is old. Atcherly refers to the many formal and informal definitions of age current in America and states that because the meanings, definitions, and experiences of ageing vary across cultures and time, “Questions about when aging begins, or what it is, can only be answered by paying attention to the social contexts in which aging takes place” (Atcherly, 1998, p.3).

Leaving the calculus of chronicity behind, how else does a woman come to decide or be told that she is 'old'? The social context of ageing for women clearly differs from that of men. Susan Sontag (1978) refers to the double standard of ageing and its social disadvantage for women to whom the visible bodily changes of age appear to come earlier and strike harder than those of men. This centrality of bodily presentation requires women to match up to the adolescent ideal throughout their lives. It is not then surprising that women are complimented on looking young for their age are and many are caught up in making enormous and expensive efforts to achieve this. These images and representations of older women as social victims could be questioned, but there is no doubt that ageism is alive and well in a society so focused on the youthful body

Chronicity, awareness of bodily wear and tear, and the fading of youthful looks are not the only markers of age. The possibility of loss of paid employment may 
be a signifier of age. Am I no longer productive? Has my social role changed, how do my children regard me? Am I a burden? What messages is society giving me? A personal answer to this came in conversation with a younger neighbour. I had expressed the desire to find some part-time employment as the writing of this thesis was coming to a conclusion. The younger woman expressed genuine dismay, “Oh, Isobel! Surely not. Not in your twilight years!” At first surprised, then amused, I came down to earth. I was old, and more seemly activities appeared to be knitting and sewing, or looking after my grandchildren and my garden.

\subsubsection{What does society expect of the elderly and who tells me this? Issues of power and language}

The issue of power is legitimately raised, for ageism effectively removes power from older women and transfers it to those who hold power over them and make judgements on behaviour. In extreme cases this takes the form of elder abuse as recorded in the New Zealand Age Concern study (1997). It is not difficult to project Shakespeare's negative images to the elderly who, being 'other', almost non-human, are easily controlled.

Society tells women when age arrives. Menopause signals the end of their reproductive life and has been interpreted as the harbinger of metaphoric autumn, of asexuality, of loss of attractiveness, the precursor of winter, of death, often occurring concurrently with the departure of children into separate adult lives. They are assigned appropriate behaviours. On his mother's marriage to his uncle, Hamlet was able to castigate Gertrude, "You cannot call it love at your age!" although she was probably under forty. Menopause often coincides with the 'empty nest' syndrome, which leaves women bereft of their perceived nurturant function at least until the arrival of grandchildren, or the expected care of their elders provides them with a socially acceptable role. Old women are sometimes perceived as wrinkled anachronisms, 'past it' and of no account other than that, because of their greater longevity, they constitute a problem for the young. Such characterisations of the aged whether male or female discount the continued 
strength and social value of older people both to their families and to the community and completely ignore the wide range and diversity in the capacities of the elderly to continue as productive and generative members of society.

The power exerted by society to reconstruct expectations of age to accommodate changing social conditions is apparent in the reassigning the concept of holidays. For a primarily paid employment population holidays are seen as a break from an everyday working life. How could this apply to the elderly who did not work? David Chaney (1995) provides an analysis of tourism as an activity for British retirees. With the advent of pensions and successful savings schemes there is now a new focus for the market, previously geared to sell to youth. The opportunity has arrived to sell to the elderly. Chaney details the changes in marketing advertising to attract this more 'conservative' group. Using brochures he shows the changes in approach to appeal to elders. A golden glow is cast upon the project; there is less emphasis on the actual destination, but more on comfort. In the provision of coach services there is a discreet recognition of problems in mobility and the need of frequent 'comfort stops'. Without mentioning 'widowhood', judicious reference is made to negotiating special rates for single rooms. An effort is made to present the holiday destination as a home away from home complete with anniversary or birthday celebrations if required. "Golden Years is for people like you looking for memorable holidays with friendly people in winning winter destinations, you will want to visit again and again” (Chaney, 1995 p.21).

Chaney sees the production of holiday memories as contributing to identity formation and sees the advertising brochures as "providing a set of instructions on mediating between the individual and their cultural identity (what I have called their idealised self)." The elderly are constantly receiving messages through the media about how they are supposed to behave in their 'golden years'. They are told what they should buy, with whom they should insure, where they should live and how they are to maintain their health and thus avoid becoming a burden to their families or to the larger society. Featherston and Wernick refer to a newspaper headline from the promoters of the newly discovered market of 
well-to-do elderly who may lead an active consumer life, “Dipping into Granny’s wallet” (1995, p. 9).

While the second half of the $20^{\text {th }}$ century has been rewriting a commercial consumer role for these affluent elderly, there are also social expectations for others. In New Zealand society a stigma attaches to joblessness, the condition of many older people who have not yet reached the age of eligibility for the old age pension. McGregor and Gray point out that "Paid work is valued and a strong work ethic is admired” (2000, p.56); this results in lowered self esteem and social isolation for many mature jobseekers who find that, experience notwithstanding, employers prefer the young. As I will indicate in the next section people show a preference for being useful in the community and gain sense of belonging by employing their skills and expertise in work, paid or unpaid.

\subsubsection{Where do I belong and am I useful? Issues for family and community}

The two arenas of belonging for older women no longer in paid employment are family and community. These present opportunities for involvement and the recognition of skills, talents and experience; they are barriers against isolation. In New Zealand there is much mobility of families and many older people do not have relatives or children living in the same neighbourhood. Belonging means communicating and letters and phone calls ensure communication when offspring live at a great distance or are overseas. Women, the traditional letter writers in a family, are now overcoming problems of cost and training and use the internet (Roorda, 1998). The recent 2001 census records access to the Internet by women over sixty-five as 12 percent. It is possible that the perception of fulfilling a needed caring function contributes to a sense of belonging in which giving, taking and sharing declare interdependence rather than dependence or independence. In the family context Armstrong (1996, p.19) suggests that being a grandmother entails a personal sense of generativity. In relation to dramatic social changes she notes the increased incidence in the numbers of grandparents who are providing primary care for grandchildren, in part resulting from "more 
divorce, remarriage and singlehood among other things” (Armstrong 1999, p.13). Missen, (1999) in her study of grandmothers found that the women considered themselves "a link in the generational chain," and that they modelled themselves on their own grandmothers and mothers while "re-inventing the role of grandmothering within the context of social change” (p.236). With grandchildren domiciled overseas grandmothers managed their feelings of loss and separation using technology to maintain reciprocally satisfying relationships. While 'grandmothering' was a deeply satisfying role, there were both emotional and financial costs to the older women; the depletion of their own resources, and worries about the well-being of their families when they were unable to give them practical support either financially or within the household. Some older women have now extended their grandmother role beyond a biological relationship into the community as in the case of 'super grans' groups of mature women assisting families by passing on their skills and knowledge in practical ways. $^{7}$

In her study of older women volunteers Cave (1998) highlights their belief that there is a social expectation that women should carry out certain unpaid work and that in most cases, because it is unpaid, it is therefore devalued. The caring, nurturing and emotionally supportive work and domestic labour provided by women inside or outside their homes was taken for granted, sometimes as a 'Christian' duty. Because of its domestic nature, caring for children or sick relatives was not considered 'Real Work'. If women gained some status through their voluntary work, however, then this was valued. The sharing of voluntary work also increased its value. For older women voluntary work within the framework of an organisation, for instance churches, Meals on Wheels, Citizen's Advice Bureaux, provides social companionship as well as the satisfaction of a worthwhile activity. Ruth Gardner ${ }^{8}$, manager for the Canterbury Volunteer Centre, which refers men and women to voluntary positions with non-profit organisations, surveyed 426 volunteers and found that the most common reasons for choosing to do voluntary work were:

\footnotetext{
${ }^{7}$ A full description of this service is given in Experience of a lifetime: Older New Zealanders as volunteers, 2001, Report of the 40+ project, Victoria University of Wellington.

8 'Value and meaning outside the paid workforce', SROW workshop, Sept.2000, Christchurch.
} 
To do something useful in the community $60 \%$

To meet people $69 \%$

To use experience and skills $66 \%$

To have fun $65 \%$

To use spare time $65 \%$

When asked what benefits they had actually gained the same respondents said:

Pride in doing something in the community $60 \%$

Met new people $60 \%$

Used experience and skills $45 \%$

Had fun 53\%

Used spare time $56 \%$

(Gardner 2000, p.3)

Not all of these volunteers were older women; for some younger persons volunteering paved the way from the private world to the public world of paid employment; this as I am personally aware has been the case with the Wellington Volunteer Centre and Citizen's Advice Bureaux trainees. Gardner also notes a trend to shorter term volunteering and the formalisation of voluntary services that some women may find off-putting, but believes that " the benefits women will gain from volunteering at any stage in their lives will still be personal empowerment, social connection and community development” (2000 p. 6).

\subsubsection{What shall I live on? Economic resources}

The wealth that a woman has in her retirement is the person that she is, her life experiences, her education and her ability to be interested in the world.

Susan St John (1996)

Material wealth represented by money and possessions, particularly a house and a car, is not indeed the sole arbiter of the quality of life an older woman may enjoy, but they underpin much of her daily living in providing access to interests and 
activities, healthcare and social contacts. The literature available on income, assets and patterns of saving shows that women are disadvantaged in relation to men. This is due to their lower earning capacity over a working life, difficulty in obtaining credit as single women, poor financial advice and other factors concerned with attitudes and behaviours (Else and St John 1998; Glass and Kilpatrick 1998; Cooke et al.1999; Gee 2002). The traditional savings patterns for families has been based on the male partner's role as chief provider and the expectation that he will make retirement provisions to support his spouse in the eventuality of his earlier death. In New Zealand this provision has been linked with home ownership. This model, however, has been challenged by the structural changes in the economy over the last two decades and the social changes that have led to many more women parenting alone.

Historically women have been largely segregated in poorly paid occupations, the value of which has been determined by the fact that the work done by women was seen by a patriarchal society as less worthy than that of male occupations. The tasks associated with reproduction, domesticity, caring and nurturance were perceived as an integral part of women's role in society and when they occurred outside the home were seen as an extension to 'women's nature'. The monetary reward thus attached to them was considerably less than that accorded to men's work, which counted as 'real work'. Brents (1993, p.159) refers to the fact that poverty in old age is associated with gender and that for women dependency is maintained through the spousal relationship and single older women were the most impoverished in industrialised nations. Another form of inequality is posited in the work of Estes et al. (1995, pp.352-355) which refers to the unpaid or poorly paid work of caregivers, mainly women, who provide savings for the state by caring for the aged. This is reflected in the 2001 report of the West Auckland Women's Centre's research project which explored the interrelationship between the ability of women to save and the increasing demands many women face to provide care for the elderly. Their interviews with women confirmed the need for a universal entitlement to a pension for the aged and the need for the recognition of the unpaid work of caring and its personal cost to women in "terms of facing an insecure and meagre retirement income” (ibid p. 32). 
While the campaign for equal pay for equal work has made much progress in New Zealand's public sector since 1955 and subsequently through the phasing in of the 1972 Equal Pay Act in the private sector, a considerable gap remains between the earnings of men and women. According to the New Zealand Institute for Economic Research (1997, p.2), women's hourly earnings in 1996 less expenses were 80.8 percent of their male counterparts. The reasons for this are complex, involving the number of hours worked as well as the actual wage rates, the relatively lower wage rates in the "caring" and domestic occupations where women are over-represented and their under-representation in those sectors which have experienced above average wage growth. Gordon and Morton (2000, p.3) argue that this disparity in remuneration continues to exist within the public sector, "Women are better educated and going into a. greater diversity of jobs than ever before, but the gender wage gap has hardly changed in the private sector and has got markedly worse in the public.”

Such disparity has consequences for women's capacity to save as discussed below. As well as experiencing lower wage rates as a group, women are more likely than men to have casual and part-time work and disrupted paid employment due to their unpaid work as caregivers in the family. The issue still remains, of course; by what means are occupations valued and reimbursed financially? The market model does not serve women well.

Women's distinctive life cycle produces a clear pattern in relation to income acquisition quite unlike men's. This is shown in the figure 3.a below (Statistics New Zealand and Ministry of Women's Affairs, 1999, p.109). Apart from the 15-19 age group at the start of their working life when both sexes may be on youth starting rates and later at age 65 when in receipt of New Zealand Superannuation there is little equivalence. In their early twenties as job experience is acquired, women's median income rises, but not at the same rate as men's. Women's median income falls in the early twenties and thirties as childbearing and rearing take place. It rises again between thirty and forty as the demands of family commitments decline. As has been shown above and in section 2.3 (pp. 25-26), this may be delayed by the need to care for disabled or aged members of the extended family. This loss of income may not be made up 
by subsequent years in the paid workforce thus women's ability to save personal income toward retirement is severely eroded. There is a gender disparity between the incomes of men and women at the peak of their lifecycle earning capacity, ages 40-49.

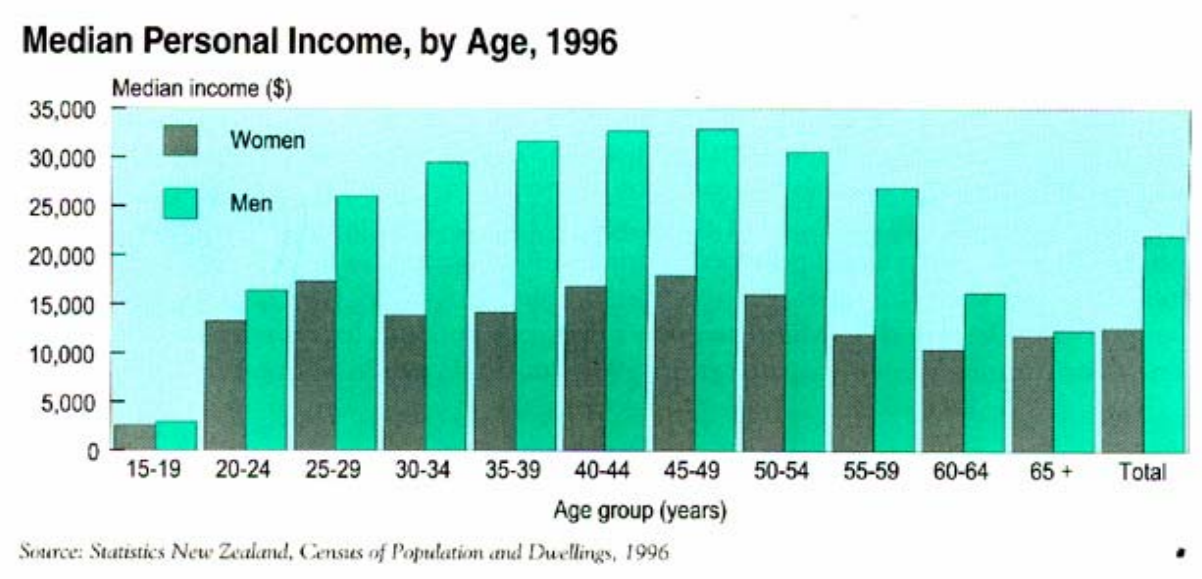

Figure 3.a

The median income for women is only 54.7 percent of that received by men in the same age group. In periods of structural unemployment both the availability and nature of the work offered doubly disadvantages women as in the 1980's restructuring of the economy. This resulted first in the loss of jobs from the manufacturing and production sectors, which affected men and Maori women more than women in general. These mainly full-time positions were frequently replaced by casual or part-time employment, which subsequently reduced the capacity for the worker to bargain for good conditions and wage rates under the 1991 Employment Contracts Act, which tended to favour the employer. Many women compensated for their loss of income by finding more than one part-time or casual job. Such work is heavily concentrated in personal care, child-care, cleaning and food preparation, tasks usually associated with the household. Women with families to feed and little free time took whatever work was available especially when transport was a problem. Levels of poverty increased significantly as indicated by the growth and use of foodbanks. 
The experience of family breakdown, divorce and solo parenting which increased from the seventies left women financially vulnerable. Their capacity to save was severely limited and in some cases non-existent. Else and St John (1998, p.10) claim that most New Zealanders---at least 85 percent of all women and 40 percent of all men do not earn enough in total to save what they would need to provide an income in old age, even at the most basic level. This is clearly shown in a study that is part of ongoing research investigating life after 40 in New Zealand (Gee et al., 2002). Women were less likely than men to have saved for retirement and were more likely to be to be solely dependent on state provided superannuation. This was especially the case for those women who had divorced or taken on care-giving responsibilities or had experienced poor health leading to reduced work opportunities and disrupted work histories. The results of this study support Marsault’s conclusion

Despite the increasing economic independence achieved by women, their position in terms of wealth accumulation remains notably vulnerable...... ultimately the capacity of women to accumulate savings will depend in a large degree on their spouse's behaviours related to money management.

Marsault (1999, p.20)

Some people still see the male 'breadwinner' as having the priority rights to employment and the female's need for paid employment as secondary. Married women with partners working are expected to leave jobs for males or single women regardless of family, personal needs or their specific skill, experience and expertise. They should be at home economising, according to Gareth Morgan, the principal author of an Infometrics report (1991) that evaluated the merit of a second family income and its relation to efficiency in the home. This paper was designed to show that the savage cuts to government benefits could be ameliorated by women staying home rather than seeking low paid employment. In so doing they would save the costs of transport and clothing, of childcare and household labour; an interesting admission of the value of traditionally unpaid women's work. Morgan argues the advantage to a couple or family of a woman staying at home, but makes no allowance for long term savings, whether or not any 'benefit' would be equitably shared in the home, or the effect that such a withdrawal from the paid labour force would make on a woman's employment record and future career. The calculations and concepts used are also open to 
challenge (Hyman 1994, pp.65-76). Most women in employment continue to do most of the household tasks themselves, occasionally with the assistance of spouse, partner or older children and a great deal of the childcare in families with low paid employment is carried out by extended family, neighbours and friends. Work hours for the poor are determined by a partner's work time, by the opening and closing times of the school day and the availability of unpaid childcare usually within the extended family, unlike women in higher paid occupations who can afford professional help. These women are a minority. Morgan and his associates did a disservice to women in justifying lower transfer payments and so increased levels of poverty among women, especially those who were solo parents receiving the Domestic Purposes Benefit.

Figure 3.b

- Personal Income Quintiles, by Sex, 1996

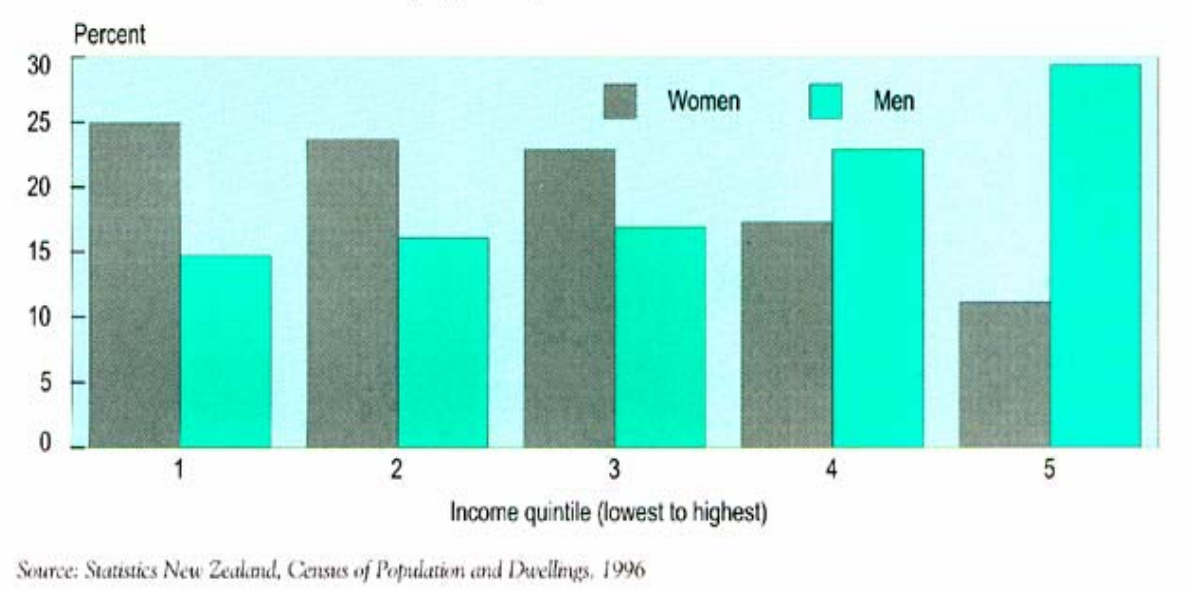

The disparity between male and female incomes is clearly represented in figure 3.b above. Compared to men, women are over-represented in the lower three quintiles and under-represented in the top two. The two lower quintiles account for the incomes of 48.7 percent of women and 38 percent of men. At the top end of the scale only 11.1 percent of women compared with 29.4 percent of men had incomes in the top 20 percent of incomes received by all adult New Zealanders. Mary Mowbray's work on distribution and disparities in household incomes shows that most New Zealand superannuitants have moved from the bottom 
quintile to the second quintile (2001, pp.47-54). This is not the result of increased income, but the outcome of their displacement in that quintile by beneficiaries whose income declined as a result of government policies that cut benefit rates. She shows that households with children are at a higher risk of financial hardship than are households generally. There is however, no doubt that low income households, which include the majority of superannuitants and women living alone, have been crucially affected by both the imposition of, and increases in, user charges for a range of public services.

Since the 1970's there has been an accelerated rate of divorce, separation, and de facto relationships and the formation of complex blended and sole parent families, all of which impact on the ability of individuals and families to save for retirement. In addition the escalated costs of tertiary education required in today's "knowledge economy" leaves young adults dependent on their families much longer than in the past and the situation is further compounded by the phenomenon of student loans creating huge drains on future earnings. The New Zealand tradition of home ownership, which constitutes the major asset for superannuitants, may become a thing of the past.

The so-called structural reforms to the economy from 1984 to 1999 together with the above-mentioned social changes have created a climate of uncertainty and insecurity tearing at the fabric of social cohesion. The ethic of personal responsibility in all things overtook notions of interdependence and social responsibility and the primacy of the individual took precedence over the needs of the group. The rationality of market forces reigned supreme, but in the process the gap between the affluent and the needy grew.

Traditionally a woman's financial status has been linked to that of her spouse. He has been seen as primarily responsible for retirement provision whether through savings or pension schemes. Women as a group have shown less interest in financial planning than have men (Gee et al. 1999; Booth et al. 1999). There is variation in individual situations and a difference between generations, but women on the whole have been less able to provide for their retirement than men, especially when they have had sole responsibility for raising children. It may also 
be the case that when women have money they are more likely than men are to spend it on their children rather than on themselves. Gee et al. (ibid) found that women who had divorced and women who had taken on care-giving responsibilities were less likely to be saving for their retirement, independent of current personal income. In this study fewer women with children were making provision for retirement than women with no children.

It is only at ages sixty-five and over that their income equates to that of men in their age group. This is due to the fact that New Zealand Superannuation, which is paid equally and separately to both men and women, comes at a time when both withdraw from the labour force. Even at this stage there is a slight variation in income in favour of men. In 1996 the Census of Population and Dwellings showed that about nine out of ten women over the age of sixty-five received government superannuation and of these nearly half had no other source of income. At that time, 42.7 percent of women over sixty-five compared with 32.3 percent men over sixty-five were totally reliant on New Zealand Superannuation. More men than women had access to other income from sources such as wages or salary, interest or investments, other pension schemes or self-employment. Marital status may very well determine a woman's financial security as she ages. Those who have never married or raised children, dependent on education and employment opportunities, may have been more able to save for retirement than those married, single, or divorced women with children who were on low household incomes. Other women unavailable for paid employment because they were caring for older or disabled members of their family, as culturally expected, would be similarly disadvantaged.

The current New Zealand superannuation provisions treat men and women equally, as individuals, so that for the first time some women have an income independent of their partner's. A small allowance is made for the extra expenditure of those who live alone. Low-income pensioners may qualify for the community services $\operatorname{card}^{9}$ which gives access to less expensive medical care, or a

\footnotetext{
${ }^{9}$ The pre-tax annual income for eligibility for the community services card is: Single living with others $\$ 18,586$, Single living alone $\$ 19,689$, Married with no children $\$ 29$, 398, Income New Zealnd (INZ) booklet, July 2001). These amounts increase where there are children, but this is not often the case with superannuitants.
} 
high users' health card which reduces the costs of doctors' services and pharmaceuticals. There is, however, no provision to assist the elderly with the high costs of spectacles, dentistry, hearing aids or densitometry to identify osteoporosis. While flu injections are free for those over sixty-four, mammograms, which are recommended two yearly, must be paid for by women over sixty-four. Older people, who are aware of its existence, may also be able to access an allowance for disability, which provides help with tasks such as garden maintenance. The importance of income and access to allowances for health related conditions are crucial to well-being and are addressed in section 3.6.5 below.

All of these provisions are subject to changes in government policies. Like superannuation they remain in the political football field. Arguments as to the sustainability of income support for the elderly, the age of entitlement and the level of remuneration constantly surface in the media, in newspapers, magazines and on television. The projected increase in the proportion of elderly in the population with their assumed lack of productivity and their perceived need for expensive healthcare towards the end of life, has raised ethical and political concerns relating to the relative distributions of the future economic cake. It may become a point of contention between the younger and older generations. Recent television commercials originating from the office of the Commissioner for Retirement used humour to promote saving for retirement, but carried an unpleasant intergenerational message. A middle-aged couple in a funeral parlour bemoaned their misfortune at the failure of an expected inheritance and a younger couple begged their unresponsive offspring, one still in a highchair, to promise to support them in their old age. ${ }^{10}$ Reductions in the proportion of persons aged 1564 and an increase in the proportion of people aged 65 and over have implications for retirement income.

According to Callister and Rose New Zealand research suggests that given current patterns of earnings and savings, over 85 per cent of 15-19 year olds in 1996 are unlikely by the time they retire, to have accumulated wealth (excluding

${ }^{10}$ These advertisements, 'Funeral' and 'Tantrum' were shown across all channels, 2000-2001. 
housing) equal to the present value of New Zealand Superannuation. In 2000 these authors produced a study based on population projections from 2001-2051 using various scenarios for net annual immigration, assumptions of low, medium and high rates of fertility, later retirement, lower levels of unemployment and further increases in the rate of female participation in the workforce. They found that none of the hypothesised variations in labour market behaviour returned the balance between taxation on personal incomes and transfer payments (including superannuation and income tested benefits) to a position similar to that of 1996 . Possible responses to an emergent fiscal pressure were those explored in the Periodic Review Group’s 1997 Interim Report on New Zealand Superannuation. These were raising the age of eligibility, lowering pension rates relative to the average wage, and the targeting of entitlement. Most debates surrounding retirement policy stress the importance of the role of increased saving behaviours in the transition to an older population structure.

In 2002 the government introduced a campaign to assist citizens to plan retirement savings. This included a website, www.sorted.org.nz, letterboxed pamphlets and television advertising on TV channels 1,2, 3 and 4 and on Prime and Sky television. Whether the topic of retirement provision arises in letters to the editor, in advertisements for savings products, or in the publications of the Office of the Commissioner for Retirement, the public is constantly reminded or exhorted to save for their old age.

To date there has been no firm political certainty as to the form or extent of future government provision for retirement income or other support to meet the health and social needs of the elderly in the twenty-first century and to fulfill the present expectation of 'Positive Ageing'. While high levels of home ownership and the present rate of New Zealand Superannuation (see section 7.4) provide a reasonable standard of living for most elderly today, the question "what shall I live on when I am old?” is not readily answered for future superannuitants. 


\subsubsection{Where shall I live? Housing and transport}

The New Zealand dream has always been to have a place of our/my own. This is none the less so in old age. For those with good income and realisable assets there is a choice. The building industry has been active in the construction of town houses suited to the needs of small families and the elderly and developers have invested heavily in retirement villages. In Towards Retirement Women's Views (SROW, 1999) the women interviewed perceived the vital requirements for retirement to be a flat section with ease of access, no stairs and a manageable house and grounds suitably located close to transport and community facilities. Sally Keeling (1999) found size and manageability of house and garden and personal attachment to the home through family memories gave meaning to the decisions made to remain in the family home or to find a smaller property. This study of 'independence' and 'ageing in place' is part of a larger longitudinal study of ageing in Mosgiel, a South Island town. Keeling found that for those persons eighty to ninety years old, the majority of whom had lived in Mosgiel for at least ten years, independence and ageing in place were almost synonymous.

The adequacy of transport facilities was an issue researched by Good for the Royal Commission on Social Policy. This report, Transport: Access or Isolation (1988, Vol. IV Social Perspectives) stressed the importance of accessibility which could be seen as a major factor in determining quality of life. It noted the substantial disadvantage that occurred to those unable to use cars, the disparities in the provision of public transport between cities and the rural areas and between inner and outer suburbs. Elderly people unable to access a car, either through the costs involved or through disability are disadvantaged when their access to public transport is limited; not all are eligible for government vouchers from Work and Income New Zealand (WINZ), can afford taxis or have helpful friends, neighbours or family available.

Neighbours are another consideration for the elderly as not all older people wish to live in a community of elderly. Some prefer the proximity of neighbours in their own age group, others prefer the stimulation of varied age groups in the neighbourhood, as evidenced in the interviews with a diversity of older folk 
(Gluckman and Tagg, 1995). The relative costs of rest home care and modifying existing home to suit the incapacitated elderly is a matter for public as well as private concern. Living in your own home is an important factor in maintaining control over your own life. For good health and well-being that home should be dry, warm and sunny, near to community facilities and transport and easy to maintain. The effect on health of damp and draughts due to poor insulation is discussed in the next section.

\subsubsection{How shall I stay well? Issues for health}

Women's Health has not been served well by earlier researchers; for the most part the focus has been on women's reproductive system, on menarche, premenstrual stress, birth, and menopause. Breast cancer and cervical cancer have received attention, but until recently, the health of postmenopausal women has not been a priority. This may have been an outcome of concerns about the ageing of Western populations and the assumed acceleration in healthcare costs. The majority of these elders will be women, especially those seventy-five and older. It is generally recognised that older women suffer more disability and chronic illnesses than men of the same age, although men may experience more acute conditions.

A New Zealand study of 252 persons over sixty-five representing an ethnically diverse section of New Zealand society (Flett et al. 1999) found that the most commonly reported chronic conditions were arthritis, sight or hearing impairment, and hypertension. Women reported a higher number and greater severity of symptoms than did men, but like their general health status physical symptoms did not increase significantly with age (ibid. p.122). Many adults in the study, even those with quite high levels of disability, functioned well in the community and felt positive about their own health. Fewer than one in twelve of older disabled are in institutions and aged care facilities. The researchers surmised that the ability to view one's health positively may be a function of the availability and utilisation of social support networks (ibid. p.128) and that timely access to health services is essential for promoting health, independence and mobility. In Britain most older women are healthy, live independently and 
provide their own self-care. According to 1985 statistics only seven percent of men and fourteen percent of women over sixty-five suffered from disabilities serious enough to require daily help to remain living in the community (Arber and Ginn 1991, 1988, p.143).

Women have had little input into research projects on ageing. In New Zealand Flett and colleagues refer to gender blindness and women having been excluded from much of health care research that guides policy (op cit. p.128). In America Johnson and Fee (1997, p.6) point out that the 1984 report of the Baltimore Longitudinal Study 'Normal Aging' contains virtually no data on women, even though women were added to the project in 1978. They cite other significant omissions of women from health research; the Harvard Physicians' Health Study that examined the relationship of moderate aspirin use and heart disease included 22,071 men and no women, despite heart disease being the most common cause of death in women. A national study of the multiple risk factors for heart disease (smoking, cholesterol levels and blood pressure) involved 15,000 men and no women. Johnson and Fee contend that the diagnostic tools, dietary guidelines and anti-hypertensive drugs used to combat the problems of high blood pressure have been developed from a study of white males and may not be applicable to women or other ethnic groups. Research by Dr Laura Klein at the University of California now suggests that men and women's responses to stress may vary from the formerly accepted fight or flight reaction to a stressor. The hormone oxytoxin is released and in women this is enhanced by oestrogen, producing a calming effect unlike the male testosterone. This has significant implications for health and may contribute to women's greater longevity.

The concept of health is now more likely to be seen in the context of overall wellbeing, but it was formerly generated by a medical model that saw health as simply the absence of disease. Disease and illness are considered to increase as the body ages. Although poor health is associated with the elderly and predicted to increase with the 'burden of years'; many elderly declare themselves to be in good health including those over eighty. Morgan and Kunkel (1998) show that physiological ageing is characterised by considerable variability in persons of similar ages and that some physiological functions can be maintained and even 
enhanced in old age. Healthy active persons tend to suffer less from other chronic diseases including cancer. While cardio-vascular fitness, measured by maximum oxygen consumption (VO2), decreases with advanced age regardless of one's health or fitness status, VO2 is higher in active individuals than sedentary ones and there is less risk of premature death from cardiovascular disease. "Aging does not cause disease nor disease cause old age, but aging is associated with greater risk of disease” (ibid. p 110).

Participants in Milligan's study (2000) described themselves as healthy at the same time as they experienced health-related conditions. She found this was consistent with the findings of other researchers who concluded that elders perceive wellness while simultaneously experiencing limitations. Milligan also found that older women's understanding of health had changed over the years and that they appreciated and thought about health more than in their younger years, “older women focus on current abilities and achievements and do not use a comparative approach to past abilities. Health is therefore defined in terms of abilities and not losses...it is contextual” (ibid. p.129)

When older women say, "I am well for my age," they do not ignore current disabilities, but tend to compare themselves with others' perceptions of aged health. On the whole, they do not expect to have the same energy and mobility as those a decade younger. ${ }^{11}$ Except in extreme cases of disability women often consider these deficits as concomitants of ageing to be managed in various ways, sometimes with assistance. The concept of 'contextual independence' of being able to do some things rather than others is congruent with Armstrong (1996) who found that older women focus on abilities and not on losses. Bonita (1996) stressed the importance for indicators of health in older women to reflect their health rather than their illness so that unduly negative constructions of ageing would not be a major focus in social policy.

\footnotetext{
${ }^{11}$ New Zealand national statistics on disability, 1998, show that $53 \%$ of women over 65 identify themselves as having more than one disability, and these include sight and hearing deficits and arthritis.
} 
Health is probably more important for quality of life than finance, but having a strong cash flow makes good health care more accessible. The perception of the inadequacies of the public health system, fuelled by media stories, and the unaffordability of medical insurance for most elderly in New Zealand leave them at risk when medical intervention is needed. All major health insurers now have higher premiums for older people. While the public hospitals respond well to emergencies, many people with chronic disabilities and less acute conditions feel neglected. ${ }^{12}$ Older persons waiting for cataract removal, joint replacement or cardiac procedures, which would improve their quality of life and lessen the burden on their carers, feel that rationing occurs and that the elderly are not a priority. For those with very low incomes some reduced costs for doctors' visits and prescription charges are available. However, mammography for women over sixty-four is not free, neither is densitometry, which is advised for the detection of osteoporosis. Orthotics and spectacles are costly, hearing aids more so. Glasses may cost $\$ 300-600$, hearing aids $\$ 1,500$ or more and even an upper denture over $\$ 1,000$. Whether for dentures or their natural teeth, dental care is a major concern for the elderly. Untreated dental conditions may create serious problems for health. WINZ may advance a loan of up to $\$ 300$ for emergency dental care, but this is must be repaid and that is difficult for those solely dependent on New Zealand Superannuation.

To promote good health housing design should allow for ease of mobility. Particular attention should be paid to areas of risk such as kitchen and bathroom. Many elderly may be unable to afford alterations to older homes or to purchase or rent a more suitable property. An interesting experiment has been taking place in Wellington. Older people, especially those on low incomes, are subject to respiratory problems and hypothermia which are environmentally related to our climate, to methods of house construction and heating costs (Howden-Chapman, Signal and Crane, 1999 p.15). To address the social gradient in health in a deprived neighbourhood a pilot study has been funded by the Health Research Council, the Energy Efficiency and Conservation Authority, the Ministry of Social Policy and Wellington City Council. The project is to eliminate winter

\footnotetext{
12 The April 2002 statistics for enquiries to the Citizen’s Advice Bureaux in Hawkes’ Bay show increased enquiries indicating the need for more medical support groups.
} 
damp, draughts and cold by fully insulating pensioner units in Wellington and is to be monitored by the Wellington School of Medicine, the Building Research Association of New Zealand and Smart Power as well as by self-reports from participants over the winter months.

Health is not simply a matter of physical competence, a good diet and adequate exercise, but is strongly influenced by psychological affect. Browne (1998) cites the work of Celia Hurwich who interviewed 10 older women in their seventies and eighties in order to identify factors contributing to vitality in old age. She surmised that diet and exercise would be seen as the attributes contributing to well-being, but found instead that attitude was the single most important factor. Palmore (1997) found that some older women may become more assertive, managerial and autonomous than previously and that this is not consistent with social discourse which presents older women as dependent.

Linda George (1995) found that social factors are strong predictors of health and mortality and considers that the presence of illness tells us little about its implications for quality of life. People with cancer and cardiovascular disease differ greatly in their ability to perform self-care tasks, the activities of daily living, but many still enjoy social activities and lead productive lives. She notes the limited and contradictory research on coping mechanisms and the need for more interdisciplinary research on the effect of social factors on health, relative to other risk factors. George sees that a sense of control, of self-esteem and mastery are related to better health and lower levels of functional impairment and fewer depressive symptoms. Similar to Hurwich's 'attitude' the 'self' mediates between physical health and depressive symptoms determining self-perceptions of the quality of life.

While in current presentations of positive ageing the opportunities for activity envisaged in Laslett's Third Age have received most public attention; less has been given to his Fourth Age in which he theorises 'dependency decrepitude and death'. This is the characteristic preserve of those requiring the largest amount of support. Featherston and Hepworth (1989) use the concept 'deep old Age' to categorise very old people based on physiological decline. Bury (1995) notes that 
the negativity associated with this allows the third age to be seen in a positive light. Since the majority of the oldest old will be women it is possible that this displacement of negativity from the young old will transfer to the oldest women. He suggests a more passive than active lifestyle as being compatible with a good quality of life at an advanced age (ibid, p.23).

\subsubsection{This is where $I$ have been: The life course}

Table 2.1 showed the events and trends likely to have affected the lives of the women in this study. While collectively living through these events each woman will have brought to them her own personal experience of both individual and shared contexts. Women's life courses are complex and diverse and from it will develop her sense of self. This is not only a matter of genetics, ethnicity and upbringing, but a product of her interactions with her social and physical environment which includes the attitudes of the culture and society in which she lives. From a life course perspective Angela O’Rand (1995, pp. 188-207) sees differentiation as an increasing function of age in a cohort, in so far as age reflects the cumulative experience of cohort members over time, placing them on different trajectories. Social class and ethnicity may determine social status at birth, but access to educational opportunities creates opportunity for change. Educational attainment is linked to the economic resources of individuals and persists throughout the life course. It explains more of the variance in wealth after age sixty-five than at any earlier stage of adult life (Crystall, 1995, p. 397). He also found that contrary to the perceived advantages of the elderly as a group, an analysis of age group adjusted income shows that after age seventy-five the worst-off forty percent of people shared fifteen percent of total wealth while the twenty percent best-off shared forty-seven percent of total wealth. Women are mainly in the lower income groups and therefore incur a cumulative disadvantage in the acquisition of assets during their lifetime. For some the happenstance of inheritance or marriage may bring increased financial resources, but this is problematic. Moen contends that, "Even in social welfare economies, women and other culturally economically disadvantaged groups are handicapped by initial ascriptive statuses that constrain economic opportunities and by public policies that do not compensate for these initial conditions” (1995, p.198). 


\subsection{Conclusion.}

The positive and negative dichotomies in historical and contemporary images of ageing have been illustrated. Post modern and critical thinking, which influenced gerontology, has led to the blurring of boundaries creating more fluid and diverse concepts of ageing. I have shown the progressive phases of theoretical development in gerontology and the input of feminist thinking. Many older Western women are shown to have accrued disadvantages over their lifetimes through the prejudices of sexism and ageism; particularly 'the double standard of ageing'. The difficulties in defining age chronologically, the damaging effects of stereotyping the aged as unproductive, and the issues of segregation and isolation have been addressed. I have noted age related changes, both physical and psychological and some responses of the elderly to them such as selectively optimising social contact and compensating for lowered physical capacity.

The newer constructs of positive and successful ageing have been examined, with their implications for the market and whether or not all aged can attain these current ideals. I have shown that the economic consequences of segregation in a poorly paid workforce, of casual and part-time employment, and of unpaid domestic labour over their life course can lead to reduced assets and income in late life women.

I have indicated that an androcentric perspective has minimised the value of some medical research to the health and well-being of women. The importance of recognising the heterogeneity of women's life courses leading to individual variations in quality of life has been acknowledged. Societal issues of power and control have been raised together with the ethical problems they pose now and in the future. The factors addressing the quality of life for older women have been reviewed. The simple decline and deterioration models of human ageing have been questioned and rejected. A significant representation of this position is that of the gerontologists Baltes and Graf reporting on the Berlin Aging Study, "Both potential and limits, gains and losses, are part of aging and an analysis of their interaction is the challenge of future scholarship” (1996, p. 457). 


\section{Methodology and Method}

When a theory is transformed into ideology, it begins to destroy the self and self knowledge...it organizes experience according to itself, without touching experience.... slowly it builds a prison for the mind.

Susan Griffin, The Way of all Ideology, 1983 p. 280.

\subsection{Introduction}

I have prefaced this chapter with Susan Griffin's comment on ideology because it expresses my concern that theory can become rigid and constraining. She writes of the conflict between an ideology and the need for creative theory capable of giving room for experience. Postmodern thinking is dismissive of universal theorising and yet theory, I believe, can be a positive construction with which to find our way around the world of our experience. Feminisms are not without their share of ideological straitjackets; one size does not fit all. I found myself caught between Scylla and Charybdis, the ideologies of feminist standpoint theory and postmodern feminism. Rose characterised the first as looking to "the possibility of a feminist knowledge to produce better and truer pictures of reality,” and the second as refusing "the possibility of any universalising discourse” (1994, p.23). In this chapter I discuss the sources of my choice of methodology and the process which led me to a feminist perspective, which I believe should promote the welfare of women.

In carrying out research there is a distance between the researcher and the researched and therefore the possibility of exploitation of the 'subject' by the 'expert'. As a feminist I have tried to reduce this by involving the subject in the process of research and by constantly reflecting on the interpretation and meaning given to the study and the provenance of both the questions asked initially and the evaluation of the data generated. In this chapter the reasons for which the study was undertaken and the ways in which my personal values have been involved in its overall design and execution, are examined in relation to feminist theory. This reflexivity constitutes a vital factor in feminist research and relates to my belief that the meanings of our realities are socially constructed. If we constructed them, so can we deconstruct them. However when this remains an individual exercise it will not facilitate societal change whether generally or for 
smaller groups. Some collective understanding and subsequent action is needed to address the structural institutions of power. This requires social cohesion and the recognition of some common agendas for diverse groups of women. Despite women's diversities situated coalitions which accept the differences among women may be formed in the pursuit of specific common goals for societal change (Braidotti et al., 1994, p.58). Knowledge generated in this study may contribute to the elimination of sexist and ageist attitudes, which oppress some older women. It may facilitate changes in public attitudes and social policies to allow the recognition of older women as valuable, respected and productive members of society, and not confine them to its margins as 'oldies' portrayed as dependent, ailing and burdensome. To find a theoretical position that would both inform my practice and be visible within it I asked three questions. What is feminist methodology? Why have I adopted this approach? How do I claim to be doing it?

Searching for answers to these questions I looked at the development of a feminist approach to knowledge and how this might be justified, a task made more difficult by the existence of a plurality of feminisms. In her introduction to Feminist Thought Rosemary Tong (1998) details its diversity and describes eight categories of feminism, devoting a chapter to each. She sees "a major challenge to contemporary feminism to reconcile the pressures for diversity and difference with those for integration and commonality” $(1998, \mathrm{p} .8)$. This is not the place to detail these differences, but rather to argue that there exists a commonality among them in the critique of the influence of male values of a patriarchal society which privileges 'rationality' in the production of knowledge. The dominance of reason is discussed below.

\subsection{Reason}

In the western world the driving force in the historical production of knowledge was reason. Rationality was seen as the essential component of philosophical discourse and even belief in God was not a simple matter of faith, but the product of reason; deduction from first principles demonstrated 'his' existence. Logic was the backbone of philosophy and the key to the natural sciences, which were seen as the preserve of rational man. Descartes' 'cogito ergo sum’ placed thinking and 
being as synonymous, and reasoning man as the arbiter of knowledge. The 'irrational' nature of women precluded her from the male pursuit of knowledge.

In patriarchal society, women could not be readily recognised as the producers or interpreters of knowledge as this would give them power. Scholars spent time classifying phenomena, finding labels for like identities. These were frequently viewed in two categories, favourable or unfavourable to man. A world that was viewed through a prism of dichotomies, separating entities into opposing polarities, resolved both material things and human experience into binary pairings, positive and negative, the one valued more highly than the other. What was perceived as masculine took precedence over the feminine. These contrasting dualisms such as strong-weak, hard-headed-soft-hearted, independent-dependent, reason-emotion and objective-subjective disallowed women's claim to produce knowledge from her inferior position. Seen as an emotional being, bound up in the earthy and mundane operations of everyday life, she was denied the capacity to reason with or about abstract concepts. For the Enlightenment, imbued with patriarchal values, true knowledge could only be deduced from an 'objective' interpretation of value free data through the agency of reason. The concept of objectivity is challenged in the following section.

\subsection{Objectivity and neutrality}

Objectivity presupposed neutrality. 'Good science' and 'bad science' rested on the supposed neutrality of the observer, in his or her observations and 'value-free' interpretation of the situation under examination. It was claimed that neutrality would ensure the absence of bias in both the experimental design of a project, and the techniques used for data collection and analysis. The values of researchers themselves would not intrude upon the project. Good science was justified by truth claims resting on the objectivity of the researcher, who was 'outside' his or her subject. Sandra Harding draws attention to androcentric values that perceive gender as a factor in the generation of objective results in research.

The results of men's research and the processes used to arrive at them by communities that exclude or marginalize women have been able to bask in the beneficial status conferred on them by the presumed greater objectivity of men. 
Feminism has challenged this belief in the neutrality of the observer, perceiving that such a concept originated in a male construction of the universe. Each person brings to research his or her philosophical stance and belief about the production of knowledge and ethical practice. These arise within that individual's social context and express values, which are implicit and unavoidable and must inform not only the methodology and method and the interpretation of data, but will determine the original questions posed and the resultant hypotheses. Neutrality is an illusion and objectivity an artifact of process.

Critical of patriarchal structures and male bias, female empiricists tried to remedy this by making male bias visible, but they were not prepared to abandon objectivity entirely. Sandra Harding (1993) posited the possibility of a stronger rather than a weaker objectivity, which could be obtained by reflecting on, and critically examining previously ignored cultural influences and taking the location of the knower into account. She argued that, while no knowledge was value free, the application of the 'stronger objectivity' would lead to less false observations and interpretations of data and to 'truer' results. The feminist economist, Julie Nelson concludes her chapter on objectivity by characterising 'strong objectivity' as being, "not based on an illusion of detachment, but rather on a recognition of one's own various attachments and on the partiality this location lends to one’s views” (1996, p.8).

This recognition of partiality of view has been extended by some feminist standpoint theorists to claim that their viewpoints are privileged and that conscious partiality is preferable to neutrality. The concept of privilege is related to being the underdog or the oppressed Marxist proletariat and who better to interpret their situation than members of that social class, group or in the case of feminists, gender. While I concur with the need for the researcher to specify their 'conscious partiality', I feel less certain about the concept of a 'privileged viewpoint'. As an older woman researching other older women, the task of interviewing and forming relationships with the subjects of the study is facilitated by my position within that group. I cannot however assume superior knowledge of this extremely diverse group simply by being an older woman or by claiming membership of such a broad social category. 


\subsection{Feminist methodology}

That women may generate knowledge and that this knowledge may differ from the knowledge of men has, until the mid-twentieth century, largely been discounted. Feminists such as Sylvia Walby, Jane Flax, Nancy Hartsock and Linda Nicholson, Luce Iragary and Helene Cixous have deconstructed Marx and Freud and reconstructed them from a woman's point of view and have used Foucault's discourse analysis of societal power structures to their advantage. Critical thinking, an ethical approach which takes the production of knowledge as its central concern (Braidotti et al., 1994, p.46) is characteristic of contemporary feminisms which reflect the diversities of women's life experiences as interpreted in a post-modern world. Jamieson, Harper and Victor (1998) instance this in a gerontological context. The emergence of multi-cultural, global and ecofeminisms has built on the earlier work of liberal, radical, psychoanalytic and Marxist-Socialist feminisms, which still co-exist. That diversity and controversy are present is a healthy sign that feminist theory however subversive of itself is alive and developing. This is reflected in their methodologies.

The meanings of methodology cannot be separated from the underlying epistemology that informs the methods used in research. Sandra Harding (1986) distinguishes method, methodology and epistemology while acknowledging their intertwined nature. A methodology is a theory and analysis of how research does or should proceed; method is a technique for gathering evidence and epistemology supposes an adequate theory of knowledge or strategy of justification. In the academic world method, methodology and epistemology are sometimes distinctly identified, as above, but in practice I find that they elide, overlap and sometimes contradict. Lynne Alice (1999, p.63) while affirming the academic definition of their difference, points to the fact that they are integrally connected in practice, the sites of most contention and concern being method and interpretation. In the context of research, Mary Maynard notes the problem of, "reconciling the abstract analyses and recommendations made at the epistemological level...with the more concrete concerns of method and methodology faced by those carrying out empirical research” (1994, p.10). The concrete concerns for me were to choose tools of research with which I had some experience and to employ them in a non-exploitative way within the constraints of cost and time. Theory did not provide a 'perfect' solution. 
Gloria Bowles (1983) reflects Susan Griffin’s concerns, which open this chapter. Writing early in the development of feminist methodology she warns feminists not to create a 'Super Methodology', a combination of methods that will become even more impenetrable than the methodologies they are built upon. Such 'impenetrability' may very well solidify into an ideology. She wishes to avoid esoteric language and defines method as "the way you go about finding out what you want to know" (ibid. p. 41). This is certainly a succinct definition of method, the how of enquiry, but I do not think it describes methodology which includes the what and the why. Methodology informs the methods used. It encompasses the social context within which the enquiry takes place, the nature of the question posed and takes into account both the resources of the researcher and researched. Methodology includes the theorising of the problem itself. It is the conceptual framework or structure by which research proceeds and this includes the methods used. Gloria Bowles was concerned that Women's Studies should not become 'just another academic discipline'. This would divide feminism from the everyday world, moving it away from its origins in the political resolution of the practical concerns of women.

Klein considers methodology as the overall conception of the research project as well as the choice of appropriate techniques for its implementation and the presentation of its results. One of her concerns is that earlier scholarship designated feminist "has not contributed to women's visibility in a feminist frame of reference, but instead continued to perpetuate the dominant androcentric one.Thus it is research on rather than for women” (1983, p.90). She defines research for women as that which, in some way, acts as an instrument to improve the lives of women. The problem of added on knowledge about women stems from the use of traditional methods that are presumed to be equally applicable to men and women. It fails to recognise that not only was our past man-made, but that our present still is. Women's answers to questions designed on a base of male knowledge cannot be rightfully compared to men's answers. Klein also points out that feminist research is transdisciplinary and not amenable to 'how-torecipes' (ibid. p.90). I have placed this study in a context of older women's everyday lives and used literature resources from diverse disciplines.

Another criticism is that some researchers had not stated why they chose a particular method or any problems they may have encountered during the project. 
She is concerned with the lack of a holistic approach occasioned by the reductionism of traditional science. Variables are isolated and tested in additive, linear fashion, manipulated as dependent or independent in a reductionist climate and the whole picture is lost. She looks for a methodology which will go beyond this and turns to the work of Maria Mies who produced some methodological guidelines for feminist research based on the replacement of 'value-free research' with 'conscious partiality' which is achieved by the researcher's partial identification with the object of research. It creates a critical and dialectical difference between researchers and their objects (Mies, 1983, p.122). This she claims corrects the distortions on both sides and widens the consciousness of both. The reciprocity developed results in the 'view from above', that of the oppressor, being replaced by 'the view from below' which leads on to liberatory or emancipatory action from oppression and exploitation. In both practice and outcome feminist research should serve social change promoting the well-being of women. My intention is that this study may promote the well-being of older women.

\subsection{Issues in feminist research}

There are a diversity of positions within the feminist world of scholarship, but few lay claim to the existence of a discrete model of feminist research. Shulamit Reinharz (1992) in her search for a model of feminist method used as a working definition three guidelines to identify such works. Firstly that the method had been used by people who identified themselves as feminist, or part of the women's movement. Secondly that such methods had appeared in published or publicly available books, journals or other works identified as feminist and thirdly that the methods used in research may have received awards from organisations that recognised feminist research. She felt that such an approach was consistent with a feminist valuing of people's self-identification, but it had a downside in that she was unable to use the work of feminists who had chosen not to use, or had been prevented from using the term 'feminist'. Reinharz found that while feminist researchers used a great diversity of methods drawn from a range of disciplines, they created others. It is, however, not method itself, which allows the naming of feminist research, but rather a perspective informing the themes present in its production. She lists ten themes (Reinharz, 1992, p.240) which are itemised below. 
- Feminism is a perspective, not a research method.

- Feminists use a multiplicity of research methods.

- Feminist research involves an ongoing criticism of nonfeminist scholarship.

- Feminist research is guided by feminist theory.

- Feminist research may be transdisciplinary.

- Feminist research aims to create social change.

- Feminist research strives to represent human diversity.

- Feminist research frequently includes the researcher as a person.

- Feminist research frequently attempts to develop special relationships with the people studied (in interactive research).

- Feminist research frequently defines a special relationship with the reader.

Other scholars articulate similar themes. Patti Lather (1991, p.71) puts the social construction of gender at the heart of feminist research as do Judith Cook and Mary Fonow who identify five basic epistemological principles found in an analysis of feminist research. These emphasise the avoidance of exploitation and the need for consciousness raising in research in order to empower women in the transformation of a patriarchal society. They reject the artificial separation of subject and object in research and stress the need for the researcher to pay continual and reflexive attention to gender (1990, pp.72-73). Because power is multifaceted and dynamic, the concept of empowerment at the heart of much feminist research is fractured and situationally dependent. Lather defines a goal for feminist research, "the overt ideological goal of feminist research in the human sciences is to correct both the invisibility and distortion of female experience in ways relevant to ending women's unequal social position” (1991, p.71).

This does not allow for the privileged position of some women in Western society and those who have acquired power, wealth and prestige in some Asian countries. Should they be excluded from feminist research since they do not appear to require 'empowerment'? This instances the dilemma of universalising the concept 'women'. Lynne Alice (1999, pp.66-67) also reminds feminists to make explicit the assumptions embedded in their "feminist" analyses and notes 
Millen's website ${ }^{1}$ warning that feminist research should not necessarily begin with definitions of females as oppressed or marginalised as not all women experience lack of social privilege.

Stanley and Wise (1994) concur with the ethics of not treating women as research objects and with the importance of reflexivity and the recognition of diversity. Benton (1997) also sees reflexivity as one of the vital aspects of feminist research, and Good expresses it as "making the filters explicit as a tool that can be applied in meaningful ways that communicate and translate and inform while keeping faith with the originals” (1999, p.86). From a study of feminist literature Worrell and Etaugh (1994) derived six themes relating to a feminist approach:

- Feminists challenge the tenets of traditional science.

- The lives and experiences of women are a locus for the development of knowledge.

- Power relations are viewed as the base for patriarchal social relations.

- Gender is recognised as an essential category of analysis.

- The use of language in its power to name.

- Feminism promotes social activism for societal change.

Worrell and Etaugh (1994, p.449)

I find commonalities in the above reviews of feminist research and will state what I find most useful for this project at the end of this section.

The discourse of feminism is both complex and contentious, no more so than in the fields of epistemology and methodology, where contradictions abound. The aliveness of the debates promotes new insights, but is confusing for me as I search for academic justifications for my methodology. A case in point are the critiques provided by Nancy Hartsock, Dorothy Smith, Patricia Hill Collins and Sandra Harding of Susan Hekman’s 1997 article 'Truth and Method: Feminist Standpoint Theory Revisited'. Hekman's main concern was the resolution of the perceived contradictions or insufficient justifications in feminist standpoint theory. These occurred when it both acknowledged a diversity of standpoints and yet privileged one locus of knowledge over the other because it could lead to an

${ }^{1}$ Millen, 1997, Doing Feminist Research. Sociological Research Online, 2 (1). <http://ww.socresonline.org.uk/1/1/1.html> 
improvement in the lives of women (a dilemma I cannot resolve for myself without reference to some essentialist sense of justice). This is relevant to my location as an older woman researching older women from a feminist perspective. Hartsock argues that "Women's lives make available a particular privileged vantage point on male supremacy" (1983, p.284). The oppressed standpoint is valorised over the oppressor's and this implies an hierarchy of standpoints. A relationship exists here between Harding's "strong objectivity" and the less false or truer claims of science. In response to Hekman's claims of a possible return to the universalisms of modernity, Harding points out that she had, indeed, intended to distance herself from the remnants of modernist ideology and that absolutes were not involved. Truth claims and knowledge were provisional and changed over time. Like Hartsock, Smith and Collins, Harding reaffirmed the justification for privilege as consisting in the actual life experiences of women.

She acknowledges feminist standpoint theorists' debt to the dialectics of Marxist epistemology, which privileged the situation of the proletarian oppressed. Their consciousness of oppression and how it was constructed in an hierarchical society could trigger social change. Standpoint theory is rooted in a perception of this need for change, in this case from a society dominated by patriarchy. The raising of women's consciousness, it was argued, would lead to political action enabling the empowerment of women and a reduction in the dominance of men. The point at issue is power relationships.

Hekman has her own solution to the problem of multiplicity, diversity privilege and political action. She sees a way through the dilemma in the use of Max Weber's theorising of 'ideal types'. These are yardsticks against which reality can be measured; they are limiting concepts, which unlike universal laws cannot be refuted by contradictory cases and their only justification is whether or not they help us to understand social reality (ibid. p.360). I find this artificial construct unacceptable. Other preferable solutions which she cites are those of Donna Harraway (1990) who postulates a new myth or story for women which will liberate consciousness rather than chase truth and reality, and that of Martha Nussbaum (1992) and Susan Moller Okin (1994) who theorise what Hekman refers to as 'quasi-universals'. These are based on notions of fundamental human 
needs and a common humanity in which one may ground ethics and feminist theory making possible the formation of successful coalitions and political action.

The issue to be resolved is the multiplicity of standpoints relating to the diversity among women, the locus of the individual and group. Is there a hierarchy of standpoints with those most oppressed at the pinnacle? If so, who decides it and what are the appropriate means for social change? From the point of view of a black American feminist looking at power relations Patricia Hill Collins says, "Race, gender, social class, ethnicity, age and sexuality are... elements of social structure [which] emerge as fundamental devices that foster inequality resulting in groups" (1997, p.376). Collins warns that if the group is theorised away there is no common perspective or experience. Braidotti (1994) argues that the precondition for political coalitions is the acceptance of differences among women as a positive factor. In this study I argue that older women constitute a group which is not invalidated because of the differences between the individuals within it.

Another issue in the discourse of feminism, which must be considered in relation to methodology, is the fiercely contested use of the words 'woman' or 'women'. In discussing the problems of developing a method for feminist analysis within a postmodern framework Jane Flax states that,

Any feminist standpoint will necessarily be partial. Thinking about women may illuminate some aspects of a society that have previously been suppressed by the dominant view. But none of us can speak for 'woman' because no such person exists

(Flax, 1990, p.56).

Sojourner Truth's ${ }^{2}$ angry affirmation “and ain’t I a woman?'(Kemp and Squires, 1997, p.143) contrasts sharply with another view, that of Denise Riley who ungraciously proposed the term 'fluctuating identity' to replace Sojourner's 'woman' and the use of 'women'. Subjectivity she argues, dictates a very fluid concept for both ‘woman' and ‘women'.

'Women' is historically discursively constructed and always relatively to other categories which themselves change; women is a volatile collectivity in which female persons can be very differently positioned,

2 The black abolitionist and freed slave who spoke out at the Akron convention in 1851, naming her own toughness, rejecting the disqualifying notion of women's frailty and using the refrain “and ain't I a woman?” to emphasise her strength in carrying out the physically and emotionally hard tasks of slavery. 
so that the apparent continuity of the subject 'women' isn't to be relied on.

(Riley, (1988, pp.1-17)

In short, 'women' is an unstable category. The denial of using the abstract 'woman' is fine theoretically, when there is the time to explicate finer points of definition, of inclusion and exclusion, and the relevance or otherwise of biology and gender roles. However, in the every day world my understanding is that society constructs and is constructed by, not an abstract, but a group of persons named 'women', identifiable by a female gender and signified by the labels of language. Within this group, there is great diversity of being. Sexual orientation, race, social class, age, ethnicity and other descriptors of persons can have fluid boundaries which may change over time, but which will define the individual at any specific time and in within a particular context.

This study is concerned with those women who responded to a questionnaire on the quality of older women's lives. They are linked by their decision to participate in the project and their self-identification as older women. They then constitute a group of older women however diverse their individual situation.

I find no simple answer to the questions of the nature of feminist research, or women's knowledge. Maynard (1994, p.25) concludes that there is no one single answer to the question "what is feminist research?" and that many contested issues of method, methodology and epistemology remain. Indeed the very use of the words women or gender pose problems; each concept is contested and deconstructed, especially with the scalpel of postmodernism. If we cannot conceive of woman or women, then how can we have women's studies or feminist research? Think of an apple. There it is in the real world, touched, smelt, its colour and shape noted; named as one variety or another. Its use and purpose clear to me, I peel it, core it and slice it, separating its parts. Perhaps I pulp it, freeze or cook it and label it 'apple filling', but it is no longer an apple, just a textured edible substance flavoured apple. This is the way I feel about the postmodern destabilisation of the subject women. Destabilising is not however destruction and the real experiential world bounces back with all its contradictions. 
Feminists research women within specific situations; try to avoid global or universal applications and at times set aside any essentialism such as that based on biological classification. While some researchers see their standpoint as privileged, presenting a truer representation of reality, others point to the problems posed in creating a hierarchy that would declare one position superior to the other.

\subsection{Feminist use of research methods}

Feminist research is frequently interdisciplinary (women are everywhere) and as such takes from other disciplines methods in use there, as well as developing modes of interaction designed to avoid hierarchical relations between the researcher and the researched. Whether crossing the traditionally perceived barrier between them actually removes the possibility of exploitation is debatable. The design of the project, however empirically based and user friendly to the subject participants, is still the conception of the researcher, the other, coming from 'outside'. Although their race, gender, age and social class may be congruent there is still a distinction between researcher and researched. This holds even in action research such as the 1976-77 'Women help Women' project in Cologne. Mies describes how she and six students started a campaign to address family violence (1983, pp.128-139). The research component arose from the need to document and analyse the progress of the project towards establishing a house of refuge for battered women and was done using 'experiential analysis' (Reinharz, 1979) which takes into account the experiences of both researcher and researched.

For me, in this project, the choice of research tools was limited to those with which I had had some experience in former occupations and study. I had constructed and critiqued some questionnaires within postgraduate studies in tests and measurements and had used these in an educational setting with captive subjects. Interviewing was a component of my work requirement. As a SROW researcher I had scribed, facilitated and been a participant observer in focus groups. I had not however canvassed for participants as these had been provided. My analysis of quantitative data had been mainly univariate describing the frequency and distribution of populations and bivariate in 
checking for simple relationships. Such an approach was in accord with my skills and adequate for my purpose in this Master's thesis.

Traditional quantitative data collection and analysis is frequently limited by the need to use questions that can be easily coded and numerically assessed. This was so with the closed questions in my questionnaire. Items such as demographic data were easy to quantify as was access to services or ownership of homes or cars. It was possible to describe the respondent population in relation to numbers and to groups by age, marital status and income. Categorising, the information provided by open-ended questions required a more complex thematic approach and shed more light on how the older women were experiencing their life and led to the selection of participants to interview as this gave a less time constrained vehicle for the women to express their views. These loosely structured interviews gave an even greater insight into how the women perceived the quality of their lives.

Two of the problems I encountered related to trying to avoid stereotyping. If I limited participants to a particular age group by chronicity, I would be discounting the women's perception of themselves. I left it to the respondents to decide whether they were older women. I claimed to be researching quality of life, but had nowhere defined it. The problems of doing so are presented below. I avoided using existing scales of life satisfaction not only because I felt they were inappropriate for the respondents, but that it would restrict them in articulating their own perceptions of quality of life. I am aware that in the construction of the questionnaire I was using my own preconceptions, but received some validation for these in the discussion in the focus group.

As reported by Jacqui Smith in the Berlin Aging Study, the concepts quality of life, life satisfaction and well-being while remaining ill-defined, have been widely and interchangeably used in gerontological literature as indicators of the effectiveness of "social policies and welfare problems, the success of medical and psychiatric treatments, as global indicators of psychological adjustment, and successful aging” (1997, p.450). Although there is consensus across many disciplines that well-being is multi-dimensional, there is debate about what factors should be measured and by what means this should be done. Sociologists and economists focus on material resources and living conditions, medicine on the functional status of health, and psychologists on the emotive 
and cognitive profile of the ageing individual. Many of the tools used in the assessment of individuals have been developed from studies of populations differing in culture, ethnicity, social class and gender from those to which they are applied. Scales developed in American and Britain may be inappropriate in a New Zealand context.

Some feminist researchers have categorised methods such as statistical surveys, whether oral or written, as inappropriate tools for feminist research; even when open-ended questions are used and more expansive answers obtained, these must still be quantified, and the original context may be lost. Quantitative approaches have sometimes been criticised as disembodied 'number crunching' with hidden bias, hiding the actual experience of women, but part of the problem may lie within the project design and formulation of the question. It may be that no allowance is made for gender differences, in the belief that men and women would interpret the question in the same way as if they occupied the same mind space as men. Quantitative procedures of data collection and analysis however, are very useful, and some feminists' negative view of their use has been challenged. They have proven useful in the quantification of women's disadvantage, thus providing a platform for political action. Toby Epstein Jayaratne (1983) confirms the value of statistics in this respect arguing that informed public opinion can influence social policy designed to remedy gender inequities. The use of statistical analysis has been reaffirmed by feminists, but with more attention being paid to the location and experience of women. Ann Pugh, a feminist social worker and statistician reviewing her use of statistics in a project assessing homelessness concludes that "with due attention to the research process of producing them, there is a place for statistics in feminist as well as other research” (1990, p.111).

The relationship between quantitative and qualitative analysis has sometimes been viewed hierarchically, the one seen as objective and scientific, the other as subjective and contestable. I do not subscribe to this view as numbers do count, especially in the context of changing public policy, and graphic representation is often a direct communication saving many words. Both techniques have their place in research and neither can avoid the issue of value judgements. Qualitative data obtained mainly from loosely structured or unstructured oral or written texts has been seen as preferable or more user friendly for women both 
as researchers and as subjects of research, but thematic analysis requires the same rigour in implementation as any other research method.

There has been debate about whether qualitatively generated data can be seen as valid because it has been filtered both through the interpretation of the researcher and the authorial presentation of this to the reader. The concept of validity seems to hark back to the earlier criticisms of objectivity and truth referred to above. In the light of postmodern readings, which seem to point to a multitude of truths or none at all, validity may be a non-issue.

Qualitative research as practised by feminists limits itself, in the main, to small projects that are specific and located. There is no claim to absolute objectivity. The knowledge generated is located and contextually created, not generalised and the practice of reflecting upon oneself in relationship with the participants during the process of the research thus clearly allows the personal voice to come through giving transparency to the project. However partial, fragmentary and contradictory the 'I' of the researcher may be, it must be acknowledged and made visible within the context of the study. Alison Jones details how this may be done within an academic framework and argues that this is essential for research (1999, pp.31-32). Against my personal desire for a private persona I have tried to follow her advice, because after all I am revealing the thoughts of other women. They however have the protection of anonymity.

In this study I have analysed data from open-ended questions in a written questionnaire, from a focus group report and from transcripts and abstracts of semi-structured interviews. The qualitative procedures adopted revealed the emotive, social and contextual aspects of the women's lives. That qualitative data has been in short supply in New Zealand research on the elderly was mentioned in chapter one.

\subsection{Conclusion}

While I accept the notion of partial truths and diverse standpoints, I nevertheless espouse social justice issues within the everyday context of my life. I am willing to take action in their pursuit rather than be paralysed by what I perceive as the contradictory confines of a post-structural ghetto or the indeterminacy of a 
postmodern void. Pauline Johnson (1994, pp.139-140) makes a case for reassessing feminists' relationship to humanism. She argues that despite its very thorough and necessary critique of mainstream formulations of humanist ideals, feminism itself remains strongly committed to humanist values. Despite the criticism that humanism aspires to the grand or meta-narratives eschewed by many feminists, humanism implies the ability to take political action which I find compatible with my own feminist standpoint. I do not, however, believe that my knowledge as a woman is superior or privileged, except in so far as being a researcher, it has facilitated my relationship with the participants of this particular study.

I write from the standpoint of an older pakeha feminist who has experienced both the advantages of a tertiary education and the disadvantages of sole parenthood, juggling family needs and paid employment. I am almost seventy, a grandmother and find later life rewarding in the opportunities it offers for personal pursuits, even within a limited income.

I have chosen to use research tools with which I am familiar to obtain data on the lives of some older women. These have been both quantitative and qualitative. I have not engaged in action research although from some women's comments during interviews I became aware that my processes had given them opportunities to regard their later life in different ways. I have used a social networking process as a non-coercive means of obtaining participants for the study.

I believe that the lives of older women living in the community have not been widely represented. Media attention has been paid to those who are different in some way from the perceived norm for older women. It may be, that like the Queen Mother, the icon of privileged age, they have reached the magical touchline of one hundred, or are women noted for exceptional talents or skills, such as mature athletes, writers, social activists or actors. The outstanding nature of their achievements however is related not to the achievement itself, but rather to the unexpected age of the individual performer. They do not conform to the socially expected norm for their age. The other common representation comes from research on frail elderly women and their caregivers. This has prompted the purpose in this study, to record something of the everyday quality of life for some 'ordinary' older women in New Zealand, whose lives, when examined, 
evidence the extraordinary diversity, yet with some commonalities, of older women's accumulated experience, and to do it with their words.

This study for women has been undertaken from a feminist perspective. I am using the term 'perspective' advisedly in relation to methodology because in the literature cited in this chapter I have found guidelines, but no consensus on what counts as feminist method or methods nor a template for feminist methodology. Perhaps a template would itself be inappropriate and confining, and the best I can hope for is a web of guidelines accepted by most feminists with which to support my thesis. These are:

- Respect for the participants in my research.

- An awareness of power relationships.

- The avoidance of hierarchical relationships

- A focus on the experiences of women.

- A welcome to diversity while acknowledging some commonality.

- A belief that gender and knowledge are socially constructed.

- An intention to provide information which will promote the well-being of older women by making them less invisible.

- The use of women's own words to present themselves.

- A commitment to reveal my own position and to be self-reflexive.

My status as an older woman may have sensitised me to observe some constructs rather than others. I am aware that there are matters I may have ignored or over-reported. Has my interpretation of another woman's words reflected the reality of her situation? Have I fairly represented the background literature? How have my personal values influenced what I observed, the questions I asked, what I wrote and how I have responded to matters of confidentiality? This last issue is discussed in the next chapter.

However contestable the results of this study may be, there will be opportunities for others to hear for themselves the words of some of the women in the study whose recorded interviews have been deposited in the Oral Archive at the Alexander Turnbull Library in Wellington. 


\subsection{Overview}

In this study I have used both quantitative and qualitative methods to collect data. A focus group of older women assessed a pilot questionnaire that was then redesigned in the light of their comments and approved by the University Ethics Committee. Two hundred and ten copies of the questionnaire were distributed with a covering letter and a reply paid envelope for response. Participants were invited to indicate whether or not they would be willing to be interviewed and told that a final report on the project would be available at the conclusion of the study. This would be posted to them if they wished. Initially I had been concerned that the questionnaire would be too long to answer and too bulky for postage in a standard envelope, but this did not prove to be the case.

From an analysis of the 175 returned questionnaires a guide for interviewing participants was formulated and trialled with one of the original focus group members. It became clear that a less structured approach would leave more opportunity for a freer input from the interviewee and this was subsequently practised in the ensuing fifteen interviews. A simple check list of topics was retained to ensure that basics were covered. From a perusal of each individual's questionnaire the researcher produced a cue card for areas of specific interest. Although questionnaires were returned from Auckland to the Bluff, for reasons of time and economy, interviews were conducted in the wider Wellington area only.

The participants for the interviews were selected partly on their demographics, by their availability and partly from the contents of their questionnaire. They represent a cross-section of those respondents willing to be interviewed who resided in and close to Wellington. Attention was paid to obtaining diversity across income, marital status, education, and previous occupations and life events. Although ethnicity was not a variable used in the questionnaire, it arose in the context of interviewing. 


\section{$5.2 \quad$ The focus group: Intention and setting up.}

The intention of the focus group was to trial a pilot for a questionnaire. It was important that any questionnaire used should be user friendly and cover the areas women thought of as relevant to the quality of their lives. The word quality was not defined, but participants did not have a problem with this.

I mentioned the project to members of three organisations to which I belong: a Community Choir, the local Citizen's Advice Bureau and a Garden Club. I asked for volunteers to trial a questionnaire on the quality of life for older women explaining that it was to be used in my thesis and that I needed input from older women to increase its credibility and ease of use as a suitable means of collecting information. Ten women contacted me and I followed this up with a letter giving a time and venue for the focus group discussion. I had known one of these women for some time as we had worked together, facilitating and scribing for focus groups on a Society for Research on Women project ${ }^{3}$ so I asked for her assistance as a participant observer in the focus group, which she was happy to do.

I hired a room at the local Community Centre, which has easy access, and provided a home baked morning tea. On the day Wellington's weather did its worst and I wondered who would come. Two apologised, one for a clash of engagements and the other for ill health. However three of the women brought friends making the numbers up to eleven. I had raised the issue of confidentiality when the women had first contacted me.

\subsection{The characteristics of the focus group}

As only some of the women knew each other, time was spent in introductions and a feeling of friendship and camaraderie developed. The issue of confidentiality was again addressed and I explained who would have access to my notes and how they would be used. This was not seen as a problem and all participants contributed to the discussion in spite of the personal content of some of the questions. The participants' ages ranged from sixty to seventy-three. Three of the

\footnotetext{
${ }^{3}$ Towards Retirement: Women’s Views, 1999.
} 
women were widowed, six were married, one divorced and one lived apart from her husband; of the women five lived alone. Most lived in the JohnsonvilleNewlands area, but three came from other suburbs in Wellington.

For three of the four women living alone their income was approximately $\$ 15,000$ with the main source being New Zealand Superannuation (NZS) at the single living alone rate. The household income of the married women was, two with $\$ 15,000-\$ 20,000$, two with $\$ 30,000-\$ 40,000$ and one with over $\$ 40,000$. For two of the three widows, income was $\$ 14,704$ (NZS with the living alone allowance) as it was for the woman divorced and the one living apart from her husband. One widow's income was $\$ 30,000-\$ 40,000$. For eight of the eleven women the primary or sole source of income was NZS.

Previous occupations included telephonist, milliner, seamstress, retailer, shop manager, school dental nurse, primary school teacher, speech therapist, librarian, physiotherapist, clerk and office administrator.

All the women were or had been voluntary workers in other areas as well as in their capacity as family caregivers. They were all grandmothers and considered this a vital part of their lives. Two used the extra paper provided to write extensively about their hobbies and interests. There was an awareness of the need to economise and they felt that skills acquired early in life stood them in good stead, but they had concerns for future women in retirement. The word retirement occasioned discussion and laughter, but the status of being no longer in full-time paid employment was seen as appropriate. One woman had recently returned to part-time work to supplement her income.

\subsection{The pilot questionnaire}

The two-page pilot questionnaire was hand written and photocopied as at that time I had no access to a computer. It had 30 items in a rather cramped format but additional coloured paper was supplied for comments. Seventeen items were for tick box responses, 6 were closed questions and 7 were open-ended. All participants completed this and were invited to share their thoughts. Omissions such as the tick box for widows and awkward phrasing or lack of clarity were 
noted. A particular concern was the need for more space to write comments. I had made the questionnaire short, addressing basic demographics and some personal issues but had brought along a list of other matters that might be addressed. These concerned preparation for retirement, use of the Internet, pets, sleep, retirement villages and the relevance of religion, spirituality or philosophy to the quality of life. This last item the women considered important. They found that it was difficult to phrase as a question, but that it should nevertheless be included in the questionnaire and were happy for me to "fix it".

There was general agreement on items addressing basic material concerns such as income, housing and health. Social issues relating to family and the community were considered essential. The morning passed rapidly and there was a very lively discussion and a great deal of laughter. All the women agreed that it was a worthwhile project and were happy to answer an improved version of the questionnaire despite the fact that it would be considerably longer, and offered to pass it on to friends. I explained that it would be a few weeks before this would be available, as it was required to meet the standards of the University Ethics Committee before I could use it in the project.

\subsection{The focus group discussion}

I include this discussion as it presaged the themes developed from the subsequent data, the enlarged questionnaire and the interviews. While the women were of diverse personalities and backgrounds what they said was reflected in the responses from the larger group. The focus group provided the basis for including questions about family, changes in household functioning, specific health concerns, use of the Internet and opinions on retirement villages in the final questionnaire. It gave me confidence to ask about more personal matters such as spirituality and funeral arrangements.

Common concern was found in a dislike of rest homes and the worries that they themselves may one day become residents. This was based on visits the women had made to friends and relatives being cared for in these institutions. There was some discussion of the physical facilities, the quality of care provided and costs involved. Retirement villages were also a topic of concern, which raised strong 
feelings. While it was acknowledged that they could provide security and companionship for residents, there was a perception that the developers and owners were making excessive profits, and were fleecing a vulnerable section of society, the elderly. Aside from the cost and complex contracts involved the generally expressed feeling was that "Retirement Villages may be all right for some, but not for me.”

Some experiences of 'ageism' were shared including the negative representation of older persons in media advertisements and television; being 'invisible' while waiting to be served in shops and then being addressed as 'dear' which was considered intrusive and patronising. The participants complained of frequently being targeted by telephone appeals, perhaps because they were at home and could be readily reached.

They expressed great concern at the increasing cost of rates, petrol and power, of medical and dental costs and the need to economise in order to replace spectacles and large whiteware items. The replacement of furnishings such as curtains and carpets posed difficulties, particularly for those in their seventies who had been retired for many years. While pension rates were now adjusted annually, it was nevertheless difficult managing on a fixed income which never seemed to keep pace with price rises. For some there was a concern that they might outlive their savings.

House maintenance was seen as a problem for some, especially painting and major repairs such as roofing. Some participants had reduced the size of gardens and lawns to make them more manageable. The women living on their own had more problems in this respect, although those with ageing husbands felt that the time was coming when their spouse would no longer be able to cope with heavier repair work. In some cases adult children were unable to assist either through distance or the demands of their own family and work hours. In others the parent was loath to ask for assistance or had a government disability allowance provided by Work and Income New Zealand (WINZ), which covered garden maintenance.

There were comments that despite gray hair or arthritis they still had much to contribute to society although this was not always recognised by the public at 
large and by some members of their families who expected them to slow down more.

Health was seen as something you could promote by remaining active and "not shutting yourself away, like some folk did”. With much laughter they acknowledged the many discomforts of ageing, declining eyesight and hearing, broken sleep, creaking and painful joints and for one woman the loss of the ability to taste. Arthritis was a common complaint and some remedies were discussed. There was a feeling of disgust at the perceived failure of the health system and the concern that age may be a factor in the rationing of health services. The importance of the community services card was mentioned and the costs of private health insurance were seen as exorbitant. Two women had medical insurance, one at the budget rate, and others said that they had given it up because of the cost or had never contemplated entering such a scheme.

Family and friends were seen as an important source, as one woman put it, of "staying alive”. Nearly all the women were involved in grand parenting activities, although for some contact was difficult as their children lived overseas or outside the greater Wellington District. Links were maintained through letters, visits and phone-calls, by video and audiocassette tapes and email. One woman described how helpful Senior Net had been in developing her emailing skills. They felt that being a grandmother should be included in the questionnaire.

Of particular concern was the debate on the sustainability of current national superannuation payments and the notion that superannuitants were 'bludgers.' The women found this particularly offensive and demeaning. "We worked and paid taxes as well as bringing up children and caring for our elders. Some of us have accepted huge responsibilities for our grandchildren and are still contributing financially or with voluntary work to many charitable organisations.” Prior to this meeting the correspondence columns of the Evening Post had featured some particularly unpleasant letters from two young men with academic aspirations, who were critical of the economic burden 'greedy oldies' would put upon their generation and this was a source of irritation for the women. 
Also mentioned were their concerns about a shortage of volunteers. So many older women and younger women with families were now working. They were unavailable for street appeals or catering groups or to provide goods or man stalls, although some offered financial donations in stead of service.

\subsection{The focus group conclusion}

The focus group exercise was valuable in showing me that there was genuine interest in the venture and that user input in designing a questionnaire was essential. I referenced it when identifying themes in the responses to opinion based questions and in analysing the interviews. I took up some of the suggestions made by the women when redesigning the questionnaire. For some time after the event women rang me up saying how enjoyable the morning had been. I felt that this was due to their opportunity to discuss issues of importance to older women in a non-threatening environment. Despite the prevalence of what they saw as agerelated disabilities, especially arthritis, the overall impression of these older women was one of positivity expressed in their engagement with family and the community.

\subsection{The redesigned questionnaire and its distribution}

The University Ethics Committee approved the longer questionnaire. It opened with an introduction to the project, continued with fifty questions, both closed and open-ended, and concluded with a section for address and signature and tick boxes for willingness to be interviewed and a request for the receipt of the final report. The questionnaire is attached in Appendix I a.

This questionnaire was sent to members of the focus group all of whom completed it. They suggested other women who might be interested in the project. With the informant's permission I sent out a covering letter and a copy or copies of the survey to the relatives or friends whose names and addresses were given to me.

I publicised the availability of the questionnaire at meetings of five organisations to which I belonged; a choir, the local counsellors' committee, a garden club, the Women's Studies Association and a local U3A (University of the Third Age). I 
also contacted friends and family for the names of older women who might be interested in the study. Some of these women spoke to other groups to which they belonged such as church social groups, a Care and Craft group, a literature appreciation group, a Probus group, and local branches of the National Council of Women and Country Women's Institute. In two instances women took copies of the questionnaire to their monthly meetings.

The distribution took on a life of its own. I received requests for the questionnaire from outside Wellington. One respondent asked for more copies as she felt that people outside the capital were often left out. While attending the 2001 Conference on Ageing held in Wellington, two delegates from Palmerston North, reading my name tag, greeted me as "the lady with the questionnaire". Both women were unknown to me and I asked them how they knew about the project. Apparently a woman, whom they knew, received one from a friend and photocopied and distributed it. I was asked for a few more copies.

\subsection{The level of response}

My intention had been to obtain 100 completed surveys for analysis and I had posted out 200 questionnaires with stamped addressed envelopes for reply. I was hoping for a fifty percent response, which was perhaps optimistic. Over a period of two months one hundred and seventy-five were returned coming from places as far away as Auckland and the Bluff. Because of the unknown numbers photocopied by the woman in Palmerston North, or the possibility that others may also have done so, I cannot calculate an actual rate of response. The level of response nevertheless appeared high and I have attributed this to older women wanting to be acknowledged, and their willingness to take this opportunity to have their views heard. The initial work on the questionnaire as a result of the focus group experience ensured that it dealt with matters that were of importance to them.

\subsection{The questionnaire: Recording responses}

The completed questionnaires arrived over an extended period (4-5 months) as additional questionnaires were requested after the initial posting. This delayed the 
completion of the questionaire analysis and the commencement of interviews as I wished to ensure a reasonable representation of older women with diverse backgrounds. On arrival the respondents' completed questionnaires received a code number and were placed in two groups, series A for those returned anonymously and Series P for those with names and addresses. Six double A4 sheets were ruled in columns and given headings and all demographic data and responses from yes/no tick boxes were entered and variables quantified. The respondent's code number was entered in the first column and their responses recorded in the adjacent columns. It was then possible to see a profile of each respondent without resorting back to the bulky questionnaire. Simple quantitative analyses were used, percentage proportions and distributions were compared by marital status, age and income. Tables and graphs in chapter seven are based on this.

Open-ended question responses were entered into word documents, one for each question with code number, age and marital status recorded for each comment. While I aimed to represent the women's views as fully as possible, in the subsequent analysis I am aware that the selection of data was subjective and what was chosen as significant by me may not have been by another researcher. This study represents my own interests and concerns at the time of writing which are therefore reflected particularly in the quotations from the women's scripts.

Within the responses to each question I identified words and phrases that commonly appeared and in their context had received emphasis indicated by exclamation marks, larger print and extensions to the margins or over the page. These keywords and phrases were recorded, counted, and colour coded as negative, positive or neutral. I cut and pasted these and observed themes in each group. This however did not apply to the final section of the questionnaire asking for any additional comments. This was dealt with separately. To a large extent it reflected views already expressed. However the colour coding of significant words and phrases produced two major themes which are discussed in section 8.4. I am acutely aware that the classification, evaluation and interpretation of the women's words is subjectively mine, but I perceived a commonality in the answers to some questions despite the diversity of the respondents. A selection of the responses to the question of being valued appears in Appendix III. 


\subsection{The interviews: Overview}

The interviews were undertaken to supplement the data collected by the questionnaire. The semi-structured interviews were based on the contents of individual women's survey responses. In a personal, relaxed and informal situation, beyond the limits of a mainly quantitative questionnaire, they were more able to convey their sense of individuality, of inner rather than outer selves, and to discuss those life events that had determined their present situation.

The constraints of time and funding resulted in a smaller sample than was originally intended; it was not possible to travel to the country areas in both the North and South Islands from where questionnaires had been returned by women willing to be interviewed. The quality of life of older women in rural settings warrants separate research.

It was possible to complete sixteen interviews with respondents living in the greater Wellington area, one in a small retirement village complex and fifteen living in their own homes. An effort was made to obtain a range across ages, education levels, previous occupations, income, marital status and mobility. This was partially achieved and reflected the women's diversity in life experiences across two generations.

I contacted the women by phone and ascertained that they were still comfortable about being interviewed. All agreed and I confirmed the arrangements in writing. The letters and consent forms appear in Appendix I b. The interviews took place at a time convenient to participants. Fourteen of the interviews took place in the women's homes and two of the women chose to come to mine.

\subsection{Interview procedures}

The equipment for recording was a professional Sony Walkman WM-D6C with twin clip on microphones. In a carrying case I had spare cassettes, a long extension cord, cue cards for general and specific topics, the interviewee's completed questionnaire and a small notepad for brief field notes. I raised the issue of confidentiality again as we filled in the thesis consent form if the 
participant had not done so earlier. The archiving consent was left till the end of the interview unless the woman wanted to do it first. I asked permission to take notes from time to time, but these were most often written up when I returned home as they interrupted the flow of our encounter. The recorder was set up in a room and a position chosen by the woman (the extension cord came in handy and on one occasion we moved from lounge to bedroom to avoid the noise of roadworks outside).

Most of the recorded interviews lasted between forty and sixty minutes, but were preceded by a discussion, which gave an opportunity for the woman, if she wished, to view her original completed questionnaire and to decide what else she may wish to add or clarify. Some women took this opportunity and others preferred to look at the topic cards I had provided. One card noted general topics, and the other, issues of particular interest that I had noted from the answers in individual questionnaires specific to the woman being interviewed. This facilitated the establishment of a good rapport. My host's hospitality included morning and afternoon teas and our discussions often continued after the formality of the interview itself was concluded. It was a privilege to be invited into the lives of these women to view their family photographs, craft and artwork, mementos of travels, gardens and ongoing projects. This was a time for mutual exchanges and for me a great deal of learning.

During the interview the card guides remained on the table, but they were rarely referred to again, until the closing minutes of the interview, when they were useful to check whether we had discussed all that had been agreed to earlier. The interviews flowed with very little interviewer direction. Occasionally references were made to previous comments or the questionnaire in order to clarify or expand on a subject that had come up in the preparatory discussion, but had not been mentioned in the questionnaire. Telephone calls, and family members passing through, and a break for coffee on two occasions, were noted in the transcripts, but the interviews easily resumed as we replayed the previous track with "where were we?” The interview started with whatever matter the participant chose, but often I was asked, "to start it off”. It usually concluded with a formal question about the advice the older woman might give to a younger woman considering retirement. One respondent subsequently wrote about this and posted it to me after the 
interview. With her permission it is included in Appendix IV. Before leaving I checked that the participant was comfortable with the recording. In some cases we replayed part of the interview. I asked them to contact me later if, on reflection, there was anything they wished to alter or delete and told them that it would be at least a week before I was able to copy the tape for transcription purposes. I would make a personal copy for them as, with their consent, the original tape was to be deposited in the Oral History Archive. Fifteen of the women requested copies of their taped interview and these have been sent.

\subsection{Processing interview data}

I copied the tapes at the Alexander Turnbull library and had them time-coded to facilitate transcription. Interviewing was not a new skill for me, but transcribing was and I found it a difficult exercise. One of the tapes was fully transcribed and entered directly into the computer. This I found extremely time-consuming, as my typing skills are very limited. For the rest I prepared a hand-written transcription on which I based typed abstracts suitable for research use at the library. I found the production of abstracts helpful in concentrating the contents of the interviews and identifying themes. As with the questionnaire responses I used colour coding in the transcripts to mark key words and concepts noting their frequency and the contexts within which they appeared. Voice nuance, repetitions, pauses, silences, hesitations and changes in pitch and volume gave a clearer picture of the participants intentionality than the raw data from the questionnaires.

From a study of the tapes, by both listening to them and reviewing the transcripts and abstracts I developed several themes, which are demonstrated and discussed in chapter nine. Where quotations appear in that text, the names used have been changed to preserve confidentiality. The women chose the names I have used, in some cases preferring to use their own given name or second name.

\subsection{Archiving}

Because of the value of her words for New Zealand's oral history I asked each participant if she would be prepared to have her tape archived. All the women agreed to this and separate library consent forms were completed. Two 
participants put caveats on some material in their tapes for the Turnbull Library, but not for the purpose of the thesis.

These interviews, together with the abstracts or transcriptions I have prepared and some photographs of these women are now archived in the Alexander Turnbull Library’s Oral History Centre in Wellington. The consent forms for interviewing and archiving appear in Appendix Ib.

\subsection{Conclusion}

The women in this study are self-selected, having responded to either a personal or networked invitation to participate. Approximately one third responded anonymously or with a signature and no address, these were recorded as series A when working with data. The remainder identified themselves with names and addresses and they were recorded as series P. In this last group ninety-nine women i.e. eighty-one percent expressed a willingness to be interviewed and most requested the final report.

Many of the questionnaires came back with positive and personally encouraging comments for the success of my research. This gave me an impetus to complete the project when progress was difficult. The interviews also provided evidence of a positive acceptance of the project by the older women, who felt that the study was worthwhile and that they had invested it with value. I have represented the women's views as fully as possible, but throughout I have stressed the subjective input in my analysis Summaries of this study have been posted to the 115 respondents who requested one. 


\section{Participants, Problems and Themes}

Personal involvement is the condition under which people come to know each other and to admit others into their lives.

Ann Oakley (1981, p.58)

\subsection{Introduction}

In this study I chose to interview women rather than rely solely on the questionnaire. I believe that this allows participants a freedom of expression not available in the more formal construct of a questionnaire, even when open-ended questions are used. However, interviewing is not an easy option. As Oakley points out, methodological problems arise when personal experience clashes with the traditional 'recipes' for interviewing that postulate the interview as a one way process with the interviewer in the driver's seat, eliciting, but not giving information, and with the interviewees perceived only as a possible data base. Reading her article I visualised an analogy of the often cold, clinical experiences in a doctor's surgery. The scientific paradigm of interviewing has no personal meaning other than the production of data that can be compared statistically with data obtained from other interviews. This, of course, poses problems for feminists "whose primary orientation is towards the validation of women's subjective experience as women and as people” (Oakley, 1981, p.30). Theory and practice are then incongruent.

Interviewing was not a new activity for me, having been a school counsellor, and I was used to establishing rapport with clients, of whom most were girls and their mothers. My training had emphasised listening 'actively,' paying attention to nuances in tone and expression and to the visual cues of body language. Experience with mothers and grandmothers taught me the value of giving as well as receiving information in appropriate situations, and I became acutely aware of hierarchical circumstances of power and privilege. Although counselling is a very different process from the interviewing in this study, it allowed me to be more comfortable in the role of interviewer and to acknowledge the boundaries of selfdisclosure while continuing to feel free to invest myself personally in the 
relationship. Listening to the tapes again after a lapse of time I notice warmth and laughter from both the women and myself. We were people, not simply a denizen of academia and a data source. I related this to Liz Stanley's discussion of the Cartesian dichotomies of object and subject, of the knower and the known. She argues that, “ for feminists, the known are also the knowers, research subjects are their own subjects; objectivity is a set of intellectual practices for separating people from the knowledge of their own subjectivity” (Stanley, 1990, p.11).

Although this project is not strictly oral history, I am conscious that in obtaining recorded interviews of some women's thoughts and feelings about being older, I am creating “a text, not a reproduction of reality” (Gluck and Patai, 1991, p.3). I am therefore subject to the common dilemmas posed for oral historians. Kristina Minister (1991) refers to the formalities of the interview situation with its very visible recording equipment, supposedly ignored by all, and the question and answer framework requiring the narrator to 'take the floor'. The situation resembles a "performance for a ghostly audience” (Minister, 1991, p.29) which ultimately shapes the meanings and interpretation of the event. This is not just talk between peers; the focus is the interviewer's need to elicit significant information for various audiences and therefore to control the direction of the communication.

The interview is a linguistic event and in producing a written text much is lost in meanings conveyed by changes in tone and emphasis and by the style and accent of the speakers and their non-verbal signals, which are not readily demonstrated by the printed text. In addition to these outward signals there are the affective and cognitive processes of emotion and memory to be considered. Has memory been triggered by a word heard or the presence of a particular object or smell? Why has this particular memory surfaced? Why is it significant for the speaker, and will this be interpreted by listeners and readers in a different frame of space, time and experience. For instance, in this study, one respondent referred to a 'glory box', a common feature in a girl's preparation for marriage in the early and mid twentieth century and for another the word 'pudding' created a reminiscent exchange on the specifics of a Southland diet.

The topic of memory has many aspects. Alessandro Portelli (1991) researching the death of Luigi Trastulli, in a political context, identified 'uchronia', a memory 
in which an individual recollects him or herself as having played a significant part in a situation which, on investigation, proved not to have occurred as they had 'remembered' it. Their recollection of the event may have been as they would have wished it to be, in some way self-affirming and lifting their self esteem. For this study the question of accuracy of memory is not the same as for an historian. What the women in this study may have remembered as influencing their present feelings about the quality of their life as older women is not a matter of objective accuracy, but is a key to their present perceptions of personal value and wellbeing.

Another issue in interviewing is the gap between interviewer and interviewee that may be created by age, culture, ethnicity, class and gender. Do the words spoken mean the same thing for each person? On what basis were the questions chosen and to whom are they meaningful? Can the participants have a mutual (not neutral) ground on which to meet? Can a climate of trust be negotiated? For this project the gender gap was not an issue and the age gap minimal for all but the two interviewees over seventy-five. As an older woman living alone, and as a parent and grandparent I had some experiences in common with some of the women interviewed. However as a divorcee my experience differed from that of a single woman and those who had experienced long-term successful marriages. Interests in gardening, music, grandmothering and social issues provided another bridge, but there were many differences in backgrounds, in ethnicity, country of birth, education and work experiences.

The issue of exploitation, which had concerned me, came up in an informal manner. I attended an annual general meeting of a voluntary organisation at which two of the interviewees were present, one as a member and the other with her husband who was a member. The women knew each other and asked me how the project was progressing. I let them know how good the responses had been and that I felt very indebted to the participants. Their response was resounding and definite, "Nonsense! It is we who should be thanking you for the opportunity". That the women had benefited in some way was evident in their consent to have their interviews archived as oral history. 


\subsection{Ethnicity}

A problem arose for me on the issue of ethnicity. In the questionnaire I left out ethnicity as a variable. This was because I felt an ethical conflict relating to the appropriateness of my analysing responses from women of other cultures or of my interviewing them. I had received conflicting opinions from the Maori and Polynesian women whom I had contacted and while enquiries to women in some other cultures brought some positive responses, this may have been on the basis of politeness or because of the personal links I had with the women. Wishing to avoid exploitation I decided not to use ethnicity as a category. In the event, among the questionnaires which had been returned with signatures and indicating the respondent's willingness to be interviewed, one was from a Maori woman, who strongly asserted her ethnicity in signing her full name in Maori and added in brackets "commonly known as Shirley". I felt that it was both courteous and important to accept her invitation to be interviewed. We discussed my concern and she felt that there was no barrier and a valuable and interesting discussion ensued.

\subsection{Confidentiality}

The issue of confidentiality was discussed with the women before the interview commenced, but on reflection after listening to the tapes again, I became concerned that some matters concerning sensitive family issues would identify participants if quoted directly. Publication in a thesis seemed to differ from recording oral history where the context was apparent. Some women preferred to use their given names and others pseudonyms. Lesley Hall (1999) points out how difficult it is to disguise identity in a small country. This is even more so in this study where the women interviewed came from a clearly defined geographic area. To avoid possible embarrassment I have presented some matters without direct attribution.

\subsection{Participants}

As described in section 5.10 the interviews were carried out with sixteen women selected from those respondents who were willing to be interviewed and lived in the greater Wellington district. They were selected in such a way as to cover both the older and younger age groups and as far as possible the range of marital status 
and income. In addition I chose women with diverse backgrounds as will be seen below.

The women were aged between sixty-one and eighty-two; four in the older elderly group, over seventy-five and eleven in the younger elderly group. This is similar to the proportions of each group in the total original responses.

Six were widowed, five married, three unmarried and two divorced, all lived in their own homes, and one in a small retirement village. Eleven lived alone and five with their husbands.

Fifteen of the women were Pakeha and one Maori and four had been born overseas coming to New Zealand as adults from Australia, England, Ireland and Hungary.

All but two of the women were dependent on New Zealand Superannuation as their main source of income and most of them had some savings. Brenda had recently capitalised savings to purchase an annuity. Previously she had tried to manage on New Zealand superannuation alone "putting myself on the rackwasting time and intellect...now I am OK. I had limited myself. Relief came from a woman adviser for free!” One woman was happy that she and her husband had enough money to do what they wanted without being silly.

I am fortunate to be able to give small gifts where they are needed. We can run a car and if going away can take someone with us. What goes around comes around.

Six of the women living alone received disability allowances from the department of Work and Income to manage their grounds. One of the women living alone was experiencing very straitened circumstances as she was repaying loans to Work and Income New Zealand (WINZ) for dental treatment and a hearing aid. Another was in receipt of New Zealand Superannuation, but her younger husband who was her dependant did not qualify. She supplemented their income by taking boarders and tutoring and teaching singing. The boarders, who were overseas students, required an expenditure of "time and energy as they need to have a 
decent meal, washing done and time for talking.” This was becoming burdensome because "I am slowing down" and Amy thought that letting a room instead might allow the necessary supplement to their income for house maintenance. All but two of the women stressed the necessity for budgeting. Letting a flat on the lower floor of her house gave Eva some disposable income, but her own access was by steps which posed a problem which at present she was loath to face; having lived there for 32 years the house and shopping area suited her needs. She thought it might be possible to rent somewhere on the flat in the same area and let her own property. A concern was the cost of rest homes and asset testing as she wished to leave something to her grandchildren, “ It was frightening to look ahead sometimes.” As Lynne said, for many widows of her acquaintance, not knowing one's 'use by date' made financial planning somewhat of a gamble.

The participants' previous occupations were varied, but in the main followed what, in the western tradition, has been perceived as women's work. Their main avenues of employment had been as nurse, schoolteacher, music teacher, shorthand typist, clerk, office administrator, factory worker, receptionist, librarian, shop assistant, dental nurse, script assessor, photographer and seamstress. There were accounts of continuities and discontinuities in their lives; leaving home, marriage, rearing children, widowhood and divorce; the effects of employment, redundancy and illness and the disruption of war and immigration. The Second World War was a major factor especially in the lives of women in the older group. As a sixteen year old Audrey had been a fire-watcher in London during the blitz, later working in naval radio communications, Reatha had suffered as a result of her husband's war experiences and Eva had experienced the holocaust and political unrest. Divorce had brought family disapproval and reduced income, and widowhood both a lower income and loss of intimate companionship.

Those in the older age group had lived through the deprivations of the economic depression in their childhood and early adult years. They had learned to 'make do'. Reatha's first work experiences were as a household servant aged 13-15 where she experienced both exploitation and sexual harassment. Lisa worked both as a nurse and a clerical worker despite her father's message that she would 
never hold down a job and that there was no opportunity for further education. With the exception of Ekengarangi, Audrey and Myra, the women's work life had been interrupted by motherhood. Brenda had raised five children in six and a half years. Elsie and Ann were widowed relatively early and raised their children on their own. Elsie's sewing and knitting skills clothed her five children and other family members. Most of the women had retrained or changed career direction at least once in their lives. Ekengarangi, who had worked for the same printing firm for over 40 years, experienced unexpected redundancy at 60 and after a depressing search for other employment looked after her mother who had suffered a stroke.

Caring is an expectation and activity running strongly through the lives of these women. Marjorie and her sister were orphaned early in life and were brought up by an aunt. Marjorie and her husband are heavily involved in the day care of grandchildren living locally. Betty and her husband (who has suffered a stroke with some loss of memory) give practical help ferrying grandchildren to events and being on call for child minding. Eva and her husband built a new life in New Zealand, and were helped by her elderly mother who emigrated to help with the children; in turn Eva cared for her mother. As well as working Myra, unmarried and the youngest of six girls, cared for her disabled, but strongly independent mother. Myra has worked as a volunteer for a number of organisations helping the elderly and regrets that circumstances did not allow her to train as a nurse. Her deep religious faith leads her to believe,

that I was put on this earth for a purpose and that was to look after my mother...I have an affinity with older people... I really think the main purpose of my life is helping older people.

Lynne cared for her husband during a serious depressive terminal illness. Helen, at the same time as nursing her husband with terminal cancer, had cared for her mother recovering from a broken hip, while remaining silent on her own diagnosis with multiple sclerosis. Brenda is recovering from a hip replacement and is "receiving exquisite care" from one of her daughters. Before marriage Amy left work and moved south to care for her ailing mother and is caring for her husband who is waiting for a cardiac bypass operation. Dorothy is currently caring for her husband who has suffered from two heart attacks. She commented, "Caring for Harry is very draining." 
Educational opportunities had been diverse and included a very limited secondary education, on-the-job training, part-time night school, teachers college, hospitalbased nursing training, school dental nurse training and tertiary study at university. For Reatha, Elsie, Ann and Myra formal education had been limited by the necessity to contribute to family finances at an early age. Betty's mother had left school in standard 4 because her illiterate mother for whom she became a scribe and reader needed her at home. This prompted her to encourage her own daughter to stay at school. After her first retirement Myra studied School Certificate English because of her love of books and subsequently found further employment as a school secretary and librarian and as a volunteer tutor in an adult literacy programme.

While all the women felt that they were in reasonable health, between them they had a range of physical disabilities. Eva, a victim of the holocaust, suffered a cardiac condition and osteoporosis that gave back pain and limited movement in ankles and wrists. Reatha had a medical alarm for her heart problem and had developed ways of coping with the difficulties of gardening and dressing and continued to make her own clothes. Betty has a stomach ulcer that is now under control and continues with many voluntary activities. Helen who is severely disabled with multiple sclerosis, uses an electric wheelchair to maintain mobility and is planning a voice activated computer to maintain access to the internet. Elsie was waiting for a second titanium wrist replacement occasioned by severe arthritis, but had managed to continue her needle work by reducing the time spent at each sitting, using her other hand and a needle threader. Brenda was in recovery from a hip replacement, but was maintaining mobility with regular structured excersises. Ekengarangi and Myra had suffered lung and leg clots and had been hospitalised. Lynne had had operations for cancer and gallbladder and was severely disabled by arthritis and had exchanged her piano and organ for a more easily managed keyboard. Audrey was recuperating from two bouts of pneumonia. Dorothy was on medication to avoid another depressive episode and was using hormone replacement therapy and exercise to counteract osteoporosis and Marjorie was coping with psoriasis.

Arthritis was the most common debilitating chronic condition affecting mobility and all the women reported it with from mild to severe symptoms; asthma, 
diabetes and cataracts were also reported. In spite of these conditions, past and present, the women while acknowledging the need to take responsibility for one's own physical health by sensible diet and exercise, stressed the importance of attitude and social involvement. Alison said, "I need to be healthy to do the things I want to do" and had carefully planned diet and exercise. They wanted to get on with life and avoid focussing on the negative aspects of ageing. Acknowledging the vicissitudes of ageing, reflected in the words of a respondent to the questionnaire who quoted Bette Davis "Old age is not for the faint hearted", the women interviewed were acting positively to make the best of things. They focused on their strengths and compensated for disability by finding alternative ways to achieve chosen goals within their capacity. This included using the help of others for physical tasks beyond them. They mentioned reducing membership of clubs which although it reduced their social contact allowed them to concentrate their energies into the most rewarding activities. They prioritised their use of time and adjusted to age related change that had resulted in many everyday tasks taking longer. A common expression was "it takes so much longer now that I just concentrate on the essentials.” Audrey had simplified her cooking using bench level quick cookers. Eva and Ann had abandoned their hillside gardens. Many of these adjustments were consonant with Baltes theory of selective optimization with compensation discussed section 3.2.

The present material circumstances of the participants' lives and their attitudes to ageing had developed through the opportunities and constraints of their life course and they reflected on these in the interviews, When asked what had contributed to her positivity Betty said,

It is easy to be positive when life is all right, if life had run a different course maybe I would not be so positive. I was born in 1929 in the depression, life was not easy with my father on the dole, but my parents had a very positive attitude in spite of things being very difficult. Now things are going very well...I was quite shy as a girl, people won't believe that now, but taking Brownies ${ }^{1}$ I learned to stand up and talk to people. When I have to give talks now [about painting porcelain dolls and making teddy bears, previously on a Regional Health committee] I just think of the audience as 'Brownies'.

\footnotetext{
${ }^{1}$ Junior girls in the Girl Guide organisation.
} 
Helen's attitude was also very positive despite her disablement (multiple sclerosis):

Things have gone my way very well. I've had a very good life and innings. A good marriage, a lot of fun, travel...perhaps things may have been very different if I had been a woman alone or a solo mother.

The skills learnt at home had contributed to their ability to economise and live simply; something they felt was lacking in the present generation. Elsie, Betty and Eva talked extensively about lifetime habits of saving, budgeting, exercising choice and 'making do'. War and economic recession had long term effects on these women and they felt critical of the present consumer society.

"That was a natural thing, not to spend, to have something to rely on when you were ill or not working was a way of life...I don't spend all my money now. I don't drink or smoke or spend unnecessarily on silly things...like too many clothes, jewellery, books or magazines, but I buy good food and don't economise on petrol and heating.” [Eva aged 78, widow]

"My mother always made soup and so do I. Managing food, being able to make a meal out of whatever is in the fridge. Young women these days may not be able to do this.” [Betty aged 71, married]

“Some young people today have a very negative attitude...if they can't have what they want when they want it...everything must be now, they must have the latest things. I feel that older people are more positive. They know how to make do...we used to make our own pleasures. My parents couldn't afford a lot of things so we made our own fun. We couldn't go out and buy the latest fashions in fact everything was homemade. This isn't done today. I made three wedding dresses for the family, which gave me great satisfaction. I learnt handcrafts from my mother which were handed down from my grandmother." [Elsie aged 68, widow]

Not all comments on the different world of the young were negative. Grandmothers were experiencing joy watching the development of their grandchildren and were happy as Elsie said, to learn from both those older and those younger than themselves. A continuing capacity to learn was a theme running strongly through all the interviews. Brenda found menopause liberating. "I blossomed as a botanist after 50". Ekengarangi aged 68 was "learning genealogy bit by bit”. Marjorie, aged 69 felt that middle age begins at 60 and is liberating, despite concerns about practical matters such as replacement of whiteware, property maintenance and finding a new place with flat access and room for the family, "you go on learning."' She has a writing task in view. As 
well as wallpapering and designing new weaving patterns Lisa was considering some family history. Dorothy aged 61 has a history project temporarily on hold because of her husband's ill health. Alison aged 66 has a thesis on community healthcare in her sights. If Ann can find the money for a computer she intends learning new skills. Audrey aged 76 is writing war-time memoirs. Three of the women were volunteers with the $\mathrm{CAB}$, which requires ongoing learning.

The women were concerned with social issues as expressed by Marjorie particularly poverty, care of children and the elderly and community attitudes:

People seem to have negative attitudes to the poor and needy...there is a focus on the individual. In New Zealand we have lost a sense of community and unity. Young girls are under pressure from males and the media...relationships between young and old are breaking down. More attention needs to be given to the needs of the very old. There is a misconception about the abilities of the elderly and a poor attitude when superannuitants are referred to as 'bludgers'. We paid our taxes.

Audrey found society today "self gratifying and money conscious." Eva was worried about student debt, her grandson had one of \$25,000. Reatha aged 82 felt that exploitation and sexual harassment were still with us and that young women today were very vulnerable as she had been when jobs were hard to find. There were some advantages thanks to technology. Helen envisaged rest homes with computers, Internet access and cell phones.

The issues of dependence, independence and interdependence and having some control over one's life however disabled were seen as crucial. Helen spoke to the next generation of women and was particularly conscious of the fine balance between wanting to be looked after and maintaining independence without offending helpers.

You'll be old one day yourself and I guarantee you won't want people taking over your life...this will be especially important for modern women who have been used to doing so much for themselves.

Marjorie was indignant at her adult children's attitude to their parents’ retirement “They started to give us 'good advice' as though we had lost our marbles.” Lynne 
found an ageist attitude in society when the elderly were regarded as having "use by dates on their bottoms." Alison was reluctant to give her age because of stereotyping.

Loneliness was an accompaniment of widowhood. The loss of bereavement never quite went away despite making new social connections and learning new skills. For some traditional marriages women had had not only to learn how to change tyres, but also to find a garage that would inflate them. Elsie had had to write a cheque for the first time and deal with other business matters. As Eva said the worst part was the loss of companionship, not the doing of outside tasks. For some of the women living alone arthritis and balance problems had made simple tasks like changing a light bulb or carrying out the rubbish impossible. They were dependent on friends, neighbours or family. Lynne described how a group of widows and widowers arranged occasional "slap up roast dinners" at one of their members' houses as cooking for one usually precludes roasts. It also gave a friendly opportunity for socialising.

A question about identifying the point at which the participants first felt that they were old brought some common responses. "I looked in the mirror and saw my mother's face, I looked at my folded hands and recognised my mother's. In the garden I just couldn't straighten up. I looked in the mirror on a bad day. I gave away high heels.” The women made a point of saying that regardless of a sagging shape, grey or white hair, wrinkles, lower energy levels and arthritis they felt the same inside, and that they did not 'think old'. This in no way suggested that there had been no inner changes in attitudes or knowledge, or that physical change did not matter. Being 'the same inside' represented a continuing sense of selfhood, a matter that society sometimes forgot and relates to what Turner (1995) saw as an issue in sociology, the contradictory relationship between our inner sense and outward appearance (see section 3.2).

The participants felt that age had some positive aspects apart from more freedom to make your own choices, "to be selfish". Brenda referred to the ability to take one's time to reflect "Taking one's time is often a privilege — not everyone has this in our 'hurry up' world." She had learned to value herself through the women's movement and had established sound personal boundaries which 
avoided exploitation, but was "experiencing joy in sharing and giving...maybe part of a personal want or need as a former teacher. Isn't that one of our roles as older people in our society, to give and pass on?” Marjorie spoke of having learned to bite her tongue and use more tolerance as she aged.

Amy, Myra and Marjorie felt that their religious faith was even stronger as they aged. Amy said "the older you grow the more you realise that there is something after this life, but you need to make it part of your spiritual life now.” Reatha could not find enough time to do all she wished, but found time to "listen to the birdsong in the Scots' College trees", and to reflect on the strength of her mother from whom she had learnt so much. "I feel life is what you make it. There's a verse 'God grant me the serenity to accept the things I cannot change, courage to change the things I can and wisdom to know the difference.' A hard lesson to learn, but I've nearly made it after 82 years.”

\section{5 Themes}

Using the methods described in section 5.12, nine themes were identified. As was expected, they reflected the findings from the questionnaire, but in the more personal context of the participants' life events. The one formal question at the close of the interview, on advice for retirement, crystallised the women's thoughts about what contributed to the quality of their lives and what information might be valuable to others. These themes are:

- Positive ageing was linked to sound preparation for retirement. This included housing', finance and social contact, and entailed making new friends across age groups to ensure social contact because in older age one's social circle shrank.

- Ageing in place was preferred.

- Attitude determined how one would experience ageing.

- Maintaining good health had to be worked at.

- Previous life experiences were important in the establishment of beliefs, practices and values, which gave skills and emotional strength for coping with the problems encountered as one aged. 
- Learning is a lifelong activity whether extending old interests or taking up new activities.

- The experience of being a grandmother promoted psychosocial generativity and a sense of family renewal.

- Independence and control over one's own life was important, but the reality of interdependence was recognised.

- Living alone and the loneliness of widowhood.

\subsection{Conclusion}

The variables I had first hypothesised as contributing to the quality of life for older women all proved relevant namely: income, health, housing, social connectedness and life history.

It was the interactions between these factors that most strongly influenced the older women's quality of life and that was determined by individual attitudes. I had not, for reasons given at the outset, researched ethnicity as a factor, but in the course of the study when the issue arose it was recorded as an important part of the woman's personal context. At one time or another each of the variables was in the foreground of each woman's thought depending on the everyday circumstance.

While in childhood and young adulthood these women's lives had been influenced by world wars and economic depression they have nevertheless in most cases succeeded in owning their own homes and in maintaining stable relationships. Material well-being in older age is currently positively related to home ownership, marital stability, the capacity to accumulate savings over a working life and to the provision of state funded pensions. Future cohorts of women, possibly burdened with student debt, uncertain of future long-term employment and living in a society characterised by less permanent family relationships and problematic access to health care may have greater difficulty in achieving well being in old age, as will some older men. 


\section{Analysis and Discussion of Questionnaire Responses Part One}

\subsection{Overview}

This chapter contains a detailed analysis of one hundred and seventy-five women's responses to a comprehensive questionnaire of over fifty items (see Appendix 1A). Here these responses have been quantified in relation to income, age, marital status, education, home ownership and suitability, living alone, use of a car and access to medical insurance and the Internet. Tables and graphs show the income levels, marital status and age range of the participants. Levels of education and previous occupations are recorded and related to material wellbeing. Differences in the responses of the older and younger age groups and those of single, married, divorced and separated women are noted and discussed as are their diverse responses to the positive and negative aspects of ageing in areas of economic resources, health and medical insurance and satisfaction with life. There are similarities to national statistics (1996 Census) in the distribution of income and marital status and to other studies of older women's health, education and community involvement.

The questionnaire proved a useful instrument for gathering a large amount of information from the respondents. There were relatively few non-responses to the questions. Two women did not give their age, and two more gave a five-year range 65-70 and 70-75. One woman stated that she did not give her age as this usually resulted in stereotyping.

Eighteen women did not complete the detailed section on income. It was not clear whether this was for reasons of privacy or because the question format was difficult to fill in. Other possibilities were that the woman was uncertain of income, or felt that her answers to the next question concerning National Superannuation (NZS) ${ }^{1}$ covered the issue of income. Of the eighteen women all but two respondents completed this section, nine of them ticking NZS as their

\footnotetext{
${ }^{1}$ See current rates page 140
} 
main source of income while seven ticked both NZS and 'other'.

Of the 155 women who reported personal income as opposed to household income, it was clear that for almost half of them, this was provided by NZS alone. While five women received less than $\$ 5,000$, of the two women at the upper end with $\$ 60,000$, one was single and one married and both had tertiary qualifications.

Some married women with no part-time work or other income were under sixtyfive and therefore ineligible for NZS giving them no personal income. Other women had personal income derived from private savings or superannuation funds, but most personal incomes were at the level provided by NZS. This information together with the questions on economising and having a reasonable income gave some indication of the respondents' economic situation in cases where details of income had not been provided.

Questions on housing, driving a car, holidays and the use of the Internet gave a further window on to material wellbeing. As well as the respondents' overall selfassessment of health, other indicators on this variable were accessed through the sections relating to disabilities, sleep, exercise, and medical insurance. Questions relating to the family and voluntary work opened up the area of social connectedness. The more open-ended questions and those that invited further comment produced valuable insights into the respondents' concerns, pleasures, spiritual and belief systems and their sense of being valued. This had been anticipated in the design for data collection and some of those responses are reported in sections 8.11 to 8.14.

\subsection{Age of respondents}

The ages ranged from fifty-six to ninety-four with a median of seventy-one. The respondents have been divided into two groups by age; those seventy-four and under the 'younger elderly' and those seventy-five and older the 'older elderly'. Twenty-eight per cent of all respondents constituted the older elderly group and seventy-two percent the young elderly group which included two women aged 
fifty-six and one aged fifty-nine who considered themselves older women. These are represented in figure $7 \mathrm{a}$ below. While there is great individual variation among the respondents there are also clear commonalities within each of the two groups in terms of activity and health.

\section{Figure 7a}

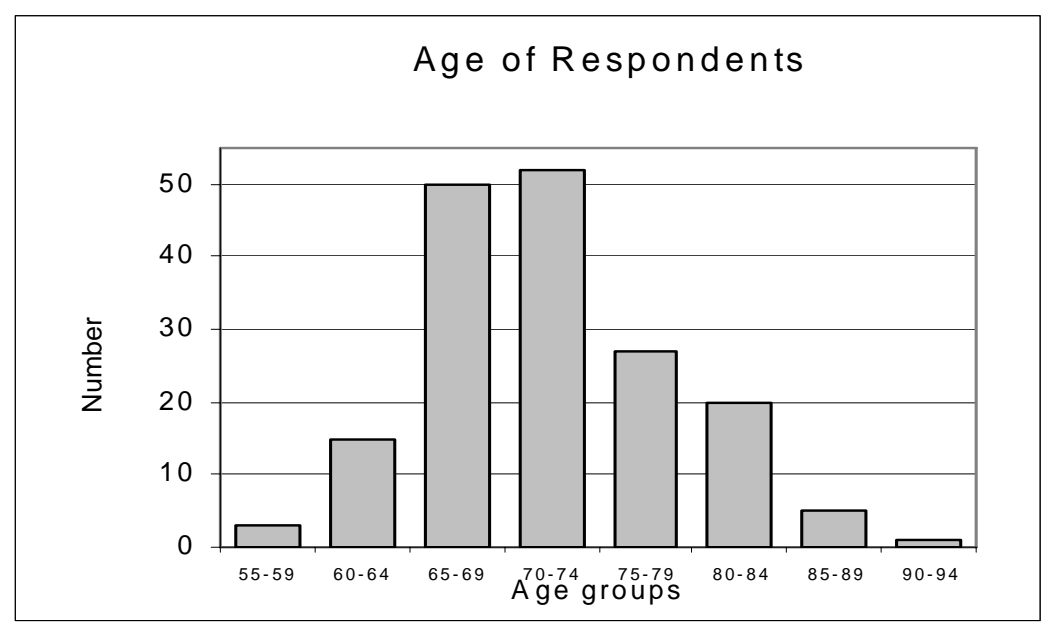

\subsection{Marital status of respondents}

All respondents completed this question. The distribution is shown in figure7b.

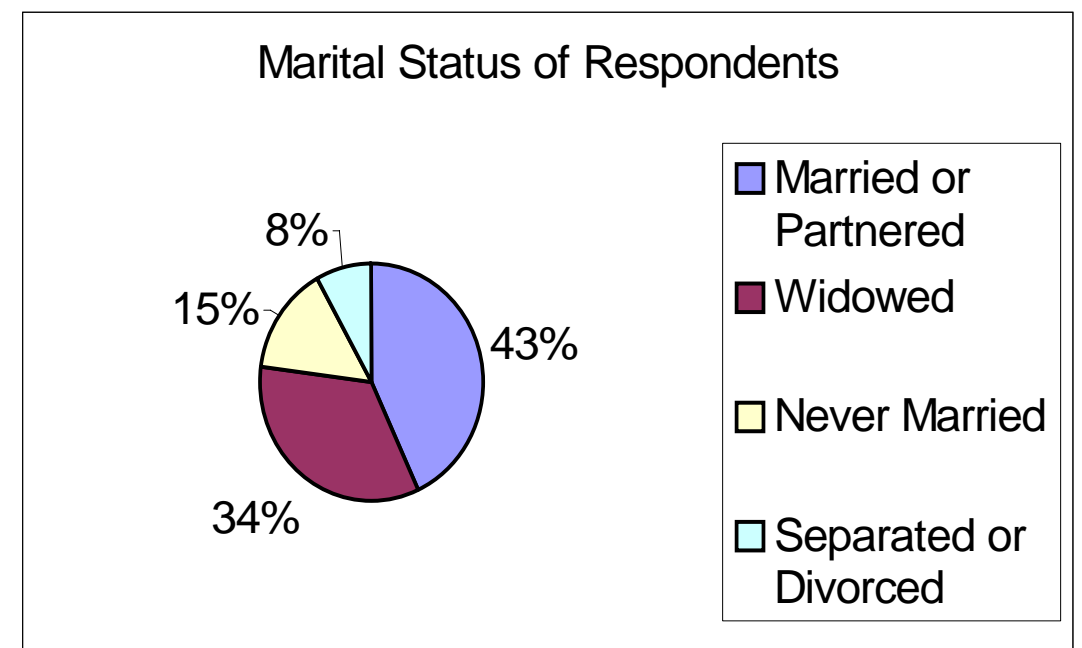

Figure7b 
Figure 7c

Age of Respondents by Marital Status

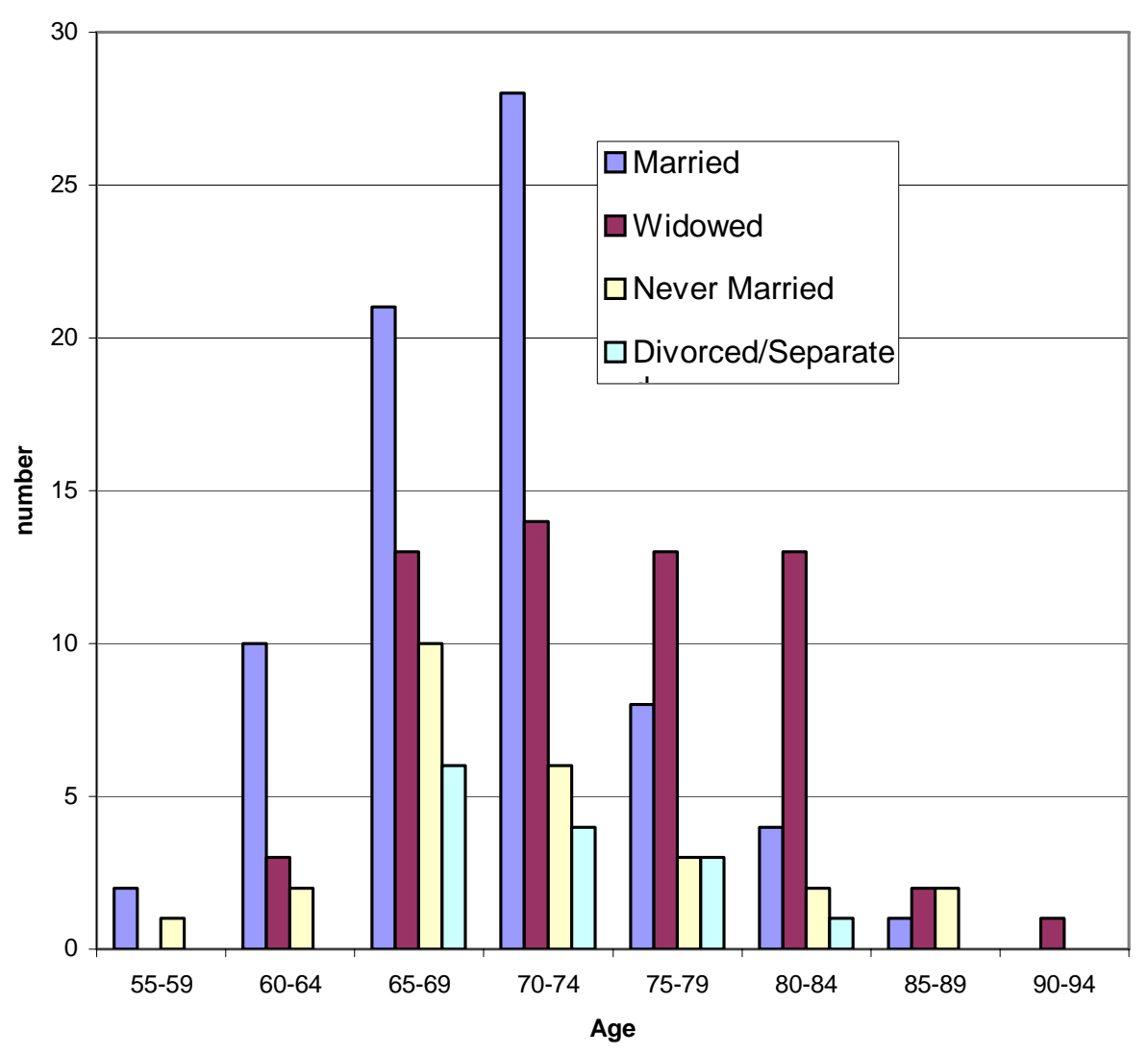

Figure $7 \mathrm{c}$ above shows the ages of respondents according to marital status. Widows predominate in ages above 74 . The largest group is married women aged $70-74$.

The percentage distribution shown in figure $7 \mathrm{~b}$ above has been compared with those shown in table 7.1 below based on the distribution of legal marital status for females aged 60 and over in the 1996 NZ Census of Population. There are similarities between the census distribution and that of the questionnaire respondents where the proportions were, married or partnered women $43 \%$, widows 34\% and those separated or divorced $8 \%$. The questionnaire brought in a much higher proportion of responses from single or never married women than the census distribution would indicate, $15 \%$ as compared to $5 \%$. 
Table 7.1 Legal Marital Status of Women aged 60 and Over 1996

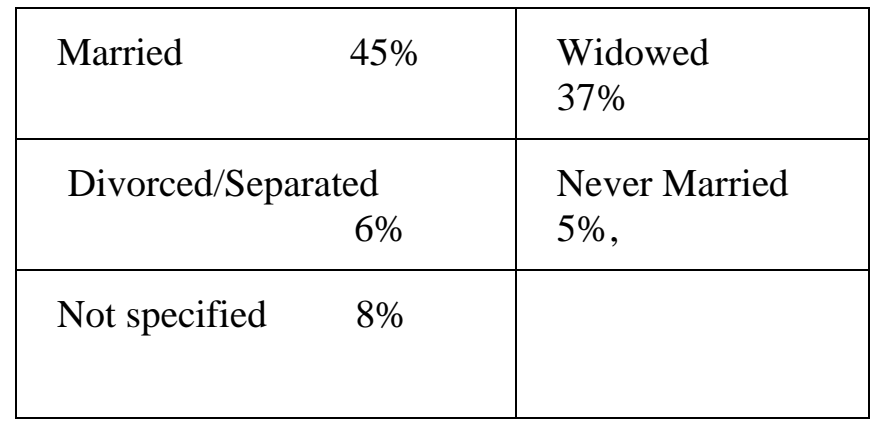

Source Davey (1998, p 181) from 1996 Census

\subsection{Household income of respondents}

The questionnaire solicited information on both personal and household income. The latter is shown as bands in table 7.2. Respondents also indicated their main source of income, as New Zealand Superannuation (NZS) or other and whether or not they considered it 'reasonable'.

Table 7.2

Levels of Income for Respondents

\begin{tabular}{|l|l|}
\hline Level 1. Under $\$ 5,000$ & Level 2. \$5,000 - \$14,999 \\
\hline Level 3. \$15,000 - \$19,999 & Level 4. \$20,000 - \$29,999 \\
\hline Level 5. \$30,000 - \$39,999 & Level 6. \$40,000 - \$49,999 \\
\hline Level 7. \$50,000 - \$59,999 & Level 8. Over \$60,000 \\
\hline
\end{tabular}

Tables 7.1 and 7.2 above are used in the following discussion of the respondents' income in relation to age, marital status and education. For those who were widowed, divorced, separated or single personal and household income were the same. For married respondents there were variations. For some personal income came from part-time work, for others from rented property and interest on savings. Table 7.3 below shows rates of payment for New Zealand Superannuation. 
Table 7.3 Rates of payment for New Zealand Superannuation, before tax, March, 2001.

\begin{tabular}{|l|l|}
\hline Single sharing accommodation & $\$ 12,148$ p.a. \\
\hline Single living alone & $\$ 13,274$ p.a. \\
\hline Married, both qualified & $\$ 19,982$ i.e. $\$ 9,991$ each p.a. \\
\hline Married, one partner qualified. & $\begin{array}{l}\text { The qualified partner may receive the “each } \\
\text { partner" amount or opt for } \$ 16,142 \text { subject } \\
\text { to an income test on their combined } \\
\text { incomes. }\end{array}$ \\
\hline
\end{tabular}

\subsection{Income and marital status}

The 2001 Standards of Living report on older New Zealanders (Ministry of Social Policy) provides data on income and savings for persons over 65, but these are not disaggregated by gender. However they are disaggregated by marital status. The income of partnered persons tended to be higher than that of single persons.

The proportions of income derived from New Zealand Superannuation or other benefits or allowances were approximately $60 \%$ for partnered persons compared with approximately $70 \%$ for single persons. The median income for each group was $\$ 21,000$ and $\$ 12,900$ respectively with ranges of $\$ 16,000$ to $\$ 40,000$ and $\$ 10,000$ to $\$ 18,000$. The median savings were $\$ 7,500$ for singles and $\$ 37,500$ for partnered. While the partnered income has to sustain two people, the expenses of accommodation are shared, and this may increase the proportion of disposable income available to a couple compared with a single person. 
Table 7.4 Median Income of Respondents, by Marital Status

\begin{tabular}{|l|r|r|}
\hline \multicolumn{1}{|c|}{ Marital Status } & Income Range & Median \\
\hline Widowed & Levels 2-6 & Level 3 \\
\hline Divorced/Separated & Levels 2-4 & Level 3 \\
\hline Never Married & Levels 2-8 & Level 4 \\
\hline Partnered/married & Levels 2-8 & Level 4 \\
\hline
\end{tabular}

Table 7.4 above shows some differences in the range and medians of household income for the respondents, grouped by marital status. Levels of income refer to table 7.2 page 137.

For those women divorced or separated the median income was $\$ 15,000$ to $\$ 19,999$ and the range was limited to the lower levels of income, $\$ 5,000$ to $\$ 29,999$. Women in this group with incomes between $\$ 20,000$ and $\$ 29,000$ showed higher levels of education and more lucrative employment before retirement as recorded in their answers to other questions. On the whole, however, women who were divorced or separated reported lower levels of life satisfaction than did the other marital status groups in response to question one.

Figure $7 \mathrm{~d}$ below shows the income ranges of the respondents to the questionnaire. For some of the single women at the upper end of the distribution her higher income clearly related to higher levels of education resulting in more highly paid employment reported elsewhere in the questionnaire. The relationship for married women was not clear although the wider range may have been influenced by the diversity of their partners' previous occupations and hence income. Because of complexities within households, such as an older woman living with family or friends and the nature of some marriages and partnerships, it is unwise to assume that income was distributed equitably in all households as evidenced by three of the respondents. One was unable to tell her partner's income and two made the following comments:

"Have difficulty in getting 80-year-old husband to spend money. Thinks he can take it with him. Find old people economise when no need to. Prefer to leave it to the children.” Age 70, married, income level 7. 


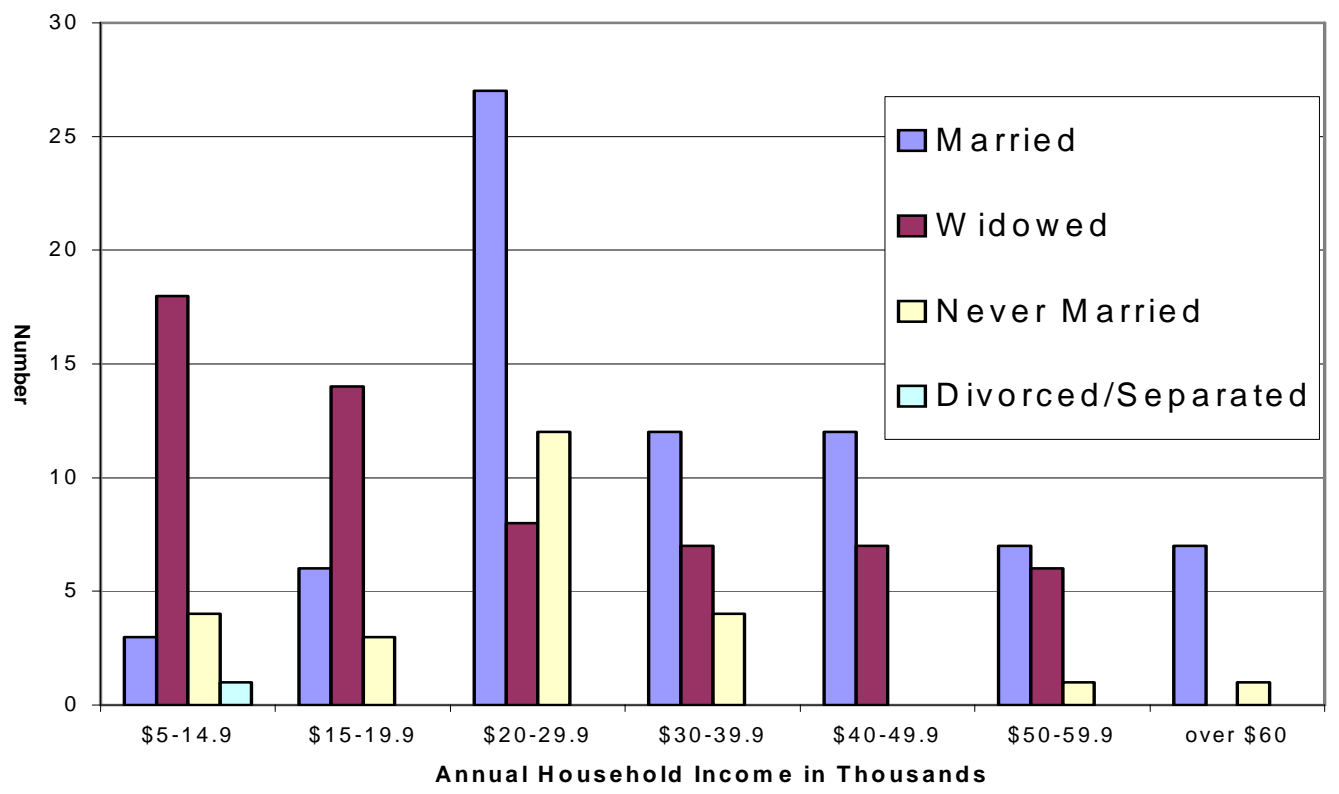

Figure 7d Household Income of Respondents by Marital Status

"I fear that my spouse is spending too much on gambling, (get rich quick USA schemes). I find I don't go to the theatre or buy books as I did when I had a disposable (working) income, or buy so many pricey presents for grandchildren, don't buy clothes and shoes very often.” Age 72, married, income level 7

Pension transfer payments such as the veteran's pension, war widow's allowance, and the transition to retirement benefit (for those over 60 unemployed, but not yet eligible for NZS) are also available. All New Zealanders aged 65 and over who meet the residential qualification ${ }^{2} \mathrm{~s}^{2}$ are eligible for NZS; in practice more than 95\% of people aged 65 and over living in New Zealand, receive NZS. There are also discretionary (targeted) benefits such as the accommodation supplement and a disability allowance available through the Work and Income NZ (WINZ), designed to assist those on a low income.

\footnotetext{
${ }^{2}$ To have lived in New Zealand for at least 10 years since the age 20, five years of which were since age 50 .
} 
The community services card, which provides a reduction in medical costs at the time of writing, is about to be phased out. It is not yet clear what will replace it to provide less costly health care for those on low incomes, of whom most are women and the elderly. The community services card has been vital to older women in assuring affordable access to doctors, as mentioned by women in the focus group and interviews. Discretionary benefits were much appreciated by respondents as they assisted in reducing financial worry and stress, Nonrefundable grants were the most helpful, as loans which required repayment solved an immediate problem, only to create another.

Other income was mainly dividends or interest from investments or savings and rentals from properties. Bonus bonds were also mentioned. It is of interest that overall savings by New Zealanders are not high by OECD standards. Figures from the 'Standard of Living Report for Older New Zealanders' (Ministry of Social Policy, 2001 Technical Account p.50) show the medians for estimated savings and investment (excluding own home) as $\$ 7,500$ for a single person and $\$ 37,500$ for a couple.

While $92 \%$ of the women reported their income as reasonable, 53\% expressed concern over the cost of items such as spectacles, hearing aids, dental treatment, doctor's fees, pharmaceuticals, insurance, house and ground maintenance, the replacement of white-ware and the increasing costs of electricity and petrol. They were concerned at the costs incurred in running a car, repairing or replacing it, and with increases in local body rates when they were on fixed incomes. Saving, planning and budgeting were the order of the day. Some women from country areas limited their trips to town, planning all business, shopping, medical and dental appointments as far as possible to one day a once a month.

The question on what changes would be made, should there be the necessity to economise, brought distinct responses from the higher and lower income groups; the latter feeling that no further economies could be made except possibly with food, clothing, and outings, while the former specified travel, car, magazines, dining out and the theatre. Both income groups mentioned reducing insurance on house, contents and car, and spending less on presents and donations to charities. 
It is noticeable that the greatest difficulties were experienced by widows and women divorced or separated. The following quotations from completed questionnaires illustrate these points and also the coping mechanisms used to reduce expenditure or to increase income. The numeral following age and marital status represents the level of household income as shown in table 7.2, p. 137.

"We would not travel. Stop our evening drink before meals. Stop the housekeeper, sell one of the cars and go to a smaller vehicle.” Age 68, married, income level 8.

"Change to a shared car, buy less clothes, have fewer holidays and downsize our house.” Age 63, married, income level 8.

“No restaurant meals/takeaways. Reduce magazine subs.” Age 70, married, income level 8.

"Reduce travel, contributions to charitable organisations and unsolicited financial support to the family." Age 70, widow, income level 6.

“Go to fewer concerts.” Age 72, married, income level 8.

“Cut out trips to see grandchildren's activities." Age 63, married, income level 2.

“Economise on food.” Age 74, divorced, income level 2.

“ Cut things I belong to, concerts, theatre, travel.” Age 69, single, income level 5

"We live reasonably comfortably because there are two of us and I have a small part-time job. Cut down on driving. Use more public transport. Limit entertainment, new clothes and presents for the family.” Age 70, married, income level 4.

"If it were not for my family we would have no treats, e.g. a bottle of wine, holidays. We lost all our savings in a bad investment (a kiwi fruit orchard) just as we retired. Entirely dependent on National super we economise all the time. We rent from our son-in-law. Our family is very supportive, so we can run a car, I'd give that up if necessary.” Age 69, married, income level 3.

"None. I live simply, no car or extravagances to cut back. No smoking or drinking. Prefer to get out and see New Zealand.” Age 77, divorced, income level 2.

“ I live so frugally, it would be hard to economise.” Age 71, divorced, income level 2.

"Probably try to lower my car, and house and contents insurance." Age 76, widow, income level 2. 
"I'm already economising — strict budget, but do use telecom more than I should, but that's my contact with special friends and family. We talk more than we could ever write.” Age 67, separated, income level 2.

"I worry about doctors and prescription bills, most elderly people need medication. Need to economise, but can't. Don't smoke or drink much, have to run a car. I go to housie as a social outing." Age 66, widow, income level 2.

Other suggestions for easing the problems of low income were: having no hairdressing appointments, growing vegetables by seed rather than buying plants, cutting out meat, letting rooms, taking boarders, finding part-time work and selling the house. No respondent mentioned reverse mortgages, a means of realising income from the otherwise fixed asset of home ownership. When this topic was raised in discussion it was generally discounted often vehemently,

"Never! I would have to be absolutely desperate."

To own one's own home was invested with feelings of security and personal achievement quite apart from the need to "leave something to the children."

Davey $(1993,1998)$ refers to older people who are asset rich and income poor, which gives rise to questions about the use of home equity to supplement income or pay for health care and other services and to policies for senior citizens consistent with the encouragement of self-reliance. She notes that although home equity conversion schemes have negative aspects such as the depletion of wealth, the inability of the owner to realise value from rising house prices and the possible default of the lender, they nevertheless improve the income flow for an older person. Hyman (1994, p. 203) argues that, in this case at least, there is some choice in the matter unlike the asset testing regime under which the income and assets of both partners are tested when an older spouse goes into long-term care. This is disadvantageous to the partner (usually a woman) who remains in the family home, since both incomes had probably contributed to its maintenance. Discussion with the women in this project left no doubt that home equity conversion was considered only as a last resort in a family emergency. Irrespective of marital status so much of a woman's life work had gone into ensuring home ownership, which has been a traditional goal for most New Zealanders, representing security in later life, that it would constitute an enormous emotional wrench. Renting was associated with insecurity and losing some 
autonomy. “ In your own house you can do what you like," and "Well it can just fall down around my ears, if I can't maintain it.” On the other hand some women were keen to purchase more suitable housing if the equity in their old home could cover the cost.

There seemed no solution to the escalating costs of health related services such as dentistry, podiatry, physiotherapy, optometry and audiometry, densitometry, pharmaceuticals, doctors' visits, surgery and mammography for those over sixtyfour. The strategy preferred was to stay as healthy as possible and some ways of doing this are documented in sections 7.6 and 7.7.

Although NZS makes an allowance for living alone it was evident that women in this situation had a harder struggle financially when savings were limited and rates and power in particular had risen. A person living on their own shoulders expenses for rent or rates, insurance, house, grounds and vehicle maintenance, and heating that might otherwise be shared. Not all women living alone were in receipt of assets from parental or marital estates or had been provided for in ways traditionally ascribed in a patriarchal society. The older women in this study had been brought up in a New Zealand still accepting the role of males in making provision for retirement and the welfare of their wives and daughters. This was evident in responses to preparation for retirement. (See section 8.1).

\subsection{Income and age}

National measures indicate that the proportion of New Zealand Superannuation to total income increases with age. Figures for $1997-98$ show that $42 \%$ of aggregate household income for older people comes from New Zealand Superannuation, $5 \%$ from other social welfare benefits, $30 \%$ from wages or self-employment and 23\% from private superannuation provision (Ministry of Social Policy, 1999).

The Social Report, 2001, records 6.5\% people over 65 reporting a low or fairly low standard of living compared with $7.4 \%$ of adults under 65 . This proportion however rises steeply to $26.3 \%$ for single parents with dependent children. While some older women in this study were "just getting by", particularly those divorced or separated or whose savings had been diminished by inflation, most of the respondents enjoyed a moderate standard of living by income standards. The median income level for all respondents was level 4, \$20,000 - \$29,000. 


\subsection{Income, education and employment}

It was not possible to determine a relationship between education, occupation and household income for the married or widowed women due to the inputs of their spouse. For the unmarried women there appeared to be a relationship between levels of income and their formal education and occupations prior to retirement. Sixteen of the 25 who reported household income had a tertiary education and of these nearly two thirds (10) had income levels 4-8, some of which came from Government Superannuation, accrued in the teaching service and government administration. They had had in the main, paid employment unbroken by child rearing. Divorced or separated women with similar educational attainment did not appear to have had this advantage. Of the 5 who had tertiary education only $40 \%$ (2) had level 4 income. The other 3 together with 9 who had some level of secondary education had income levels 2-3. The numbers involved are very small so comparisons are difficult.

New Zealand Census statistics for 1996 show that 57\% of the population of older women had no formal educational qualification. ${ }^{1}$ Women's participation in education has increased over the last 40 years, but for women over 65 in 1996 about a quarter had some school qualification and less than ten percent had some post-school qualification (Statistics New Zealand and Ministry of Women's Affairs, 1999, p.77). In this present study 57\% of the women respondents to the questionnaire had had some form of training beyond secondary school and $44 \%$ had achieved some form of tertiary education, mainly through teacher's college and nursing courses, although marriage and child rearing had interrupted studies. As their children became more independent, some women took up tertiary studies related to improving employment opportunities when they rejoined the work force. It is likely that the nature of the questionnaire and the networking by which it was distributed has led to heavier weighting of higher education levels than is general for older women in the community. It is however consistent with the lower levels of formal education in the older community. More than two thirds of spondents had finished in about the second or third year of their secondary education. This probably reflected the expectation for girls at that time; some form of domesticity was to be their lot and higher education was unnecessary.

\footnotetext{
${ }^{1}$ Statistics New Zealand (1998), p.26; Social Policy Agency (1999), Table 5, p.31.
} 
The seven respondents who had left after primary school were all in their late seventies or aged over eighty, but on the other hand twelve of the women over seventy-five had studied at university level. In both the older and younger groups there were diverse levels of education. The respondents' levels of formal education were as follows:

\section{Table 7.5 Respondents' Levels of Education}

\begin{tabular}{|c|l|c|}
\hline Level & Description & Percentage \\
\hline 1 & Primary School & $4 \%$ \\
\hline 2 & Secondary School & $39 \%$ \\
\hline 3 & $\begin{array}{l}\text { Trade/ } \\
\text { Commercial } \\
\text { College }\end{array}$ & $13 \%$ \\
\hline 4 & $\begin{array}{l}\text { Tertiary Training } \\
\text { Institute }\end{array}$ & $32 \%$ \\
\hline 5 & University & $12 \%$ \\
\hline
\end{tabular}

For many of the older women an extended secondary education had been out of the question in the depression years. Secondary education in New Zealand was not freely available to all young people until 1936. The war years and after required an instant work force and many women gained their skills on the job and in commercial night school classes.

The figures for household and personal income provided by the respondents to the questionnaire were aggregates of state pensions, private or government superannuation, annuities, part-time employment, dividends and interest on savings. The later interviews with some of the women provided information concerning assets or income derived from inheritance or by widows accessing half a deceased spouse's superannuation. For most of the widows or married women there was not a clear relationship between their income and education as this had been affected by the education and employment of their spouse. However in the never married group fifteen out of twenty six women had tertiary 
education and of these, seven had incomes $\$ 20,000-\$ 29,000$, four had incomes from $\$ 30,000-\$ 40,000$, one $\$ 50,000-\$ 59,000$ and one over $\$ 60$ thousand. Although a quarter of the divorced or separated respondents had tertiary education their median income was between $\$ 15,000$ and $\$ 19,999$. The unmarried women had had the advantages of unbroken employment and time related opportunities to improve their qualifications and gain promotion. As stated above some of the married women had retrained thus gaining the advantage of higher salaries and increased possibilities to save for retirement.

\subsection{Home ownership}

Table 7.6 Respondents' Homes

\begin{tabular}{|l|c|}
\hline \multicolumn{1}{|c|}{ Respondents } & Percentage \\
\hline Mortgage-free & $93 \%$ \\
\hline Mortgaged & $1 \%$ \\
\hline Renting & $5 \%$ \\
\hline Not Specified & $1 \%$ \\
\hline
\end{tabular}

The respondents reported a mortgage-free home ownership of 93\% which was higher than the level of home ownership among older people in the general population of whom almost $90 \%$ live in their own homes, $75 \%$ of which were mortgage-free (Davey, 1998, p.181). Sixty-eight per cent of women over 65 live in freehold homes (Ministry of Women's Affairs, 1999). Owning their home provided a sense of security and an asset which could be drawn upon only in an emergency, but reverse mortgages were not favoured as many of the respondents wanted to leave legacies, however small, to their family. Fergusson, Hong, Horwood, Jensen and Travers (2001) found 68\% of single respondents and $86 \%$ of couples owned their own homes, most of them freehold, and this resulted in lower portions of income being required for accommodation. 


\subsection{Housing satisfaction}

Most women were satisfied with their accommodation. The reasons given for dissatisfaction with their present home mainly concerned the costs of home and grounds maintenance, including driveways. Steep sections with steps and paths, potentially dangerous to older people who feared a fall, were worrying. Staircases were also a problem. For some the desire to move to a low maintenance smaller home was restricted by cost. An older, large family home when sold, did not necessarily realise enough capital to purchase a newer more suitable property.

The women made clear distinctions between needs and wants, what it would be nice to have and what was essential. Some women, who were happy with their homes, stated that they had made changes before formal retirement in anticipation of their needs as older people.

Table 7.7 Respondents' Satisfaction with their Home

\begin{tabular}{|l|c|}
\hline \multicolumn{1}{|c|}{ Respondents } & Satisfied with house \\
\hline Younger elderly & $87 \%$ \\
\hline Older elderly & $90 \%$ \\
\hline Total elderly & $88 \%$ \\
\hline
\end{tabular}

They decreased their possessions requiring extra storage, allowed for "hobby" space when deciding on a new home, planned manageable grounds and garden and ensured flat access and proximity to public transport, shopping and medical facilities. Other women chose to stay on in their family home, although it required refurbishment, rather than to shift house to something smaller. The larger, older properties provided space for family and grandchildren and better storage facilities than they had been able to find in affordable pensioner units or town houses. 
'Ageing in place' maintained the advantage of proximity to neighbours and friends. While warmer climates were tempting, there was value in staying in the familiar community, especially when children and grandchildren lived locally. Again the high cost and limited availability of smaller town houses in the locality was a factor in deciding to remain in the family home. For some older women the thought of having to shift house was intimidating.

\subsection{Living alone}

Fifty-one percent of the elderly lived alone: forty-four percent of the younger elderly and eighty percent of the older elderly. In the general population 37\% of older women live alone compared with 16\% of men (Ministry of Women's Affairs, 1999), a reflection of the fact that women are frequently younger than their husbands and have greater longevity.

The increased rate of living alone in the older respondents' age group is consistent with widowhood, the mobility of families and the preponderance of Pakeha women in this group. Pakeha women have a greater life expectancy than most other ethnic groups in New Zealand and also a longer period from age 65 when they may be free from disability which requires assistance in the home or full-time care (Ministry of Social Policy, 2001, Figure H3.1, p.20). Some of the women in this study indicated that they had assistance with gardening, housework and the provision of meals, which enabled them to remain in their own homes, which they strongly desired. Telephones were essential, not just for emergencies, but for maintaining everyday contacts. One elderly woman felt it was, "my lifeline, I can talk to my friends every day regardless of the weather." Another wrote, “I can’t get out much now, but people can phone.” While ageing in place is the preferred option, women also experience worries living alone, but resist the alternatives of a retirement village, living with family or of rest home care. Only 6\% of New Zealanders over 65 live in a rest home or with a caregiver and of those over 85 only 1 in 4 live in residential care (Ministry of Women's Affairs, 1999).

One respondent was severely disabled by multiple sclerosis, and was aware that her deteriorating condition would ultimately result in her need of full-time care in 
a rest home or hospital. She was maintaining her independence as long as possible because her previous short term experience, in just such a facility, had been extremely negative.

Living alone brought particular problems for some respondents across both age groups. There was a tension between valuing one's independence and the need for assistance with some tasks. Unless family or friends were geographically close there was no one to talk things over with, whether it was to choose new wallpaper or make funeral arrangements. Nights especially were lonely when disrupted sleep patterns were present. Listening to talk back radio was a common coping activity.

\subsection{Use of car and availability of public transport}

This question asked if the respondent drove a car, not whether they owned or had access to one and I have assumed that a car was available to them and that they drove it.

\section{Table 7.8 Respondents' Use of a Car}

\begin{tabular}{|l|c|}
\hline Respondents & Use of Car \\
\hline Younger elderly & $84 \%$ \\
\hline Older elderly & $60 \%$ \\
\hline Total elderly & $76 \%$ \\
\hline
\end{tabular}

Respondents indicated that this was important for mobility and access to services, not just for pleasure. Most of the urban respondents had adequate public transport with, in some areas, concession rates at off peak hours, but this did not replace the freedom of movement provided by a car. In the older elderly group there was more use of taxis and the driver services available through some voluntary agencies and from friends and family. In some Wellington suburbs concern was 
expressed that the local commuter trains would be lost. Country respondents were mostly dependent on cars for transport, and as shown above would plan trips carefully to avoid expenditure on petrol. Some women in the older elderly group were very concerned about the perceived severity of the older persons' driving test and the additional costs incurred with eye tests and medical certificates. A car, like a telephone was valued as a link with family, friends and the community.

Robyn Hunt (1988, p.780) points out that impaired mobility is the most common type of disability for women and since this is less likely than for men to be the result of an accident, they do not have the services provided for accident related disability and transport becomes a problem. Access to cars is an indicator of wellbeing. Mary Mowbray (2001) showed that lack of access to a vehicle was more prevalent with all-women households in the lowest quintile of disposable mean equivalent income. In 1998 20\% of households in the lowest quintile had no access to a vehicle, for women only households it was 38\%. All-women households include women living on their own and many of these may be elderly superannuitants who may no longer drive.

Of those respondents who did not drive a car 36\% were widows, $16 \%$ separated or divorced and $24 \%$ single. They had indicated that they lived alone. This compares with the $24 \%$ of married women who did not drive although they may of course have had partners who drove. The majority of the women in the not driving group tended to have lower household incomes than the women who drove. Forty per cent of the non-drivers were in the over 75 age group compared with $16 \%$ of the younger group.

\subsection{Use of the Internet}

Twenty-eight percent of respondents currently used the Internet, thirty-one percent of the younger elderly and twenty-two percent of the older group. Several women stated that they were about to do so, and others that they were prevented from doing so because of the high cost of computers, not because they were averse to learning to use new technology. Adult children encouraged them to come on line and a grandchild was anxious to "teach Gran". A few used a public facility or adult children's computers where they lived locally. Email was a quick and inexpensive means of keeping in contact with family, especially those 
overseas. A disabled respondent who lived alone stated that it was her lifeline into the world of news and information and contact with friends and family.

\subsection{Medical insurance}

Just over a third (35\%) of the respondents had medical insurance and there was no significant difference between the younger and older groups. Respondents expressed concern about the costs of medical insurance and some indicated that they had ceased these payments recently or were about to do so because of the escalating costs of the insurance premiums. Fear of the waiting lists for surgery in the public health system and the perception that older people would be overlooked in preference to younger patients kept some women paying health insurance that they could ill afford.

\subsection{Summary}

This chapter has recorded the demographics of the respondents and their responses to the shorter items in the questionnaire. A simple analysis has been provided and represented in graphs and tables. While numbers were small in some cases the distributions have been related to national statistics. Statements from the women themselves in regard to their material situation have been included. The following chapter continues the analysis of questionnaire responses and will focus on the more detailed responses to questions about activities and health, to matters of concern and pleasure and on those more open ended questions addressed to conceptions of personal value, of spirituality, religion and philosophy. 


\section{Analysis and Discussion of Questionnaire Responses, Part Two}

\subsection{Overview}

Chapter eight analyses the responses to the more open-ended questions. The extent and nature of the respondents' voluntary work is shown as well as their activity as grandmothers. What the respondents found pleasurable or matters of concern or worry are described, as are the preparations they made for retirement and the allocation of household tasks after leaving paid employment. Extensive use has been made of their own words. The place of religious, spiritual and philosophical belief systems in their lives is addressed and a selection of written responses to the significant issue of value has been included in Appendix III.

\subsection{Preparation for retirement}

There were 144 positive responses to the question about preparing for retirement (18 did not answer and 13 had made no preparation). The main activities of those who did prepare concentrated first on securing a debt free home, preferably with low maintenance requirements, with easy access and close to facilities.

"Found a single storey low maintenance house on a flat section within walking distance of the shops, doctor, etc.”

"Moved from a steep section and no drive on access to a better one with more opportunity to develop a garden."

"Paid off the house mortgage and made major house alterations to meet future needs."

"Built a retirement home in a suitable locality."

Various forms of savings plans were set up to provide capital and income to supplement New Zealand Superannuation. Several had purchased rental properties to provide retirement income. 
"Bought two rental properties ten years before retirement by which time they were paid off."

"Purchased a small property with inherited funds for rental which gave income from 1992-98 when I became eligible for National Superannuation. This precluded me from being eligible for the $55+$ benefit after redundancy.”

"Converted some assets to more readily accessible finance.”

“Paid into National Provident Fund, but not until I was 52.”

Where possible major property maintenance such as alterations, re-roofing and painting had been carried out, and indebtedness reduced by paying off a car loan. Household linen and appliances were replaced or upgraded and cars updated.

"Paid off house and car and tried to save.” "Replaced car.”

"Painted house exterior and roof (myself), installed a new hot water system and bought a computer and printer."

"Replaced essential whiteware and made house durable as far as possible.”

"Made sure appliances were in good repair and extra linen and clothing."

"Renovated the house to suit our requirements, bought new furniture and furnishings.”

Some respondents put savings aside specifically for medical expenses or had prepaid funerals.

"Saved on a long term investment plan to cover hospital treatment, holidays etc."

"I have a pre paid funeral."

Various studies of savings behaviours in relation to retirement (Else and St John, 1998: Cooke et al., 1999: Infometrics, 2000: Gee et al. 2002) found that women’s 
patterns of saving, the value of their accumulated wealth, and the financial advice they received differed from that for men. The average savings of a woman are less than the average man's at all ages. Arber and Ginn (1999) contend that women in Britain are more than twice as likely to experience poverty in old age, due to their lower earning power and lower participation in the work force due to family caring and hence reduced capacity to save. Divorce or care giving for others can negatively affect retirement preparation, particularly when women are custodial parents with limited access to employment. Traditional patterns have entrenched the expectation that men should provide for their retirement and ensure the financial security of their widows. Gee et al. (2002) confirm that divorced women with care-giving responsibilities are less likely to be saving for retirement, independent of personal income. They also found that one in every ten married women was relying solely on someone else to make financial provision on her behalf, and that poor health leading to reduced income lowered the capacity to make financial provision for retirement.

Another factor in savings is the quality of the investment. Cooke et al. (1999) conclude that when men and women have similar access to financial education and advice men tend to invest in assets with higher yields (and more risk) than women and this accounts for their greater wealth. Else and St John (1998) suggest that women do not receive the same quality of financial advice as do men, often receiving 'patronising' advice from male investment advisers. They also have less access to housing as an investment. My own experience and that of at least one of my respondents was that access to mortgage funds was dependent on finding a male guarantor. Women over seventy-five would have had less access to pension funds than younger women today would. The 1999 SROW study of women's expectations for retirement found that very few women had sought professional financial planning advice (pp.16-17), but there was a greater diversity in planning than apparent with the older women in the current study. Insurance salesmen had pressured some women into buying retirement schemes and others were suspicious of financial advisers they perceived as self-serving. Jane, divorced, aged 50 asked: "Who do you believe, who can you trust?” Carole, married, aged 51 belonged to one scheme with her husband, but also had an individual plan, “to keep me financially independent.” Few expected inheritances and the younger women who were working felt that the government could not be 
relied upon for superannuation support, so were planning other means of supporting themselves in retirement such as businesses and rental properties. Those sole parenting were too concerned with the immediate problems of raising a family to consider retirement. Their priorities were housing, food, clothing and education.

One third of the women responding to the questionnaire had attended a day seminar or brief course on retirement. This had occurred mainly in the context of a spouse's retirement and had been provided variously by the work place, insurance companies, financial advisers, or by organisations such as the Women's Division of Federated Farmers and the Workers Educational Association. Most of these were helpful, but some were not.

"Financial advice was helpful. I bought a new car, installed a woodburner and painted the house.”

"Attended a work sponsored course on retirement [specified] and joined the government super fund. Upped my investment to maintain income."

"The course was helpful, I freeholded the house and started a fund to cover maintenance.”

"Worked to earn, saved, invested, took advice on financial management."

“The course was not helpful for women on their own.”

“Tried the plan, but couldn't stay the course.”

For the majority of the women in the survey, financial provision for retirement was a husband's responsibility. Comments such as "My husband paid into a pension fund” or “ My husband arranged super” or " My husband took care of the finances" were very frequent.

Advice was commonly sought from friends and relatives already in retirement and from reading available literature.

"Read as much as possible and discussed it with retired friends.”

"Read the literature and talked to siblings.” 
Decisions were made whether to 'age in place' or to shift to a more suitable environment or to be near family.

"Did a little financial planning. Moved to Wellington to be near family for both their and my convenience”.

"My main preparation was mental, but had a small super scheme and bought a low cost house in a small town and welcomed retirement."

Not all preparations were related to material assets and finance. Provision was made for hobbies and interests and travelling. Some respondents made plans to travel both within New Zealand and overseas. In some instances this was to visit far-flung family and they wanted to do this before savings ran out.

“Travelled widely while I could afford it.”

"Coped well for the first ten years, did a lot of travelling, but now things seem to have changed."

Married couples often planned together for both shared activities and separate hobbies so that each had personal emotional and physical space.

"Placed more emphasis on interests that could be pursued at home together."

"Prepared mentally, determined to live positively and do what I wanted.”

"Considered hobbies and interests, things that we could do together and separately.”

Not all plans, however, ran smoothly and not all husbands co-operated.

"Had shared clubs with husband and was used to working together, but with no separate interests, I felt trapped in retirement.”

"I went to a local seminar on retirement, but my husband wouldn’t”

"My husband refused to face the future."

Sometimes unforeseen events disrupted living patterns. 
"My husband looked after the finances until recently. I am now involved, with the help of family, as my husband is now dependent."

"Considered clubs and activities we could share and do individually, but very quickly had to do it alone”[Due to early death of husband].

By making new social contacts in the year or two before retirement some women had ensured ongoing interests were already set up. Planning this required the purchase of equipment or rearranging space, sometimes resulting in clearing cupboards and passing on unused possessions to family, friends, charities or the tip. Some women set their plans in motion a few years before retirement.

"Made sure of ongoing interests in the year or two beforehand."

"Made arrangements to do time consuming voluntary work immediately after retirement."

"Cut down on book collection. Painfully gave away bric a brac. [and gave] family china and silver to offspring."

“Joined local women’s groups and attended night classes.”

"Kept actively involved with present activities.”

"Planned to be involved in the community."

"Attended a creative writing course and read about retirement issues.”

This entering of new activities and renewing old was particularly common when there had been a period of part-time work, which allowed a gradual entrance to retirement. The workplace provides a social environment, which must be replaced when paid employment ceases. As increasing numbers of women had entered full-time employment many of their previous social networks had become eroded and for widows the loss of a husband had narrowed their social arena.

A number of women indicated life events that had promoted or cut short their ability to provide for retirement. One stated that her father had encouraged her to join the government superannuation scheme when she first started work. Others mentioned small inheritances that had enabled them to be debt free or to purchase a rental property, which would provide income in retirement. Having had a good education, which resulted in highly paid work, made saving a possibility 
particularly when this had not been interrupted by motherhood. A few women were currently working part-time or had a small home-based business.

"I have been lucky enough to do some relieving work."

"We are still on our small farm."

"I have a small home-based fabric business."

For women less fortunate, their plans for a financially secure retirement had been curtailed. The contributors to misfortune included having large families and a low income, being separated or divorced, experiencing early widowhood, a chronic illness, an unexpected stroke, accident or business failure Living longer than anticipated was also a problem.

"Our loss of capital during the final years of working, ruined plans.”

"My money was lost from a retirement fund---insurance company that lost heavily on the market."

"No preparation. Had five children, hard then and hard now."

"No preparation. A stroke cut short my plans."

"Have lived longer than anticipated, so savings have disappeared."

Women in the older elderly group had been unable to gain access to employer subsidised funds and with low wages and salaries had been unable to maintain payments into various usually insurance based savings schemes.

"Super schemes were only available for the bosses.”

"No super schemes were available in industry until the Labour

Government in the seventies, and that was dismantled by Muldoon.” 2

Some had stayed in the home as caregivers or joined the work force too late to make superannuation savings. For others periods of unemployment or unforeseen redundancy had absorbed retirement savings.

"I have no actual time for retirement as am caring for an ailing partner."

\footnotetext{
${ }^{2}$ Robert Muldoon was Prime Minister in the National Government at that time.
} 
"I joined a super fund attached to employment, but too late for a significant pay out.”

It is clear that for the women in this study retirement preparation had been diverse. Differences appeared within and between cohorts as individual circumstances changed driven by significant life events. It is clear that a woman's life course greatly influences her situation in retirement as is indicated in section 2.5 .

\subsection{Changes in the allocation of household tasks on retirement}

For seventy of the respondents the question did not apply, as these were women who were unmarried, divorced, separated or widowed often before retirement. In the cases of married or partnered women twenty indicated that no change had taken place on retirement. Twenty-three widows responded either by describing the changes that had taken place before the death of their spouse or their present situation, living alone with the difficulties it entailed. The diversity of the respondents was immediately visible. The following quotations from their responses are typical.

For some couples the traditional division of inside work and outside work still operated or in some cases was commenced and in one instance a boundary was invaded.

"I do more inside, he does more outside.”

"He now does the vegetable garden” and “ He now mows the lawns.”

"My husband has come into my kitchen (my domain!), not doing daily tasks, but organising freezer, shopping at the supermarket etc.”

Much depended on a couple’s relationship before retirement.

"I have always had a helpful husband" and "Always helpful, my husband now helps more when he is not busy elsewhere."

"We both lead busy lives so that my husband can take over if need be. I still do washing, ironing and most of the cooking, but if I need help he is always willing." 
The words 'helpful' and 'helping' were used more frequently than 'shared' or 'sharing'.

For some work was happily and equitably shared on the basis of choice and skill rather than on sex role stereotypes, and was facilitated by the husband's retirement when his wife was still working.

" My husband retired before me and took over the vacuuming, general housekeeping and incidental shopping."

"When my husband retired he did the laundry and cooked the evening meal on the days when I was working."

"An increased sharing of both indoor and outdoor tasks."

"I sometimes get breakfast in bed. He hangs out the washing if I am rushing off to my engagements."

The husband learned to do housework and his wife acquired some skills for minor maintenance inside and outside the home.

"I've encouraged my husband to learn all aspects of household tasks and he could now manage on his own if he needed to."

"My husband helps with the housework, so we have more shared time together."

"Many chores have been shared, and some my husband has relieved me of altogether."

Change had occurred when illness and disability intervened.

"My partner (now deceased) retired early while I worked full-time and he took over a considerable amount of household duties, when his health permitted. He also began to consult me a great deal on household purchases, particularly major ones.”

"Since my first hip replacement, my husband has given more help with cooking and washing, for which I give thanks."

"I have had an arthritic complaint for five years. This has affected my hands and wrists. I often have difficulty lifting and holding. My husband has no home experience, but now does washing, carrying on anyway he can.”

"My husband has Parkinson's and my life has taken a dramatic change.

He is now in a rest home with full care.” 
Where the division of work was not equitably shared there was a tendency for the men to cook meals regularly or occasionally, rather than engage in more menial cleaning tasks. Some men preferred a set menu of tasks rather than general help.

"My husband is quite willing to cook some meals."

"My spouse regards dishwashing as his job. He does breakfasts I do dinner. He buys food-he loves shopping. No other changes. I do cleaning, ironing and laundry.”

For some other women, husbands gave little or no help to their wife or did so reluctantly and unreliably.

"No change. I still do household chores.”

"Sometimes does the vacuuming." and " he does help, with dishes alone.”

"Some help with housework and meals, but grudging and not to be relied upon. My husband likes to 'do his own thing', but he has been a bit more helpful and sympathetic recently.”

As mentioned above many widows responded to this question indicating the extra burden that had fallen on their shoulders with the demise of their spouse. This was particularly so when death was early and unexpected. Help with household and garden was available through Work and Income New Zealand (WINZ) or the Accident Compensation Corporation (ACC) for some widows on low income and with disabilities or accident related conditions. In some cases families were able to assist and age was a factor in readjusting to living alone.

"Since the death of my husband, I must cope with everything alone." Aged 78.

“ACC provides household help, WINZ provides lawn mowing.” Aged 82.

"My husband died seven years ago, consequently a lot of household tasks he was able to do, have now fallen on me and I find it difficult to realise that improvements should be done.” Aged 76.

"My husband died six years ago, since have moved house, [done] building alterations. Laid out a garden, now independent.” Aged 65.

"Daughter, son-in-law and their three children have bought two thirds into family home, MY third, (granny flat) relieves me of many tasks.” Aged 75. 
Overall, positive changes on retirement had occurred within the allocation of household tasks, but in some cases the redistribution or sharing was by no means equitable.

\subsection{Retirement villages}

Although very few of the respondents stated that they lived in retirement villages, this topic raised some strong opinions. Negative aspects were concerned mostly with cost and isolation: Comments such as: the following were typical:

"A rip off of the elderly, subject to extra charges in 'dodgy contracts', very expensive.”

"Ghettos to hide old people away from society."

"They tend to isolate old people from the mainstream of life, emphasising ageing and frailty.”

Positive aspects were mainly concerned with security, companionship and support. Representative comments were:

"A fine solution for people who want the security of knowing that care is available if and when needed."

“Good for the lonely and disabled when the family can’t cope.”

"Great for those unable to care for a large home and property."

On the whole respondents saw retirement villages as useful for some, but few were keen to take up the option. For some they were seen as desirable, but unaffordable. However, three respondents who currently lived in retirement villages were happy with their choice. The fact that so many women disliked the idea of living in a retirement village was not solely on the costs involved, but on the social aspects of putting so many older people together and the lack of personal choices that it might entail. Villages vary in their requirements of residents and sometimes restrictions on parking and space do not allow for extended family visits, as one of the women later interviewed explained. 
Most of the respondents wanted to stay in their present home for family and community reasons. They were happy to 'age in place' where they knew their neighbours and community facilities and public transport were nearby. In spite of problems they may have with current accommodation, they were not convinced, other than for security and companionship which they felt applied to others not themselves, that retirement villages were a good option. This is interesting in relation to the burgeoning industry creating these villages which are presently quite aggressively marketed to the elderly. Has the market got it wrong? Present legislation ${ }^{3}$ proposed by the government is directed at making sure that the contracts involved in their lease or purchase is not exploitative of older persons.

\subsection{Satisfaction with life}

Table 8.1

Life Satisfaction Percentage Ratings

\begin{tabular}{|l|l|l|l|l|}
\hline Marital Status & Very good & Good & Satisfactory & Poor \\
\hline $\begin{array}{l}\text { Married or } \\
\text { Partnered }\end{array}$ & 58 & 36 & 6 & 0 \\
\hline Widowed & 29 & 48 & 23 & 0 \\
\hline $\begin{array}{l}\text { Divorced or } \\
\text { Separated }\end{array}$ & 23 & 54 & 15 & 8 \\
\hline $\begin{array}{l}\text { Never } \\
\text { Married }\end{array}$ & 52 & 40 & 8 & 0 \\
\hline
\end{tabular}

This was rated from very good to poor. Only one respondent rated her satisfaction as poor. One woman indicated that it varied from very good to low, another that it varied from satisfactory to poor and one added that the variation

\footnotetext{
${ }^{3}$ The Minister for Senior Citizens outlined the proposed legislation for retirement villages on 6th December 2001. Villages will be required to have a comprehensive disclosure document. Potential residents will have a 10 day cooling off period to change their mind after signing and each retirement village will have a code of residents rights, a statutory supervisor and a disputes resolution process.
} 
from good to satisfactory was due to current poor health, a second bout of pneumonia. The provisos attached to life satisfaction responses must be kept in mind. They may have been influenced by recent events, or the mood of the day at the time of completing the questionnaire.

It is noticeable that the most positive ratings for satisfaction came from married or partnered women and those who had never married, while the least positive came from divorced or separated women with low incomes. Widows too experienced lower levels of satisfaction and were more likely than the other groups to report loneliness.

\subsection{Disabilities}

These ranged from mild to serious and $89 \%$ of respondents reported some disability. The impairments most commonly reported were:

$$
\text { Arthritis 54\% } \quad \text { Eyesight } 37 \% \quad \text { Hearing } 27 \% \text {. }
$$

All of the older group reported some impairment compared to $84 \%$ of the younger group

While these are statistically noted as 'disabilities' many women, especially those who had worn glasses from an early age did not consider them a 'disability', but were concerned with the cost of replacements for spectacles and hearing aids. Others who required the removal of cataracts or who were on hospital waiting list for hip, knee or wrist replacements and other surgical procedures were subject to ongoing discomfort which limited their mobility in varying degrees. While not rated as a disability, dental problems raised concern. Ongoing dental care was very costly, but necessary for good health.

As shown above disability or impairment increased in the older age group, but only $8 \%$ of the older elderly reported their health as less than good, (see below). 


\subsection{Health}

Respondents rated their health on a five-point scale as excellent, very good, good, poor or very poor.

Overall no respondent rated her health as very poor and excellent health was reported by $15 \%$ of all respondents. Of those under seventy-five $16 \%$ considered their health excellent and for those over seventy-five 10\% considered their health excellent. There was much individual variation, but the decrease in those reporting excellent health may relate to the ageing process. Overall age related percentage ratings are as follows:

Table 8.2

Respondents' Ratings of Health

\begin{tabular}{|l|l|l|l|}
\hline Respondents & $\begin{array}{l}\text { Better } \\
\text { than } \\
\text { good }\end{array}$ & Good & $\begin{array}{l}\text { Less than } \\
\text { good }\end{array}$ \\
\hline Younger elderly & $62 \%$ & $36 \%$ & $2 \%$ \\
\hline Older Elderly & $46 \%$ & $46 \%$ & $8 \%$ \\
\hline
\end{tabular}

Despite the disabilities described above and self-reported illnesses such as diabetes, cancer, high blood pressure and cardio-vascular disease, the women generally rated their health as good or better. Well-being can clearly co-exist with disability and impairment. One respondent reported good health as she recovered from double bouts of pneumonia, another on recovery from a double coronary bypass and others after recent hip replacements and ongoing treatment for cancer. Milligan (2001) found health to be a contextual concept, not simply the absence of disease. Flett et al. (1999, p.128) found that many older adults with chronic conditions and increased levels of disability function well in the community and look positively on their own health. 


\subsection{Exercise, sleep and holidays}

Exercise was recognised as being beneficial for health, and many women engaged in three or four different forms of exercise on a regular basis. A few women felt that they had quite enough exercise coping with daily housework. While walking, gardening, housework and swimming were most commonly reported, particularly by the older group, other activities mentioned included cycling, acqua-aerobics, badminton, bowls, petanque, yoga, taichi, croquet, tennis, table-tennis, dancing, house and farm maintenance, tramping and the use of exercycles and treadmill. The most commonly reported forms of exercise are shown below.

Table 8.3

Respondents' Exercise

\begin{tabular}{|l|c|}
\hline Exercise & Participation \\
\hline Walking & $66 \%$ \\
\hline Gardening & $37 \%$ \\
\hline Swimming & $12 \%$ \\
\hline Housework & $12 \%$ \\
\hline $\begin{array}{l}\text { Aerobics and gym } \\
\text { Classes }\end{array}$ & $11 \%$ \\
\hline
\end{tabular}

Sleep proved difficult for $50 \%$ of the women, but they saw this as common in the ageing process and had developed strategies to deal with it, not going to bed too early, reading, listening to talkback radio, warm milk drinks, sleeping pills, herbal remedies and warm baths.

Holidays are important for people's well-being. ${ }^{4}$ Of the women who had least access to holidays $39 \%$ were widows and 35\% were divorced or separated. These

\footnotetext{
${ }^{4}$ Having an annual holiday is one of the factors in the 2001 Ministry of Social Policy's recently
} developed standard of living measure for older people. 
two groups were also those with a low median income (level 3). The slightly higher median income and a wider range of income (levels 2-8) may have contributed to the greater proportion of married (79\%) and single respondents (72\%) who took a holiday at least once a year.

\subsection{Concern for safety}

Of the 155 responses to this question 32\% answered no without further comment. It was therefore not possible to tell whether feelings of safety were due to safety precautions having been taken or to personal temperament. However there were other 'no' and 'not really' responses, qualified by references to specific occasions of concern or to beliefs as to why the respondent felt safe.

Most women were very aware of unsafe situations. Some reported instances of themselves or their friends having been burgled or attacked. A common feature was fear of walking or driving alone at night. Some feared a fall or injury in the house or garden. Home invasions and violence were mentioned. A few married women thought that they were safe enough now with their husbands at home, but were concerned should they be alone.

Women alone expressed more worries about safety and gave much thought to avoiding situations which could prove dangerous. In some cases this restricted their freedom and mobility. Walking alone at night was considered unwise. Isolated locations and lack of street lighting were to be avoided and neighbourhoods where they thought danger might lurk. Rather than take a risk on their own, they would take a taxi. One respondent said that she would never carry a handbag in case it was an invitation to muggers.

Positive actions giving confidence were: locking all doors and windows at night, acquiring personal medical alarms, burglar alarms, smoke alarms, security lights, a dog, deadlocks, carrying cell phones if travelling and living in an upstairs apartment or a retirement village where they felt more secure.

\subsection{Being a grandmother}

Seventy-nine per cent of the women were grandmothers and as expected it was a valued social role, which had developed a sense of psychosocial generativity and 
was a social marker of age (Armstrong, 1996, 1999). Some respondents without their own children had surrogate 'grandchildren', provided by nephews and nieces and friends.

Whilst most responses valued the 'grandmother' experience an occasional response was reminiscent of Baba Copper's warning about societal expectations for older women as serving others,

"Mostly old women know how to serve. The roles reserved and expected of women in old age-grandmothers, self-effacing volunteers to the projects and priorities designed by others, caretakers of old men — are custom-fit to our powerless status” Baba Copper, (1988) p.86.

Most women had a close involvement with their grandchildren. Where families were geographically distant, telephone, letters, e-mail, videotapes and audiotapes helped maintain contact and there were occasional visits by grandparents and holiday stay-overs for the children.

Local grandparents in the main (exceptions appeared to be due to family breakdown) saw a great deal of their grandchildren, taking responsibility for them in the school holidays and with day-care when the parents were both in paid employment. In some cases, where parents were absent or deceased, grandparents accepted the full responsibility of raising their grandchildren. Great distress was caused when, in a few cases of separation and divorce, access was prevented either by distance or bad feeling.

Attendance at the children's school events, sports and cultural functions was a common supportive activity of grandmothers. Knitting, sewing and providing 'goodies', birthday and Christmas presents afforded much pleasure. In some cases the women maintained contact with young people through the children of nieces nephews or neighbours because they wanted the stimulus they felt came from youngsters. The contact seemed to decrease as the grandmothers aged and as teenagers spent more time with their peers outside the family. Where income permitted, some grandparents had made financial provision for the children's further education. Several women said that while they derived pleasure from their grandchildren they were very happy not to have the full responsibility of them 
and were happy to see them return to their parents at the end of the day or the school holidays. Much planning went into finding activities to share with the children. On the whole the respondents reported a sense of joy and fulfillment in their relations with their grandchildren.

\subsection{Voluntary work}

This study did not make a distinction between formal or informal volunteering, whether it was physical or emotional, secretarial or administrative, whether performed in the home or the community. The respondents decided what was a voluntary activity. Some women may have made this distinction and underreported their activities in the informal caring category as this seemed to them a normal expected activity for females and volunteer activities were perceived as those carried out through formal helping agencies. Other women specified being 'listening ears' for those in stress inside and outside the family and giving help when and where needed.

Eighty-four percent of respondents recorded current voluntary work, 88\% of the younger women and $64 \%$ of the older women. Of those who had no current voluntary work, all but one had had some previous involvement and most of them were in the older elderly group, where infirmity or lack of mobility frequently precluded this activity. Only two women among the total respondents had at no time participated in voluntary work, and one of them commented, "to my shame," which is indicative of the social expectation that women should perform these unpaid tasks. Marital status did not appear to relate to participation rates.

The actual activities whether formal i.e. organisations or informal i.e. individual fell into three main categories, Administrative, Practical Help and Emotional Support. There was no clear dividing line between these for individuals as the women tended to address a particular situation that may require a multiplicity of skills. Thus a member of a trust board involved in policy making may also be contributing to the catering for fund raising or take on clerical work unpaid for the organisation. Within church groups practical help and emotional work went hand in hand with knitting, sewing, baking and food bank duties supporting the spiritual and physical needs of the community. 
Women used the skills acquired through life, educational and workplace experiences to assist in school literacy programmes, local libraries and historical societies. Several were actively engaged in environmental projects and in women's refuges. Others worked with organisations such as Age Concern and Amnesty International. A few were 'background ladies' for political campaigns organising canvassing, arranging cottage meetings and catering for fund raising events.

From the pattern of responses to the questions on past and present voluntary activities, it was clear that many of the women had first become involved through the activities of their children. School and preschool, Plunket, playcentres and kindergarten, sporting commitments and hobbies, the membership of church groups and the scout and guide movements drew women into unpaid supportive work in the community not represented in our statistics of national productivity.

As more time became available, through lowered demands for care-giving or paid employment, voluntary activities changed from child focused to those more related to personal hobbies and community interests, but which still required the clerical, administrative, catering and nurturing skills of their previous activities.

This high rate of participation in voluntary work, may be an artifact of the networking distribution of the questionnaire. It was distributed initially through women who belonged to some community organisations in a Wellington suburb: a choir, a garden club, the Citizen's Advice Bureau (CAB) and the University of the Third Age (U3A).

The high level of social activity and family involvement reflects the traditional perceptions of women's nurturing and caring roles. While some of the women saw their practical and emotional work within the family as concomitant with their role as mothers and grandmothers it was nevertheless a voluntary activity and was extended to other members of their community, to neighbours and others whom they perceived as having unmet needs.Some women performed this work individually and others as members of organisations such as Care and Craft, 
Meals on Wheels and churches. Working with groups had the added advantage of providing an opportunity to socialise away from the house.

There was no relationship between income levels and voluntary work, but higher levels of education seemed to result in more formal types of voluntary work e.g. tutoring, administrative work on national committees, local citizen's advice bureaux, historical and environmental projects and public advocacy on health, welfare and equity issues.

The voluntary work covered a great number of activities, both formal and informal. In the older group the rate of participation of volunteers fell by almost a quarter and comments indicated that this was due to infirmity or lack of independent mobility e.g. no longer driving. In some cases older women were continuing in their voluntary activities longer than they wished because younger volunteers were not available due to work commitments or lack of childcare and this was perceived as an ongoing problem for community

Continued participation in the community was strongly valued by the women as adding positively to the quality of their life. Voluntary activities were a source of getting out of the house, of socialising, feeling useful, helping others, learning, passing on skills and of contributing to society in a productive way.

A list of the women's activities appears in Appendix II b

\subsection{Things that please, worry or concern}

The question about pleasure brought a $99 \%$ response compared to a $92 \%$ response for matters of concern. This is a small difference, which may reflect reality, or that it is perhaps easier to record the sources of our happiness than of our sorrow. Some respondents said no worries, or referred to upsets or being annoyed rather than worried. Their concerns about adequate resources are recorded in section 8 2. The quotation below represents the mix of personal sorrow and concern for people other than themselves common to many responses. 
“I don't have the word 'worry' in my vocabulary. The things that upset me are: Injustice, Cruelty to human beings, War. The loss of a loved and loving daughter four years ago when she drowned when out tramping."

Seventy-two percent of respondents reported family and friends as a source of pleasure, but twenty-seven percent also recorded them as a cause of worry or concern as in family breakdown, illness and unemployment. While there was concern over their own wellbeing, more concern was expressed for others. A quarter of the women mentioned supportive husbands. Several were worried about their spouse's declining health and the prospect of being left on their own, particularly the long nights they would have alone after the intimacy of many years.

Twenty-two percent of the women took pleasure in their gardens and the native bush. For others the proximity of libraries and theatres was a joy. Many were thankful for good public transport and/or the ability to drive. In the older group concern was expressed over the cost of driving licences and the difficulty and expense of driving tests. A quarter of the women referred specifically to freedom and over half to time. Freedom and time were most commonly expressed as freedom from the constraints of family and employment responsibilities, and freedom in terms of time for oneself to pursue leisure interests. Autonomy was valued, good health, financial and physical security were important. Being in control of one's life and having choices was possible when living in your own home unlike rest homes, or in some cases retirement villages.

"Having reasonable health. Having leisure time and being able to enjoy activities at my own pace."

"Having enough money to do what I want. Having a partner through life to keep me company.”

"Having children and grandchildren whose activities I can enjoy close up or at a distance."

"Free time. Able to decide what I want to do, but time to put into some organisations and people.”

"Having the house to myself, wonderful neighbours and friend. I can play the piano when I want to. Being in control of my life."

Location of their home was also a source of pleasure. 
"Queenstown district with many opportunities for outdoor living and activities."

"Living in a lovely town like Oamaru."

"Living in a small town. The ease of getting about—no traffic hasslesLots of friends."

"Wellington and all it offers-the waterfront, Te Papa, Bond Store, Botanic Gardens etc. Organisations catering to the interests of the elderly, particularly U3A which provides on-going learning opportunities.”

Reading the responses to the things of worry or concern the overall impression was of women looking outside themselves to the world around them and into the future. There was an overwhelming reaction to violence in the community and the abuse of children. Beyond individual concerns for possible loss of independence, of deteriorating health and diminishing income and resources, was a strong focus on society's ills and social issues, both in New Zealand and in the world at large. Poverty, crime, violence, abuse, inequities, war and generally man's inhumanity to man (and especially to women and children) came in for comment as well as a perceived change in moral values.

"Abused women and children. Conflicts around the world. Loss of my kind of values in New Zealand and around the world."

"What the future holds for the younger generation."

"World affairs. Abuse of children and animals. Present violence on TV and films. The lack of caring for the elderly and those in trouble. Everyone is so busy."

"1. The expectations of wealth of our young. 2. The lowering of moral standards as I know them. 3. Lack of employment and direction for the young. 4. The widening gap between rich and poor.”

These responses were written before the current 'war on terrorism'.

\subsection{Being valued}

The perceptions of belonging and of being valued are germane to the concept of well-being and this question brought out strong feelings in the women. The question was phrased as closed, "Do you feel valued as an older woman? Please 
explain.” and perhaps this was not the best presentation, however, there were only 13 non-responses in the 175 returned questionnaires. Many responses were lengthy. These were analysed by identifying themes indicating the source of their sense of value. Words and phrases representative of positive and negative perceptions stood out. The answers fell into three groups; those clearly positive, those definitely negative and those where both experiences were represented. I have listed those phrases with the most positive and negative connotations. The agencies of value were seen as oneself, family and friends and the community.

$\begin{array}{ll}\text { Positive Connotation } & \text { Negative Connotations } \\ \text { Helping and listening } & \text { Patronised and overlooked } \\ \text { Advice and assistance } & \text { Unused talents and capabilities } \\ \text { Experience appreciated } & \text { Invisible, ignored, useless } \\ \text { Kindness and respect } & \text { Lack of understanding. } \\ \text { Active and able-bodied } & \text { Silly, dumb, a nuisance. } \\ \text { Voluntary work, skills } & \text { Being called 'dear' } \\ \text { Mother and grandmother } & \text { Discourtesy, put down } \\ \text { Friends and family } & \text { Stereotyped so don’t give my age. } \\ \text { Church and community } & \text { Lonely, a joke . }\end{array}$

Negative attitudes were ascribed mainly to the public arena and to the young; some tradespeople, shop assistants, restaurant workers and professionals were perceived as overlooking and patronising older women. Advertisers and the media were criticised. One woman felt that the treatment she received was related more to being a woman than to being old. Being invisible, overlooked, or ignored were words frequently used in negative perceptions of value.

A few women felt valued for themselves; some described themselves as stroppy, articulate, assertive and intolerant of put downs, while others stated that they had always been valued all their lives and that age made no difference. There was a great diversity in women's responses, but patterns of how and why they felt valued or undervalued emerged. Paramount was a feeling that they 'belonged' 
and were still 'useful'. When this was not acknowledged it often resulted in lowered self esteem. Some of these responses appear in Appendix III.

\subsection{Spirituality and belief systems}

Question 42 in the survey was worded: “ How important is your spirituality, inner life, religious belief or philosophy to your well-being as an older woman?” Ninety-eight percent of the respondents completed this question and of these ninety-four percent considered these matters of some importance and in their various interpretations presented a diversity of view that did not focus solely on religious belief. The main interpretation was not focused solely on religious affiliations even when these were specifically mentioned by many of the older elderly.

The women showed both continuity and change in their beliefs over the years as life's experiences marked them. While for some women prayer was vital, for others implementing their code of ethics in personal life, and practising 'good deeds' in the community was important regardless of a religious framework.

In the younger elderly group there was some indication of movement from formal established religion. For all age groups belief in God did not mean regular church attendance and a spiritual dimension in life was not the prerogative of the church.

“I’m not a Christian and up until recently death hasn't entered my mind. It does now as a sort of ground bass, [musical background] and I'll be sad to leave a lot of things. But it makes me savour life. I've gained a lot from seeing the goodness of many people, and from literature, that's been a sustaining part of my life. I'm with whoever it was who said they would be good without hope of heaven or fear of hell.” [Aged 68]

"I'm an atheist. I guess I feel quite free to express my belief about people and getting on together. Certainly feel freer to express them now than when younger and employed."

[Aged 62]

“All experiences have built inner strength over time.”

[Aged 72]

"I try to live well so that I am a good example to those I work with or for."

Aged 70]

"I have no conventional religious beliefs, but I do believe in a strong power for good which can be nurtured in our society. I have always been an optimist with a positive and independent outlook.” [Aged 66] 
"I was brought up to believe in duty to husband, to family and to carrying out God's word in the manner of doing unto others as you would have them do unto you. I was educated in the belief of the emancipation of women. As a younger woman these two ideas conflicted and caused me a great deal of stress. Circumstances (or was it lack of will power?) have over the years confined me to the former, a more relaxed and altogether easier way of life. Yes, I think your ideals are important, but they may not be the ideals you thought important once."

[Aged 64]

"Religion - not overly important, but I still go to church, perhaps five or six times a year. Inner Philosophy-I have a very strong code of ethics (as many of my age group has) which, I feel, has helped me through life a great deal.”

[Aged 70]

"Very important as I regard contentment and happiness in life is important, and is for those able to live within the limitations of their own abilities and this counts (in my opinion) for any age group. Both myself and my late husband were not materialistically inclined, but always tried to improve our knowledge of many different subjects within our reach.”

[Aged 76]

"Vital. All the thinking, questioning, reading, discussion etc over the years (and experience) come together so that the remaining years and death at the end (I prefer the term transition) hold no fears.” [Aged 67]

"I am not a particularly religious person, but we go to church regularly and this supplies us with fellowship and peace of mind.” [Aged 71]

“That's a curly one! I was a 'cradle Catholic' and conditioned to marry a Catholic. My doubts began with birth control limitations and became focused when I was on the organising group for the 1988 Women's Spirituality Conference (Christchurch). I publicly left the church then and for several years attended non-denominational spirituality groups and meditated regularly. The groups have folded, or I've lost touch and I do feel the need for some spiritual direction in my life now." [Aged 73]

"My religious faith has always been the basis of my life, but not an inoculation against problems and doubts. These don't evaporate with age, nor does the stress of dealing with conflicting personal demands. But without this spiritual dimension I'd feel only half alive, a sense of wonder, zest for living are all connected with faith as well as outrage at injustice and the destruction of the environment and crusading zeal (slightly muted by age).”

[Aged 77]

"The importance of spirituality, inner life and religious belief has grown with advancing age and contributes to my well-being now. Our church has always tried to give good support to people in the parish.” [Aged 81]

"Always feel deeply the good principles in our early family life and parents' example. Age is no barrier. Life is short. Love what you do. 
One cannot discover new oceans unless one has courage to lose sight of the shore."

[Aged 94]

\subsection{Additional matters and conclusion}

This section allowed the respondents to expand on their earlier answers or to add any new material they thought relevant. In the main this reinforced what they had already written, but concentrated on the themes outlined below. The comments came in two categories, positive and negative: themes of opportunity and personal enrichment and themes of sorrow and loss.

The women expressed their enjoyment of freedom and independence, family life and friendship. Retirement had brought opportunities for new learning and interests, which the gift of leisure made possible. For some it was freedom "from the rat race and having time to stand and stare.” Enjoyment of good health and warm companionship was mentioned together with the security of home ownership and adequate finances. They talked positively about the maintenance of fitness and mobility, the need to dispel the negative images of ageing and the importance of individual attitude. Many referred to 'not thinking old'.

"I am just retired, am loving being a human being instead of a teacher. I have friends ranging from two and a half to ninety-five, but do not think either of them or myself in terms of age or sex. So older woman thinking is not something I do! Someone once told my father 'Life can be a bugger, when you are young, you have enough energy and no money. When you are old you have money and no energy.' I hope I've struck a balance.”

The quality of one's life was not solely dependent on material things. They spoke of the adaptation to change and the acceptance of change, of " beautiful stretches of time and calm" of periods of serenity and contemplation as well as a busy life contributing to the family's welfare, helping others and pursuing hobbies and interests. "But the hours, weeks, months and years fly too fast." While enjoying life the women found time to reflect on the less fortunate situation of others and the social changes they had observed:

“As one of the fortunate 'older women', [single] I guess it's easy for me to say 'quality of life' is dependent on self. But I'm certainly aware that many older women have a struggle, e.g. married (widows now) grown- 
up family all away, trying to live on National Super, worried about power costs, losing drivers licence (no public transport) etc., no spare cash for the little odd extra - box of chocs, hair set etc.”

"I feel fortunate to be an older woman in this period of history, when roles and expectations are not so closely defined, although thinking of my answers to this questionnaire, I realise I've been involved in the process of widening boundaries of age and gender."

"I enjoy the freedom between men and women, of being able to hug and speak my mind and not be thought of as forward."

"I think it's a great time to be an older woman in New Zealand. I consider I am financially secure, but if I were dependent on National Super alone, like some others, my life would not be so enjoyable.”

The sadder side of ageing and retirement was also recorded. Most comments dealt with the losses of widowhood, of friends and family and with previous tragic events from which it was difficult to move on. Making new social affiliations was not easy. The concerns of future decline and loss of abilities was apparent. Many were worried about the sustainability of their income, and declining social contacts.

"The most sobering thought is the death of relatives and close friend and knowing that the lives of some others are much more restricted.”

"I’m concerned about finance and debt."

"As a single older woman it is difficult for me to sustain friendships with married couples of my own age even though they were friends of mine before my husband died. It is difficult to find people to socialise with for outings like films, concerts or even eating out, and none of these activities are rewarding on their own."

"I was widowed at sixty. This is comparatively young to be widowed and many of the clubs and other organisations catering for the older woman are attended by women aged seventy plus. I have found that those ten years make quite a difference - I am not accepted as 'old' by the seventy pluses, but I am 'old' to the under sixties."

"I hate being widowed. Miss the intimacy of sharing everything with a committed loving partner."

"Because of deteriorating health, my quality of life seems to be less than when younger as I am unable to complete tasks I would like to do.”

"Loneliness! Facing old age on your own can be frightening.”

"Quality of life is affected by constant pain and lack of mobility." 
While these women's words have been set out in a contrasting manner, in fact many of the situations described co-existed and the women coped stoically or with humour. Many described earlier experiences which had prepared them to cope with little money ${ }^{5}$ and many succeeded in putting aside the 'baggage of the past' such as desertion and betrayal of trust to age positively in the community. They were connected to life.

Sixty-seven per cent of the respondents gave definite positive statements about their feelings of being valued, twelve per cent felt definitely under-valued and twenty-one per cent had experienced both polarities.

Compared with the married women the widows tended to report more negative experiences and the younger elderly to present more positive comments than the older elderly. This may reflect the preponderance of widows in the older group and an increase in the incidence of loneliness and disability among the elderly. Only $8 \%$ of the younger elderly gave solely negative responses compared with $15 \%$ of the older elderly. Some of these clearly related to perceptions of no longer being perceived as useful to the community. Overall more than two thirds of the women surveyed felt valued in some way.

The feeling of being valued, for the majority of women, was internalised from perceptions of their usefulness to others whether family neighbours, friends or the community, spheres to which they belonged. This supports the stereotype of women's nurturing capacities as a source of self-esteem and recognition, but dependent on personal feedback; as one respondent wrote "I know my family value me, but I wish they would say so.”

Where feelings of negativity existed they related to life events such as compulsory retirement at sixty and the subsequent devaluation of talents and capabilities. The media representation of older women was often demeaning; the growing debate in the public arena on whether or not the elderly posed a growing burden on society in the continuing provision of universal superannuation was particularly galling. The valuing of the young for their productivity ignored the productive capacities of the old, as their public and private contributions were rarely acknowledged.

${ }^{5}$ Low incomes, large families, experiences during war and depression years of 'making do'or going without often reinforced by the memories of their mother's hardships. 
Responses from some of the older elderly women predicated their value on being treated with kindness and consideration, of being included in activities. They felt valued as recipients of respectful attention, which engendered a sense of belonging, rather than the alienation experienced by some others for whom increasing frailty and perceptions of isolation, loneliness and ageism left them feeling of no account.

Overall perceptions of being valued rested on being useful and belonging whether in the private sphere of the family and friends or in the public arena of the community. This applied to both positive and negative responses. Throughout this section I have concentrated on presenting issues in women's own words. The respondents often indicated in their scripts that they valued the opportunity to present their view

The responses to the questionnaire have highlighted more positive aspects of older women's lives than is apparent from the perceptions of ageing presented by literature reviewed in chapter two. For many the experiences in the role of grandmother, a strong community engagement and the joy of "time to oneself" have provided the valued aspects of ageing. The present level of New Zealand superannuation and targeted allowances, together with high levels of home ownership ensure some security for older women. This is not to discount the concerns about health, income, security and concern for others experienced by many women, or the feelings of loneliness experienced by some women on their own. The uncertainty of our 'use by date' puts pressure on the allocation of limited financial resources. The issues of independence, dependency or interdependence become immediate. Widowhood, the distance of family in a mobile society such as New Zealand, and the probable shrinking of social circles with advancing age are all challenges for older women. 


\section{Conclusions and Avenues for Future Research}

Women's standpoint returns us to the actualities of our lives as we live them in the local particularities of the everyday / everynight worlds in which our bodily being anchors us.

Dorothy Smith (1997, p.393)

\subsection{The end of the journey}

In this study I set out to examine those factors which contributed either positively or negatively to the well being of older women and so to the quality of their life. It was clear that these variables did not stand alone, but were strongly interrelated, strands closely woven together in individual contexts, which in some cases formed patterns for a group of women, and each factor was capable of exerting both negative and positive influences both directly and indirectly. The journey has been a long one and has been sustained for me through the everyday words of the women themselves, rather than the theories and investigations of academics or by the picture presented by statistics derived from the census. These sources of knowledge are important and inform my interpretation of what the women in this study wrote in their responses to the questionnaire and stated on interview. It was, however, what the women said and my personal experience as an older woman that gave substance and reality to this study of the quality of our life rather than the more formal references consulted.

\subsection{The question of representation}

Although the profile of the 175 women in this study is fairly similar to the national distribution of older women in terms of age, marital status, income levels, home ownership and living alone as shown in chapter six, they do not represent all older women. The situation for older women living in rental accommodation or boarding houses may be very different from those owning their own homes or for those living in institutional care whose autonomy is restricted. The women in this project have responded to a social networking process that did not directly address those women who for various reasons are living in socially isolated situations. This condition concerned both the 
respondents and interviewees, although they referred to it mainly in the context of 'others' or to the ways by which they had constructed their own environment to avoid this problem. Issues of ethnicity or the situation of recent older immigrant women were not part of this study.

\subsection{The implication of the level of response}

The level of response to the questionnaire and the willingness to be interviewed was high. It is clear that the women considered it worthwhile to respond to an opportunity for their individual views on being older women to be heard and recorded. This view has been reinforced by the positive comments of encouragement for the project, which they added to the questionnaire.

\subsection{What I have found}

The dominant determinants of the quality of life for the older women represented here have proved to be their individual life events and the societal context within which these have taken place. Their family of origin has been the source of beliefs and attitudes which have established a particular life course moderated by the opportunities available to them or the barriers confronting them at particular points in their life cycle. Early participation in the life of the community as instanced by church membership and voluntary work in organisations such as those related to children's activities, Plunket, mothers' clubs, guides, scouts, cubs and brownies and many sports, hobby and welfare groups were followed up by voluntary work in their later years. The responses from both the questionnaire and from interviews tended to support the theory of continuity in personality, but changes in assertiveness and tolerance levels had occurred. Some of the women said that, as older women, they were both more understanding and more likely to speak their mind than they had been as younger women. This they felt had resulted from the greater experience of age, but also from the changes in society itself in relation to women.

The interviews provided more information on age related adjustments of activities and attitudes that support Baltes' theory of Selective Optimization with Compensation discussed in sections 3.2 and 6.4. Physical activities were maintained despite disablement with arthritis or impairment of sight and hearing. 
Various devices and strategies were employed to maintain both necessary and preferred activities.

The clearest representations of commonality in the quality of the participants' lives were the importance of home ownership, a continuing involvement in the social framework of family and community and the place of New Zealand Superannuation as the foundation of their income in retirement.

There was clear support for 'ageing in place' where possible, and for this there needed to be good community support for the elderly. Even when houses were changed the women felt that access to friends in the locality was important and preference was given to the purchase of a house within a familiar neighbourhood. While it was an advantage to be near family this was seen as difficult because of the mobility of adult children within the country and overseas.

There were differences between the younger elderly and the older elderly as groups, but individual attitudes and health status moderated these. The older group was more likely to feel tired, had more health concerns and expressed feelings of loneliness and occasionally of isolation. When fixed incomes had not kept pace with inflation and savings had been run down the older age group experienced greater difficulty with house repair, maintenance, rates and insurance.

Preparation for retirement showed the most diversity and greatest effects of a woman's life history. Emphasis had been placed not on financial support alone, or on the renewal of household resources, but on the provision for social engagement, such as planned activities with partners, preparation to continue previous hobbies and interests and plan new ones. Organisations were joined to ensure on-going social contact once the social activities associated with employment were no longer available.

The formal question at the close of each of the sixteen interviews concerned advice to younger women on retirement and brought a very similar response from all participants. This is represented by 'Growing Older' posted to me by Audrey Harper a day or two after my interview with her (see Appendix IV). 
Well-being encompassed health and satisfaction with life, but did not exclude the co-existence of illness or disability. A frequent comment was "pretty good for my age”, acknowledging that bodies wear out. Attention was paid to self-care in maintaining good health, by exercise, diet, social engagement and maintaining an active interests.

There was a distinct focus on usefulness in relation to the women's perception of being valued, which reinforced the feeling of belonging within both the family and formal or informal groups represented by churches, organisations, neighbours and friends. This was commonly presented in the expression "it makes me feel good to still be of some use”, but underlying this was a sense of loss should this no longer be possible.

There was strong evidence of 'generativity' rather than 'disengagement' as a mode of living in later life. The mainly positive attitudes of these women rose above the negativities apparent in comments on disability, low income, social attitudes, family problems and the conflicts and injustices of the world.

For the most part the women in this study were experiencing 'positive ageing' within their communities, but some were at the margins of their present resources. They were resisting the possibility of dependence with determined effort and were concerned not with death, but with impairment. I found in the words of Shirley Meredeen, whose poem prefaces this study, an apt summary of many of the participants' attitudes.

I don't fear death itself, but gradual disintegration, pain and the ignominy of dependence. The prospect of a limited income worries me less than the loss of health. Having been brought up in the 1930's with memories of my parents saving everything possible for recycling (even though such terminology was not then in our awareness), I have a lived memory of making do on a pittance.

Meredeen (1993, p.190).

The 'making do' that Shirley Meredeen refers to was a constant feature in my discussions and interviews with older women. They frequently stated that they perceived younger women as having lost this skill. Socks were no longer darned, collars turned, sheets recycled sides to centres; preserving food or growing it had declined, even knitting (except when fashionable) was infrequent among the 
young, odds and ends were no longer saved for a rainy day. This being said, the women laughed and admitted that they were thankful for the ready-mades and disposables of our consumer society.

\subsection{Avenues for future research}

- The women interviewed in this project were living in the greater Wellington area. There is a need to record the views of those living in rural areas where facilities for support and access to medical facilities may be more limited. Women responding to the questionnaire from rural localities expressed a willingness to be interviewed on the quality of their lives as older women.

- The majority of older women in this study owned their own home freehold and this gave them a sense of security and a lower expenditure on accommodation. The situation of older women living in rental accommodation or boarding houses may be significantly different.

- There is a need to identify the extent and nature of the barriers which increase the social isolation for some women, especially those in the older age group living in the community, without family, and who have outlived their circle of friends. This will require an investigation of existing support services to determine their ease of access and suitability.

- The current level of student indebtedness said to be over five billion, may have consequences for home ownership in the future. Not all students will be able to access highly paid careers allowing ease of repayment of student loans, particularly women who work at the lower paid end of the employment market and take time out for raising families. The future cohort of older women may or may not have better access to well-paid employment than the current cohort of older women. Research is required on the effect of student loans on future home ownership for women, who have traditionally been disadvantaged in access to mortgage funds. 
- The "Welcome to your Retirement “ campaign of public information and education developed by the Office of the Retirement Commissioner is admirable in its intent and advice, for those who wish to attain the 'Retirement Dream', but for many women it is impracticable as their actual capacity to save is limited. Employment for women is still mainly in the lower paid sector and parenting duties, especially as a parent alone and as caregivers to others, are not conducive to saving. The costs of education and health care have risen in the last quarter century and have the potential to reduce disposable income, which may be available for saving. While New Zealand Superannuation is equal for men and women as retirement income, it is does not compensate for the lesser accumulation of assets experienced by women in comparison with men and the fact that these resources must last longer because of her greater longevity. Although some women who are widowed may continue to be well provided for by their spouse, with the changes in traditional family formation and an increase in family breakdown, a woman can no longer rely on a male partner for the provision of retirement income. Research is necessary on ways in which this deficit might be ameliorated.

- The recent increases in premiums for medical insurance, the projected removal of the community services card and a perceived rationing of health services for the elderly, have impacted heavily on the older person at a time when they are most in need of good healthcare. Research is needed on the effects this anxiety over healthcare may have on the quality of life of older women who already suffer from many chronic disabling conditions.

- Ageism as a social attitude was experienced by some of the women, either by being made invisible, ignored and discounted or by being patronised and treated as incompetent. Researchers could well direct their attention to determining how extensive such behaviours are and their provenance. The women themselves were not sure whether this was an extension of sexism to age or a reaction to age itself.

- The work of Jocelyn Armstrong on the role of grandmother has shown the different significance it has for New Zealanders of Maori, Chinese and 
Central European ethnicity. This suggests the need for further research on the influence of ethnicity in the perceived roles of older women from other cultures in New Zealand, including those of more recent immigrants.

- MacGregor and Gray’s (2001) research on mature job seekers has highlighted employers' lack of enthusiasm in hiring older persons and this raises a number of policy issues including the ways in which such a pool of skill could best be utilised. One suggestion has been that of exploring wage differentials, wage subsidies and tax credits with employers and trade unions. This solution needs research as it has a great potential for devaluing the skills of the elderly. 


\title{
Epilogue
}

\author{
After Sixty \\ Everyone says the world is flat and infinite \\ on the other side of sixty \\ That I will fall clear off the edge \\ into darkness \\ That no one will hear from me again \\ or want to \\ But I am ready for the knife slicing into the \\ future \\ for the quiet that explodes inside \\ to join forces with the strong old woman \\ to throw everything away and begin again...... \\ ...There are places on this planet \\ where women past the menopause \\ put on the tribal robes \\ smoke pipes of wisdom \\ ...fly
}

Marilyn Zuckerman (1988) 


\section{BIBLIOGRAPHY}

Age Concern, 1997, Elder Abuse Services: Pilot Programme Evaluation, Age Concern New Zealand, Wellington.

Aiken, Lewis R., 1995, Aging: An Introduction to Gerontology, Sage Publications: California.

Alice, Lynne, 1999, Power, Experience and Process in Feminist Research, in Social Science Research in New Zealand, Many Paths to Understanding, Davidson, Carl and Tolich, Martin, Pearson Education: Auckland, pp. 62-68.

Anderson, Kathryn, and Jack, Dana, 1991, Learning to Listen: Interview Techniques and Analyses, in Women's Words: The Feminist Practice of Oral History, Gluck, S. B. and Patai, D. (eds.), Routledge: London, pp. 11-26.

Arber, Sara, and Ginn, Jay, 1991, Gender and Later Life: A Sociological Analysis of Resources and Constraint, Sage Publications: London.

Arber, S. and Ginn, J., 1995, Connecting Gender and Ageing: A New Beginning, in Connecting Gender and Ageing, A Sociological Approach, Arber, Sara and Ginn, Jay, (eds.), Open University Press: Buckingham, Philadelphia, pp. 173-178.

Arber, S. and Ginn, J., 1998, Health and Illness in Later Life, in Sociological Perspectives on Health, Illness and Health Care, David Field and Steve Taylor (eds.), Malden: Oxford, UK. pp. 134-152.

Arber, S. and Ginn, J., 1999, Women's Pension and Poverty: Prospects and Options for Change, in New Agendas for Women, Sylvia Walby (ed.), St Martin's Press: New York, pp. 75-97.

Ardelt, Monika, 1997, Wisdom and Satisfaction in Old Age, in Journal of Gerontology, vol. 52 b, No. 1, pp. 15-27.

Armstrong, M. Jocelyn, 1996, More of Living: New Zealand Women's Perspectives on Ageing and Old Age, in New Zealand Studies, July 1996; vol. 6 No. 2, pp. 16-20.

Armstrong, M. Jocelyn, 1999 'Ageing into the Twenty-first Century: Perspectives on Women's Experience of Social Aging,' keynote address, Wellington Gerontology Conference 1999, Senior Citizen’s Unit of the Social Policy Agency: Wellington.

Atcherly, R .C., 1971, The Social Forces in Later Life, Wadsworth: Belmont, C.A.

Baltes, P. and Baltes, M., 1990, Psychological Perspectives on Successful Aging: The Model of Selective Optimization with Compensation, in Baltes, P. and Baltes, M. (eds.), Successful Aging: Perspectives from the Behavioral Sciences. Cambridge University Press: Cambridge, U K. pp.1-27.

Baltes, P and Graf, P., 1996, Psychological Aspects of Aging: Facts and Frontiers, in The Lifespan Development of Individuals: Behavioural, Neurobiological and Psychosocial Perspectives, A Synthesis, David Magnusson (ed.), Cambridge University Press, pp. 427-460. 
Baltes, Paul and Mayer, Karl, (eds.) 1997, Introduction in The Berlin Aging Study, Aging from 70 to 100. Cambridge University Press, pp. 1-8.

Bandura, Albert, 1997, Self-efficacy: The Exercise of Control, W. H. Freeman: New York.

Barker, R, Caughey F. and Guthrie, M., (eds.) 1982, Ageing New Zealanders, A Report to the World Assembly on Ageing, Department of Health: Wellington, New Zealand.

Barrett, Michele, 1992, Words and Things: Materialism and Method in Contemporary Feminist Analysis, in Destabilizing Theory: Contemporary Feminist Debates, Polity Press: Cambridge, pp. 1-9.

Beaglehole, Ann, 1993, Benefiting Women: Income Support for Women 1893-1993. A Women’s Suffrage Centenary Project: Social Policy Agency, Wellington.

Beauvoir, Simone de, 1978 [1970], The Coming of Age, [La Vieillesse] trans. Patrick O’Brien, Warner: New York.

Becker, Gary, 1976, The Economic Approach to Human Behaviour, University of Chicago Press.

Becker, Gary, 1985, 'The Economic Analysis of the Family', Geary Lecture for The Economic and Social Institute, Ireland.

Bell, Marilyn J. 1986, (ed.), Women as Elders: The Feminist Politics of Aging, Harrington Park: New York.

Bengston, Vern L, Burgess, Elisabeth O., and Parrott, Tonya M., 1997, Theory, Explanation, and a Third Generation of Theoretical Development in Social Gerontology in Journal of Gerontology: Social Sciences, vol. 52 B, No.2 pp. S72 S88.

Benton, Paulette, 1997, Feminist Ethnography: On the Politics of Doing Research on Women, in Women's Studies Journal, 13, (1), pp. 105-122.

Bergmann, Barbara, 1991, The Economic Risks of Being a Housewife, in American Economic Review, Papers and Proceedings, May, 1981 pp. 81-85.

Bernard, Miriam, 2000, Promoting Health in Old Age: Critical Issues in Self Health Care, Open University Press: Buckingham, Philadelphia.

Bond, John and Coleman, Peter (eds.), 1990, Ageing in Society, Sage Publications: London.

Bonita, Ruth, 1993, Older Women a Growing Force, in New Zealand's Ageing Society, the Implications, Peggy Koopman-Boyden (ed.), Daphne Brasell Associates Press: Wellington, pp. 189-212.

Bonita, Ruth, 1996, Women, Aging and Health: Achieving Health Across the Life-span, World Health Organisation: Geneva. 
Booth, Tony, Grimmond David, and Stroombergen, Adolf, Infometrics Ltd., 2000, "Determinants of Saving Behaviour", a research report for the Office of the Retirement Commissioner, Wellington, New Zealand.

Borland, Katherine, 1991, “That's Not What I Said”: Interpretive Conflict in Oral Narrative Research, in Women's Words: The Feminist Practice of Oral History, Gluck, Sherna Berger, and Patai, Daphne, 1991, (eds.), Routledge: London, pp. 6375.

Bould, Sally and Longino H., 1997, Women Survivors: The Oldest Old in Handbook on Women and Aging, Jean Coyle (ed.), Greenwood Press: Westport, Connecticut, pp. 210-222.

Bould, Sally, 1997, Women as Caregivers for the Elderly, in Handbook on Women and Aging, Jean Coyle (ed.), Greenwood Press: Westport, Connecticut, pp. 430-442.

Bowles, Gloria, 1983, Is Women's Studies an Academic Discipline? in Theories of Women's Studies, Gloria Bowles and Renate Duelli Klein (eds.), Routledge: London, pp. 32-45.

Bowles Gloria and Klein Renate Duelli, 1983, (eds.), Introduction: in Theories of Women's Studies, Routledge: London, pp. 1-26.

Bradsher, Julia, 1997, Older Women and Widowhood, in Handbook on Women and Aging, Jean Coyle (ed.), Greenwood Press, Westport: Connecticut, pp. 418-429.

Braidotti, Rosi, 1994, Women, the Environment and Sustainable Development, International Research and Training Institute for the Advancement of Women, London. Atlantic: Highland, New Jersey.

Brents, B., 1993, Aging, Healthcare and Public Policy, in Critical Perspectives in Sociology, Berberoglu (ed.), Kendall and Hunt: Duburque, I A. pp. 151-174.

Briar, Celia, Munford, Robyn, Nash, Mary, 1992, Super Woman, Where are You? Social Policy and Women's Experience, Dunmore Press: Palmerston North.

Briar, Celia, Women, Economic Dependence and Social Policy, in Super Woman Where are You? Social Policy and Women's Experience, Dunmore Press: Palmerston North.

Brown, Victoria Bissell, 1998, Biography in the Mother Tongue, in Journal of Women's History, 10 (2) pp. 198-206.

Browne, Colette V. 1998, Women, Feminism and Aging, Springer Publishing Company: New York.

Bunkle, Phillida, 1980, The Origins of the Women's Movement in New Zealand: The Women's Christian Temperance Union 1885-1895, in Women in New Zealand Society, Phillida Bunkle and Beryl Hughes, (eds.) Allen and Unwin: Sydney, pp. 5276.

Bunkle, Phillida, 1992, Becoming Knowers: Feminism, Science, and Medicine in Feminist Voices, Women's Studies Texts for Aotearoa / New Zealand, Oxford University Press: Auckland, pp. 59-73. 
Bury, M., 1988, Arguments about Ageing, Long life and its Consequences, in The Ageing Population: Burden or Challenge? Wells, N. and Freer, C. (eds.), Macmillan: Basingstoke.

Bury, M., 1995, Ageing, Gender and Sociological Theory in Connecting Gender and Ageing: A Sociological Approach, Arber, S. and Ginn, J. (eds.), Open University Press: Buckingham.

Butler, Judith, 1990, Feminism and the Subversion of Identity, in Gender Trouble, Routledge: New York and London, pp. 1-25.

Butler, Robert, 1975, Why Survive? Growing Old in America, Harper \& Row: New York.

Bywater, Marian, 1989, Income Security for older women, Ministry of Women's Affairs, Wellington, pp. 2-10.

Carstensen, L. L., 1992, Social and Emotional Patterns in Adulthood: Support for Socioemotional Selectivity Theory, in Psychology and Aging, vol. 7, pp.331-338.

Bytheway, B., 1982, Fries and Crapo Review Symposium: Ageing and the Rectangular Survival Curve, in Ageing Society, vol. 2 no. 2: pp. 389-1.

Calasanti, T. M., 1993, Introduction, in A Socialist-Feminist Approach to Aging in Journal of Aging Studies, (Special Issue), Calasanti, T. and Hendricks, J. (eds.), No. 7, pp. 107-109.

Calasanti, T. M. and Zajicek A.M., 1993, A Socialist-Feminist Approach to Aging: Embracing Diversity, in Journal of Aging Studies Special Issue), No. 7, pp.117-131.

Callister, P. and Rose, D. 2000, Implications of Labour Market Change for Retirement Income Policy, a paper prepared for the Ministry of Social Policy, Wellington.

Campell, John, 1993, Physiology and Health Status of the Elderly in New Zealand's Ageing Society: The Implications, Peggy Koopman-Boyden (ed.), Daphne Brasell Associates Press. pp. 55-75.

Cave, June, 1998, The Perceived Value of Women's Unpaid Work as Experienced by Eight New Zealand Women born between 1922-194, Master's Thesis, Massey University: Palmerston North.

Chaney, David, 1995, Creating Memories: Some Images of Ageing in Mass Tourism, in Images of Ageing: Cultural Representations of Later Life, Featherston, M. and Wernick, A. (eds.), Routledge: London, pp. 227-244.

Cheng, Shu-ju Ada, 2001,The Locational Politics of Power, Knowledge and Identities, in Currie, Gail and Rothenburg, Celia, 2001, Feminist (Re)visions of the Subject: Landscapes, Ethnoscapes and Theoryscapes, Lexington Books: Lanham.

Chrisler, Joan C. and Laurie Ghiz, 1993, Body Image Issues of Older Women, in Faces of Women and Ageing, Nancy Davis, Ellen Cole and Esther Rothblum (eds.), Harrington Park Press: New York, pp. 67-75. 
Clayton, V. P. and Birren, J.E., 1980, The Development of Wisdom across the Lifespan: a Reexamination of an Ancient Topic, in P. B. Baltes and O. G. Brim Jr. (eds.), Lifespan Development and Behaviour Academic Press: New York.vol. 3, pp. 103-135.

Code, Lorraine, 1991, What Can She Know? Feminist Theory and the Construction of Knowledge, Cornell University Press: New York.

Code, Lorraine, 1993, Taking Subjectivity into Account, in Feminist Epistemologies, Linda Alcoff and Elizabeth Potter (eds.), Routledge, Chapman and Hall: New York.

Cole, Thomas R. and Holstein Martha 1995, Ethics and Aging, in Handbook of Aging and Social Sciences, Robert H. Binstock and Linda K. George, (eds.), Academic Press: San Diego, California.

Cole, Thomas, 1986, The 'Enlightened' View of Aging, Victorian Morality in a New Key, in What does it Mean to Grow Old? Reflections from the Humanities, Thomas R. Cole and Sally A. Gadow (eds.), Duke University Press: Durham, NC, pp. 480497.

Cook, Diana and Briggs, Phil, 1997, Gender Wage Gap: Scenarios of the Gender Wage Gap, a report for the Ministry of Women's Affairs, Wellington.

Cook, Judith A. and Mary Fonow, 1990, Knowledge and Women's Interests: Issues of Epistemology and Methodology in Feminist Sociological Research, in Feminist Research Methods: Exemplary Readings in the Social Sciences, Neilson, Joyce McCarl (ed.), Westview Press: Boulder, pp. 69-93.

Cooke, Jackie, King, Anthony and Peacock, Graeme, 1999, Women's Economic Status Equal Worth-Final Report, Output 4, a report prepared for the Office of Women's Affairs, Canberra.

Copper, Baba, 1988, Over the Hill, Reflections on Ageism between Women, The Crossing Press: Freedom, California.

Cowgill, D. O., 1974, Aging and Modernization: A Revision of the Theory in J.F. Gubrium, (ed.), Late Life, Charles C. Thomas: Springfield, Illinois, pp. 123-146.

Cooper, Annabel and Molloy, Maureen, 1997, Poverty, Dependence and 'Women': Reading Autobiography and Social Policy from 1930's New Zealand, in Gender and History, vol. 9:1, pp. 36-59.

Cox, Shelagh, 1987, Public and Private Worlds; Women in Contemporary New Zealand, Allen and Unwin, Port Nicholson Press: Wellington.

Coyle, Jean, M., 1997, (ed.), Handbook on Women and Ageing, Greenwood Press: Westport, CT.

Craig, Alison, 2000, ' Needs of the Senior Citizens in the Northern Suburbs', Report for Wesley Care, Wellington.

Cribb, Joyce, 1995, Maintaining Identity through Reminiscence, Oral History Association of Australia Journal, no. 17, pp. 36-39. 
Cumming E. and Henry W.E., 1961, Growing Old: The Process of Disengagement, Basic Books: New York.

Currie, Gail and Rothenburg, Celia, 2001, Feminist (Re)visions of the Subject: Landscapes, Ethnoscapes and Theoryscapes, Lexington Books: Lanham.

Curthoys, Ann, 1986, The Sexual Division of Labour: Theoretical Arguments, in Australian Women: New Feminist Perspectives, Norma Grieve \& Ailsa Burns (eds.), Allen and Unwin: Sydney, pp. 319-339.

Curthoys, Ann, 1988, For and Against Feminism: A Personal Journey into Feminist Theory and History, Allen and Unwin: Sydney.

Dailey, Nancy, 1998, When Baby Boom Women Retire, Preager Publishers: Westport, Connecticut.

Dalziel, Raewyn, 1986, The Colonial Helpmeet, in Women in History, Brookes, Barbara, Macdonald, Charlotte and Tennant, Margaret, (eds.) Allen and Unwin: Wellington, pp.55-68.

Dalziel, Raewyn, 1993, Political Organisations, in Women Together: A History of Women's Organisations in New Zealand, Else, Anne, (ed.), Historical Branch, Department of Internal Affairs, Daphne Brasell Associates Press: Wellington.

Dann, Christine, 1985, Up from Under: Women and Liberation in New Zealand, Allen and Unwin: Wellington.

Dannefer, W. D., 1994, Reciprocal Cooptation: Some Reflections on the Relationship of Critical Theory and Social Gerontology, revised version of a paper presented at the session 'Explorations in Critical Gerontology', International Sociological Association, Bielefeld, Germany, July.

Davey, Judith, 1993, Asset Rich and Income Poor: Home Equity Conversion as an Option for Older Women, in Women's Studies Journal, vol. 9, no.2, pp. 148-149.

Davey, Judith, 1998, Tracking Social Change: From Birth to Death $1 \mathrm{~V}$, Institute of Policy Studies, Victoria University of Wellington: Wellington.

Davidson, Carl and Tolich, Martin, (eds.) 1999, Social Science Research in New Zealand, Many Paths to Understanding: Longman, Pearson Publication, New Zealand.

Davis, Peter, 1982, Health and Healthcare, in New Zealand Sociological Perspectives Spoonley, Paul, Pearson, David and Shirley Ian, (eds.), Dunmore Press: Palmerston North, pp. 217-238.

Department of Social Welfare, 1988, Income Security for the Elderly, a discussion paper, Wellington.

Douglas, Ian, 1983, The Prejudice of Ageism, address to the annual meeting of the Presbyterian Social Service Association (Otago), Dunedin, in New Zealand in Change:Policies and Attitudes, New Zealand Planning Council, 1984: Wellington. 
Dowd, J. J., 1975, Aging as Exchange: A Preface to Theory, in Journal of Gerontology, 30, pp. 584-594.

Dowd, J.J., 1987, The Reification of Age: Age Stratification Theory and the Passing of the Autonomous Subject, in Journal of Aging Studies, 1: 4, 317-335.

Dowling, Winifred, 1997, Voluntarism among Women, in Handbook on Women and Aging, Jean Coyle (ed.), Greenwood Press: Westport, Connecticut, pp. 242-252.

Duncan, Peggy, Kerekere, Elizabeth and Malaulau, Dinah, 1996, Women on Low Incomes: An Initial Study Examining the Situation of Women Living on a Low Income, New Zealand Council of Christian Social Services and the Young Women's Christian Association of Aotearoa-New Zealand.

Dunstall, Graeme, 1981, The Social Patterns, in The Oxford History of New Zealand, W. H. Oliver (ed.), Clarendon Press: Oxford, pp. 397-429.

Du Plessis, R., 1992, (ed.), Feminist Voices: Women's Studies Texts for Aotearoa/New Zealand, Oxford University Press: Auckland.

Du Plessis, R and Alice, L., 1998, Feminist Thought in Aotearoa/NewZealand: Connections and Differences, Oxford University Press: Auckland.

Dwyer, Maire, Gray, Alison, Renwick, Margery, 2000, Factors Affecting The Ability of Older People to Live Independently, a report for the International Year of Older Persons, Ministry of Social Policy: Wellington.

Dwyer, M and Gray, A, 1999, Maintaining Independence in Old Age: Policy Challenges, in Social Policy Journal of New Zealand, No.13, December 1999, pp. 83 -94.

Easterlin, Richard A., 1995, Economic and Social Implications of Demographic Patterns, in Handbook of Aging and the Social Sciences. Robert H. Binstock and Linda K. George (eds.), Academic Press: San Diego, California, pp. 73-93.

Eisenstein, Hester, 1984, Contemporary Feminist Thought, Unwin: London.

Elder, Glen, H. Jnr., 1975, Children of the Great Depression, University of Chicago Press: Chicago.

Elder, Glen, H., Jnr., 1982, Historical Experiences in the Later Years, in Ageing and Life Course Transitions an Interdiciplinary Perspective, Tavistock Publication: London.

Else, Anne, 1993, (ed.), Women Together: A History of Women's Organisations in New Zealand, Historical Branch, Department of Internal Affairs, Daphne Brasell Associates Press: Wellington.

Else, Anne, 1996, False Economy: New Zealanders Face the Conflict Between Paid and Unpaid Work, Tandem Press: Auckland.

Else, Ann and St John, Susan, 1998, A Super Future: The Price of Growing Older in New Zealand, Tandem Press: Auckland.

Erikson, E., 1950, Childhood and Society, $2^{\text {nd }}$ edn., 1963, Norton, New York. 
Erikson, E., Erikson, J. and Kivnick, H. Q., 1986, Vital Involvement in Old Age, Norton: New York.

Estes, Carroll, L, 1979, The Aging Enterprise, Jossey-Bas: San Francisco.

Estes, C. L., Gerard, L., Zones, J.S. and Swan, J.H., 1984, Political Economy, Health and Aging, Little-Brown: Boston.

Estes, Carroll, Linkins, Karen W. and Binney, Elizabeth A., 1995, The Political Economy of Aging, in Handbook of Aging and Social Science, Robert H. Binstock and Linda K. George, Academic Press: San Diego, California, pp. 346-361.

Evans, Mary, 1983, In Praise of Women's Theory: The Case for Women's Studies, in Theories of Women's Studies, Gloria Bowles and Renate Klein (eds.) Routledge: London, pp. 219-228.

Evans, Donald, 1999, Ethical Issues for Older People and Their Carers, Gerontology Conference Proceedings, 1999, Senior Citizen's Unit of the Social Policy Agency: Wellington.

Fairhurst, Eileen, 1998, Recalling Life: Analytical Issues in the Use of 'Memories', in Critical Approaches to Ageing and Later Life, Anne Jamieson, Sarah Harper and Christine Victor, Open University Press: Buckingham, Philadelphia, pp. 63-73.

Featherston, Mike, 1995, Post-Bodies, Aging and Virtual Reality, in Images of Ageing: Cultural Representations of Later Life, Featherston, M. and Wernick, A. (eds.), Routledge: London, pp. 227-244.

Featherstone, M. and Hepworth, M., 1995, Images of Positive Aging, in Images of Aging: Cultural Representations of Later Life, Mike Featherstone and Andrew Wernick (eds.), Routledge: London, pp. 29-47.

Featherstone, M. and Hepworth, M., 1998, Ageing, the Life Course and the Sociology of Embodiment, in Modernity, Medicine and Health: Medical Sociology Towards 2000, Scambler G. and Higgs P., Routledge: London, pp. 147-175.

Fergusson, David, Hong, Bev, Horwood, John, Jensen, John and Travers, Peter, 2001, Living Standards of Older New Zealanders A Technical Account, Ministry of Social Policy: Wellington.

Fleming, Robin and Spellerberg, Anne, 1999, Using Time Use Data, Statistics New Zealand.

Flax, Jane, 1987, Postmodernism and Gender Relations in Feminist Theory, in Feminism/ Postmodernism, 1990, Linda Nicholson, (ed.), Routledge: New York, pp. 39-62.

Flax, Jane, 1992, Women Do Theory, in Women and Value: Readings in Recent Feminist Philosophy, Marilyn Pearsall (ed.), Wadsworth Publishing: Belmont, California.

Flax, Jane, 1993, Disputed Subjects: Essays on Psychoanalysis, Politics, and Philosophy, Routledge: New York. 
Flett, R., Kazantzis, N., Long, N., Millar, M., and MacDonald, C., Health Care Needs for Older Adults, Social Policy Journal of New Zealand, No. 13, December 1999, pp. $115-135$.

Ford, Janet, and Sinclair, Ruth, 1987, Sixty Years On: Women Talk About Age, The Women's Press: London.

Friedan, Betty, 1993, The Fountain of Age, Simon and Schuster: New York.

Fries, J.E., 1980, Ageing, Natural Death and the Compression of Morbidity, in New England Journal of Medicine, 303, 3, pp. 130-135.

Fry, Christine, 1995, Age, Aging and Culture, in Handbook of Aging and Social Science, Robert H. Binstock and Linda K. George, Academic Press: San Diego, California, pp. 117-136.

Gannon, Linda, 1999, Women and Ageing: Transcending the Myths, Routledge: London.

Gardner, Ruth, 2000, 'The Value of Volunteering', an unpublished paper presented at the S.R.O.W. workshop on Value and Meaning Outside the Paid Workforce Christchurch.

Gee, Susan and Baillie, John, 1999, Happily Ever After? An Exploration of Retirement Expectations, Educational Gerontology, 25, pp. 109-128.

Gee, S., Ng, S.H., Weatherall, A., Liu, J, Loong, C. and Higgins T. R., 2002, Saving Ourselves: Gender Issues in Making Provision for One's Own Retirement, in Australian Journal of Ageing, Vol. 21, No 1 pp. 30-35.

George, Linda K., 1995, Social Factors and Illness, in Handbook of Aging and Social Sciences, Robert H. Binstock and Linda George, (eds.), Academic Press: San Diego, California, pp. 229-252.

Gerike, Ann, E., 1990, On Grey Hair and Oppressed Brains, in Journal of Women and Ageing, Vol., 1, nos. 1-3, pp.35-46.

Gibson, Diane, 1996, Broken Down by Age and Gender: 'The Problem of Old Women' Redefined in Sociology of Aging: International Perspectives, Minichello, V., Chappell, N., Kendig, H. and Walker, A. (eds.), International Sociological Association for Research on Aging, pp. 16-30.

Gibson, Diane, 1998, Aged Care: Old Policies, New Problems, Cambridge University Press: Melbourne, Australia.

Giddens, Anthony, 1989, Sociology, 1992 edition, Polity Press: Cambridge.

Gilligan, Carol, 1982, In a Different Voice, Harvard University Press: Cambridge, MA.

Gilling, Ana and Gilling Marg, 1996, Older People in New Zealand: An Annotated Bibliography of Research on Older People in New Zealand, 1986-1996, pp. 9-12. Age Concern New Zealand: Wellington.

Gilling, Marg, (ed.), 2000, Research and the Art of Juggling, Massey University: Wellington. 
Ginn, Jay and Arber Sara, 1995, 'Only Connect': Gender Relations and Ageing, in Connecting Gender and Ageing. A Sociological Approach, Open University Press: Buckingham, pp.1-14.

Ginn, J. and Arber, S. 1993, Ageing and Cultural Stereotypes of Older Women, in Ageing and Later Life, Johnson, J. and Slater, R. (eds.), Sage Publications: London.

Gluck, Sherna Berger, and Patai, Daphne, 1991, (eds.), Introduction in Women's Words: The Feminist Practice of Oral History, Routledge: London, pp. 1-6.

Gluckman, Ann and Tagg, Mary, 1995, Ageing is Attitude, Tandem Press: Auckland.

Good, Raewyn, 1988, Transport: Access or Isolation? in The Royal Commission on Social Policy vol. 1V, Social Perspectives, Government Printer: Wellington, pp. 386453.,

Greer, Germaine, 1991, The Change: Women and Menopause, Fawcett: New York.

Good, Raewyn, 1999, The Qualitative Researcher-- Scientist, Artist, Artisan or Up Market Voyeur? in Research the Art of Juggling, Gilling, Marg (ed.), Massey University: Wellington, pp. 85-96.

Gordon, Elizabeth and Morton, Missy, 2001, Women-Well-educated and Poorly Paid: Gender Pay Discrimination in the Public Service, Parliament, Government: New Zealand.

Graham, Jeanine, 1981, Settler Society, in The Oxford History of New Zealand, W. H. Oliver (ed.), Clarendon Press: Oxford, pp.112-139.

Griffin, Susan, 1983, The Way of All Ideology in Feminist Theory, A Critique of Ideology, Keohane, N. Rosaldo, M. and Gelpi, B. University of Chicago Press: Chicago, pp. 273-292.

Grosz, Elizabeth, 1986, What is Feminist Theory? In Feminist Challenges: Social and Political Theory, Pateman, Carol and Gross, Elizabeth (eds.), Allen and Unwin: Sydney, pp.190-204.

Gubrium, J.F., 1973, The Myth of the Golden Years: A Socio-environmental Theory of Aging, Charles Thomas: Springfield, IL

Gubrium, J.F., 1993, Voice and Context in a New Gerontology, in Voices and Visions of Aging: Toward a Critical Gerontology, Cole T.R., Achenbaum W. A., Jakobi P.L. and Kastenbaum R. (eds.) Springer: New York.

Hall, Lesley, 1999, Confidentially Speaking: Feminist Ethics in an Interview Situation. Paper presented at the Women's Studies Association (NZ) Conference, November 1999, Wellington.

Hamilton City Council, 1999, Older Person’s Policy, 1999-2004, Celebrating Life.

Harding, Sandra, 1986, Is There a Feminist Method? Introduction in Feminism and Methodology, Indiana University Press: Bloomington, pp.1-13. 
Harding, Sandra, 1986, Is There a Feminist Method? reprinted in Feminisms, Sandra Kemp and Judith Squires 1997 (eds.), Oxford University Press: New York, pp.160170.

Harding, Sandra, 1993, Rethinking Standpoint Epistemology: "What Is Strong Objectivity?” in Feminist Epistemologies, Linda Alcoff and Elizabeth Potter, (eds.), Routledge, Chapman and Hall: New York.

Harding, Sandra, 1995, Can Feminist Thought Make Economics More Objective? in Feminist Economics, 1, (1), 1995, pp. 182-210.

Harding, Sandra, 1997, Comment on Hekman's Truth and Method: Feminist Standpoint Theory Revisited, in Signs, Winter, Vol. 22, No. 2 pp. 382-391.

Hareven, Tamara, 1982, The Life Course and Aging in Historical Perspective, in Ageing and Life Course Transitions: An Interdisciplinary Perspective, Tavistock Publications: London.

Hareven, Tamara, 1995, Changing Images of Aging and the Social Construction of the Life Course, in Images of Aging: Cultural Representations of Later Life, Featherston, M. and Wernick, A. (eds.), Routledge: London, pp. 119-134.

Harper Sarah, 1998, Constructing Later Life / Constructing the Body: Some Thoughts from Feminist Theory, in Critical Approaches to Ageing and Later Life, Jamieson, Anne, Harper, Sarah and Victor, Christine, Open University Press Buckingham: Philadelphia.

Harper, Barbara, 1980, Petticoat Pioneers, A. H. \& A. W. Reed: Wellington.

Harraway, Donna, A Manifesto for Cyborgs: Science, Technology and Socialist Feminism in the 1980's, in Feminism/Postmodernism, Linda Nicholson, (ed.) Routledge: New York, pp.190-233.

Hasan, Miriam, 1998, The Baby Boomers' Generation: Mid-life Experiences and Perceptions of Being Older. Thesis, M. A. Applied, Social Work, Victoria University of Wellington.

Hartsock, Nancy, 1983, The Feminist Standpoint: Developing the Ground for a Specifically Feminist Historical Materialism, in Discovering Reality: Feminist Perspectives on Epistemology, Metaphysics, Methodology and the Philosophy of Science, Harding and Hintikka, (eds.), Reidel: Dortrecht, pp. 283-310.

Hartsock, Nancy, 1997, Comment on Hekman's Truth and Method: Feminist Standpoint Theory Revisited, in Signs, Winter, Vol. 22, No. 2 pp. 367-374.

Havighurst, R. J. and Albrecht, R., 1953, Older People, Longmans Green: New York.

Havighurst, R. J., Neugarten, B. L. and Tobin, S. S., 1968, Disengagement and Patterns of Aging, in B.L. Neugarten, (ed.), Middle Age and Ageing, University of Chicago Press: Chicago, pp. 161-172.

Haseltine, Florence, P. and Jacobson, Beverly, 1997, (eds.), Women's Health Research: A Medical and Policy Primer, Society for the Advancement of Women's Health Research, American Psychiatric Press: Washington, D C. 
Hazan, Haim, 1980, The Limbo People, Routledge and Kegan Paul: London.

Hazan, Haim, 1994, Old Age: Constructions and Deconstructions, Cambridge University Press: Cambridge.

Healey, Shevy, 1993, Confronting Ageism: A MUST for mental Health, in Faces of Women and Aging, Nancy Davis, Ellen Cole and Esther Rothblum (eds.), Harrington Park Press, New York, pp. 41-54.

Hekman, Susan, 1997, Truth and Method: Feminist Standpoint Theory Revisited, in Signs, Winter, Vol. 22 No. 2 pp. 341-365.

Hendricks, Jon, 1995, Qualitative Research: Contributions and Advances, in Handbook of Aging and the Social Sciences, $4^{\text {th }}$ edition, Robert H. Binstock and Linda K. George (eds.), Academic Press: San Diego, California, pp. 52-72.

Hockey, Jenny and James, Allison, 1995, Back to Our Futures, Imaging Second Childhood, in Images of Aging: Cultural Representations of Later Life, Mike Featherstone and Andrew Wernick (eds.), Routledge: London, pp. 135-148.

Hooyman, Nancy R., 1999, Research on Older Women: Where is Feminism? in The Gerontologist, Vol. 39, No. 1, pp. 115-118.

Howden-Chapman, P., Signal, L. and Crane J., 1999, Housing and Health in Older People: Ageing in Place, in Social Policy Journal of New Zealand, 13, December 1999, pp. 14-30.

Hunt, Robyn, 1988 People with Disabilities in The Report of the Commission on Social Policy: Vol. 4, Social Perspectives. Government Printer: Wellington, pp. 764-804.

Hurwich, Celia, 1982, Unpublished Master's Thesis on Older Women, Antioch University: San Fransico West.

Hyman, Prue, 1992, Income Adequacy for Older Women: Why Government and Private Provision are Both Failing and Some Possible Improvements, Women's Studies Journal, Vol.8 No.1, March 199, pp. 95-111.

Hyman, Prue, 1994, Women and Economics, A New Zealand Feminist Perspective, Bridget Williams Books: Wellington.

Hyman, Prue, 1997, Gender Inequality in Paid Employment, in The Political Economy of New Zealand, Chris Rudd and Brian Roper (eds.), Oxford University Press: Auckland, pp. 141-159.

Hyman, Prue, 1998 Rethinking Feminist Economics, Chapter 2 in Du Plessis, Rosemary and Alice, Lynne (eds.), Feminist Thought in Aotearoa / New Zealand: Differences and Connections, Oxford University Press: Auckland.

Ironmonger, Duncan, 1996, Counting Outputs, Capital Inputs and Caring Labour: Estimating Gross Household Product, in Feminist Economics Vol. 2 No. 3, pp. 3764.

Jackson, Stevie et al., 1993, Introduction in Readings in Feminist Theory, New York University Press: Albany, pp. 3-33. 
Jacobs, Ruth Harriet, 1979, Life After Youth, Female 40 What Next? Beacon Press: Boston.

James, Joy, 1993, Experience, Reflection, Judgement and Action: Reprinted in Radically Speaking, 1996, Renate Klein (ed.) Spinifex Publications: Melbourne, pp. 37-44.

Jamieson, A, Harper, S. and Victor C (eds.) 1998, Critical Approaches to Ageing and Later Life, Open University Press: Buckingham, Philadelphia.

Jamieson, Anne and Victor, Christina, 1998, Theory and Concepts in Social Gerontology, in Critical Approaches to Ageing and Later Life, Open University Press: Buckingham, Philadelphia, pp. 175-187.

Jayaratne, Toby Epstein, 1983, The Value of Quantitative Methodology for Feminist Research, in Theories of Women's Studies, Gloria Bowles and Renate Klein, (eds.), Routledge: London and New York, pp. 140-161.

Johnson, Pauline, 1994, Feminism as Radical Humanism, Allen and Unwin: St. Leonards, NSW.

Johnson, Pauline, 1995, Does Post Modern Feminism have a Future? in Australian Feminist Studies, Summer, Vol. 22, pp. 121-138.

Jones, Alison, 1992, Writing Feminist Educational Research: Am 'I' in the Text? in Women and Education in Aotearoa 2, Sue Middleton and Alison Jones (eds.), Bridget Williams Books: Wellington, pp. 18-32.

Jones, Vida and Estes, Carroll, 1997, Older Women: Income, Retirement and Health, in Women's Health: Complexities and Differences, Rusek, Olesen and Clarke, (eds.), Ohio State University: Columbus.

Joseph, Jenny, 1987, Warning, in When I am an Old Woman I Shall Wear Purple, S. Martz (ed.), Papier-Mache Press: Manhattan Beach, CA.

Joseph, Alun and Chalmers, Lex, 1999 Residential and Support Services for the Older People in the Waikato 1992 -1997: Privatisation and Emerging Resistance, Social Policy Journal of New Zealand 13, December, pp. 154-169.

Katz, Steven, 1995, Imagining the Lifespan: from Premodern Miracles to Postmodern Fantasies, in Images of Aging: Cultural Representations of Cultural Life, Mike Featherston and Andrew Wernick (eds.), Routledge: London, pp. 61-75.

Keeling, Sally, 1999, Ageing in (a New Zealand) Place: Ethnography, Policy and Practice, Social Policy Journal of New Zealand 13, December, 1999, pp. 95-114.

Kemp, Sandra and Squires, Judith, 1997, Introductions in Feminisms, Oxford University Press: New York, pp. 3-12.

Keohane, N.O., Rosaldo, M.Z. and Gelpi B. C., 1981, (eds.), Feminist Theory: A Critique of Ideology, University of Chicago Press: Chicago.

Kendrick, June, 1988, The Medicalisation of Ageing and its Legacy to Social Work: Some Strategies for Change, in New Zealand Social Work, Vol. 12 nos. 3 \& 4, pp. 20-22. 
Klein, Renate Duelli, 1983, How To Do What We Want to Do: Thoughts About Feminist Methodology, in Theories of Women's Studies, Gloria Bowles and Renate Duelli Klein, (eds.), Routledge: London, pp. 88-104.

Knaggs, Patricia, 1996, Older Women's Fear of Crime, Contributing Factors and Effects, Master's Thesis, Victoria University of Wellington.

Koopman -Boyden, P. G. 1988, Theoretical Perspectives on the Elderly in New Zealand: Myth and Reality of Ageing, in The Royal Commission on Social Policy, April Report. Government Printer, Wellington Vol. 4: pp. 631-710.

Koopman-Boyden, P. and Brown, D., 1991, July, 'Ageing of the Baby Boomers', a paper presented at N Z Planning Council Conference.

Koopman-Boyden, Peggy G. (ed.) 1993, Introduction and Theories of Ageing and old Age in New Zealand's Ageing Society, the Implications, Daphne Brasell Associates, Wellington pp. 1-28.

Laslett, Peter, 1989, A Fresh Map of Life: The Emergence of the Third Age, Weidenfeld and Nicholson: London.

Lather, Patti.1999 Feminist Perspectives on Empowering Research Methodologies, in Getting Smart: Feminist Research and Pedagogy With/in the postmodern, Lather, Patti (ed.), Routledge: NewYork, pp. 70-80.

Levin, Jack and Levin, William, 1980, Ageism: Prejudice and Discrimination Against the Elderly, Wadsworth Publishing: Belmont, California.

Lim Swee, Ann, Raphael, 1990, Informal Social Support of Elderly Coping in the Community: Fifty Old People Share Their Experience, Thesis: Social Work. M.A. Applied, Victoria University of Wellington.

Lowenthal, David, 1986, The Past is a Foreign Country, Cambridge University Press: Cambridge.

Lynott, Robert J. and Passuth Lynott P., 1996, Tracing the Course of Theoretical Development in the Sociology of Aging, in The Gerontologist, Vol.36, No.6, pp. 749-760.

Macdonald, Barbara with Rich, Cynthia, 1983, Look Me in the Eye: Old women, Ageing and Ageism, The Women's Press: London.

Macdonald, Charlotte, 1993, The Vote, the Pill and the Demon Drink: A History of Feminist Writing in New Zealand 1869-1993, Bridget William Books: Wellington.

McCallum, John and Geiselhart, Karin, 1996, Post Modern Ageing: Unpicking Poorly Knit Structures, in Australia's New Age: Issues for Young and Old, Allen and Unwin: St Leonards, NSW, Australia, pp. 15-33.

McGregor, Judy and Gray, Lance, 2001, Mature Job-seekers in New Zealand, Massey University: Palmerston North.

McLean, Joan, (ed.) 2000, At the end of the Day, Ten New Zealanders in their Eighties Reflect on Life in Old Age. Steele Roberts Ltd: New Zealand. 
Mack, Ruthanna, Salmoni Alan, Viverais-Dressler, Gloria, Porter, Elaine and Garg, Rashmi; 1997 Perceived Risks to Independent Living: The Views of Older Community-Dwelling Adults, The Gerontologist, Vol. 37 No. 6, pp. 729-736.

Mandelbaum, Maurice, 1967, The preface in The Problem of Historical Knowledge; an answer to Relativism, Harper Row: New York, pp. vii-ix.

Markson, Elizabeth, W., 1997, Sinful, Sagacious or Superfluous? in Handbook on Women and Aging, Jean Coyle (ed.), Greenwood Press: Westport, Connecticut, pp. 53-71.

Marshall, V. W, 1996, The State of Theory in Aging and the Social Science, in Handbook of Aging and the Social Science, R. H. Binstock and L.K. George (eds.), Academic Press: San Diego, pp. 12-30.

May, Helen, 1992, Minding Children and Managing Men: Conflict and Compromise in the Lives of Postwar Pakeha Women, Bridget Williams Books: Wellington.

Mazengarb, Oswald Chettle, 1954, Report of the Special Committee on Moral Delinquency in Children and Adolescents, Government Print: Wellington.

Maynard, Mary, 1994, Methods, Practice and Epistemology: The Debate about Feminism and Research in Researching Women's Lives from a Feminist Perspective, Mary Maynard and June Purvis (eds.), Taylor and Francis: London, pp. 10-26.

Maynard, Mary and Purvis, June, (eds.), 1994, Doing Feminist Research, introduction to Researching Women's Lives from a Feminist Perspective, Taylor and Francis: London, pp. 1-8.

Maynard, Mary, 1999, What do Older Women Want? in New Agendas for Women, Sylvia Walby (ed.), St. Martin’s Press: New York.

Maynard, Mary, 1999, Gender Relations, chapter 6 in Sociology Issues and Debates, Steve Taylor (ed.), Palgrave: New York.

Mehta, Kalyani, 1998, (ed.), Untapped Resources: Women in Ageing Societies, Times Academic Press: Singapore

Meredeen, Shirley, 1993, Goodbye to All That, in Growing Old Disgracefully, The Hen Co-op, Judy Piatkus: London, pp. 126 and 190.

Middlebrook, Diana Wood, 1990, Postmodernism and the Biographer in Revealing Lives: Autobiography, Biography and Gender, Susan Groag Bell and Marilyn Yalom (eds.), State University of New York Press: Albany, pp. 155-165.

Mies, Maria, 1983, Towards a Methodology for Feminist Research in Theories of Women's Studies, Routledge: London, pp.117-139.

Mies, Maria, 1991, Women's Research or Feminist Research? The Debate Surrounding Feminist Science and Methodology, in Beyond Methodology: Feminist Scholarship as Lived Research. Margaret Fonow and Judith A. Cook (eds.), Indiana University Press: Bloomington, pp. 60-84.

Milligan, Kaye, 2000, A Feminist Study of Older Women's Health and Health Promotion, Master’s Thesis, Massey University: Palmerston North. 
Minichiello, Victor, Chappell, Neena, Kendig Hal and Walker, Alan, 1996, (eds.), Sociology of Aging: International Perspectives, International Sociological Association, Research Committee on Aging: Melbourne.

Minister, Kristina, 1991, A Feminist Frame for Interviews, in Women's Words: The Feminist Practice of Oral History, Sherna Berger Gluck and Daphne Patai, (eds.) Routledge: London, pp. 27-42.

Ministry of Social Development, 2001, Positive Ageing in New Zealand: Diversity, Participation and Change, Wellington.

Ministry of Social Policy, 1999, Factors Affecting the Ability of Older People to Live Independently, Wellington.

Ministry of Social Policy, 2001, The Social Report, 2001: Indicators of Social Wellbeing in New Zealand, Wellington.

Ministry of Women's Affairs, 1989, September, Discussion Paper: Valuing Women's Unpaid Work, Wellington.

Ministry of Women's Affairs, 1996, June, Report of the Retirement, Women and Income Conference, Wellington.

Ministry of Women’s Affairs, 1999, Older Women, Panui, April 1999, Wellington.

Ministry of Women's Affairs, 2000, Briefing to the Incoming Minister-Status of Women in New Zealand, Panui, March 2000, Wellington.

Missen, Sue, 1999, From a Distance: Being a Grandmother. Paper presented at the Women's Studies Association (NZ) Conference, November 1999, Wellington.

Moen, Phyllis, 1995, Gender, Age, and the Life Course, in Handbook of Aging and Social Sciences, Robert H. Binstock and Linda K. George (eds.), Academic Press: San Diego, California, pp. 171-187.

Moody, Harry R., 1988, Toward a Critical Gerontology: the Contribution of the Humanities to Theories of Aging in James E. Birren and Vern L. Bengtson (eds.), Emergent Theories of Aging, Springer: New York, pp. 19-40.

Moody, Harry R., 1998, Aging, Concepts and Controversies, Pine Forge Press: California.

Morgan, Elaine, 1972, The Descent of Woman, Stein and Day: New York.

Morgan, Leslie and Kunkel, Suzanne, 1998, Aging the Social Context, Pine Forge Press: California.

Mowbray, Mary 2001, Distributions and Disparity: New Zealand Household Incomes, Ministry of Social Policy: Wellington.

Nadien, Margot B. and Denmark, Florence L. 1999, Aging Women: Stability or Change in Perceptions of Personal Control, in Females and Autonomy: A Life-span Perspective, Nadien and Denmark (eds.), Allyn and Bacon: Boston. pp. 130-154. 
National Advisory Committee on Health and Disability, 2000, 'Report of the National Health Committee on Health Care for Older People', Wellington.

Neysmith, S., 1984, Poverty in Old Age: Can Pension Reform Meet The Needs of Women? in Canadian Women's Studies, Vol.5 No.3, pp.17-24.

Ng Sik Hung, Weatherall, A., Liu, J., Loong, C. (eds) 1998, Ages Ahead, Promoting Intergenerational Relationships: Victoria University Press, Wellington.

Nicholson, Linda and Fraser, Nancy, 1999, Social Criticism without Philosophy: An Encounter between Feminism and Postmodernism, in The Play of Reason, Open University Press: Buckingham, pp. 99-115.

Nussbaum Jon F. and Coupland Justine (eds.), 1995, Handbook of Communication and Aging Research. Lawrence Erlbaum Associates: Mahwah, New Jersey.

Nussbaum, Martha, 1992, Human Functioning and Social Justice: in Defence of Aristotelian Essentialism in Political Theory Vol. 20, no. 2, pp.202-46.

Oakley, Ann, 1981, Interviewing Women: a Contradiction in Terms, in Doing Feminist Research, Helen Robert (ed.) Routledge, Kegan, Paul: London, pp. 30-61.

Oakley, Ann, 2000, Experiments in Knowing: Gender and Method in the Social Sciences, Polity Press: Cambridge, UK.

Ogonowska-Coates, Halina, 1993, I'm still Elva Inside: Bridget William Books, Wellington.

Okin, Susan, Moller, 1994, Gender Inequality and Cultural Differences, in Political Theory, Vol. 22. No.1, pp.5-24.

Olssen, Erik, 1980, Women, Work and Family: 1880-1926, in Women in New Zealand Society, Phillida Bunkle and Beryl Hughes, (eds.). Allen and Unwin: Sydney, pp.159-183.

Opie, Anne, 1992, Qualitative Research: Appropriation of the 'Other' and Empowerment, in Feminist Review, Spring, 40: 52-69.

Opie, Anne, 1999, Unstructured Interviewing in Social Science Research in New Zealand: Many Paths to Understanding (eds.), Carl Davidson and Martin Tolich, Pearson Education: Auckland, pp. 220-230.

O’Rand, Angela M., 1995, The Cumulative Stratification of the life Course, in Handbook of Aging and Social Science, Robert H. Binstock and Linda K. George, (eds.), Academic Press: San Diego California, pp. 188-207.

O’Reilly, Evelyn, 1997, Decoding the Cultural Stereotypes about Aging: New Perspectives on Aging Talk and Aging Issues, Garland Publishing: New York.

Palmore, Erdman, 1997, Sexism and Ageism in Handbook on Women and Aging, Jean Coyle (ed.), Greenwood Press: Westport, Connecticut, pp. 3-5.

Payne, Sarah, 1991, Women, Health and Poverty, Harvester Wheatsheaf: Hertfordshire, U.K. 
Pearlin, C. S., 1982, Discontinuities in the Study of Aging, in Aging and Life Course Transitions: an Interdisciplinary Perspective, Tamara Hareven and Kathleen Adams (eds.), Tavistock Publications: London, pp. 55-74.

Phillips, Jock, 1987, A Man's Country? The Image of the Pakeha Male, a History, Penguin Books: Auckland.

Phillipson, Chris, 1982, Capitalism and the Construction of Old Age, Macmillan: London.

Pong, Raymond, W., 1998, Ageing as a Resource: Lessons Learned from an Emerging Retirement Community, in Ng Sik Hung, Weatherall, A., Liu, J., Loong, C. (eds.), 1998, Ages Ahead, Promoting Intergenerational Relationships, Victoria University Press: Wellington.

Portelli, Alessandro, 1988, 'Uchronic Dreams: Working Class Memory and Possible Worlds, in Oral History Journal, 16 (2), 46-56.

Portelli, Alessandro, 1991, The Death of Luigi Trastulli and Other Stories: Form and Meaning in Oral History, Albany State University Press: Albany, Chapter 1 pp. 1-26.

Prime Ministerial Task Force on Positive Ageing.1997, Facing the Future: a Strategic Plan. Department of the Prime Minister and Cabinet: Wellington.

Pugh, Anne, 1990, My Statistics and Feminism - A True Story, in Feminist Praxis: Research Theory and Epistemology in Feminist Sociology, Liz Stanley (ed.), Routledge, Chapman and Hall: New York, pp. 103-112.

Ray Ruth E., A Postmodern Perspective on Feminist Gerontology in The Gerontologist Vol. 36, no. 5, 674-680.

Reinharz, Shulamit, 1983, Experiential Analysis: a Contribution to Feminist Research, in Theories of Women's Studies, Gloria Bowles and Renate Duelli Klein (eds.), Routledge: New York, pp. 162-191.

Reinharz, Shulamit, 1992, Feminist Methods in Social Research, Oxford University Press: New York and Oxford.

Rich, Cynthia, C., 1988, Ageism and the Politics of Beauty, in Macdonald and Rich, Look Me in the Eye; Old Women, Aging and Ageism, 1991 edition, Spinsters Books Company: San Francisco, pp. 139-146.

Riley, Denise, 1988, Am I that Name? Feminism and the Category of 'Women' in History, in Feminisms, 1997, Sandra Kemp and Judith Squires (eds.), Macmillan: New York. pp. 241-246.

Riley, M. W., 1971, Social Gerontology and the Age Stratification of Society, in The Gerontologist, 11, 79-87.

Roberts, Nigel and Levine, Stephen, 1993, Elderly People and the Political Process, in New Zealand's Ageing Society, P. Koopman-Boyden (ed.), Daphne Brassell Associates: Wellington. 
Roorda, Matthea, Bendino, Shulamith, 1998, Older Women On Line: Gender, Ageing and Networked Computing. Thesis, M.A. (applied) Social Science Research, Victoria University of Wellington.

Rose, A. M., 1964, A Current Theoretical Issue in Social Gerontology, in The Gerontologist, 4, 46-50.

Rose, Hilary, 1994, Love, Power and Knowledge: Towards a Feminist Theory of Human Sciences, Polity Press, Blackwell: Oxford.

Rosenthal, Evelyn R, (ed.), 1990, Women, Aging and Ageism, The Haworth Press: New York.

Rosier, Pat, 1992, (ed.) Twenty Years of Broadsheet Magazine, a Selection Introduced by Pat Rosier, New Women's Press: Auckland.

Rowe, John and Khan Robert, 1997, 'Successful Aging', in The Forum, Vol. 37, No 4, pp. 433-440.

Russell, Cherry, 1987, Aging as a Feminist Issue, in Women's Studies International Forum, Vol. 10, No. 2, pp. 125-131.

Ruzek, Sheryl, 1997, Access, Cost and Quality of Medical Care: Where Are We Heading? in Women's Health:Complexities and Differences, Ohio State University Press: Columbus.

Ruzek, Sheryl, Olesen, Virginia and Clarke, Adele, 1997, (eds.), Women's Health: Complexities and Differences, Ohio State University Press: Columbus.

Sarton, May, 1983, As We Are Now, The Women’s Press: London.

Saville-Smith, Kay, 1993, The State and the Social Construction of Ageing, in New Zealand's Ageing Society, the Implications. Peggy Koopman-Boyden (ed.), Daphne Brasell Associates: Wellington, pp. 76-94.

Scott, Anne and Wenger, Clare G. 1995, Gender and Support Networks in Later Life, in Connecting Gender and Ageing: A Sociological Approach Arber, S. and Ginn, J. (eds.), Open University Press, London, pp. 158-172.

Schofield, Verna, 1987, A Radical Alternative for Social Work Practice with Elders in New Zealand in New Zealand Social Work Journal Vol. 11, No. 1 pp.7-11.

Senior Citizens Unit, 2000, International Year of Older Persons 1999: Final Report Ministry of Social Policy: Wellington.

Silverstein, Meril and Angelelli, 1998, Older Parents' Expectation of Moving Closer to Their Children, in Journal of Gerontology: Social Sciences, Vol. 53B, pp.158-172.

Smith, Dorothy, 1997, Comment on Hekman's Truth and Method: Feminist Standpoint Theory Revisited, in Signs: Journal of Women in Culture and Society, Vol.22: No. 2, p.392-398. 
Smith, Jacqui, Fleeson, William, Geiselmann, Bernard, Settersten, Richard and Kunzmann, Ute, 1997, Sources of Well-Being in Very Old Age, in The Berlin Aging Study: Aging from 70 to 100, Baltes, P. and Mayer, K, (eds.), Cambridge University Press: Cambridge, pp. 450-471.

Sontag, Susan, 1972, The Double Standard of Ageing, in Saturday View of the Society, September 1972, pp. 29-38.

Society for Research on Women in New Zealand, Wellington Branch, 1982, In Those Days: A Study of Older Women in Wellington, Wellington.

Society for Research on Women, Christchurch Branch, 1994, The Effects of Unemployment on Women, Christchurch.

Society for Research on Women in New Zealand, Wellington Branch, 1999, Towards Retirement —Women's Views, Wellington.

St John, Susan and Ashton, Toni, 1993, Private Pensions in New Zealand: Can they Avert the Crisis? Institute of Policy Studies, Victoria University of Wellington: Wellington.

St John, Susan, 1993, Income Support for an Ageing Society, in New Zealand's Ageing Society: The Implications, Peggy Koopman- Boyden (ed.), Daphne Brasell Associates: Wellington, pp.122-148.

St John, Susan, 1996, Opening Address at Women and Retirement Income Conference Ministry of Women's Affairs, Wellington.

Stanley, Liz and Wise, Sue, 1990, Method, Methodology and Epistemology in Feminist Research Processes, in Feminist Praxis: Research Theory and Epistemology, Liz Stanley (ed.), Routledge, Chapman and Hall: New York, pp. 20-47.

Stanley, Liz, 1990, Recovering Women in History from Feminist Deconstruction, in Women's Studies International Forum, 13/1-2.

Stanley, Liz, 1990, 'A Referral was Made'. Behind the Scenes During the Creation of a Social Services Department 'Elderly' Statistic in Feminist Praxis: Research Theory and Epistemology, Liz Stanley (ed.), Routledge, Chapman and Hal: New York, pp. 113-122.

Stanley, Liz, 1993, Breaking Out Again: Afterword, in Stanley, Liz and Wise, Sue, Breaking Out Again, Routledge, London and New York, pp. 186-233.

Stanley, Liz, 1995 'Women Have Servants and Men Never Eat: Issues in Reading Gender Using the Case Study of Mass Observation's 1937 Day Diaries', Women's History Review, 4 (1) pp. 85-102.

Statistics New Zealand, 1993, Work - Highlights - 100 Years Ago and Now, in All about Women in New Zealand, Wellington.

Statistics New Zealand and Ministry of Women's Affairs, 1999, New Zealand Now, Women, Wellington. 
Statistics New Zealand, 2001, Around the Clock: Findings from the New Zealand Time Use Survey 1998-1999, Statistics, New Zealand, Wellington.

Steinberg Margaret, 1999, Healthy Ageing in Rural Communities in Queensland. Report to the Department of the Premier and Cabinet, University of Queensland.

Stoller, E. P., 1993, Gender and the Organization of Lay Healthcare: A SocialistFeminist Perspective, in Journal of Aging Studies, 7, pp.151-170.

Sutch, W. B., 1966, The Quest for Security in New Zealand 1840-1966, Oxford University Press: Wellington.

Sutch, W. B., 1969, Poverty and Progress in New Zealand: a Reassessment: A. H. and A. W. Reed: Wellington.

Sutch, W. B., 1973, Women with a Cause, New Zealand University Press:Wellington.

Tennant, Margaret, 1986 a, Brazen-faced Beggars of the Female Kind, in Women in History, Brookes, Barbara, Macdonald, Charlotte and Tennant, Margaret, (eds.) Allen and Unwin: Wellington, pp.35-54.

Tennant, Margaret, 1986 b, Natural Directions, in Women in History, Brookes, Barbara, Macdonald, Charlotte and Tennant, Margaret, (eds.) Allen and Unwin: Wellington, pp.87-100.

Tennant, Margaret, 1989, Paupers and Providers: Charitable Aid in New Zealand, Historical Branch, Department of Internal Affairs and Allen and Unwin: Wellington.

The Hen Co-op, 1993, Growing Old Disgracefully, Judy Piatkus: London.

The Royal Society of New Zealand, 1999 revision, The Intergenerational Impacts of Ageing: a Research Strategy Prepared for the Ministry of Research, Science and Technology, The Royal Society of New Zealand: Wellington.

Thomson, David, 1991, The Selfish Generation, Bridget William Books: Wellington.

Thompson, Denise, 1996, The Self-Contradiction of "Post-modernist" Feminism, in Radically Speaking, Renate Klein (ed.), Spinifex Press: Melbourne, pp. 325-338.

Tong, Rosemary, P., 1998, Feminist Thought, Allen and Unwin: Australia.

Torrez, D. J., 1997, The Health of Older Women: A Diverse Experience, in Handbook on Women and Aging, Coyle, Jean (ed.), Greenwood Press: Westport, Connecticut, pp. 131-148.

Troll, L. E., Israel, J and Israel, K., 1977, Looking Ahead: A Woman's Guide to the Problems and Joys of Growing Old, Prentice Hall: Englewood Cliffs, New Jersey.

Turner, Brian, 1995, Aging and Identity: Some Reflections on the Somatization of the Self, in Images of Aging: Cultural Representations of Later Life, Mike Featherstone and Andrew Wernick (eds.), Routledge: London, pp. 245-260. 
Uhlenberg, Peter and Miner, Sonia, 1995, Life Course and Aging: A Cohort Perspective, Handbook of Aging and Social Science, Robert H. Binstock and Linda K. George (eds.), Academic Press: San Diego, California, pp. 208-228.

Van Tilburg, Theo, 1998, Losing and Gaining in Old Age: Changes in Personal Network Size and Social Support in a Four-year Longitudinal Study, in Journal of Gerontology: Social Sciences Vol. 53 B, No. 6 pp. s313- s323.

Verbrugger, L. M., 1984, Longer Life, but Worsening Health? Trends in Health and Mortality of Middle-aged and Older Persons, in Milbank Memorial Fund Quarterly, Health and Society, Vol.62, No.3, pp. 475-519.

Verbrugger, L. M., 1989, Gender Ageing and Health, in Aging and Health: Perspectives on Gender, Race, Ethnicity and Class, Markides, K. S. (ed.), Sage: Newbury Park, CA.

Victor, Christina, R., 1991, Health and Health Care in Later Life, 1995 reprint, Open University Press: Milton Keynes, Philadelphia.

Victoria University of Wellington and Age Concern: Positive Ageing and Intergenerational Research Programme, The 40+Project Reports:

$2000 \quad$ Life after 40: Work and Retirement Plans.

2000 Creating Communities for all Ages: Local Government and Older New Zealanders.

2001 Experiences of a Lifetime: Older New Zealanders as Volunteers.

2002 Ageing in a Diverse New Zealand / Aotearoa

Wada, Shuichi, 1995, The Status and Image of the Elderly in Japan: Understanding the Paternalistic Ideology, in Images of Aging: Cultural Representations of Later Life, Featherstone, M. and Wernick, A., (eds.), Routledge: London, pp. 48-60.

Walby, Sylvia, 1990, Introduction to Theorising Patriarchy, Oxford University Press: U.K., pp. 1-24.

Walker, Barbara, G., 1985, The Crone: Woman of Age, Wisdom, and Power. Harper Row: San Francisco.

Waring, Marilyn, 1987, 'The Invisible Women', Ch. 7 in Public and Private World, Shelagh Cox (ed.), Allen and Unwin: London, pp. 125-142.

Waters, Kristin, 1996, (Re) Turning to the Modern: Radical Feminism and the Postmodern Turn in Radically Speaking, Renate Klein (ed.), Spinifex Publications: Melbourne, pp. 280-286.

Waugh, Patricia, 1992, Modernism, Postmodernism, Gender: The View from Feminism in Practising Postmodernism / Reading Modernism, Edward Arnold: London, pp. 119-135. 
Waugh, Sue, 1991, A Critical Review of Projections and Findings in Gerontology which have Implications for Family Sociology, New Zealand Population Review, Vol. 17, No.2, pp. 125-142.

Whelahan, Imelda, 1999, Modern Feminist Thought: from the Second Wave to Post Feminism, New York University Press: New York.

Wither A. and Hodges I., (1987) Elderly People in View: a Bibliography of New Zealand Research 1972-1985, Occasional Paper, No 29, Department of Health: Wellington, 1987.

Wolf, Naomi, 1990, The Beauty Myth, Vintage Press edition: 1991, London.

Women's Centre West Auckland, 2001, Women and Income: A Complex Web, writer, Carmel Cervin, published with the assistance of the New Zealand Federation of Graduate Women (Auckland Branch): Auckland.

Woodward, Kathleen, 1995, Tribute to the Older Woman: Psychoanalysis, Feminism and Ageism, in Images of Aging: Cultural Representations of Later Life, Mike Featherston and Andrew Wernick (eds.), Routledge: London, pp. 79-96.

Worell, J, and Etaugh, C. (1994) Transforming Theory and Research with Women: Themes and Variations, in Transformations: Reconceptualizing Theory and Research with Women, Psychology of Women Quarterly, Special Issue, Vol. 18, 4, 443-450.

Wright, Elizabeth, 1989, Thoroughly Post-modern Feminist Criticism, in Between Feminism and Psychoanalysis, Teresa Brennan (ed.), Routledge: London, pp. 146150.

Zuckerman, Marilyn, 1988, After Sixty, in Ourselves Growing Older: Women Aging with Knowledge and Power, Doress, P. and Siegal, D. (eds.), Simon and Schuster: New York, p. 40. 


\section{Appendix I a}

\section{Introductory Letter and Questionnaire}

Isobel Munro

83 Madras Street,

Khandallah,

Wellington.

July 2000

\section{To Whom it May Concern}

I am a mature student in my sixties completing a Masters degree by thesis at Victoria University of Wellington. My thesis concerns the quality of life for older women no longer in full-time paid employment. This research is undertaken through the Department of Women's Studies at the university and uses both questionnaires and interviews. The questionnaire below has been developed from a pilot discussed with a focus group of older women and has been approved by the university's ethics committee.

I would appreciate it if you were to find the time to complete it and return it in the envelope provided. All responses will be treated confidentially and will be accessed only by myself or my supervisors, Associate Professor Prue Hyman and Head of Department Alison Laurie.

Should you be willing to be interviewed in depth and /or would like a summary of the study when completed please fill in the section at the end with name, address and phone number so that I can contact you, otherwise your response can be anonymous.

Yours sincerely

Isobel Munro 


\section{The Quality of Life for Older Women}

Please tick the boxes or complete the statement or question.

1. My overall satisfaction with life at present is:

very good $\square \quad$ good $\square \quad$ satisfactory $\square \quad$ poor $\square \quad$ low

The things that please me most are:

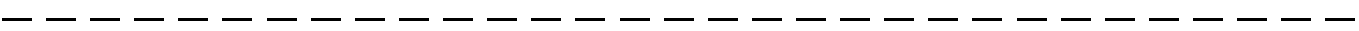

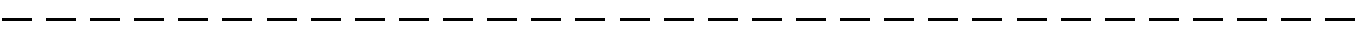

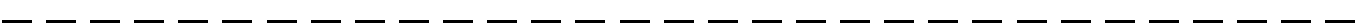

3. The things that worry or upset me are:

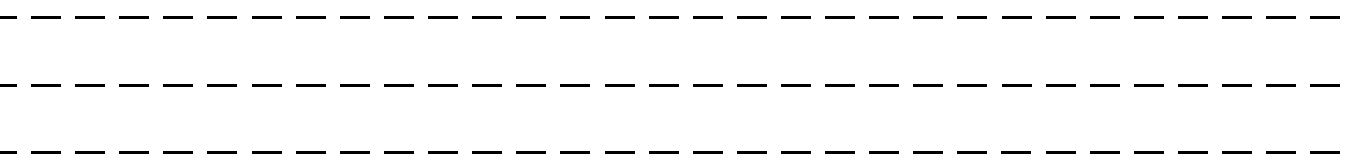

4. (a) My hobbies and interests in the past were:

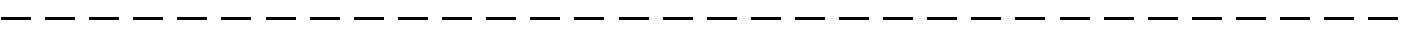

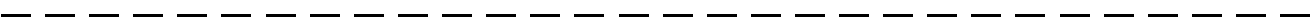

(b) At present my hobbies and interests are:

$---------------------$

$------------------------$

5. (a) What voluntary work have you been involved with in the past?

$---------------------$

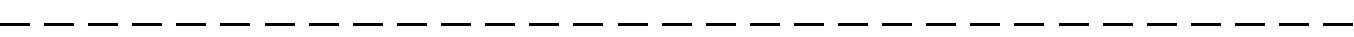

(b) What are your present voluntary activities?

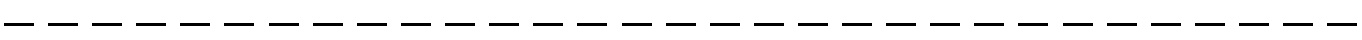

$--------------------1$

6. At present my overall health is:

excellent $\square \quad$ very good $\square \quad \operatorname{good} \square \quad$ poor $\square \quad$ very poor 
7. I have some disability, e.g. hearing $\square \quad$ eyesight $\square \quad$ arthritis $\square$ other please specify:

$------------------------$

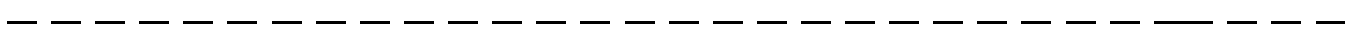

8. My main form of exercise is:

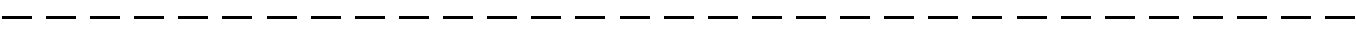

$---------------------1---$

9. I have difficulty sleeping

10. I have medical insurance

11. I have easy access to medical facilities

12. Since your own or your partner's retirement, has the allocation of household tasks changed in any way?

13. If there has been a change, then in what way?

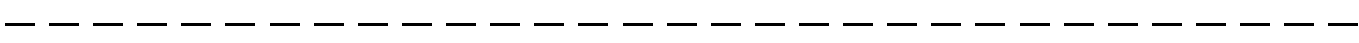
$--------------------$

14. Do you take a holiday at least once a year? yes $\square$ no $\square$

15. Do you live alone? yes $\square$ no $\square$ If yes please go to question 19 .

16. Who else lives in your household?

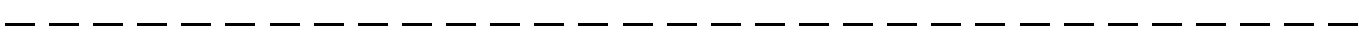

17. Are any of them dependent on you for full-time care? yes $\quad \square \quad$ no $\square$

18. If so please specify.

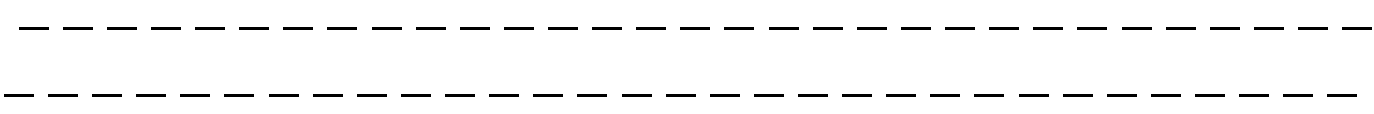

19. Does your family live locally?

yes no $\square$ 
20. If not locally, please state where:

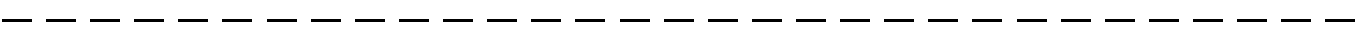

$--------------------1---$

21. How many adult children do you have?

22. How many grandchildren do you have?

23. How often do you see your family?

24. Having grandchildren has involved me in....

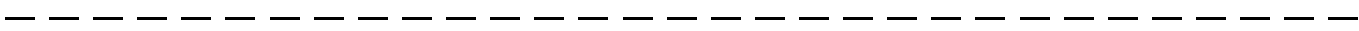

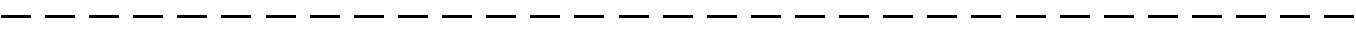

25. If you needed assistance in any way, which of the following would be helpful? Tick more than one if appropriate.

family $\square \quad$ friends $\square \quad$ neighbours $\square$ other please specify:

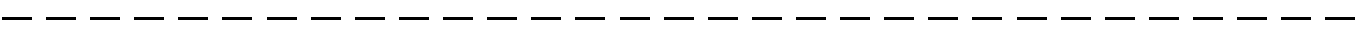

26. Do you keep a pet? $\quad$ cat $\square \operatorname{dog} \square \quad$ other please specify:

$------------------------$

27. (a) What community facilities for older persons are available in your locality?

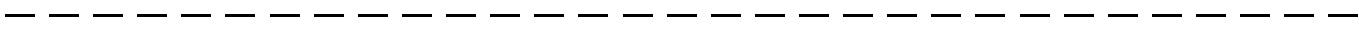

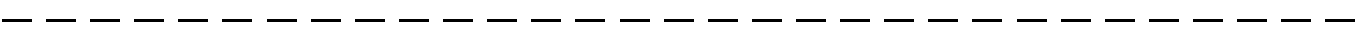

(b) Which facilities do you use?

$-----------------------$

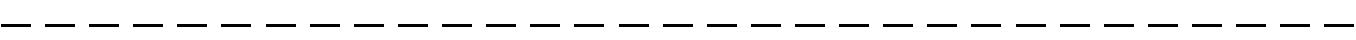

28. There are some organisations especially for older persons. These are some of them. Please tick those you know, and add any others.

$$
\text { Age Concern } \square \quad \text { Grey Power } \square \quad \text { Probus } \square \quad \text { U3A }
$$

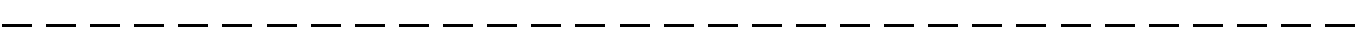

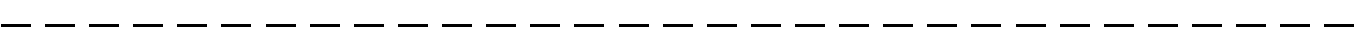


29. Do you feel you have enough to live on reasonably? $\quad$ yes $\square$ no $\square$

30. Do the costs of the following worry you?

glasses $\square$ hearing aids $\square \quad$ Legal costs, e.g: wills $\square$ funeral arrangements other please specify:

31. If you needed to economise, what changes would you make?

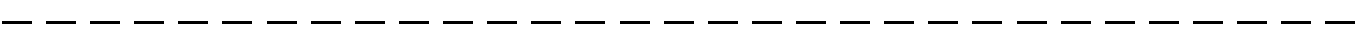

$---------------------1---$

$-------------------------$

32. (a) Have you or your partner attended any pre-retirement courses, please specify:

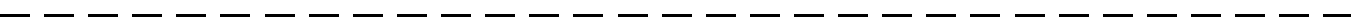

(b) Were these helpful?

yes $\square$ no $\square$

(c) What other preparations did you make for retirement?

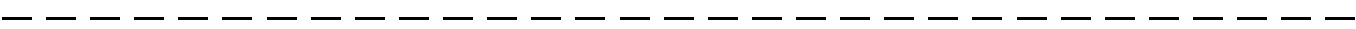

$------------------------$

33. Do you have any concerns about your personal safety?

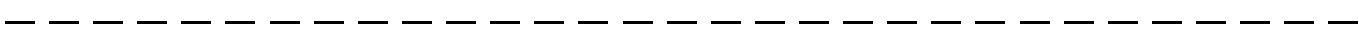

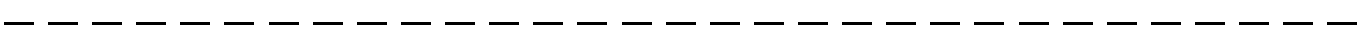

$--------------------$

34. (a) How long have you lived in your present house?

$----$

(b) Is your home? $\quad$ Mortgage-free $\square$ mortgaged $\square$ rented $\square$

35. (a) Does this house satisfy your needs?

Yes $\square$ no $\square$

(b) If not, what changes would you wish to make?

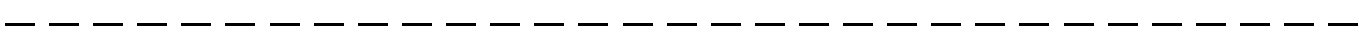

36. (a) Do you prefer to continue living in this locality?

yes $\square$ no 
(b) If not, where would you wish to go?

$----------------------------$

(c) Have you any problems with house or garden maintenance? Please specify:

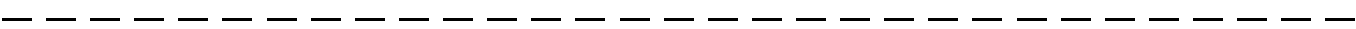

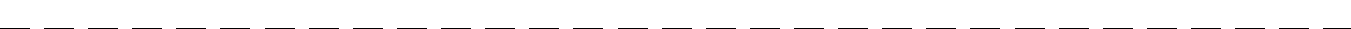

37. (a) Have you ready access to public transport? yes $\square$ no $\square$

(b) Is this service adequate for your needs? $\quad$ yes $\square$ no $\square$

(c) Are there concessions for older travellers? yes $\square$ no $\square$

38. Do you drive a car?

yes $\square$ no $\square$

39. Do you use the internet?

yes $\square$ no $\square$

40. Do you feel valued as an older woman? Please explain

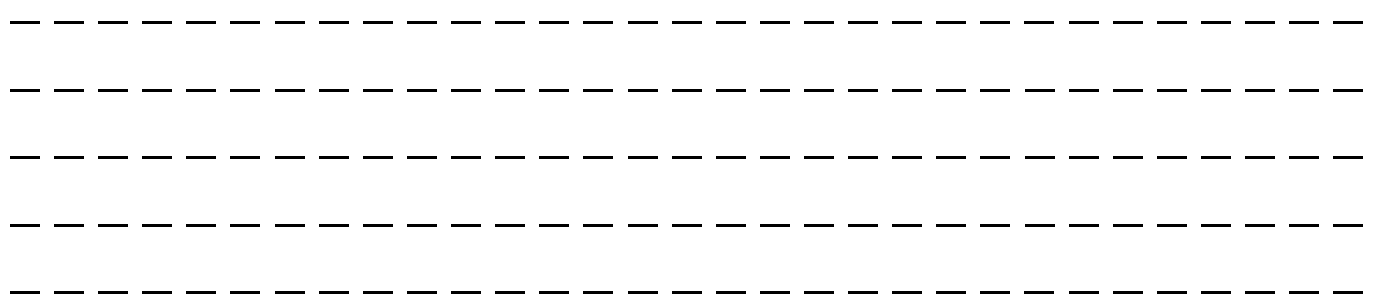

41. What is your opinion of retirement villages?

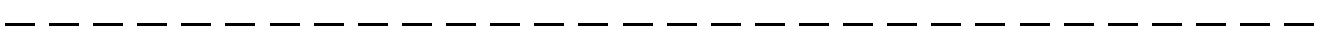

$-------------------------$

42. How important is your spirituality, inner life, religious belief or philosophy to your well-being as an older woman?

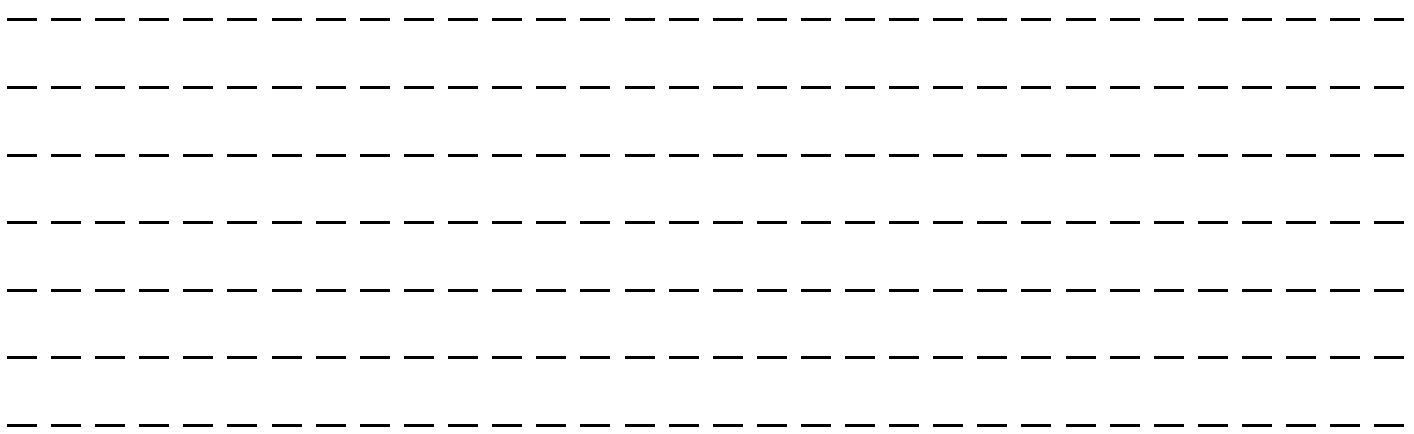


43. Marital Status and Age

married $\square$ partnered $\square \quad$ divorced/separated $\square \quad$ widowed $\square \quad$ single $\square$

44. Education:

primary $\square$ secondary $\square$ polytech $\square$ trade $\square$ university

45. Previous paid employment, please give details:

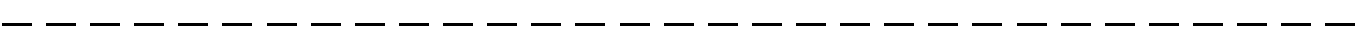

$--------------------------$

46. Current paid employment, please give details:

$--------$

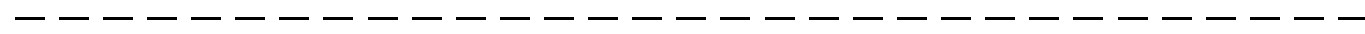

$------------------------$

47.Personal Income (before tax)

$$
\begin{aligned}
& \text { Under } \$ 5,000 \square \$ 5,000-14,999 \square \$ 15,000-19,999 \square \$ 20-29,999 \square \\
& \$ 30,000-39,999 \square \$ 40,000-49,999 \square \$ 50,000-\$ 59,999, \square \$ 60,000+\square
\end{aligned}
$$

48. Household Income (before tax)

$$
\begin{aligned}
& \text { Under } \$ 5,000 \square \$ 5,000-14,999 \square \$ 15,000-19,999 \square \$ 20-29,999 \square \\
& \$ 30,000-39,999 \square \$ 40,000-49,999 \square \$ 50,000-\$ 59,999, \square \$ 60,000+\square
\end{aligned}
$$

49. Your main source of personal income is: $\quad$ National Super $\square$ other $\square$

50. Household main source of income is: $\quad$ National Super $\square$ other $\square$

Please add any other comments about your quality of life as an older woman.

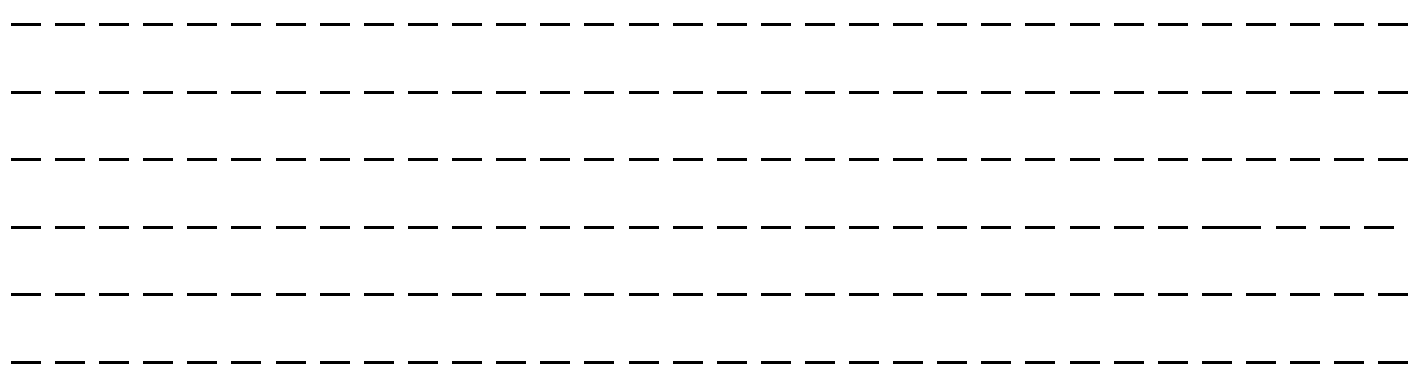


Thank you for your time and effort in filling out this questionnaire. It really is appreciated.

I am hoping to do some follow-up interviews.

If you are interested in being interviewed, please fill in your name below, although this does not commit you to an interview should you change your mind.

Yours sincerely,

Isobel Munro

I am willing to be interviewed

yes

no

My contact details are:

Name $----------------------$

Address

Phone

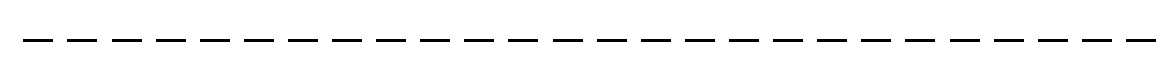

A summary of this report will be available, please indicate if you would like a copy.

I would like a copy of the report.

yes

no

Signature 


\section{Appendix 1 b}

\section{Consent Form and Interview Confirmation}

83 madras Street,

Khandallah,

Wellington.

Dear

Thank you for agreeing to participate in this research. Your interview will be taped and transcribed using a code name to preserve confidentiality. All the information obtained and used in the completed study will not be personally identified unless you wish this.

If you require any further information about the project please contact me on 04479 7556 or my supervisors, Associate Professor Prue Hyman or Alison Laurie acting Head of the Department of Women's Studies, Victoria University of Wellington, P O Box600, Wellington, phone 044721000.

We will meet as previously arranged by phone at.

on-

At the conclusion of the interview you may review the tape or at a future time convenient to you. With your permission the original maybe deposited at the Alexander Turnbull Library’s Oral History Archive and a copy returned to you or the original returned to you and any copies destroyed on the completion of this study.

Please complete the enclosed consent form for the interview and indicate your preference for the disposal of the tapes. I will collect this when we meet. 


\title{
Appendix I b
}

\section{Interview Consent Form}

\section{Project: The Quality of Life for Older Women}

\author{
Person Interviewed (full name)------------------------------------------------ \\ Date of Interview-------------------------- \\ Interviewer Isobel Munro
}

1. I, the person interviewed agree to a taped interview with Isobel Munro on the quality of my life as an older woman and that this will provide material for her master's thesis at Victoria University of Wellington.

2. I understand that this has been approved by the University Ethics Committee and that my confidentiality will be respected and all records kept securely.

3. I understand that this consent form does not affect my rights and responsibilities under the Privacy Act 1993.

4. I note below any restrictions I wish to place on the publication of the material.

5. At the conclusion of the study I wish the tapes to be disposed of in the following manner.

$\begin{array}{lcr}\text { Returned to me } & \text { yes } & \text { no } \\ \text { Copies stored in the Oral History Archive } & \text { yes } & \text { no } \\ \text { Destroyed } & \text { yes } & \text { no }\end{array}$

Signatures:

Person interviewed-Interviewer- 
Appendix II a

\section{Locations of Respondents Requesting Project Reports.}

$\begin{array}{lll}\text { Alexandra } & \text { Arrowtown } & \text { Auckland } \\ \text { Bluff } & \text { Camborne } & \text { Christchurch } \\ \text { Hawera } & \text { Hastings } & \text { Kapiti } \\ \text { Invercargill } & \text { Levin } & \text { Linden } \\ \text { Lower Hutt } & \text { Mangakino } & \text { Martinborough } \\ \text { Masterton } & \text { Napier } & \text { New Plymouth } \\ \text { North Canterbury } & \text { Oamaru } & \text { Palmerston North } \\ \text { Papamoa } & \text { Paremata } & \text { Plimmerton } \\ \text { Porirua } & \text { Queenstown } & \text { Raumati } \\ \text { Rongotea } & \text { Rotorua } & \text { Taradale } \\ \text { Tawa } & \text { Upper Hutt } & \text { Waimate } \\ \text { Wainuiomata } & \text { Waikanae } & \text { Wanganui } \\ \text { Whitby } & & \end{array}$

Respondents from Wellington Suburbs

Hataitai Johnsonville Karori

Mount Victoria Newlands Newtown

Ngaio Miramar Ohariu Valley

Ngaio Wellington Central 


\section{Appendix IIb}

\section{List of Respondents’ Formal Voluntary Activities:}

Local Information Centres, Libraries, Museums, Art Galleries

\& Historical Societies. Widows \&Widowers Associations

Befrienders International, Senior Citizens, Probus

Amnesty International, Adult Literacy, Foodbanks

Citizens Advice Bureau, Save the Children, Abbeyfield

Budget Advice Service , Community Houses, Age Concern

Downtown Ministry, $\quad$ Meals on Wheels, Samaritans

Hospital Auxiliaries , $\quad$ Civil Defence, $\quad$ Red Cross

Intellectually Handicapped, ESL Tutoring ${ }^{1}$, Age Concern

Arthritis Foundation, $\quad$ Care and Craft, $\quad$ Grey Power

Driving for the Elderly, Cancer Society, Hospice

W.E.A., $\quad$ N.C.W., $\quad$ U.3A, R.S.A., ${ }^{2} \quad$ Counselling

This list does not include the work done within the churches such as catering and visiting the sick, nor the administrative and secretarial work given to sports and hobby clubs political parties and the police.

The women were frequent collectors for street appeals and informal care givers for friends, neighbours and new immigrants. Hospital visiting and knitting for premature babies was done on both formally and informally as was work on environmental and health campaigns and local beautification programmes.

\footnotetext{
${ }^{1}$ English as a second language.

${ }^{2}$ Workers Eduational Association, National Council of Women, University of theThird Age, Returned Servicemens’ Association.
} 


\section{Appendix III}

\section{Selected Responses to the Question on Values:}

The following quotations are typical of responses. Perceptions of value were commonly expressed in terms of being useful, advice giving, helping, working in the community and being appreciated for skill and experience. A very small number of respondents stated that they valued themselves for who they were. Acceptance and belonging were important aspects of being valued. To avoid personal identification, I have not included those comments in which the women listed membership of, or positions held in various organisations.

- "Valuing oneself is probably the key to this."

Divorced aged 71

- "My social set is all women over 60, I am valued as being able-bodied and mentally alive."

Married aged 64

- "No feelings either way really! I've never been made to feel I'm an 'older person'; I feel just accepted for what I am.”

Married aged 70

- "Valued. My daughter makes me feel very valued as a mother and a grandmother. The local school teachers seem to think we do a worthwhile job in our one to one contact with pupils in a reading recovery programme.”

Married aged 65

- "Yes, I am well educated, confident, secure, articulate and I am good at people relations which I find is reciprocated."

Widow, aged 70

- I feel valued by helping people and listening."

Widow aged 65

"I feel I have respect for what I have previously done and valued as a friend and neighbour. Family do value me as a support person, a listener and always there to help.”

Married aged 60

- "Everyone is very kind to me in every way. Help me in my shopping and will drive me to my appointments. I feel very valued."

Widow aged 79

- "I feel valued as a person. I tutor an adult class in 'writing your memories'. Recent support following my illness has been wonderful, so many seem to value me and I am extremely thankful I've always done what I can for others.”

Single aged 76

- $\quad$ "Yes, our / my views on life are valued by family as one who has experienced much living. Also, at church we find ourselves being consulted on a variety of subjects, presumably because of our age and years connected with the church.”

Married aged 71

- I am very independent and it’s nice to be wanted."

Widow aged 85

- "Valued. Young people ask me for advice. Help former young colleagues with their problems. Enjoy respect from my friends and members of groups.” Widow aged 66 
- "Undervalued - Have white hair, forget names of people. Have not lived here all my life. Therefore my track record is not known and therefore unappreciated."

Married aged 67

- "Undervalued. There seems to be a rather sneering attitude to the elderly in New Zealand. Some TV ads infuriate me.”

Widow aged 79

- "Undervalued in that people think you have nothing to give. To compensate I keep in touch with children. Have two school girls $(10-11)$ who visit and we chat about all kinds of things.

Divorced aged 74

- "Feel left to my own devices. Silly and old seem to be synonyms. As you do something it is implied that, well, it will keep you out of mischief, whatever that might be.”

Widow aged 72

- "Undervalued. I have lots of talents and capabilities that could be made better use of and I find being a widow is sometimes seen as a threat or situation to be taken advantage of. Having grey hair seems to suggest senility or loss of usefulness to some people.”

Widow aged 65

- "Undervalued. Was compelled to retire from the Public Service at sixty - no suitable employment available although I had much to offer in organisation and leadership skills.” Single aged 86

- “Sometimes people think you're not capable because you're old, so I don't tell my age."

Widow aged 84

"Sometimes I feel undervalued, some people seem to treat older people as nonentities, or worse as idiots and lack patience, especially when there is a hearing problem.”

Widow aged 73

"Have never felt that age made any significant difference to the way I am regarded, or to the way my 'contribution' is valued. I do however get mad at the economists and some politicians who persistently accuse the elderly of being a drain on the economy! And generally being a burden on society. It is time that they realised that the elderly are big contributors to the economy they are so fixated on.”

Widow aged 70 .

- "I do not consider myself as an older woman. I know who I am and I know my value. The occasional patronising of younger people does not worry me, as I know that in 40 years time they will be where I am now."

Married aged 74

- "Valued among contemporaries. Definitely not valued by younger people, but perhaps older people are of no value to younger people. What can we offer? ”

- “I’ve never really felt undervalued, younger or older. But now that physical energy is no longer as abundant as it was and activities are more restricted, I may be valued for different things---people do listen to the voice of experience.”

Married aged 77

- 'Depends. Unless one is assertive there is a tendency to relegate me to the 'dear' category, which is patronising and infuriating. If one stands up for oneself there is no problem."

Widow aged 68 
- $\quad$ "I feel valued most of the time. Family do ask my opinion. However I feel some tradespeople and professional people talk down to me, but I believe that is more about being a woman than an older woman.”

Widow aged 69

- $\quad$ "My main contacts are in the same age group, but some younger people are inclined to undervalue our age group. Many of us have considerable abilities, but this is the age of the young. I know of an over 80 years old lady who teaches her peers at Senior Net. ${ }^{3}$ I don't feel undervalued myself.”

Married aged 74

\section{Appendix IV}

\section{Audrey Harper's Advice on Retirement:}

\section{Growing old? Growing older is better.}

1 don't like to think of myself as 'growing old' but as 'growing older' - that's what I've have been doing since birth. That happens to all of us.

Yes, there are phases and stages in the duration of one's life but these are no different than the phases of the moon or the months of the year. Some phases show rapid physical growth, others mental or spiritual growth, some are static, others show rapid change; but all phases are working alongside each other - some stronger, more dominant at one time or another.

When I look back on my own life I can identity phases, where some activity or happening caused me or my life to change. The obvious ones are school, war-service, emigrating to New Zealand, moving jobs and homes from time to time.

But to all of us, sooner or later, there comes a moment of great change. Despite feeling full of life and energy or sometimes a feeling of slowing down and tiredness, there comes a desire to make the most radical change of all, with as much uncertainty and insecurity as it did when 1 chose to come to New Zealand. I decided to retire three years before the then retirement age of sixty.

Suddenly I was free of all the restrictions laid on me by my work. I could do what I liked, when I liked, and how I liked. I soon found it was not quite as free as that, but I had considerably more choice as to when 1 did a particular activity. I could sleep late, be active into the small hours, do my washing in the dawn, read a book until the small hours.

The most practical thing I had done over my working years was to ensure I had a reasonable income on which to retire, a home which was free of mortgage, and a community in which I would enjoy living.

Thus started that phase of life where I would be known as the 'older woman'. Sometimes it was accepted I had useful knowledge and experience, sometimes I was considered a bit 'past it'. Enough of the first usually balanced the second. But there was nothing to stop me learning new things or enlarging old skills and knowledge. I have

\footnotetext{
${ }^{3}$ Senior Net is an organisation which teaches older citizens computer skills. The tutors are older persons.
} 
always believed that "the day we stop learning is the day we start to die." What have I learned as the older woman?

\section{Take each day as it comes -}

Don't worry about the past or the future. The first has come and gone, the second has a length unknown to us all.

Whatever possessions you might leave, plan (by a will) what you want to happen the legatees, etc. Give a family member or close friends your desires for your funeral service. Then forget those things and get on with your life.

\section{Keep your mind stimulated -}

Like your body it must have exercise - read, do puzzles, crosswords, word games, computer skills, crafts; try a new hobby or activity, write about your family history.

\section{Take care of yourself -}

Keep as fit as you can, eat wisely (even if you do indulge occasionally). Exercise where possible - a garden is very useful for this, even if you are only bending over to weed or cut back.

\section{Maintain your property -}

House, car, other items you use, to as high a standard as you can manage. If money gets short as the years roll on you will have some time before you need to repair or replace. Take care to keep up insurance.

\section{Keep in contact with people}

Through organisations, craft and hobby groups, your neighbours, voluntary work. It is often very inspiring when attending the funeral of a friend to learn of the many groups with whom she had contact and particularly the many she influenced by her support and activity. It is so sad when someone dies and few attend the funeral, and no one knows much about her because she made little contact with anyone. Loneliness can be even more damaging than poor health.

\section{Enjoy yourself as much as you can}

Ill-health, aches and pains, may often restrict us - but recently I had a letter from an American friend who at ninety six uses her computer for E-mails all over the world, despite being crippled with arthritis, somewhat deaf, and with not very good sight. Her sense of humour is a delight.

Childhood, adolescence, young woman, middle-aged, now 'older woman'. Enjoy this phase - you have knowledge and experience you never had in those earlier phases in your life. Make good use of them. It's great to be an 'older woman"

Audrey Harper, 19-02-01 